\title{
Generating EARLY CONTINENTAL CRUST
}

\author{
Dissertation \\ for the award of the degree \\ "Doctor rerum naturalium" (Dr.rer.nat.) \\ of the Georg-August University Göttingen \\ within the doctoral program Geoscience \\ of the Georg-August University School of Science (GAUSS)
}

submitted by

Alexander Wellhäuser

from Kassel

Göttingen, $29^{\text {th }}$ of February 2020 
Thesis Committee

Prof. Dr. Gerhard Wörner

Geochemistry Department, Georg-August University Göttingen

A/Prof. Dr. Tracy Rushmer

CCFS, Earth and Environmental Sciences, Macquarie University

Members of the Examination Board

Reviewer : Prof. Dr. Gerhard Wörner

Geochemistry Department, Georg-August University Göttingen

Second Reviewer : A/Prof. Dr. Tracy Rushmer

CCFS, Earth and Environmental Sciences, Macquarie University

Further members of the Examination Board:

Prof. Dr. Jonas Kley

Department of Structural Geology and Geodynamics, Georg-August University Göttingen

Prof. Dr. Andreas Pack

Isotope Geology Department, Georg-August University Göttingen

Dr. Burkhard Schmidt

Department of Experimental and Applied Mineralogy, Georg-August University Göttingen

Prof. Dr. Simon Turner

CCFS, Earth and Environmental Sciences, Macquarie University

Date of the oral examination: 18.05.2020 




\section{Kurzfassung}

Alexander Wellhäuser

\section{Die Entstehung erster kontinentaler Kruste}

Archaische Kratone sind Relikte der geodynamischen Prozesse, die das Antlitz der Erde in ihrer frühen Entwicklung prägten. Sie bestehen aus Plutoniten felsischer Zusammensetzung, umschlossen von gefalteten vulkanisch und sedimentär geprägten Abfolgen. Jedoch bilden diese Gesteine kein repräsentatives Archiv der krustalen Entwicklung, sondern sind einzelne Fragmente, räumlich und zeitlich voneinander getrennt. Je älter die geologischen Formationen, desto uneindeutiger ist ihre Entstehungsgeschichte, nicht zuletzt aufgrund von zum Teil mehrfacher metamorpher Überprägung. Vor allem die Zusammensetzung der Granitoide unterscheidet sich deutlich von jüngeren, postarchaischen magmatischen Gesteinen. Am weitesten verbreitet in archaischen Plutonen ist eine Assoziation von Tonaliten, Trondhjemiten und Granodioriten (TTG). Deren gemeinsames Auftreten ist möglicherweise der Schlüssel zum Verständnis des vorherrschenden geodynamischen Systems im Archaikum und beinhaltet entscheidende Hinweise zum Einsetzten der modernen Plattentektonik. Die wahrscheinlich größten Unsicherheiten in der Entstehung von TTGs ist die Verfügbarkeit von Wasser während der Schmelzbildung und ihr Differentiationsmechanismus.

Ziel der vorliegenden Arbeit ist, die Druck- und Temperaturbedingungen sowie Menge des benötigten Wassers bei der Entstehung von TTG Schmelzen mithilfe verschiedener Herangehensweisen einzugrenzen: (i) einer experimentellen Ti-Sättigungsstudie an einem eoarchaischen Granodiorit aus dem Nuvvuagittuq Grünsteingürtel der Nordöstliche Superior Provinz in Kanada sowie der Kalibration eines Ti-Löslichkeitsmodells für Silikatschmelzen; (ii) der Betrachtung der in Liquidusnähe gesättigten Mineralphasen mithilfe von Kristallisationsexperimenten und Modellierung, sowie der Herausarbeitung möglicher kotektischer Pfade an dem selben Granodiorit und (iii) der Kalibration eines auf publizierten, wasserhaltigen Schmelzexperimenten beruhenden Hilfsvektorregressionsmodells (SVR) zur Bestimmung von Temperatur und Druckbedingungen sowie Wassergehalt der Schmelze am Liquidus, basierend auf der Hauptelementzusammensetzung. Die drei Methoden werden auf einen TTG Datensatz chemischer Analysen, zusammengetragen aus verschiedenen Publikationen, angewendet.

Die Ti-gesättigten Liquidustemperaturen, berechnet für den TTG Datensatz, liegen im Durchschnitt zwischen 750 und $900{ }^{\circ} \mathrm{C}$ und definieren ein Minimum für die Schmelzbildungstemperatur. Jedoch sind viele berechnete Ti-Temperaturen unterhalb einer aufgrund der Hauptelementzusammensetzung zu erwartenden Liquidustemperatur. Entsprechend können diese Gesteine an ihrem Liquidus nicht mit Rutil oder Ilmenit gesättigt gewesen sein, was Konsequenzen für die Interpretation der TTG-typischen Nb-Verarmung hat. Diese, generell mit der Liquidussättigung mit Rutil in Verbindung gebracht, ist vorhanden, unabhängig davon ob die jeweilige Zusammensetzung am Liquidus mit Rutil oder Ilmenit gesättigt sein kann 
oder nicht. Daher ist die Bedeutung von Rutil und Ilmenit für die TTG Schmelzentstehung wahrscheinlich begrenzt und die Nb-Verarmung entweder vom Ausgangsgestein ererbt oder das Resultat anderer Titan-führender Phasen wie zum Beispiel Amphibol oder Glimmer. Basierend auf dem Vergleich mit experimentellen Schmelzen müssen 8-12 Gew.\% $\mathrm{H}_{2} \mathrm{O}$ in den TTG-Schmelzen gelöst sein, damit der Liquidus innerhalb des berechneten Temperaturintervalls erreicht wird. Diese Wassermenge spricht für die Anwesenheit eines freien Fluides während der Schmelzbildung. Das SVR-Modell bestätigt die Menge des benötigten Wassers für die Ti-gesättigten Liquidustemperaturen mit einer unabhängigen Kalibration.

Für wässrige Bedingungen sprechen auch mögliche TTG-Differentiationspfade. Die Verhinderung von Plagioklaskristallisation bei Wassergehalten über 5 Gew.\% führt zu einem konstanten $\mathrm{K}_{2} \mathrm{O} / \mathrm{Na}_{2} \mathrm{O}$-Verhältnis, typisch für die Differentiation hin zu trondhjemitischen Schmelzen. Unter wasserärmeren Bedingungen entstehen durch Anwesenheit von Plagioklas granodioritische und granitische Schmelzen, vergleichbar mit rezenten Magmen. Daher muss das archaische magmatische System wasserreich gewesen sein.

Es ist wahrscheinlich, dass TTGs nicht auf einem einzelnen kotektischen Pfad liegen sondern, eher auf mehreren von Hornblende/Klinopyroxen - Granat/Orthopyroxen kontrollierten kotektischen Pfaden, deren Position von Druck und Wassergehalt abhängig ist.

Das geodynamische System, in dem sich TTGs entwickeln, muss in der Lage sein genügend Wasser für eine $\mathrm{K}_{2} \mathrm{O}$ arme Schmelzentwicklung zur Verfügung zu stellen. Ein Recyclingmechanismus, der subduktionsartig hydratisierte basaltische Kruste in die Schmelzentstehungsregion bringt, ist dafür ein plausibler Rahmen. 


\section{Abstract}

Alexander Wellhäuser

\section{Generating early continental crust}

Archean cratons are the products of geodynamic processes governing the evolution of the early Earth. They comprise felsic granitoids enclosed by folded volcano-sedimentary successions. However, these rocks may not be representative archives but rather accidental fragments in time and space. The further back the rock record reaches in time, the more ambiguous it becomes, not least because of multiple subsequent overprinting events. The composition of Archean granitoids is distinctly different to post-Archean felsic rocks that are associated with modern continental crust forming processes. Most common is an association of tonalites trondhjemites and granodiorites (TTG). The joint occurrence of TTG potentially holds key insights about the Archean geodynamic environment, including the timing of the onset of modern-day plate tectonics, which is yet to be resolved. A major uncertainty regarding their formation is the availability of $\mathrm{H}_{2} \mathrm{O}$ during melting of their protolith and the mechanism of their differentiation.

This research focusses on constraining P-T- $\mathrm{H}_{2} \mathrm{O}$ conditions of TTG melt formation by combining different approaches: (i) an experimental Ti saturation study on an Eoarchean granodiorite from the Nuvvuagittuq greenstone belt, North-eastern Superior Province and subsequent calibration of a Ti solubility model for silicate melts, (ii) an experimental and modelling investigation of saturated liquidus phases and potential cotectic paths on the same rock and (iii) using published glass analyses of hydrous melting experiments to calibrate a support vector machine regression (SVR) model capable to predict temperature, pressure and $\mathrm{H}_{2} \mathrm{O}$ conditions of a TTG sample based on the major element composition. The three methods are applied to a compilation of natural TTG analyses from published literature. Ti saturated liquidus temperatures for natural TTGs are on average between 750 and $900{ }^{\circ} \mathrm{C}$, constraining a minimum melt formation temperature. However, many TTGs have temperatures below expected liquidus temperatures based on their major element composition. Congruously these can not have been saturated with rutile or ilmenite at their liquidi. This has consequences for the interpretation of the Nb depletion in TTGs, as it is observed, irrespective of whether or not a composition could have been saturated in Ti. Therefore the role of Ti accessory phases in TTG formation might be limited. The Nb depletion could instead be inherited from a precursor rock or the result of other Ti-bearing phases involved in TTG formation, as for example amphibole or mica.

Based on comparison with experimental data, TTGs in equilibrium with a Ti phase at the liquidus require 8-12 wt $\% \mathrm{H}_{2} \mathrm{O}$ dissolved to be at liquidus conditions. This elevated amount favours the presence of a free fluid during melting. The SVR model independently confirms the amount of $\mathrm{H}_{2} \mathrm{O}$ required for Ti saturated liquidus temperatures. 
Hydrous conditions are also favoured when retracing the differentiation paths of TTG via crystallisation experiments and modelling. Plagioclase suppression by $\mathrm{H}_{2} \mathrm{O}$ contents $>5 \mathrm{wt} \%$ results in a low $\mathrm{K}_{2} \mathrm{O} / \mathrm{Na}_{2} \mathrm{O}$ ratio throughout differentiation that is typical for melt evolution towards a trondhjemitic composition. Less hydrous conditions result in granodioritic and granitic melt compositions, as is commonly observed in post-Archean magmatic systems. Therefore the Archean environment producing TTGs must have been more hydrous than recently active magmatic systems that produce felsic crust.

It is most likely that TTGs do not align along a single cotectic path, but along several hbl/cpx - grt/opx controlled cotectics, whose position is shifted by varying pressure and/or $\mathrm{H}_{2} \mathrm{O}$ conditions.

The geodynamic environment that gave rise to TTGs must provide an elevated amount of $\mathrm{H}_{2} \mathrm{O}$. This favours a model of the recycling of hydrated basalt into the region of melt formation in a subduction-like setting. 


\section{Statement of Originality}

This thesis is being submitted to Macquarie University and Georg-August University Göttingen in accordance with the Cotutelle agreement dated 12.12.2016.

To the best of my knowledge and belief, the thesis contains no material previously published or written by another person except where due reference is made in the thesis itself.

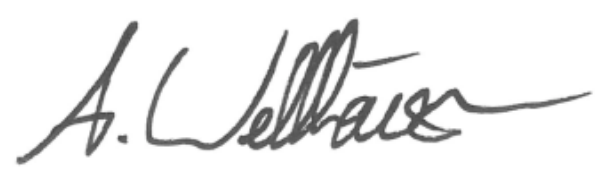

28.02.2020, Göttingen

Alexander Wellhäuser 



\section{Acknowledgements}

I would like to thank Tracy Rushmer and Gerhard Wörner for giving me the opportunity to write this cotutelle PhD thesis at Macquarie University and Georg-August University, and for their professional advice and of course for their guidance and support along the way. Tracy was an amazing, encouraging supervisor who always had an open door, supported me in the directions that I pursued and made it possible to meet a lot of different scientist. Already in my first undergraduate course Gerhard Wörner inspired me to study geochemistry with his ability to break down highly complex topics into almost common sense. My understanding of geochemical processes benefited exceedingly from knowledge.

I am deeply thankful to John Adam who taught me how to conduct piston cylinder experiments and gave me an understanding of the "old school" petrological methods and their timelessness to approach magmatic systems. I want to thank Simon Turner for interesting discussions about early Earth. Tim Murphy for helping me at the microprobe, Raman spectrometer, and SEM at Macquarie. Andreas Kronz for his help analysing my experiments in Göttingen and his in-depth knowledge about the analytical complexities in analysing Ti-bearing glasses. Peter Wieland for major and trace element analyses. Trevor Green gave me interesting insights into his work.

I would like to thank Rucheng Wang for the possibility to visit Nanjing University and work in his labs. During my stay in at NJU I was outstandingly supported by Xudong Che and Zhaoyu Yang who took care of everything and I also thank Fangfang Huang for the supervision in the laboratory.

I would like to thank the coordinators of the DFG-Schwerpunktprogramm 1833 "Building a Habitable Earth" Carsten Münker und Daniela Hülle for organising incredible field workshops that greatly expanded my knowledge and understanding of the Archean. Within the same breath I want to thank Martin van Kranendonk, for taking me along to the Pilbara for a great excursion and thereby making it possible for me to meet the SPP group.

I thank Matthias Pospiech for sharing his extensive LaTeX thesis template in which my thesis is written. I am grateful to the online community at stackexchange.com and similar pages, not only in case of LaTeX but also $R$, to take the time to elaborately answer even beginners questions.

A great thanks to my fellow PhD students at Macquarie University and in Göttingen with whom I had a wonderful time. My stay at Macquarie would not have been the same without 
you and I really enjoyed your company, whether in lab, at lunch or during our weekly adventures in and around Sydney.

I want to thank my parents for always supporting me and Julian for being the best brother that I could imagine. I also want to thank my partner Marina who had the patience to bear me over the last three years. I am glad that we managed it and I am looking forward to our future. 


\section{Contents}

1 Introduction 1

1.1 Early continental felsic crust 1

1.2 Possible geodynamic environments on Early Earth 2

1.3 Objective of the thesis 4

1.4 Mechanisms and conditions of TTG formation 4

1.4.1 The source of TTGs 5

1.4.2 Experimental and modelling constraints on TTG formation 5

$\begin{array}{ll}\text { 1.4.3 TTG evolution by crystal fractionation } & 8\end{array}$

1.5 The Eoarchean granodiorite PC-103 8

$\begin{array}{llr}1.6 & \text { Manuscript contribution } & 9\end{array}$

2 The Eu-anomaly in tonalite-trondhjemite-granodiorites (TTGs) and its relevance $\quad 11$

2.1 Preface 11

2.2 Introduction 11

2.3 The Eu-anomaly in TTGs 13

2.3.1 Alteration of petrogenetic markers by Eu-anomaly generating processes 14

$\begin{array}{lll}2.4 \text { Conclusions } & 17\end{array}$

3 A new titanium solubility model for silicate melts 19

$\begin{array}{lll}3.1 & \text { Preface } & 19\end{array}$

$\begin{array}{lll}3.2 & \text { Abstract } & 19\end{array}$

3.3 Introduction 20

3.4 Ti-thermometry on TTGs - a key to their origin 21

3.4.1 Previous experimental studies of titanium solubility in silicate melts $\quad 22$

3.4.2 Assessment of previously published Ti-solubility models 23

3.5 Calibration of a new Ti-saturation thermometer 26

3.6 Ti solubility experiments on an Archaean tonalite 28

3.6.1 Experimental methods $\quad 29$

$\begin{array}{ll}3.6 .2 \text { Analytical methods } & 29\end{array}$

$\begin{array}{ll}3.6 .3 \text { Results } & 32\end{array}$ 
3.7 Application of the new Ti-solubility model to the experimental results for PC-103 34

3.8 Application of the new thermometer to Archean TTGs 35

3.8.1 Calculated Ti-saturation temperatures for TTGs 36

$\begin{array}{ll}\text { 3.8.2 The controls on Nb-depletions in TTGs } & 37\end{array}$

$\begin{array}{ll}\text { 3.8.3 Implications for the evolution of TTG magmas } & 37\end{array}$

$\begin{array}{lll}3.9 & \text { Summary and conclusions } & 38\end{array}$

3.10 Remarks and usage of the model 38

3.11 Acknowledgements 41

4 TTG suite differentiation paths as a function of water availability 43

4.1 Preface 43

4.2 Abstract 43

4.3 Introduction 44

4.3.1 Formation conditions for TTGs 45

$\begin{array}{llr}4.4 \text { Methods } & 49\end{array}$

$\begin{array}{ll}\text { 4.4.1 Petrological modelling } & 49\end{array}$

$\begin{array}{ll}\text { 4.4.2 Experimental methods } & 49\end{array}$

$\begin{array}{lr}\text { 4.4.3 Analytical methods } & 50\end{array}$

$\begin{array}{lll}4.5 & \text { Results } & 51\end{array}$

4.5.1 Experimentally determined saturated liquidus $\quad 51$

4.5.2 Calculated phase diagrams $\quad 52$

4.5.3 Comparison of experimental and calculated phase stabilities 56

$\begin{array}{lll}4.6 & \text { Melt evolution via crystal fractionation } & 57\end{array}$

$\begin{array}{ll}\text { 4.6.1 The experimental system } & 57\end{array}$

$\begin{array}{ll}\text { 4.6.2 The modelled system } & 58\end{array}$

4.6.3 Was crystal fractionation involved? 60

$\begin{array}{lll}4.7 & \text { Conclusions } & 62\end{array}$

4.8 Acknowledgements $\quad 63$

4.9 Appendix 63

5 Empirical estimate of temperature, pressure and $\mathrm{H}_{2} \mathrm{O}$ at liquidus conditions $\quad 81$

$\begin{array}{lll}5.1 \text { Preface } & 81\end{array}$

5.2 Abstract 81

$\begin{array}{llr}5.3 & \text { Introduction } & 82\end{array}$

5.4 Methods 83

5.5 Building the model $\quad 85$

5.5.1 The experimental dataset $\quad 86$

$\begin{array}{ll}\text { 5.5.2 Temperature calibration } & 88\end{array}$ 
$\begin{array}{lll}\text { 5.5.3 Pressure calibration } & 89\end{array}$

$\begin{array}{ll}5.5 .4 \mathrm{H}_{2} \mathrm{O} \text { calibration } & 91\end{array}$

5.5.5 Interdependent $\mathrm{T}-\mathrm{P}-\mathrm{H}_{2} \mathrm{O}$ estimate 93

5.6 Application to Archean TTGs 94

5.6.1 T-P-H ${ }_{2} \mathrm{O}$ estimate for TTGs with the interdependent model 96

5.6.2 $\mathrm{H}_{2} \mathrm{O}$ and pressure estimate for Ti saturated liquidus temperatures $\quad 97$

$\begin{array}{lll}5.7 & \text { Summary and conclusions } & 101\end{array}$

$\begin{array}{lll}5.8 & \text { Appendix } & 102\end{array}$

6 Conclusions 109

Bibliography 111 


\section{Acronyms}

\section{Notation Description}

E-MORB enriched mid oceanic ridge basalt

EPT East Pilbara Terrane

FQM fayalite-quartz-magnetite

HFSE high field strenght element

HP high pressure

HREE heavy rare earth element

ISB Isua Supercrustal Belt

LILE large ion lithophile element

LP low pressure

MP medium pressure

NAC North Atlantic Craton

$\mathrm{NBO} / \mathrm{T}$ non bridging oxygen per tetrahedra

NCC North China Craton

NESP Northeastern Superior Province

NGB Nuvvuagittuq Greenstone Belt

NNO nickel-nickel oxide

PM primitive mantle

REE light rare earth element

REE rare earth element

RMSE root mean square error

sd $\quad$ standard deviation

SVM support vector machine 
Notation Description

SVR support vector machine regression

TTG tonalite-trondhjemite-granodiorite

WM wüstite-magnetite

\section{List of Symbols}

\begin{tabular}{ll} 
Notation & Description \\
\hline $\mathbb{R}$ & real numbers \\
$\alpha$ & Lagrange multiplier \\
$\epsilon$ & distance of hyperplane to margin \\
$\Lambda$ & optical basicity \\
$\omega$ & orthogonal vector to hyperplane \\
$\xi$ & soft margin for SVR \\
\hline
\end{tabular}





\section{CHAPTER 1}

\section{Introduction}

The face of the earth, as we see it today, is the result of a complex interaction between litho-, hydro- and atmosphere. The steady exchange between these chemical reservoirs gave rise to a manifold biosphere, unique in our solar system. Driving force of the exchange is a high temperature gradient toward earth's interior, resulting in magmatism and plate tectonics. The questions how, when and why these mechanisms, especially Wilson Cycle plate tectonics started operating, remain unresolved to date. What processes governed the newly accreted planet? Were they different than today's processes? How did the first continents form?

A window into earth's early history is given by rock formations having outlasted time since the Archaean in cratons. These are commonly an amalgamation of magmatic plutons enclosed by greenstone belts that consist of volcanic and sedimentary sequences (Condie, 1981). However, the rock record preserved in cratons is not continuous, becoming more sparse with age and is often overprinted by younger magmatic or metamorphic events (O'Neil et al., 2012; Zhang et al., 2012; Upadhyay et al., 2014; White et al., 2017), which leads to ambiguity in understanding the geodynamic processes governing early earth and the emerge of life. It is not trivial to interpret rocks of Archean age and great care has to be taken as even the applicability of one of the most fundamental principles in geology, uniformitarianism is uncertain (Glikson, 1981; Park, 1982; Smithies et al., 2003).

\subsection{Early continental felsic crust}

The majority of Archaean felsic plutonic rocks are distinct from granitoids that form during the Proterozoic and Phanerozoic aeon (Moyen and Martin, 2012). Whereas post-Archaean plutonic felsic rocks are mainly of granitic composition, most Archaean plutonic rocks are tonalite-trondhjemite-granodiorites (TTGs). Monzodiorites and granites are of subordinate importance.

The classification as TTG suite was first introduced by Jahn et al. (1981) in a trace element and isotope study on plutonic rocks from the Pilbara craton, Western Australia. They distinguished the suite from other Archaean granitoid rocks by their low-K and high-Na content, as well as a highly fractionated rare earth element (REE) pattern. A recent review (Moyen and Martin, 2012) summarises general geochemical features of TTGs. First order 
important feature is a sodic composition with a $\mathrm{K}_{2} \mathrm{O} / \mathrm{Na}_{2} \mathrm{O}$-ratio below 0.6. The $(\mathrm{La} / \mathrm{Yb})_{\mathrm{N}}$ ratio is typically between 15-50, but can reach values up to 200. This depletion in heavy rare earth element (HREE) is commonly associated with the presence of residual garnet, either in the residue or by crystal fractionation. A high $\mathrm{Sr} / \mathrm{Y}$ ratio can be attributed to garnet as well, but furthermore hints to the absence of feldspar during the magmatic history. An on average missing Eu-anomaly, in contrast to modern granitoids, is used as further evidence for plagioclase not being involved in TTG melt formation and evolution. TTGs are enriched in large ion lithophile elements (LILEs), and depleted in Nb-Ta-Ti, considered as a classical arc signature (Pearce and Parkinson, 1993). The LILE enrichment is attributed to the source, though could be the result of the involvement of a fluid phase (Hastie et al., 2016).

Major mineral phases are quartz, plagioclase and biotite, with K-feldspar and amphibole occurring in respect to the degree of differentiation of the individual rock (Moyen and Martin, 2012). Common accessory phases are allanite, pistacite, apatite, zircon, titanite, titanomagnetite and epidote.

The subdivision in tonalite, trondhjemite and granodiorite is based on the normative anorthitealbite-orthoclase triangle (O'Connor, 1965). Adjacent to the classification via feldspar composition, Moyen (2011) introduced a subdivision for TTGs related to the potential P-Tconditions of their formation, respectively their melt extraction depth based on the ratios of $\mathrm{La}_{\mathrm{N}} / \mathrm{Yb}_{\mathrm{N}}$ and $\mathrm{Sr} / \mathrm{Y}$ and the amount of $\mathrm{Al}_{2} \mathrm{O}_{3}$ at $70 \mathrm{wt} \% \mathrm{SiO}_{2}$. Thereby TTGs were classified as low- medium- and high pressure origin rocks. However, recent studies propose that there was no high pressure melting $\geq 1.5 \mathrm{GPa}$ in the Archean, ascribing the high pressure signature to either hornblende fractionation or feldspar accumulation (Smithies et al., 2019; Laurent et al., 2020).

\subsection{Possible geodynamic environments on Early Earth}

A key aspect of the research on TTGs is the geodynamic implication that arises from the common occurrence of these rocks and their difference to felsic granitoids that are associated with modern continental crust production (Moyen and Martin, 2012). The open question is whether or not some type of plate tectonics was already operating during the Archean (Hawkesworth et al., 2010; Tang et al., 2016; Brown et al., 2020). It is important to state that subduction is not the same as plate tectonics. Subduction can occur locally whereas plate tectonics is a globally operating system. Therefore the presence of subduction zone features in Archean cratons do not prove the existence of plate tectonics (Cawood et al., 2018; Brown et al., 2020). It is likely that not a single geodynamic environment is responsible for the formation of continental crust (Van Kranendonk, 2010; Sizova et al., 2015) as a single scenario cannot account for the heterogeneity of Archean cratons.

The presence of subduction zone settings already in the Eoarchean has been proposed for different cratons. Turner et al. (2014) describe a geochemical stratigraphy from the Nuvvuagittuq Greenstone Belt (NGB), Canada, as closely resembling the Izu-Bonin-Mariana forearc 
subduction initiation sequence. However, Pearce and Reagan (2019) argue that the sequence rather represents an arc-basin boninite, though still related to subduction. A subduction related origin is also proposed for the Isua Supercrustal Belt (ISB), North Atlantic Craton (NAC) in West Greenland, being interpreted as a "proto arc" (Komiya et al., 1999; Polat and Hofmann, 2003; Jenner et al., 2009; Nutman et al., 2015). Besides a lithostratigraphic sequence that resembles arcs, Eoarchean tectonic structures are preserved, interpreted as caused by convergence. Thereby slices of oceanic crust were piled up until a sufficient depth for melting in presence of garnet was reached to produce rock of TTG composition. In addition to individual areas of the NAC showing subduction features, an accretionary origin is proposed for the whole craton by Polat et al. (2015) due to Neoarchean shear zones amalgamating individual terranes. The difference in chemical composition of TTGs to granitic rocks formed in modern arc settings is ascribed to different conditions of melting. Whereas in modern subduction zones melting occurs in the mantle wedge (McCulloch and Gamble, 1991; Grove et al., 2006) due to fluid release of the subducting slab, the melt formation of TTG is thought to happen by melting of the lower, or respectively subducting slab (Drummond and Defant, 1990; Laurie and Stevens, 2012; Nagel et al., 2012; Hastie et al., 2016), comparable to modern day adakites (Defant and Drummond, 1990; Martin et al., 2005; Castillo, 2012). The interpretation of NAC terranes having formed by subduction related processes is recently been challenged (Webb et al., 2020; Yakymchuk et al., 2020). They propose a heat-pipe model (Moore and Webb, 2013; Rozel et al., 2017) to form intrusive and supracrustal sequences with subsequent folding/shearing as a feasible mechanism to form the NAC. Webb et al. (2020) reject the previously identified metamorphic gradient (Windley and Garde, 2009) and strain variation along the proposed subduction zone within the ISB based on field evidence. They identified homogenous prograde metamorphism and strain, from which they interpret the ISB to be an a-fold and not a subduction zone.

In contrast to convergent settings there are Archean cratons that do not show features indicating horizontal movement or subduction zone like stratigraphy. The most prominent example is the East Pilbara Terrane (EPT), consisting of a Paleoarchean dome and keel structure (Collins et al., 1998; Sandiford et al., 2004; Wiemer et al., 2018). This structure is thought to have formed by consecutive mantle plumes interacting with a "proto crust" to form a thick oceanic plateau. By remelting of the volcanic plateau, granitoids were emplaced leading to partial convective overturn within the crust (Smithies et al., 2009; Hickman and Van Kranendonk, 2012). Evidence for subduction in the Pilbara is not present before 3.12 Ga (Smithies et al., 2005). A similar setting involving a volcanic plateau is proposed for the Kaapvaal craton (Van Kranendonk et al., 2015).

Numerical modelling by Sizova et al. (2015) allows different geodynamic settings to coexist. The early crustal evolution is driven by lower crust delamination, underplating of basaltic melts as well as crustal overturns resulting in the formation of a dome and keel structure. 
Short lived subduction events are triggered by oceanic spreading due to hot mantle upwelling. Bédard (2018) proposes a similar environment where long-lived mantle upwelling reworked oceanic crust and induced mantle currents that dragged pre-existing continents, letting them develop convergent margins. A different option to trigger subduction events is by extraterrestrial impactors, which were common in the early solar system proposed by O'Neill et al. (2017) and King (2020).

\subsection{Objective of the thesis}

This work combines different methods to constrain the formation conditions of Archean TTG and infer relevant geodynamic processes in their origin. Their formation conditions bear uncertainty because additionally to the lack of knowledge about the geodynamic environment, the source of TTGs is not preserved or identified within the geologic record of Archean cratons. To bypass this limitation I focus on constraining their liquidus conditions based on their major element composition. Here, the term "liquidus conditions" is solely used for felsic compositions, describing the conditions at which they are almost completely molten. At these conditions they might have formed by partial melting of a protolith.

Appropriate liquidus conditions must provide a starting-point to account for the differentiation mechanism that results in the variety of compositions occurring in TTG suites. My major focus hereby is on the amount of $\mathrm{H}_{2} \mathrm{O}$ present during TTG melt formation, the least certain, but most crucial parameter. The focus of the thesis comprises the following topics:

I. An experimental Ti solubility study on the Archean granodiorite PC-103 comprising the calibration of a Ti solubility model for silicate melts and calculation of Ti saturated liquidus temperatures for TTGs.

II. Crystallisation experiments and modelling of phase stabilities on the Archean granodiorite PC-103 under various conditions to investigate possible differentiation paths.

III. The calibration and application of an experiment-based statistical P-T- $\mathrm{H}_{2} \mathrm{O}-$ liquiduscondition prediction model to estimate TTG liquidus conditions by comparison to hydrous melting experiments.

In the following sections I will outline constraints made by experimental, modelling and field studies on the formation conditions of TTGs and introduce the literature relevant to each topic.

\subsection{Mechanisms and conditions of TTG formation}

It is not certain how TTGs formed, not even if they represent true magmatic liquids. In case they do, or at least part of the series, they could be formed by partial melting or by crystal fractionation. Distinguishing between these two processes is difficult as both result in similar major- trace and isotope compositions (Brophy, 2008). As there are no mafic to felsic evolutionary trends observed in Archean cratons, it is generally assumed that TTGs 
formed by partial melting (Moyen and Martin, 2012). However, several authors argue for crystal fractionation being involved in forming TTGs (Martin, 1993; Kleinhanns et al., 2003; Bédard, 2006a; Jagoutz et al., 2013; Hoffmann et al., 2014; Liou and Guo, 2019; Smithies et al., 2019; Laurent et al., 2020).

\subsubsection{The source of TTGs}

A major uncertainty in respect to the origin of TTGs is the lack of knowledge about their source rocks, respectively, parental magmas. They are either not preserved in the geologic record or have not yet been clearly identified. This complicates setting constraints on TTG formation conditions as their geochemical features could result from forming under specific conditions or be inherited from their source (Hoffmann et al., 2019).

Based on a variety of experimental petrological studies on potential source rocks (Beard and Lofgren, 1991; Rapp et al., 1991; Rushmer, 1991; Rapp and Watson, 1995; Sen and Dunn, 1994; Patiño Douce and Beard, 1995; Skjerlie and Patiño Douce, 1995, 2002; Winther, 1996; Springer and Seck, 1997; Xiong et al., 2005; Adam et al., 2012; Hastie et al., 2016) and TTG like compositions (Green and Ringwood, 1968; Green, 1972; Lambert and Wyllie, 1974; Allen et al., 1975; Allen and Boettcher, 1978, 1983; Johnston and Wyllie, 1988) there is common agreement that hydrated basaltic compositions likely served as a TTG precursor (Wyllie et al., 1997; Moyen and Stevens, 2006; Hoffmann et al., 2019). The hydrated basalt hypothesis is supported by recent findings of heavy $\delta^{30} \mathrm{Si}$ values for Archean granitoids, that are interpreted as signals from silicified basaltic precursor rocks (André et al., 2019). However, boron isotopes from different cratons suggest that the source was unaffected by seawater or seawater altered rocks (Smit et al., 2019).

Trace element modelling suggests that no depletion or an enrichment of the source is required to produce the trace element pattern typical for TTGs by melting (Springer and Seck, 1997; Martin et al., 2014; Johnson et al., 2017). An enrichment by fluids during melting is another possibility (Hastie et al., 2016). The signature comprises an enrichment of LILE and a depletion in $\mathrm{Nb}$ and $\mathrm{Ta}$, similar to a classic arc signature. It could likely have formed by recycling of older crustal material into the region of melting. This kind of composition is preserved in different Archean cratons (Thurston and Fryer, 1983; Crow and Condie, 1987; Puchtel et al., 1997; Jenner et al., 2009; Hoffmann et al., 2011b; Adam et al., 2012; Parks et al., 2014), though making up only a subordinate fraction of the preserved basaltic rocks.

\subsubsection{Experimental and modelling constraints on TTG formation}

The formation conditions of TTGs have been intensively studied with numerous melting experiments and modelling on basaltic potential source compositions (the "forward" approach), as well as by liquidus studies on TTGs or similar compositions (the "reverse" approach). The forward approach implies the simplification that TTGs are produced by batch partial melting and TTG compositions are primary melts. However, this might only be true for part of the 
TTG suite (Laurent et al., 2020).

Moyen and Stevens (2006) summarised forward melting experiments on basaltic rocks and favoured TTG melt formation above $1.5 \mathrm{GPa}$ between $900{ }^{\circ} \mathrm{C}$ and $1100{ }^{\circ} \mathrm{C}$ under fluid absent conditions. Several forward melting experiments from different studies (Rapp and Watson, 1995; Winther, 1996; Skjerlie and Patiño Douce, 2002; Adam et al., 2012; Laurie and Stevens, 2012; Hastie et al., 2016) resulted in glasses of TTG composition (or came close), based on major element requirements as summarised in Moyen and Martin (2012). Rapp and Watson (1995) produced a trondhjemite at $1000{ }^{\circ} \mathrm{C}, 1.6 \mathrm{GPa}$ by fluid absent melting of an amphibolite with a low-K enriched mid oceanic ridge basalt (E-MORB) composition, $4.25 \mathrm{wt} \% \mathrm{H}_{2} \mathrm{O}$ dissolved in the melt and a restite assemblage of amphibole, plagioclase, clinopyroxene (cpx) and garnet. Winther (1996) matched a trondhjemite major element composition at $800{ }^{\circ} \mathrm{C}$, $2.14 \mathrm{GPa}$ by water saturated melting of an artificial average Archean tholeiite mixture with 15 wt $\% \mathrm{H}_{2} \mathrm{O}$ dissolved in the melt and a residual assemblage of cpx, garnet, quartz and amphibole.

Skjerlie and Patiño Douce (2002) produced tonalitic compositions in three runs by fluid absent melting of a zoisite-bearing quartz eclogite. At $950{ }^{\circ} \mathrm{C}, 1.5 \mathrm{GPa}$ with cpx, zoisite, quartz, plagioclase, kyanite and garnet as restite and for $1025^{\circ} \mathrm{C}$ and $1050{ }^{\circ} \mathrm{C}$ at $2.1 \mathrm{GPa}$ with a cpx, zoisite, plagioclase, quartz, kyanite and garnet phase assemblage. 4 to $5 \mathrm{wt} \% \mathrm{H}_{2} \mathrm{O}$ is present in the produced melts.

Adam et al. (2012) produced a tonalitic to granodioritic melt from a boninite with a subduction zone trace element signature at $950{ }^{\circ} \mathrm{C}$ and $2 \mathrm{GPa}$ with a residual mineralogy comprising cpx, garnet, orthopyroxene (opx) and chromite without the addition of water. However, the $\mathrm{K}_{2} \mathrm{O}$ content is slightly too high to be considered as a typical Archean TTG.

Laurie and Stevens (2012) produced trondhjemitic compositions by water-saturated eclogite melting at $870-900{ }^{\circ} \mathrm{C}$ and 1.9 to $3.0 \mathrm{GPa}$. Residual mineralogy is garnet, cpx, rutile and ilmenite at pressures up to $2.2 \mathrm{GPa}$. Their starting material is peculiar by being almost $\mathrm{K}_{2} \mathrm{O}$ free, enriched in incompatible elements and depleted in HREE compared to MORB. Hastie et al. (2016) approached tonalitic compositions by melting a primitive and depleted (light rare earth element (REE), Th and $\mathrm{U}$ ) tholeiite from the Java plateau at $900-950{ }^{\circ} \mathrm{C}$ at various depths (1.6-2.2 GPa) and 2-3 wt\% $\mathrm{H}_{2} \mathrm{O}$ present. However, their alkali content, especially $\mathrm{K}_{2} \mathrm{O}$ is too low, which they argue can be solved by addition of a slab fluid or using a more differentiated rock as the starting composition. All experiments that successfully reproduced TTG composition used starting materials that were particularly low in $\mathrm{K}_{2} \mathrm{O}$ (0.08-0.17 wt\%). The TTG formation by melting of basaltic compositions was furthermore studied by phase equilibrium modelling (Nagel et al., 2012; Palin et al., 2016; Johnson et al., 2017; Hoffmann et al., 2019). Nagel et al. (2012) modelled the melting of an Eoarchean hydrated tholeiite from the ISB and matched TTG-like major and trace element compositions at 1.0 and 1.4 GPa with 15-20\% melt. This corresponds to temperatures between 836 and $928^{\circ} \mathrm{C}$.

Palin et al. (2016) modelled TTG compositions by melting hydrated, enriched Archean 
tholeiite (Condie, 1981) at $\mathrm{H}_{2} \mathrm{O}$ saturated solidus conditions at 0.6, 1.2 and 2.0 GPa pressures which translates to 1.6, 2.1 and $1.0 \mathrm{wt} \% \mathrm{H}_{2} \mathrm{O}$ present during melting. Their modelling results suggest conditions of formation between $800-950{ }^{\circ} \mathrm{C}$ and 1.0-1.8 GPa.

Johnson et al. (2017) modelled partial melting along different geotherms of an average basalt composition from the 3.5 Ga Coucal Formation (Smithies et al., 2009), East Pilbara Terrane (EPT). These Coucal compositions are similar to the starting materials of Adam et al. (2012) and Laurie and Stevens (2012) and already bear an enrichment in LILE and mild depletions in HREE. Johnson et al. (2017) proposed TTG production at a melt fraction between 20 to $30 \%$ along a geotherm higher than $700{ }^{\circ} \mathrm{C} / \mathrm{GPa}$ resulting in melting temperatures between 800 to $950{ }^{\circ} \mathrm{C}$ at pressures below $1.3 \mathrm{GPa}$. Water content of $1.4 \mathrm{wt} \%$ was chosen to saturate the solidus at $1 \mathrm{GPa}$. The modelling did not result in TTG major element compositions of the partial melts according to the classification of Moyen and Martin (2012) as melts contained either too much $\mathrm{K}_{2} \mathrm{O}$ or $\mathrm{FeO}$ and $\mathrm{MgO}$. Closest fits were obtained around $900{ }^{\circ} \mathrm{C}$ and $30 \%$ melt fraction.

Reverse studies on TTG compositions were conducted by Wyllie et al. (1997) and Clemens et al. (2006).The study of Wyllie et al. (1997) summarises the work of earlier liquidus studies on an Archean trondhjemite from Nuuk and a Sierra Nevada tonalite, with both being studied over a broad range of temperature, pressure and $\mathrm{H}_{2} \mathrm{O}$ conditions. Furthermore, they combined forward and reverse approaches to identify P-T conditions of matching liquidus and residual phases. In amphibolite facies $(<1.2 \mathrm{GPa})$, trondhjemites will form between $750-900{ }^{\circ} \mathrm{C}$ and 5-12 wt\% $\mathrm{H}_{2} \mathrm{O}$ present, whereas tonalites need temperatures between $850-975{ }^{\circ} \mathrm{C}$ and 9-17 wt\% $\mathrm{H}_{2} \mathrm{O}$. For this amount of $\mathrm{H}_{2} \mathrm{O}$, an external influx is required. However, amphibole partitioning coefficients are insufficient to account for HREE depletion in TTGs (Bédard, 2006a; Tiepolo et al., 2007). In eclogite facies conditions (> 1.2 GPa) Wyllie et al. (1997) proposed trondhjemite formation above $900{ }^{\circ} \mathrm{C}$ and $5 \mathrm{wt} \% \mathrm{H}_{2} \mathrm{O}$ and tonalite at approximately $975{ }^{\circ} \mathrm{C}$ and $9 \mathrm{wt} \% \mathrm{H}_{2} \mathrm{O}$. Clemens et al. (2006) investigated the stability of garnet in a Barberton trondhjemite and defined the minimum pressure for TTG melting at 1.47 GPa.

The conclusions from these studies that consider TTGs a magmatic liquid are not unambiguous. Whereas in forward melting experiments TTG compositions do not form below 1.5 GPa, the modelling suggest a pressure range of 1-1.5 GPa. This difference might be at least partially caused by the different methods used. Hirschmann et al. (1998) observed differences between experimental and modelled phase stabilities resulting in an offset in melt fraction by $100{ }^{\circ} \mathrm{C}$. The temperature range of formation is broad for both modelling and experiments from $800-1050{ }^{\circ} \mathrm{C}$, with trondhjemites preferably forming at lower temperatures. The position of the liquidus is strongly dependent on the amount of $\mathrm{H}_{2} \mathrm{O}$ available (Green, 1972; Green and Ringwood, 1972; Wyllie et al., 1976; Holtz and Johannes, 1994) which makes it the crucial major uncertainty for TTG formation. 


\subsubsection{TTG evolution by crystal fractionation}

The alternative to TTGs being primary melts is that they were formed by crystal fractionation. Models proposing this vary strongly in the extend of which fractionation is involved in TTG formation. As an "end-member" model Kleinhanns et al. (2003) propose that Barberton TTGs evolve directly from mantle wedge derived basaltic magmas under hydrous conditions by fractionating garnet/amphibole \pm pyroxenes, plagioclase or olivine depending on conditions, similar to what Macpherson et al. (2006) proposed for adakites. Other studies favour a combination of partial melting and subsequent crystal fractionation (Martin, 1993; Bédard, 2006a; Jagoutz et al., 2013). Liou and Guo (2019) investigated a Neoarchean TTG suite from the North China Craton (NCC) and identified tonalites and trondhjemites with an complementary hornblendite to match a primary liquid of dioritic composition, which was also identified in the field. They propose up to $27 \%$ hornblende fractionation are able to provide a generic link between the individual rocks. However, even though the diorites already have low $\mathrm{K}_{2} \mathrm{O} / \mathrm{Na}_{2} \mathrm{O}$ ratios $($ mean $=0.42$ ), hornblende fractionation is not capable to produce $\mathrm{K}_{2} \mathrm{O} / \mathrm{Na}_{2} \mathrm{O}$ ratios of 0.13 , the observed minimum ratio in the trondhjemites.

Based on a Neoarchean supracrustal felsic succession that follows a differentiation sequence toward high pressure TTG signature, Smithies et al. (2019) argue that this signature is the result of hornblende dominated fractionation and that high pressure melting ( $\geq 40 \mathrm{~km})$ did not occur in the Archean. Laurent et al. (2020) argue, that because of TTGs being granitoids they should be affected by magma chamber processes involving fractionation, accumulation, mixing and melt segregation. Thereby they explain the compositional heterogeneity of Barberton TTGs by mid- to upper crustal feldspar and hornblende accumulation. Their model does not require high pressure melting. The two studies Smithies et al. (2019) and Laurent et al. (2020) contradict the conditions proven feasible by partial melting experiments shown above and are rather in line with thermodynamic modelling.

The same way as Archean crust was not formed by one geodynamic process (Van Kranendonk, 2010), the formation of TTGs is not either by partial melting or fractional crystallisation but rather an interplay of both with varying contribution of the two processes.

\subsection{The Eoarchean granodiorite PC-103}

In this thesis, experiments conducted on the granodiorite PC-103 from the Nuvvuagittuq Greenstone Belt (NGB), Northeastern Superior Province (NESP), Canada (O'Neil et al., 2008, 2012; Adam et al., 2012) play an important role, wherefore I give an introduction into the geologic setting. The NGB is part of the Hudson bay terrane, which is interpreted as the oldest part of the NESP (O'Neil and Carlson, 2017). It is one of the oldest known metavolcanic-sedimentary succession on earth with a disputed earliest formation age varying between 3.8 and 4.4 Ga (O'Neil et al., 2008, 2012; Guitreau et al., 2013). The minimum age is constrained by zircon ages of trondhjemitic bands intruded into the sequence (Cates and Mojzsis, 2007) and Sm-Nd/Lu-Hf data on metavolcanic and metasedimentary rocks (David 
et al., 2009; Guitreau et al., 2013). The Hadean age (O'Neil et al., 2008, 2012) is based on the short-lived ${ }^{146} \mathrm{Sm}^{1}{ }^{142} \mathrm{Nd}$ isotope system, however disputed by Guitreau et al. (2013) and interpreted as an early Hadean mantle refertilisation. In any case some Hadean component is reworked by the formation of the NGB due to a ${ }^{142} \mathrm{Nd}$ deficit (O'Neil and Carlson, 2017). Rocks within the sequence are interpreted to represent mainly primitive oceanic crust that has been hydrothermally affected (O'Neil et al., 2011). The majority of sediments are chemical (e.g. banded iron formations), with very few siliciclastic layers (O'Neil et al., 2019). Most of the NGB experienced at least upper amphibolite facies metamorphic conditions in two episodes (O'Neil et al., 2012) at 2.7 and $3.6 \mathrm{Ga}$, most likely related to the intrusion of felsic granitoids that enclose and intruded the belt. A part of the chemical stratigraphy of the NGB has similarities to modern forearcs (Turner et al., 2014) with high Ti-tholeiites being overlain by boninite-like rocks and a calc-alkaline suite on top, interpreted as a subduction initiation sequence (Stern et al., 2012).

Granodiorite PC-103 is part of the TTG plutonic rocks that surround and rarely intruded the NGB. Trondhjemitic bands that intruded the NGB bear an age of 3.75 to 3.82 Ga. The tonalites and granodiorites surrounding the NGB have an age of 3.66 Ga. The last felsic magmatic episode is marked by the intrusion of granitic pegmatites of Neoarchean age (2.69 Ga, David et al., 2009). The rocks bear typical signatures of Archean TTG as described in section 1.1, with a depletion in HREE and no Eu-anomaly in most rocks (O'Neil et al., 2012). As the metavolcanic rocks, they have a deficit in ${ }^{142} \mathrm{Nd}$, hinting towards a Hadean source being reworked. The early trondhjemites tend to be more depleted in HREE than the later slightly less sodic compositions.

PC-103, classified as a tonalite in Adam et al. (2012), belongs to the 3.6 Ga intrusive suite (O'Neil et al., 2012) and was affected by metamorphism, seen by a preferred orientation of ferro-magnesian minerals. The rock consists of quartz, plagioclase, K-feldspar, biotite, hornblende, epidote, titanite, apatite and zircon. Opaque phases are small and rare. It was affected by alteration, visible by sericitised feldspars and chloritised biotite. Being of classic TTG composition, PC-103 is depleted in HREE, Nb-Ta-Ti and does not have an Eu-anomaly. Due to its major element dependent position in the feldspar classification diagram of O'Connor (1965), PC-103 is a granodiorite and not a tonalite as in Adam et al. (2012). The major element composition of PC-103 is displayed in table 1.1.

Table 1.1: Major element composition of the sample PC-103 from O'Neil et al. (2012) in wt\%.

\begin{tabular}{ccccccccccc}
\hline $\mathrm{SiO}_{2}$ & $\mathrm{TiO}_{2}$ & $\mathrm{Al}_{2} \mathrm{O}_{3}$ & $\mathrm{FeO}_{t}$ & $\mathrm{MnO}$ & $\mathrm{MgO}$ & $\mathrm{CaO}$ & $\mathrm{Na}_{2} \mathrm{O}$ & $\mathrm{K}_{2} \mathrm{O}$ & $\mathrm{P}_{2} \mathrm{O}_{5}$ & $\mathrm{LOI}$ \\
\hline 66.1 & 0.45 & 15.9 & 3.74 & 0.08 & 2.17 & 3.67 & 3.66 & 2.44 & 0.11 & 1.3 \\
\hline
\end{tabular}

\subsection{Manuscript contribution}

The thesis design is cumulative, wherefore several authors contributed to the chapters. Chapters 3,4 and 5 and are self-contained manuscripts and chapter 3 has been submitted to $\mathrm{G}^{3}$ - 
Geochemistry, Geophysics, Geosystems. The following table 1.2 shows the contributions of each author based on the Contributor Roles Taxonomy.

Table 1.2: Contribution to individual manuscripts

\begin{tabular}{lccc}
\hline & chapter 3 & chapter 4 & chapter 5 \\
\hline Conceptualisation & AW, TR, JA, GW & AW, TR, JA & AW \\
Data curation & AW & AW & AW \\
Formal analysis & AW & AW & AW \\
Investigation & AW & AW, JA & AW \\
Methodology & AW & AW & AW \\
Supervision & AW & AW & AW \\
Visualisation & AW & AW & AW \\
Writing - original draft & AW & AW & AW \\
Writing - review \& editing & AW, TR, JA, GW & AW, TR, JA & AW, GW \\
\hline AW = Alexander Wellhäuser, GW $=$ Gerhard Wörner, JA = John Adam, \\
TR =Tracy Rushmer
\end{tabular}




\section{CHAPTER 2}

\section{The Eu-anomaly in tonalite-trondhjemite-granodiorites (TTGs) and its relevance}

\subsection{Preface}

To investigate the formation conditions of tonalite-trondhjemite-granodiorites (TTGs) it is important to study compositions that are likely to have been primary melts and not have been affected by crystal fractionation, accumulation or magma mixing. Within the chapters chapters 3 to 5, I use a compilation of TTG datasets from different literature sources. One filter that I apply on the compilation is that the Eu-anomaly must be smaller than $\pm 0.1 \mathrm{In}$ this chapter I argue why it is essential to apply such a strict condition.

\subsection{Introduction}

The argument about the geodynamic environment of tonalite-trondhjemite-granodiorite (TTG) formation comprises the issue of a clear definition for these rocks. Moyen and Martin (2012) showed that a large amount of rocks commonly called TTG gneisses are not of this composition. They blame a lacking formal definition and present a classification scheme for Archean TTGs based on major and trace elements. However, an implementation of their classification $\left(\mathrm{SiO}_{2} \geq 64,\left(\mathrm{FeO}+\mathrm{MgO}+\mathrm{MnO}+\mathrm{TiO}_{2}\right) \leq 5,0.5<\mathrm{K}_{2} \mathrm{O}<2.0, \mathrm{Na}_{2} \mathrm{O}>4.0\right.$, $0.3<\mathrm{K}_{2} \mathrm{O} / \mathrm{Na}_{2} \mathrm{O}<0.6, \mathrm{Yb}<1.5, \mathrm{La}_{\mathrm{N}} / \mathrm{Yb}_{\mathrm{N}}>15,0.9<$ Eu-anomaly $^{1}<1.1,20<\mathrm{Sr} / \mathrm{Y}$ $<500)$ shrinks their own database of 1749 samples down to 18. This overreaches the goal to provide guidance for classification. $\mathrm{La}_{N}, \mathrm{Yb}_{N}$ and the Eu-anomaly are chondrite normalised (Masuda et al., 1973).

Besides the very strict rules, the classification seems inconsistent in handling the Eu-anomaly. While stating Martin (1986) that TTGs lack significant Eu-anomalies, Moyen and Martin (2012) translate this as absence of an anomaly. When examining TTGs based on their classification, a positive Eu-anomaly is observable for high pressure (HP), low heavy rare earth element (HREE) and a negative anomaly for low pressure (LP), high HREE samples (fig. 2.1a), even though it is against their own rules of classification. This is apparent in the summary table for chemical composition of TTG groups in Moyen and Martin (2012), where low HREE TTGs have an average Eu-anomaly of 1.19 and high HREE TTGs an average

1 The range is assumed based on their statement of no Eu-anomaly present. 
value of 0.84. Medium pressure (MP) samples scatter around Eu-anomaly $=1$. Only on average the Eu-anomaly in TTGs does not exist.

The formation of Eu-anomalies is well studied and quantified for magmatic processes. It
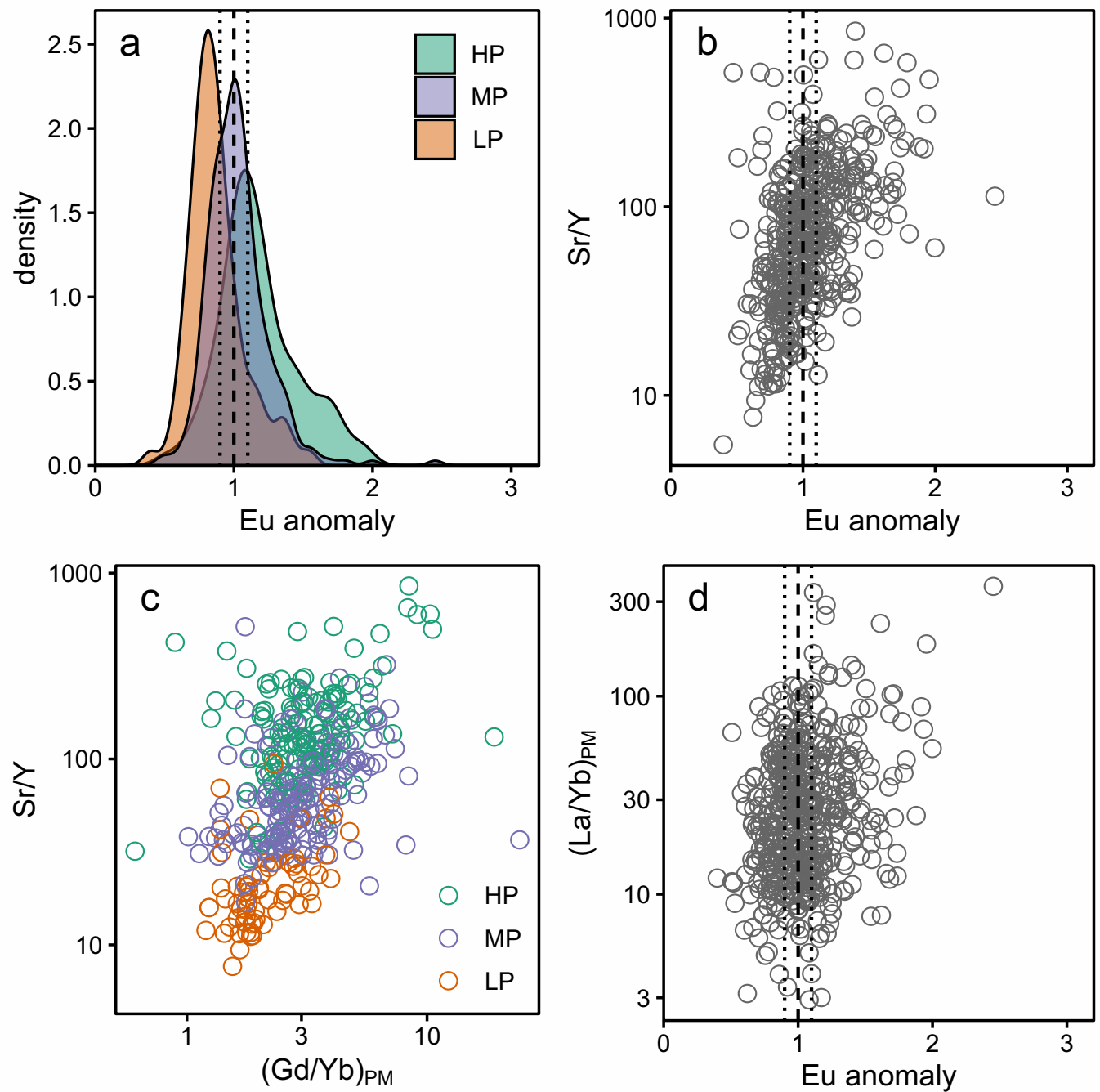

Figure 2.1: a: Eu-anomaly of TTGs categorised by their most likely formation conditions based on the classification of Moyen and Martin (2012). The dataset is from Moyen and Martin (2012). The dotted lines represent an Eu-anomaly of $1 \pm 0.1$. b: Correlation between $\mathrm{Sr} / \mathrm{Y}$ and the $\mathrm{Eu}$-anomaly for TTGs. The $\mathrm{Sr} / \mathrm{Y}$ ratio is plotted as $\log _{10}$. c: The two pressure indicating ratios $\mathrm{Sr} / \mathrm{Y}$ and $(\mathrm{Gd} / \mathrm{Yb})_{P M}$ plotted colour coded by their pressure classification from Moyen and Martin (2012). Both ratios are plotted as $\log _{10} \mathbf{d}$ : Scatter plot without a correlation between $(\mathrm{La} / \mathrm{Yb})_{P M}$ and the Eu-anomaly. The dotted lines represent an Eu-anomaly of $1 \pm 0.1 .(\mathrm{La} / \mathrm{Yb})_{P M}$ is plotted as $\log _{10}$. Theses and following diagrams were created via the $R$ package ggplot2 (Wickham, 2016). The primitive mantle (PM) composition is from McDonough and Sun (1995).

is based on the reducibility of $\mathrm{Eu}^{3+}$ to $\mathrm{Eu}^{2+}$ by low oxygen fugacity in contrast to the rest of the rare earth element (REE) suite (Möller and Muecke, 1984). Therefore Eu behaves different during magmatic processes as rest of the REE and an so called Eu-anomaly forms. Most prominent is the negative Eu-anomaly of granites (Emmermann et al., 1975; Thorpe 
et al., 1977) associated with the fractionation of plagioclase, incorporating $\mathrm{Eu}^{2+}$ for $\mathrm{Ca}$ (Weill and Drake, 1973). Conversely the accumulation of plagioclase, results in a positive anomaly (Rudnick, 1992; Deering and Bachmann, 2010). Another process that generates a positive Eu-anomaly is the fractionation of hornblende (Arth and Barker, 1976; Klein et al., 1997). However, Dessimoz et al. (2012) attribute the negative Eu-anomaly in hornblende to crystallisation in presence of plagioclase. Fulmer et al. (2010) obtained hornblende partitioning coefficients from a plagioclase free natural system without an Eu-anomaly, though ascribe it to high oxygen fugacity. Based on a literature data review, Tiepolo et al. (2007) find the Eu partitioning of amphibole-melt variable, with positive Eu anomalies in potassic richterites and negative anomalies in calcic amphiboles. In the experimental study of Nandedkar et al. (2016), amphiboles bear a constant negative Eu-anomaly, however plagioclase is present in the experimental charges.

Other processes leading to the development of an Eu-anomaly are the stabilisation of $\mathrm{Eu}^{2+}$ by aluminosilicate complexes in highly polymerised, dry melts (Möller and Muecke, 1984) and the accumulation or fractionation of allanite (Martin, 1987), which has a strongly negative Eu-anomaly.

\subsection{The Eu-anomaly in TTGs}

In the context of TTGs, the Eu-anomaly is of striking importance to identify primary, unfractionated melt compositions and evaluate the applicability of the $\mathrm{Sr} / \mathrm{Y}$ ratio. The Eu-anomaly correlates with the Sr/Y ratio, as observable in fig. 2.1b. Therefore the often used pressure indicator $\mathrm{Sr} / \mathrm{Y}$ is most likely biased. When comparing $\mathrm{Sr} / \mathrm{Y}$ to $(\mathrm{Gd} / \mathrm{Yb})_{P M}$, another pressure indicator, a correlation between both of them is observable. However, it is not possible to distinguish between $\mathrm{MP}$ and $\mathrm{HP}$ rocks based on the $(\mathrm{Gd} / \mathrm{Yb})_{P M}$ ratio (fig. 2.1c) as they overlap in range. Only the LP TTGs are distinguishable from MP and HP samples. It might be, as suggested by Smithies et al. (2019) and Laurent et al. (2020), that high pressure melting did not or only sparsely contribute to the formation of TTGs.

There are several possibilities that can produce a positive EU-anomaly. As TTGs are thought to form by melting of hydrous basaltic compositions (Moyen and Stevens, 2006; see also chapter 3 and 5), partitioning by an highly polymerised and dry melt (Möller and Muecke, 1984) can be ruled out. The fractionation of allanite is a feasible process, however this would also produce a flattening of the whole REE pattern correlating with an increasing Eu-anomaly, which is not observed (fig. 2.1d). There is no correlation between the slope of REE and the amplitude of the Eu-anomaly.

The two other possibilities to create a positive Eu-anomaly are (i) by hornblende fractionation, as hornblende carries a negative Eu-anomaly in most cases (Arth and Barker, 1976; Klein et al., 1997; Liou and Guo, 2019), and (ii) accumulation of plagioclase bearing a positive anomaly, (Rudnick, 1992; Deering and Bachmann, 2010; Laurent et al., 2020). 


\subsubsection{Alteration of petrogenetic markers by Eu-anomaly generating processes}

By modelling crystal fractionation it is possible to quantify the impact of feldspar accumulation and hornblende fractionation on trace and major elements in relation to the amplitude of the Eu-anomaly. My focus hereby is on changes in Sr/Y. To quantify the influence of plagioclase accumulation on the Eu-anomaly, I use an average Eu-anomaly free TTG (table 2.1, Euanomaly $=1 \pm 0.1$ ) as starting composition, calculated from the dataset of Moyen and Martin (2012). The composition of the cumulate is calculated by crystal fractionation from a Eu-free melt into the same composition by adding the calculated residue to the average Eu-anomaly free TTG. For this I use an adjusted version of the fractional crystallisation equation:

$$
C_{\text {cum }}=C_{0}\left(2-F^{D-1}\right)
$$

with $C_{\text {cum }}$ being the element concentration in the cumulate, $C_{0}$ the concentration of the starting composition, $\mathrm{F}$ the melt fraction and $\mathrm{D}$ the partitioning coefficient. Feldspar partitioning coefficients are calculated via the equations from Bédard (2006b):

$$
\begin{aligned}
& R T \ln \left(D_{S r}^{\text {plag } / l i q}\right)=-10+0.38 * \mathrm{SiO}_{2}-3.5 * A n \\
& R T \ln \left(D_{Y}^{\text {plag } / l i q}\right)=-118+1.3 * \mathrm{SiO}_{2}-2 * A n \\
& R T \ln \left(D_{S m}^{\text {plag } / l i q}\right)=-82+0.9 * \mathrm{SiO}_{2}-6 * A n \\
& R T \ln \left(D_{E u}^{\text {plag } / l i q}\right)=88-3.0 * \log \left(f_{2}\right)-2 * \mathrm{SiO}_{2}-2.9 * \mathrm{MgO} \\
& R T \ln \left(D_{G d}^{\text {plag } / l i q}\right)=-80+0.9 * \mathrm{SiO}_{2}-20 * A n
\end{aligned}
$$

$\mathrm{R}$ is the gas constant, $\mathrm{T}$ the temperature in Kelvin, $\mathrm{SiO}_{2}$ and $\mathrm{MgO}$ are in wt\% melt concentration and $\mathrm{An}$ is the normative molar anorthite component of plagioclase calculated via CIPW norm in GCDkit (Janoušek et al., 2006). As all equations contain the same temperature factor and the results of interest are ratios, the actual temperature for partitioning can be neglected and is chosen to be $850{ }^{\circ} \mathrm{C}$. I calculated partitioning coefficients for varying $\log _{10} f \mathrm{O}_{2}$ from -7 to -17 , resulting in $\mathrm{D}_{E u}^{\text {plag/liq }}$ between 0.03 and 0.93 . The partitioning coefficient being below 1 even under reduced conditions is caused by the differentiated composition used for modelling (table 2.1). At lower silica content $\mathrm{D}_{E u}^{\text {plag/liq }}$ can be easily above 2 (Bédard, 2006a). Archean magmatic processes are thought to have been more reduced than today's. (Foley, 2011), with Archean cratonic lithosphere having a mean $\log \mathrm{fO}_{2}$ of $-2.83 \Delta$ fayalite-quartzmagnetite (FQM), two log units below the average of post-Archean continental lithosphere. Considering this, $\log f \mathrm{O}_{2}=-17$ is a reasonable estimate at $850{ }^{\circ} \mathrm{C}$.

Results of the accumulation calculation are displayed in fig. 2.2a. At the maximum $\mathrm{D}_{E u}$ calculated with the compositional terms (table 2.1) and $\log \mathrm{fO}_{2}=-17$, up to $30 \%$ of feldspar addition are required to produce the observed Eu-anomaly in natural TTGs. A small amount 
of accumulation $(<10 \%)$ results in an Eu-anomaly of 1.1 while almost doubling the $\mathrm{Sr} / \mathrm{Y}$ ratio from 66 to 127 . The formation of a negative Eu-anomaly by plagioclase accumulation under high $\log \mathrm{fO}_{2}=-7$ is an artefact of the model. At high $\log \mathrm{fO}_{2}$ Eu behaves as the rest of the REE and no anomaly should develop. At $\log f \mathrm{O}_{2}=-10$ no Eu-anomaly forms, which seems to be the limit of the model.

A similar calculation can be done for hornblende, based on the partitioning regressions of
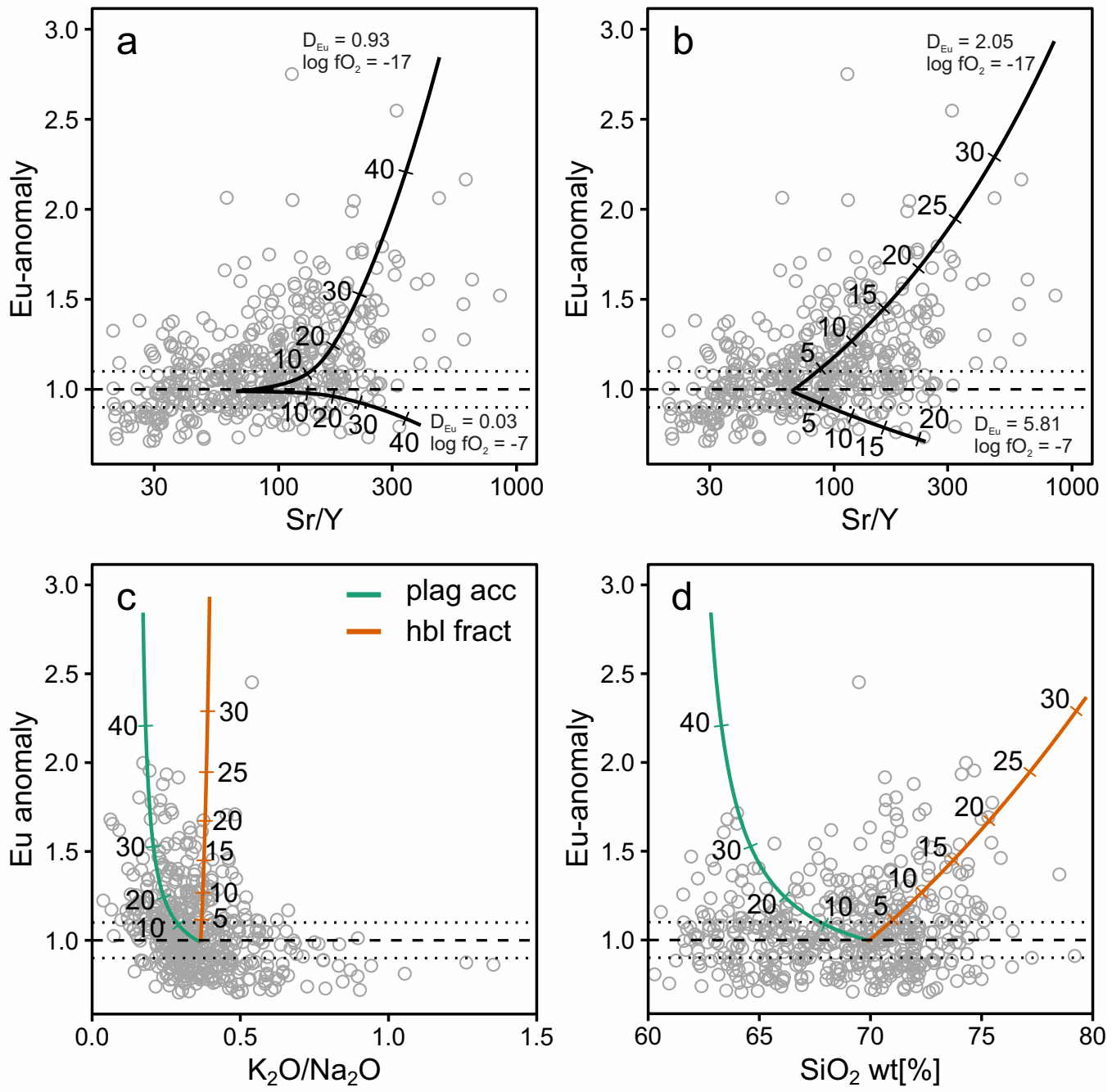

Figure 2.2: Modelling results for trace and major element evolution by fractional crystallisation of hornblende and accumulation of feldspar starting from an average Eu-anomaly free TTG composition (table 2.1). Values along evolution lines represent the amount of fractionation/accumulation in \%. Natural TTG compositions from from Moyen and Martin (2012) are plotted as open circles. a: Change in Eu-anomaly and $\mathrm{Sr} / \mathrm{Y}$ ratio by feldspar accumulation calculated via partitioning coefficients from Bédard $(2006 \mathrm{~b})$. The $\mathrm{Sr} / \mathrm{Y}$ ratio is plotted as $\log _{10}$. b: Change in Eu-anomaly and $\mathrm{Sr} / \mathrm{Y}$ ratio by hornblende fractionation calculated via partitioning coefficients from Nandedkar et al. (2016). The $\mathrm{Sr} / \mathrm{Y}$ ratio is plotted as $\log _{10}$. c: Change in Eu-anomaly and $\mathrm{K}_{2} \mathrm{O} / \mathrm{Na}_{2} \mathrm{O}$ by plagioclase accumulation and hornblende fractionation. Both are modelled for $\log \mathrm{fO}_{2}=-17$. d: Change in Eu-anomaly and $\mathrm{SiO}_{2}$ by plagioclase accumulation and hornblende fractionation. Both are modelled for $\log \mathrm{fO}_{2}=-17$. 
Table 2.1: Average Eu-anomaly free $(1 \pm 0.1)$ TTG element concentrations based on the database of Moyen and Martin (2012) and the temperature used for calculating partition coefficients. Oxides are in given in wt\% and trace elements in ppm. An is the molar anorthite content calculated by CIPW norm via the $R$ package GCDkit (Janoušek et al., 2006).

\begin{tabular}{ccccccccc}
\hline $\mathrm{SiO}_{2}$ & $\mathrm{MgO}$ & $\mathrm{Sr}$ & $\mathrm{Y}$ & $\mathrm{Sm}$ & $\mathrm{Eu}$ & $\mathrm{Gd}$ & $\mathrm{An}$ & $\mathrm{T}\left[{ }^{\circ} \mathrm{C}\right]$ \\
\hline 68.9 & 1.18 & 522 & 7.87 & 3.30 & 0.89 & 2.33 & 0.27 & 850 \\
\hline
\end{tabular}

Nandedkar et al. (2016). Their trace element partitioning depends on the partitioning of Ca between amphibole and melt as proposed by Sisson (1994) and displayed in following equations:

$$
\begin{aligned}
& \ln \left(D_{S r}^{h b l / l i q}\right)=0.25 * \ln \left(D_{C a}^{h b l / l i q}-1\right) \\
& \ln \left(D_{Y}^{h b l / l i q}\right)=1.8 * \ln \left(D_{C a}^{h b l / l i q}-0.2\right) \\
& \ln \left(D_{S m}^{h b l / l i q}\right)=1.6 * \ln \left(D_{C a}^{h b l / l i q}-0.5\right) \\
& \ln \left(D_{G d}^{h b l / l i q}\right)=1.5 * \ln \left(D_{C a}^{h b l / l i q} \pm 0\right)
\end{aligned}
$$

As I only investigate ratios, the actual value of $\mathrm{D}_{\mathrm{Ca}}^{h b l / l i q}$ is negligible. However, as Nandedkar et al. (2016) determined the partitioning coefficients of $\mathrm{Eu}^{2+}$ and $\mathrm{Eu}^{3+}$ by Young's modulus of the M4 site for each experiment individually and not by regression, I choose $\mathrm{D}_{C a}^{h b l / l i q}=$ 3.02 from their experiment RN13V2. In this experiment $\mathrm{D}_{E u^{2+}}^{h b l / l i q}$ is 0.50 and $\mathrm{D}_{E u^{3+}}^{h b l / l i q} 5.85$. Selecting both, Ca and Eu partitioning coefficients from one experiment ensures consistency between the partitioning of Eu and the other trace elements. By varying the proportion of Eu oxidation state I calculate trace element behaviour during hornblende fractionation the same way as for plagioclase accumulation (fig. 2.2). In experiment RN13V2 Nandedkar et al. (2016) calculate $35 \% E u^{2+}$ and $65 \% E u^{3+}$ while being above the nickel-nickel oxide (NNO) buffer at $860{ }^{\circ} \mathrm{C}$. To translate the $E u^{2+}-E u^{3+}$ proportion into oxygen fugacity for comparability to the feldspar modelling, I use the empirical equation of Burnham et al. (2015):

$$
\frac{E u^{3+}}{\sum E u}=\frac{1}{1+10^{\left(-0.25 * \log \mathrm{O}_{2}-6410 / T-14.2 \Lambda+10.1\right)}}
$$

$\mathrm{T}$ is the temperature in Kelvin and $\Lambda$ is the optical basicity calculated from Lebouteiller and Courtine (1998). Applied to the glass composition of the experiment RN13V2 the model of Burnham et al. (2015) confirms oxygen fugacity being above NNO.

The change in oxygen fugacity for modelling purpose does not affect the other trace elements of interest. The calibrations of Nandedkar et al. (2016) (eq. (2.3)) are solely dependent on Ca partitioning, which is not influenced by fugacity (Spear, 1981; Dalpé and Baker, 2000). Fractionation paths are calculated for $\log f O_{2}=-17$ and -7 . At $\log f O_{2}=-7, \mathrm{Eu}^{3+}$ makes up $99 \%$ of the total Eu. With a $\log f \mathrm{O}_{2}=-17, \mathrm{Eu}^{3+}$ makes up $29 \%$. Results of 
the fractional crystallisation of hornblende are displayed in fig. 2.2b. As for plagioclase accumulation, a positive Eu-anomaly is present at $\log \mathrm{fO}_{2} \leq-10$. At reasonable conditions of $\log f_{2}=-17$ (Foley, 2011), the majority of Eu-anomalies can be produced within $15 \%$ of hornblende fractionation, of course depending on fugacity. The effect on $\mathrm{Sr} / \mathrm{Y}$ is smaller than observed by plagioclase accumulation, due to a smaller difference between $D_{S r}^{h b l / l i q}$ and $D_{Y}^{h b l / l i q}$.

The magmatic process that leads to the development of an Eu-anomaly can be determined by the major element composition. The $\mathrm{K}_{2} \mathrm{O} / \mathrm{Na}_{2} \mathrm{O}$ ratio and $\mathrm{SiO}_{2}$ concentration allow to distinguish between the two processes. As the $\mathrm{K}_{2} \mathrm{O} / \mathrm{Na}_{2} \mathrm{O}$ ratio of plagioclase is very low, accumulation will result a decrease of the ratio (fig. 2.2c). Hornblende slightly prefers $\mathrm{Na}_{2} \mathrm{O}$ over $\mathrm{K}_{2} \mathrm{O}$ which produces an increasing ratio along fractionation. However, this effect would be small unless large amounts of hornblende fractionate. The process results are diametrical to each other. The same is true for $\mathrm{SiO}_{2}$ (fig. $2.2 \mathrm{~d}$ ), as it decreases by feldspar accumulation and increases by hornblende fractionation.

It is difficult and not the scope here to determine the governing process behind the Eu-anomaly for the literature compilation. Depending on the chosen starting composition of the model, either hornblende fractionation or feldspar accumulation can be possible. The magmatic evolution of a sample needs to be interpreted in context of its surrounding cogenetic rocks as done by Liou and Guo (2019).

The point at which a deviation in $\mathrm{Eu}^{*} / \mathrm{Eu}$ is an Eu-anomaly is not tightly constrained. To quantify this, the approach of O'Neill (2016) who describes the REE pattern by orthogonal polynomials can be used. The polynomials return an idealised REE slope with the real samples scattering around it. Only samples with 7 or more REE analysed should be considered for the calculation. The deviation of individual element analyses from the calculated slope is analytical noise and if Eu deviates significantly from that, an Eu-anomaly is present. I consider the Eu-anomaly not an analytical noise if the standard deviation (sd) is greater than $4 \sigma$ of the scatter of the analyses, Eu and Ce excluded. $2 \sigma$ are considered as analytical uncertainty of Eu and $2 \sigma$ for the other REE. With an average $1 \sigma$ of 0.07 for the TTG dataset from Moyen and Martin (2012) it can be assumed that the range of Eu-anomaly $=1 \pm 0.1$ may be partly or completely caused by analytical uncertainty only and not by a magmatic process.

\subsection{Conclusions}

Considering the Eu-anomaly is of great importance for investigating the magmatic history of TTGs. Already small anomalies of \pm 0.1 can indicate big changes in $\mathrm{Sr} / \mathrm{Y}$, disqualifying this ratio as a petrogenetic marker. Furthermore the increase of $\mathrm{K}_{2} \mathrm{O} / \mathrm{Na}_{2} \mathrm{O}$ by plagioclase accumulation shifts the major element composition towards a more trondhjemitic characteristic. Based on major element trends accompanying the Eu-anomaly in local cogenetic rock suites, 
it is possible to determine the process responsible for creating a positive Eu-anomaly. The natural TTG dataset shows that TTGs have not only been formed by partial melting but that processes as crystal fractionation and accumulation were involved as well. For the investigation of primary tonalitic and trondhjemitic magmas, it is necessary to remove samples bearing an Eu-anomaly from the data. Samples with an Eu-anomaly smaller \pm 0.1 can be safely regarded as non affected by Eu-anomaly producing magmatic processes. The deviation is more likely to be of analytical origin. 


\section{CHAPTER 3}

\section{A new titanium solubility model for silicate melts with implications for conditions of Archaean crust formation}

\subsection{Preface}

This manuscript was submitted to $\mathrm{G}^{3}$ - Geochemistry, Geophysics, Geosystems on the $14^{\text {th }}$ of January 2020. Co-authors are Tracy Rushmer, John Adam and Gerhard Wörner. The idea for studying Ti solubility of TTGs was brought up by John Adam in a discussion about where the liquidi of these rocks are. This study is designed to provide reasonable liquidus temperatures for further investigation of phases saturating the liquidus. I conducted the Ti solubility experiments with the help of John Adam. Data analysis, literature review and the calibration of the model were done by myself. All authors were involved in the interpretation of the data. The first draft of the manuscript was written by myself and significantly improved in respect to content, structure and style by Tracy Rushmer, John Adam and Gerhard Wörner.

\section{Key points}

- TTGs can form in presence of a Ti rich accessory phase between 750 and $900{ }^{\circ} \mathrm{C}$

- The temperature range requires $8-12 \mathrm{wt} \% \mathrm{H}_{2} \mathrm{O}$ dissolved, thus the presence of an aqueous fluid.

- Ti-temperatures for many TTGs are lower than expected liquidus temperatures; they can not have formed at these conditions.

\subsection{Abstract}

We calibrated a new Ti solubility model for silicate melts that are saturated in either rutile and/or ilmenite by a regression on published data for 389 experiments. This calibration has been validated using new Ti-solubility data for an Archean tonalite. We find that temperature, melt polymerisation (expressed as non bridging oxygen per tetrahedra $(\mathrm{NBO} / \mathrm{T})$ ) and the ratio of singly to doubly charged cations $((\mathrm{Na}+\mathrm{K}) /(\mathrm{Fe}+\mathrm{Mg}+\mathrm{Ca}))$ are the most significant parameters controlling Ti solubility. Additional parameters, such as pressure, $\mathrm{H}_{2} \mathrm{O}$ and oxygen fugacity, are insignificant for the solubility of $\mathrm{Ti}$ in natural igneous systems.

We apply the Ti-saturation thermometer to tonalite-trondhjemite-granodiorite (TTG) compositions, which are the characteristic granitoids of Archean cratons, to better constrain their 
conditions of formation. By comparing the temperatures required for Ti saturation with expected whole-rock liquidus temperatures we can distinguish between TTG melts that were either saturated or under-saturated in Ti. More evolved compositions are more likely to have been saturated in $\mathrm{Ti}$ with calculated saturation temperatures of $750-900{ }^{\circ} \mathrm{C}$. Corresponding liquidus relations for the bulk rocks require dissolved $\mathrm{H}_{2} \mathrm{O}$ of 8 to $12 \mathrm{wt} \%$. Such concentrations may reflect the presence of aqueous fluid during the melting of basaltic source rocks. Both, Ti-saturated and under-saturated TTGs carry Nb depletions. Consequently, fractionation involving rutile and/or ilmenite cannot be the sole reason for $\mathrm{Nb}$ depletions in TTGs. These must have been either inherited from source rocks and/or parent magmas, caused by other crystal phases (e.g. amphibole or sphene), or be the result of mixing between Ti-saturated and under-saturated melts.

\section{Plain Language Summary}

The formation mechanisms of the first continents on Earth are uncertain because their composition is different to modern continents. It is unknown if modern plate tectonics were operating at that time or when they started. To better understand the formation conditions of early continents we calibrated a thermometer based on the solubility of titanium into melt to constrain temperatures of melt generation. This method works because rocks from early continents are depleted in $\mathrm{Nb}$, Ta and Ti. This is commonly associated with the presence of a titanium rich accessory phase (e.g. ilmenite or rutile) during melt formation, buffering the Ti concentration in the melt and retaining $\mathrm{Nb}$ and $\mathrm{Ta}$.

Applied to rocks from early continental crust we calculate melt formation temperatures of 750-900 ${ }^{\circ} \mathrm{C}$. From these temperatures we can infer the amount of water present during melting because water significantly influences the temperature of melting. Estimated water is between 8 and $12 \mathrm{wt} \%$ which requires the presence of free water during melting, because dehydration melting cannot produce such elevated water concentration. This leads to the requirement of a process that provides enough water to the melt formation region which is easiest by recycling of water-rich oceanic crust into the mantle.

\subsection{Introduction}

Archaean cratons are a significant fraction of the modern continental crust and generally consist of greenstone belts and enclosed granitoids. The latter are mostly rocks of the tonalite-trondhjemite-granodiorite (TTG) series that differ significantly from the rocks usually associated with post-Archaean continent formation (Martin, 1986). These differences have prompted questions about the continuity of crust-forming processes over time, including the timing of the onset of modern plate tectonics (Martin et al., 2005; Smithies et al., 2009; Moyen and Martin, 2012; Turner et al., 2014; Hastie et al., 2016; Tang et al., 2016; Greber et al., 2017; Bédard, 2018; Moyen and Laurent, 2018; Wiemer et al., 2018). Within this context, a range of contrasting mechanisms and geodynamic settings have been proposed for 
the origin of TTGs. These include: (i) the melting of steeply-subducted basaltic crust directly analogous to what has been proposed for modern adakites (Martin et al., 2005); (ii) shallow subduction and underplating as described for the Isua province (Polat et al., 2015; Nutman et al., 2015) with the melting of stacked slabs of oceanic crust (Nagel et al., 2012; Hastie et al., 2016); and (iii) construction of thick oceanic plateaus, or "proto-crust" (Johnson et al., 2017), with basal melt generation at high pressures (Smithies et al., 2009) and subsequent crustal overturns (Collins et al., 1998; Bédard, 2006a, 2018; Wiemer et al., 2018). These alternative proposals do not necessarily preclude one another as observations from different cratons are not accounted for by any single model of TTG formation (Van Kranendonk, 2010).

There is common agreement that hydrated basalts are likely source rocks for TTG magmas (Smithies, 2000; Condie, 2005; Moyen and Martin, 2012) and that variations in HREE concentrations are reflective of different depths of source rock melting (Moyen, 2011). The hydrated basalt hypothesis is supported by numerous experimental studies (see Moyen and Stevens (2006) and Hoffmann et al. (2019) for compilation). However, just how hydrous TTG magmas actually were isn't known. Thus the validity of generally accepted models of TTG formation are difficult to rigorously assess. To address this problem, we have developed a temperature-dependent solubility model for $\mathrm{TiO}_{2}$ in silicate melts and used this to first constrain the liquidus temperatures of TTG magmas, and then (indirectly) their $\mathrm{H}_{2} \mathrm{O}$ concentrations as well. On this basis, we show that TTG magmas are likely to have been strongly hydrous (with up to 8-12 wt\% of $\mathrm{H}_{2} \mathrm{O}$ ) necessitating a fluid-saturated source.

\subsection{Ti-thermometry on TTGs - a key to their origin}

The behaviour of titanium in TTGs holds a potential clue to their conditions of origin due to the consistent negative correlation between $\mathrm{TiO}_{2}$ and $\mathrm{SiO}_{2}$ (fig. 3.1) that suggests a temperature-dependent solubility control. If it can be shown that a Ti-rich mineral (rutile, ilmenite) was a liquidus phase during TTG crystallisation, the minimum temperatures of their formation can be constrained and the potential role of rutile or ilmenite in controlling the Nb depletion in TTGs can be assessed. We use the term "Ti-rich mineral" for Ti bearing minerals that buffer Ti-activity at 1.0 in an equilibrium silicate melt and thus would only form in Ti-saturated melts. Even though the Ti-activity of ilmenite is below 1.0, we do not see a statistically significant difference for saturation between ilmenite and rutile, as described later.

TTGs characteristically show relative depletions of Nb-Ta-Ti on mantle-normalised plots (Moyen and Martin, 2012). However, the role of rutile as a saturating oxide during TTG formation has been strongly debated due to the highly variable but commonly subchondritic $\mathrm{Nb} / \mathrm{Ta}$ ratios (5-60) of TTGs. Low ratios can be produced by amphibolite fractionation (Foley et al., 2002; Hoffmann et al., 2011a) whereas higher ratios should result from the presence of rutile (Xiong et al., 2011; Hoffmann et al., 2011a). Furthermore, mica also has the potential 


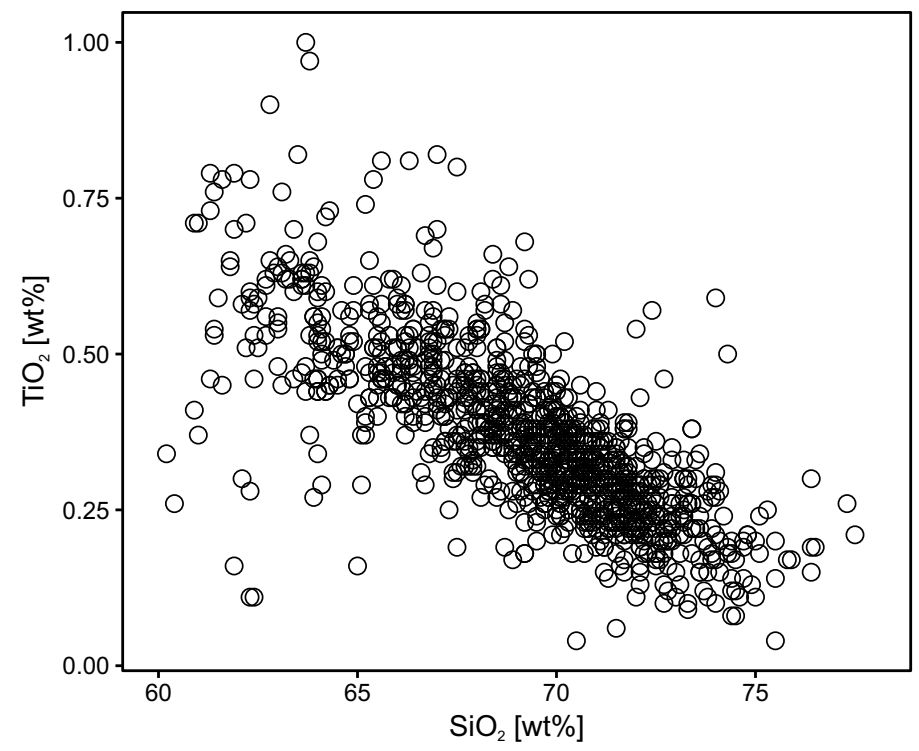

Figure 3.1: $\mathrm{TiO}_{2}$ vs $\mathrm{SiO}_{2}$ for TTGs. Data from Nutman et al. (1999), Moyen (2011), Huang et al. (2013), Laurent et al. (2014), O'Neil and Carlson (2017) and Johnson et al. (2019). After merging the data, duplicates are identified by the normalised major element composition and removed. This and all following images were made with ggplot2 (Wickham, 2016).

to fractionate $\mathrm{Nb} / \mathrm{Ta}$ towards low ratios (Stepanov and Hermann, 2013). Variability of the $\mathrm{Nb} /$ Ta ratio might also be inherited from fluid alteration prior to melting (Rapp et al., 2003). However, these objections can be set against the need for some kind of Ti-rich phase to control $\mathrm{TiO}_{2}$ variations during the differentiation of TTGs. The most effective phases are rutile and/or ilmenite whose solubility in silicate melts is sensitive to temperature, $\mathrm{SiO}_{2}$ content and other compositional variables, but not to magmatic $\mathrm{H}_{2} \mathrm{O}$ (Hellman and Green, 1979; Green and Pearson, 1986). Thus there is the potential for using Ti-solubility to constrain the liquidus temperatures of TTG magmas which can then be used to estimate magmatic $\mathrm{H}_{2} \mathrm{O}$ concentrations via the concentration-dependent liquidus point depressions caused by dissolved $\mathrm{H}_{2} \mathrm{O}$ in silicate melts.

\subsubsection{Previous experimental studies of titanium solubility in silicate melts}

The first experimental study of Ti solubility in silicate melts was conducted by Hellman and Green (1979) who recognised the regular occurrence of Ti-rich accessory phases (rutile, ilmenite and titanite) in natural rocks as well as experimental charges. They identified rutile as a dominantly high pressure phase with titanite predominating at intermediate pressures $(<1.5 \mathrm{GPa})$. Green and Pearson (1986) conducted an extensive solubility study for rutile and ilmenite using a range of mafic to felsic starting compositions at temperatures of $900-1100{ }^{\circ} \mathrm{C}$ and pressures from 0.75 to $3.0 \mathrm{GPa}$, with 2, 5 and $10 \mathrm{wt} \%$ of dissolved $\mathrm{H}_{2} \mathrm{O}$. Their experiments revealed that $\mathrm{TiO}_{2}$ solubility correlates positively with temperature and negatively with $\mathrm{SiO}_{2}$ but is relatively unaffected by $\mathrm{H}_{2} \mathrm{O}$ in melts. Ryerson and Watson (1987) conducted a similar 
study of rutile solubility in mafic to felsic melts at $1000-1350{ }^{\circ} \mathrm{C}$ and $0.6-3.0 \mathrm{GPa}$ and found similar dependencies on temperature and melt composition. However, they also found a negative pressure dependence as well as a positive effect of excess alkalis relative to alumina (i.e. there is an increased solubility of Ti for peralkaline compositions).

Green and Adam (2002) determined a negative correlation between Ti-solubility and pressure as well as a slightly decreased solubility with increasing $\mathrm{K}_{2} \mathrm{O}$ concentration in melts. Hayden and Watson (2007) presented a solubility model for a lower temperature range (650-1000 ${ }^{\circ} \mathrm{C}$ ) at $1 \mathrm{GPa}$ with evolved compositions. The model was based on a combination of temperature dependence and melt composition effects. Gaetani et al. (2008) published a Ti solubility model for a pressure range from 0.0001 to $3.5 \mathrm{GPa}$ and temperatures from 1150 to $1450{ }^{\circ} \mathrm{C}$ for a similar compositional range. Xiong et al. (2009) calibrated a rutile solubility model specifically for TTG compositions at $1.5-3.5 \mathrm{GPa}, 750-1250{ }^{\circ} \mathrm{C}$, and dissolved melt $\mathrm{H}_{2} \mathrm{O}$ concentrations of 8-14 wt\%. Their solubility model is dependent on rutile composition, temperature, pressure, melt composition and dissolved water concentration.

In conjunction, the described studies show that the primary controls on Ti-solubility in silicate melts are temperature and melt composition. In particular, the effect of melt polymerisation is important together with alkali to alumina relations that exert a strong secondary effect on melt polymerisation. Pressure and $\mathrm{H}_{2} \mathrm{O}$ dissolved in melts have subordinate influences on Ti-solubility.

\subsubsection{Assessment of previously published Ti-solubility models}

We assessed published Ti-solubility models using the results from 465 experiments in which the melt phase was saturated in a Ti-rich accessory mineral (ilmenite, rutile and/or sphene). The data used for this assessment are from Green and Pearson (1986), Ryerson and Watson (1987), Conrad et al. (1988), Beard and Lofgren (1991), Patiño Douce and Johnston (1991), Rapp et al. (1991), Skjerlie and Johnston (1992), Skjerlie and Johnston (1993), Skjerlie and Johnston (1996), Sen and Dunn (1994), Gardien et al. (1995), Patiño Douce and Beard (1995, 1996), Rapp and Watson (1995), Skjerlie and Patiño Douce (1995), Springer and Seck (1997), Pickering and Johnston (1998), Castro et al. (1999), Green and Adam (2002), Pertermann and Hirschmann (2003), Klemme et al. (2002), Yearron (2003), Spicer et al. (2004), Patiño Douce (2005), Sisson et al. (2005), Xiong et al. (2005), Xiong et al. (2009, 2011), Hayden and Watson (2007), Gaetani et al. (2008), Spandler et al. (2008), Alonso-Perez et al. (2009), García-Arias et al. (2012), Laurie and Stevens (2012), and Qian and Hermann (2013). A list of the experimental conditions and results for individual studies is given in table 3.5. In the next section we apply published thermometers to our experimental dataset and compare recorded experimental temperatures with calculated values.

The first model we examine is that of Ryerson and Watson (1987) (fig. 3.2a). It describes the solubility of rutile in silicate melts as a function of temperature, pressure, and melt 
composition with the latter described by the parameter FM (eq. (3.1)). All iron is assumed to be ferrous. The calibration range is from 1000 to $1300{ }^{\circ} \mathrm{C}$ and pressures of 0.8 to $3.0 \mathrm{GPa}$. A total of 66 six experiments from the experimental dataset are both within the calibration range and saturated with rutile (fig. 3.2a). For these experiments there is an average temperature deviation of $-82 \pm 138{ }^{\circ} \mathrm{C}$ ( $1 \sigma$ uncertainty). Temperatures outside of the calibration range are also underestimated. An exception are temperatures around $700{ }^{\circ} \mathrm{C}$ which are calculated correctly.

$$
F M=\frac{N a+K+2(C a+F e+M g)}{A l * S i}
$$

The solubility model of Hayden and Watson (2007) (fig. 3.2b) also describes solubility as a function of temperature and the melt parameter FM (eq. (3.1)) but at a constant pressure of $1 \mathrm{GPa}$. It is calibrated for a temperature range between 650 and $1000{ }^{\circ} \mathrm{C}$ and $\mathrm{FM}$ between approximately 0.75 and 2.0. Temperatures for 12 experiments within calibration range are estimated by $-124 \pm 45{ }^{\circ} \mathrm{C}$, with the deviation increasing with temperature. Temperatures calculated for experiments outside of the calibration range also increase in underestimation with increasing temperature. A possible reason for the persistent underestimation of temperature is that most of the experiments used to calibrate the Hayden and Watson (2007) thermometer were saturated only with rutile. Because of this, FM values for the melts are not codependent on temperature and pressure as they would be in the presence of silicate minerals and thus the relative effects of melt structure and temperature on Ti solubility are insufficiently described without additional information.

Xiong et al. (2009) (fig. 3.2c) described Ti-solubility as a function of temperature, pressure, melt composition as FM (eq. (3.1)), $\ln \left(\mathrm{TiO}_{2}\right)$ for rutile, and $\mathrm{wt} \% \mathrm{H}_{2} \mathrm{O}$ dissolved. The calibration is for temperatures of $750-1250{ }^{\circ} \mathrm{C}$, pressures of 1.5-3.5 GPa, and FM between 1.35 and 2.47. 57 experiments are within the range of calibration and are overestimated by an average of $19{ }^{\circ} \mathrm{C}$. Only Xiong et al. (2009) provide data for $\mathrm{TiO}_{2}$ concentrations in rutile and on this basis we set the $\mathrm{TiO}_{2}$ content of rutile at $90 \mathrm{wt} \%$. This produces good results even for experiments where rutile is not present but instead ilmenite is the saturating phase. Experiments outside of the calibration range are underestimated by an average of $-16{ }^{\circ} \mathrm{C}$. Xiong et al. (2009) do not report uncertainties based on their regression but give an estimated error of $10-15 \%$.

In summary, the model of Ryerson and Watson (1987) is not reliable for temperatures $<1000{ }^{\circ} \mathrm{C}$ due to the systematic underestimation of temperatures. The model of Hayden and Watson (2007) also has limited utility as its calibration is limited to $1 \mathrm{GPa}$ and even within the range of its calibration temperatures are systematically underestimated. The model of Xiong et al. (2009) returns good results even outside of its calibration range, however, its application requires prior knowledge about pressure, temperature and/or melt $\mathrm{H}_{2} \mathrm{O}$ concentrations. Ti-solubility can be adequately described by less parameters because the melt composition 

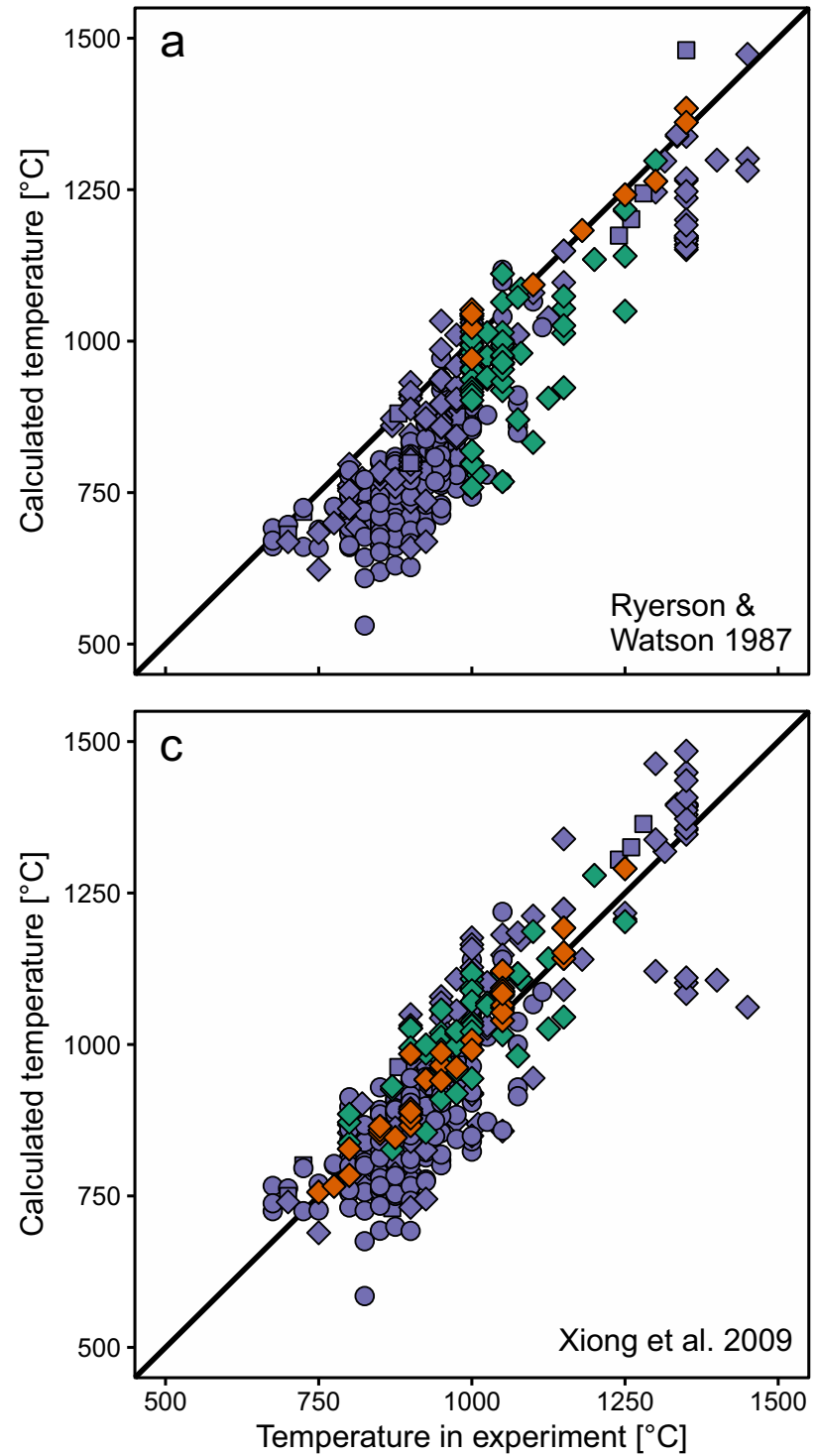

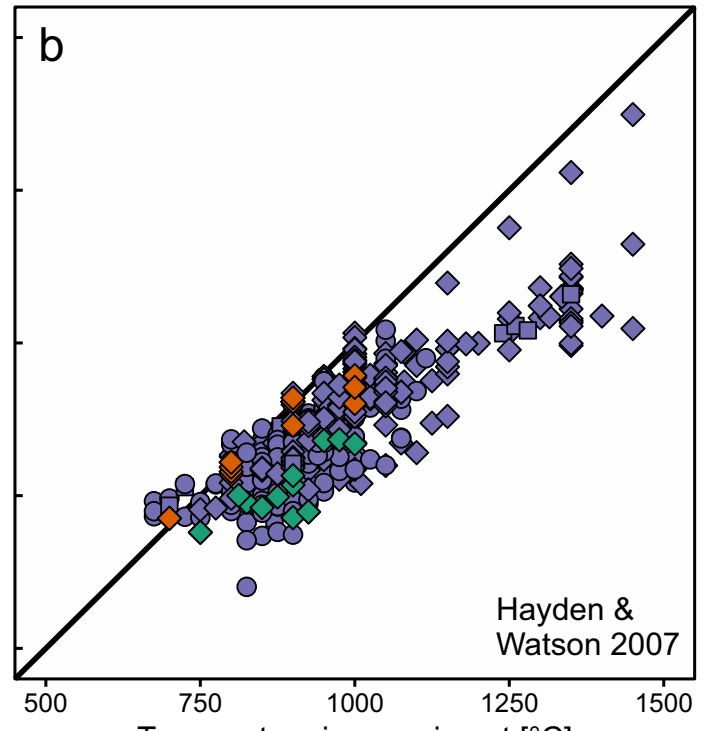

Temperature in experiment $\left[{ }^{\circ} \mathrm{C}\right]$

experiments used for calibration

- experiments within calibration range

experiments outside calibration range

O ilmenite

$\square$ ilmenite \& rutile

$\diamond$ rutile

Figure 3.2: Published Ti-solubility models of a: Ryerson and Watson (1987), b: Hayden and Watson (2007) and c: Xiong et al. (2009) applied to the Ti excess phase saturated experiments (table 3.5). Calculated temperatures are plotted against recorded experimental temperatures.

depends on the unconstrained parameters. It changes with pressure, temperature and $\mathrm{H}_{2} \mathrm{O}$. By performing regression analysis on Ti as $\log _{10}$ in mol\% (table 3.1) we see that the model does not significantly improve by adding $\mathrm{H}_{2} \mathrm{O}$ and pressure into the regression as displayed by $r^{2}$. Using the two parameters improves the models $r^{2}$ by 0.02 and decreases the residual standard error by 0.01 Therefore, pressure and $\mathrm{H}_{2} \mathrm{O}$ parameters are not necessary to describe Ti-solubility. However, by neglecting them, uncertainty is introduced because for a given melt composition a decreased solubility could be result of either higher pressure, less $\mathrm{H}_{2} \mathrm{O}$ or lower temperature. This uncertainty remains well within error of the method. Due to the identified deficiencies of published Ti-solubility models, we calibrate a new model based on 
the experimental dataset.

Table 3.1: Statistical evaluation of parameters controlling Ti solubility: temperature, FM, pressure and $\mathrm{H}_{2} \mathrm{O}$. Ti is described as $\log _{10}$ in mol\%. RSE is the residual standard error.

\begin{tabular}{lccccccc}
\hline & Intercept & $\mathrm{T}\left[{ }^{\circ} \mathrm{C}\right]$ & $\mathrm{FM}$ & $\mathrm{P}[\mathrm{GPa}]$ & $\mathrm{H}_{2} \mathrm{O}[\mathrm{wt} \%]$ & $\mathrm{RSE}$ & $\mathrm{r}^{2}$ \\
\hline Estimate & -3.33 & 0.0027 & 0.126 & -0.06 & 0.02 & 0.20 & 0.81 \\
Std. error & 0.09 & 0.0001 & 0.009 & 0.01 & 0.003 & & \\
$t$ value & -37.27 & 26.9 & 14.5 & -4.63 & 7.91 & & \\
$\operatorname{Pr}(>|t|)$ & $<2 \mathrm{e}-16$ & $<2 \mathrm{e}-16$ & $<2 \mathrm{e}-16$ & $4.64 \mathrm{e}-06$ & $1.38 \mathrm{e}-14$ & & \\
\hline Estimate & -2.87 & 0.00223 & 0.141 & - & - & 0.21 & 0.79 \\
Std. error & 0.07 & 0.00008 & 0.009 & - & - & & \\
$t$ value & -40.3 & 27.53 & 15.89 & - & - & & \\
$\operatorname{Pr}(>|t|)$ & $<2 \mathrm{e}-16$ & $<2 \mathrm{e}-16$ & $<2 \mathrm{e}-16$ & - & - & & \\
\hline
\end{tabular}

\subsection{Calibration of a new Ti-saturation thermometer by regression of previously-published experimental data}

Before calibrating our model we filtered the database of previously-published experiments based on three criteria. These were that: (1) experiments are saturated in either rutile and/or ilmenite, (2) experimental glasses contain $>0.10 \mathrm{wt} \% \mathrm{TiO}_{2}$, and (3) experiments are saturated in one or more silicate minerals. This reduces the original total of experiments from 465 to 389 . In spite of this, the filtered dataset covers a wide range of physical conditions and melt compositions with temperatures of $675-1350{ }^{\circ} \mathrm{C}$, pressures of 0.0001-5.0 GPa (fig. 3.3a), melt $\mathrm{H}_{2} \mathrm{O}$ concentrations from 0-20.8 wt\%, and melt $\mathrm{SiO}_{2}$ concentrations from 43.0-82.0 wt\%. Further processing of the data is necessary owing to the over-representation of experiments at temperatures between 850 and $1000{ }^{\circ} \mathrm{C}$ (see fig. 3.3a, density distributions). This complicates the regression of the entire range of conditions, since sparsely sampled regions are underweighted. In order to remove the effects of the sampling bias without discarding individual experiments, we used the group_by() function of the dplyr package (Wickham et al., 2018) in R (R Core Team, 2017). Group_by() reads a dataset and bins it according to one or multiple parameters, in our case $\log _{10}$ of the mol\% Ti. Using a cut option we decided the number of bin based on the $\log _{10}$ of Ti mol\% which was cut into 200 equi-spaced bins. This resulted in 116 data points with 84 bins remaining empty. Average values for all dataset parameters were then calculated for each bin. This procedure attenuates the scatter in oversampled areas and accentuates less well determined areas in the modified dataset. The value 200 was chosen after testing different cut values to create the best working model.

After initial tests, we found that temperature, non-bridging oxygens per tetrahedra $(\mathrm{NBO} / \mathrm{T}$, eq. (3.3), Virgo et al., 1980), and the ratio of single to doubly charged cations $((\mathrm{Na}+\mathrm{K}) /(\mathrm{Fe}+$ $M g+C a)$ ) are the most significant factors controlling the solubility of Ti in silicate melts (fig. 3.4a \& b). We tested several other parameters as for example the alumina saturation index but discarded them due to low statistical significance for Ti-solubility. All iron is 

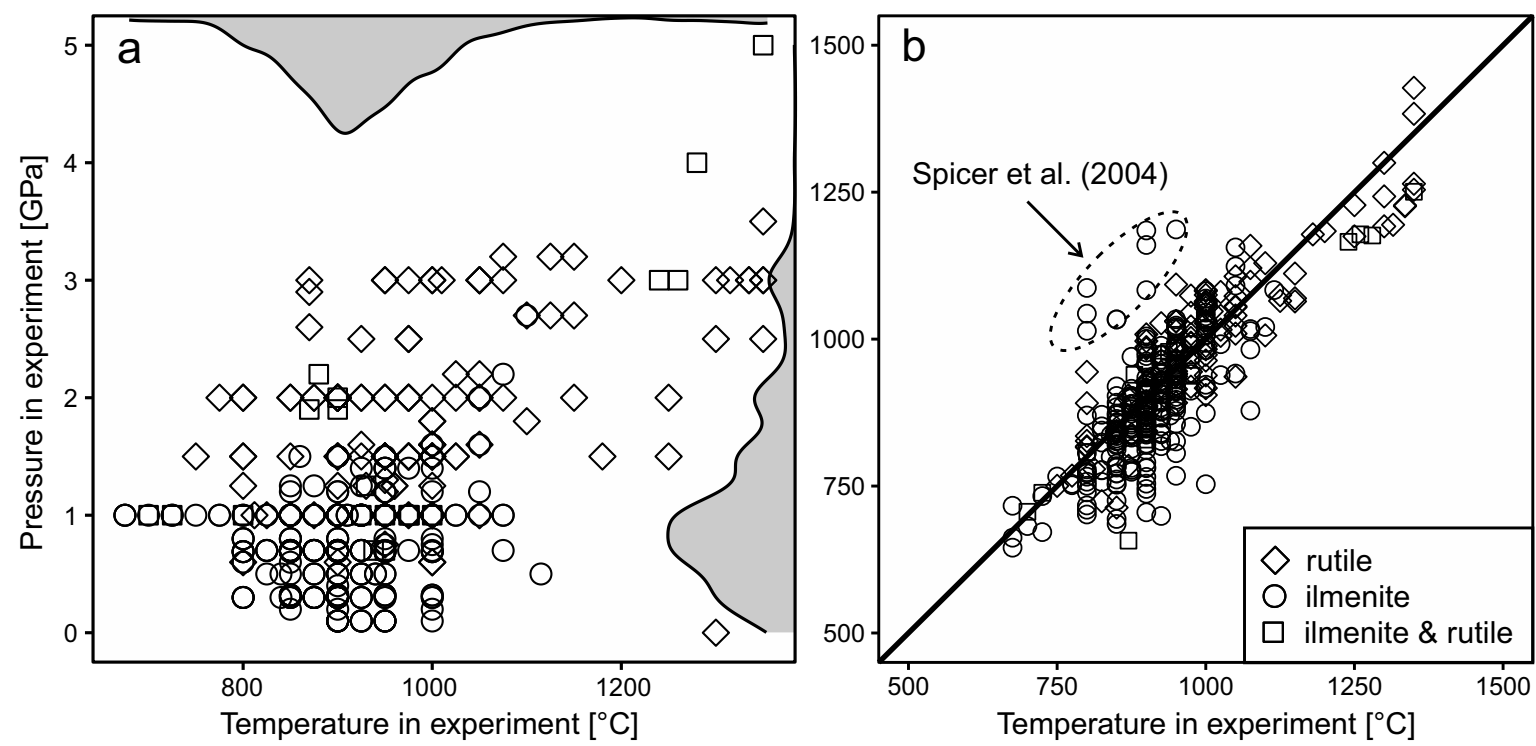

Figure 3.3: a: P-T plot of the filtered literature dataset comprising 389 rutile and/or ilmenite saturated experiments. Grey areas on the secondary axes display the density distribution of experiments regarding pressure and temperature settings without a scale. $\mathbf{b}$ : The model calibrated on the modified dataset (table 3.1) applied to the filtered dataset shown in fig. 3.3a. Outlying data from Spicer et al. (2004) are melts produced in pelite melting with very high $\mathrm{K}_{2} \mathrm{O}$ content.

assumed as ferrous for both parameters. While ferrous/ferric ratios are available in the experimental dataset, they would have to be assumed for natural data, wherefore we decided to simplify the model. Ti solubility correlates positively with both temperature and NBO/T (fig. 3.4a) but negatively with the ratio of uni to divalent cations (fig. 3.4b). In general, the less polymerised the melt the greater the Ti solubility. There is no or only a weak correlation between the ratio of uni to divalent cations and the other two parameters (temperature and $\mathrm{NBO} / \mathrm{T})$. With these factors in mind, we chose a regression based on temperature, NBO/T and the uni to divalent cation ratio. This predicts Ti solubility more accurately (with $\mathrm{r}^{2}$ of 0.84, table 3.2) than regressions including the effects of pressure and melt $\mathrm{H}_{2} \mathrm{O}$, with $\mathrm{r}^{2}$ of 0.81 , (table 3.1). It also results in a good fit over the whole range of temperatures (Figure 3b). Besides an expected scatter around the target temperature there is a significantly overestimated group of samples. These are from the study of Spicer et al. (2004) and are characterised by elevated $\mathrm{K}_{2} \mathrm{O}$ generated by pelite melting.

The final calibration on the modified dataset is displayed in Table 3.2 and Equation 3.4. The $1 \sigma$ deviation is around $11 \%$. 
Table 3.2: Regression analysis for Ti solubility on the original and the modified dataset. Ti is described as $\log _{10}$ in mol\%. RSE is the residual standard error.

\begin{tabular}{lcccccc}
\hline & Intercept & $\mathrm{T}\left[{ }^{\circ} \mathrm{C}\right]$ & $\mathrm{NBO} / \mathrm{T}$ & Cation ratio & $\mathrm{RSE}$ & $\mathrm{r}^{2}$ \\
\hline unmodified dataset & & & & & & \\
Estimate & -2.42 & 0.00212 & 1.2 & -0.053 & 0.16 & 0.84 \\
Std. error & 0.09 & 0.00009 & 0.1 & 0.005 & & \\
$\mathrm{t}$ value & -28.5 & 22 & 10.5 & -10.18 & & \\
$\operatorname{Pr}(>|t|)$ & $<2 \mathrm{e}-16$ & $<2 \mathrm{e}-16$ & $<2 \mathrm{e}-16$ & $<2 \mathrm{e}-16$ & & \\
\hline modified dataset & & & & & \\
Estimate & -2.63 & 0.00248 & 0.8 & -0.097 & 0.11 & 0.92 \\
Std. error & 0.08 & 0.00009 & 0.1 & 0.007 & & \\
$\mathrm{t}$ value & -31.7 & 28.4 & 7.57 & -14.5 & & \\
$\operatorname{Pr}(>|t|)$ & $<2 \mathrm{e}-16$ & $<2 \mathrm{e}-16$ & $2.75 \mathrm{E}-13$ & $<2 \mathrm{e}-16$ & & \\
\hline
\end{tabular}
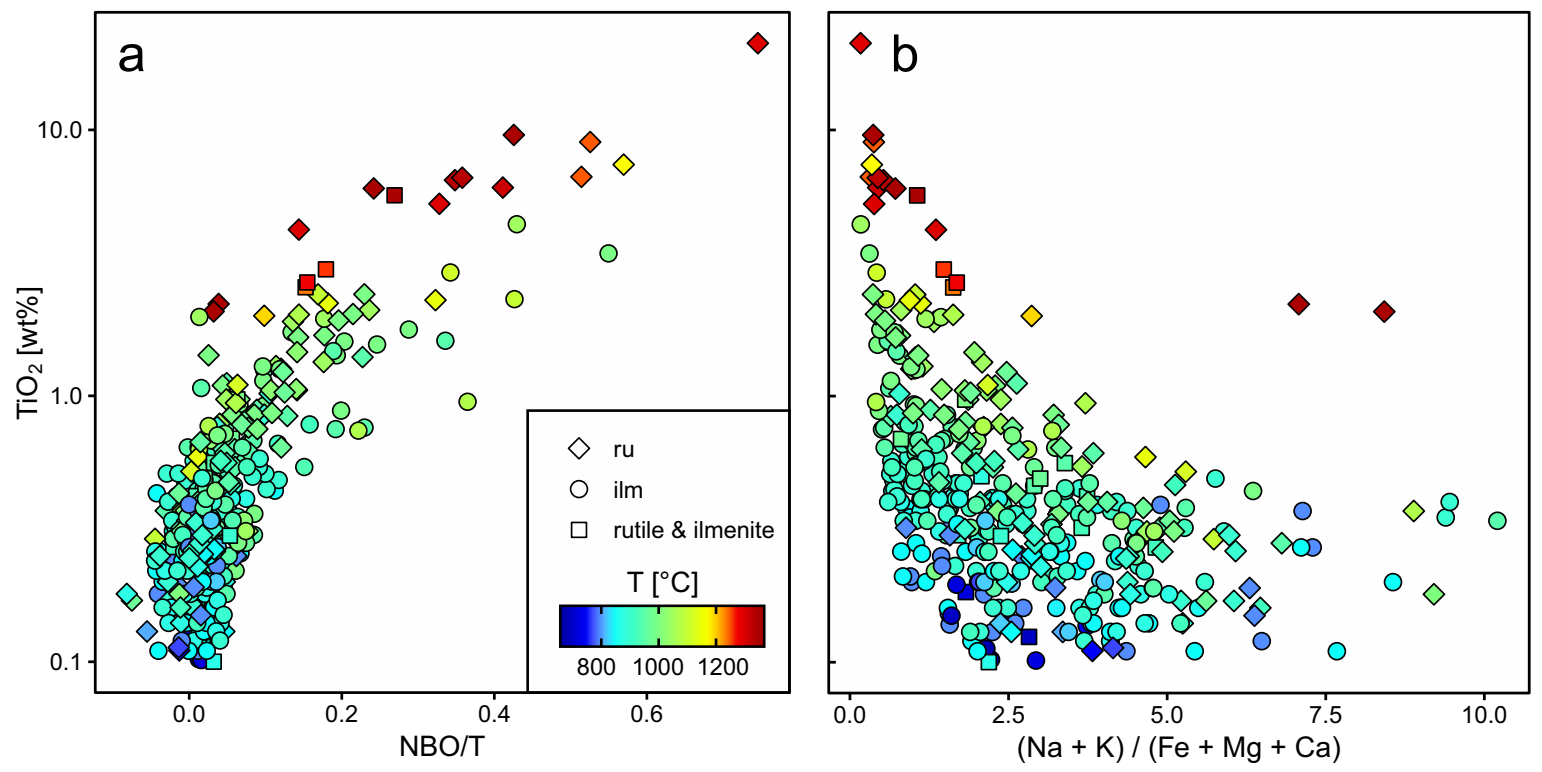

Figure 3.4: Literature experimental data plotted to display the relation of $\mathrm{NBO} / \mathrm{T}(\mathbf{a})$ and the cation ratio (b) with Ti concentration in silicate melts.

\subsection{Ti solubility experiments on an Archaean tonalite}

To independently test our new calibration we performed solubility experiments at Macquarie University on an ilmenite-doped Archaean tonalite (PC-103 of O'Neil et al., 2012) from the Nuvvuagittuq Belt of the Superior province, Canada. Classified via feldspar diagram of O'Connor (1965), the composition is granodioritic, however we will keep the original classification as set in Adam et al. (2012). A list of run conditions and results is given in table 3.3. 


\subsubsection{Experimental methods}

All experiments were conducted in end-loaded piston-cylinder apparatus of the type described by Boyd and England (1960) using a cold piston-in technique. Furnace assemblies were of $12.7 \mathrm{~mm}$ diameter and $32 \mathrm{~mm}$ length with talc outer sleeves and Pyrex inner sleeves. Internal components were made of ALSIMAG. Temperatures were monitored using $\mathrm{Pt}-{ }_{90} \mathrm{Rh}_{10}$ thermocouple and automatically controlled by a Leeds \& Northrup Electromax V temperature controller. A minus $10 \%$ correction for the effects of friction were applied to measured pressures (Green et al., 1966). Oxygen fugacity was unbuffered but believed to have been between fayalite-quartz-magnetite (FQM) and wüstite-magnetite (WM) in the furnace type used (Green, 1976). Run conditions varied from 700 to $1100{ }^{\circ} \mathrm{C}$ and 0.5 to $2.0 \mathrm{GPa}$.

The starting materials used in experiments were powdered glass prepared from the natural tonalite PC-103, natural ilmenite, and distilled $\mathrm{H}_{2} \mathrm{O}$. To ensure Ti saturation for the broad range of experimental conditions $4 \mathrm{wt} \%$ of ilmenite was added to starting compositions. This was in-creased to $6 \mathrm{wt} \%$ for run 2077 (at $1000{ }^{\circ} \mathrm{C}$ and $0.5 \mathrm{GPa}$ ) as the previously run 2070 conducted under the same conditions was Ti-undersaturated with only $4 \mathrm{wt} \%$ of added ilmenite. The use of ilmenite has the advantage that rutile stability can also be assessed. The concentration of added $\mathrm{H}_{2} \mathrm{O}$ varied from 5-15 wt\% to ensure a broad range of liquidus temperatures. For comparison, two titanite-doped (5 wt\%) experiments $(2103,2104)$ were also conducted owing to its common occurrence as an accessory mineral in TTGs.

During experiments starting materials were contained in $\mathrm{Ag}_{70} \mathrm{Pd}_{30}$ capsules with a total sample mass of $15 \mathrm{mg}$ in each capsule. $\mathrm{H}_{2} \mathrm{O}$ was added with a graduated micro-syringe and a careful check of weights kept at each stage of capsule preparation to guard against unwanted loss. Capsules were sealed using a PUK 3 spot-welder with capsules wrapped in wet tissue during welding. After welding, the watertight integrity of capsules was checked by placing capsules in an oven at $110{ }^{\circ} \mathrm{C}$ for ten minutes before re-weighing. To enhance crystal growth during experiments, experiments were first overheated by $100{ }^{\circ} \mathrm{C}$ for 30 minutes and then progressively cooled to target temperatures at $4-5{ }^{\circ} \mathrm{C} /$ minute. At the finish of experiments, samples were quenched by turning off power to the furnace assemblies. After capsule recovery, capsules were longitudinally sectioned with a diamond saw and then mounted in epoxy and polished preparatory to analysis.

\subsubsection{Analytical methods}

The major element compositions of the run products were analysed with a Caméca SX100 based at Macquarie University Sydney and a JEOL JXA-8900RL at the Geoscientific Centre Göttingen University. Beam diameters between 20 and $30 \mu \mathrm{m}$ were used for glass analyses with an acceleration voltage of $15 \mathrm{kV}$ and beam current of 15 to $20 \mathrm{nA}$. Acquisitions times were $10 \mathrm{~s}$ for $\mathrm{Na} ; 15 \mathrm{~s}$ for $\mathrm{K}, \mathrm{Al}, \mathrm{Si}, \mathrm{Fe}, \mathrm{Mn}, \mathrm{Mg}$ and $\mathrm{Ca} ; 30$ seconds for $\mathrm{P}$ and 60 seconds for Ti. To evaluate Na loss during measurement we explored different beam diameters from 5 to $30 \mu \mathrm{m}$ over time. Figure 3.5a displays the decline of Na counts during a measurement with 


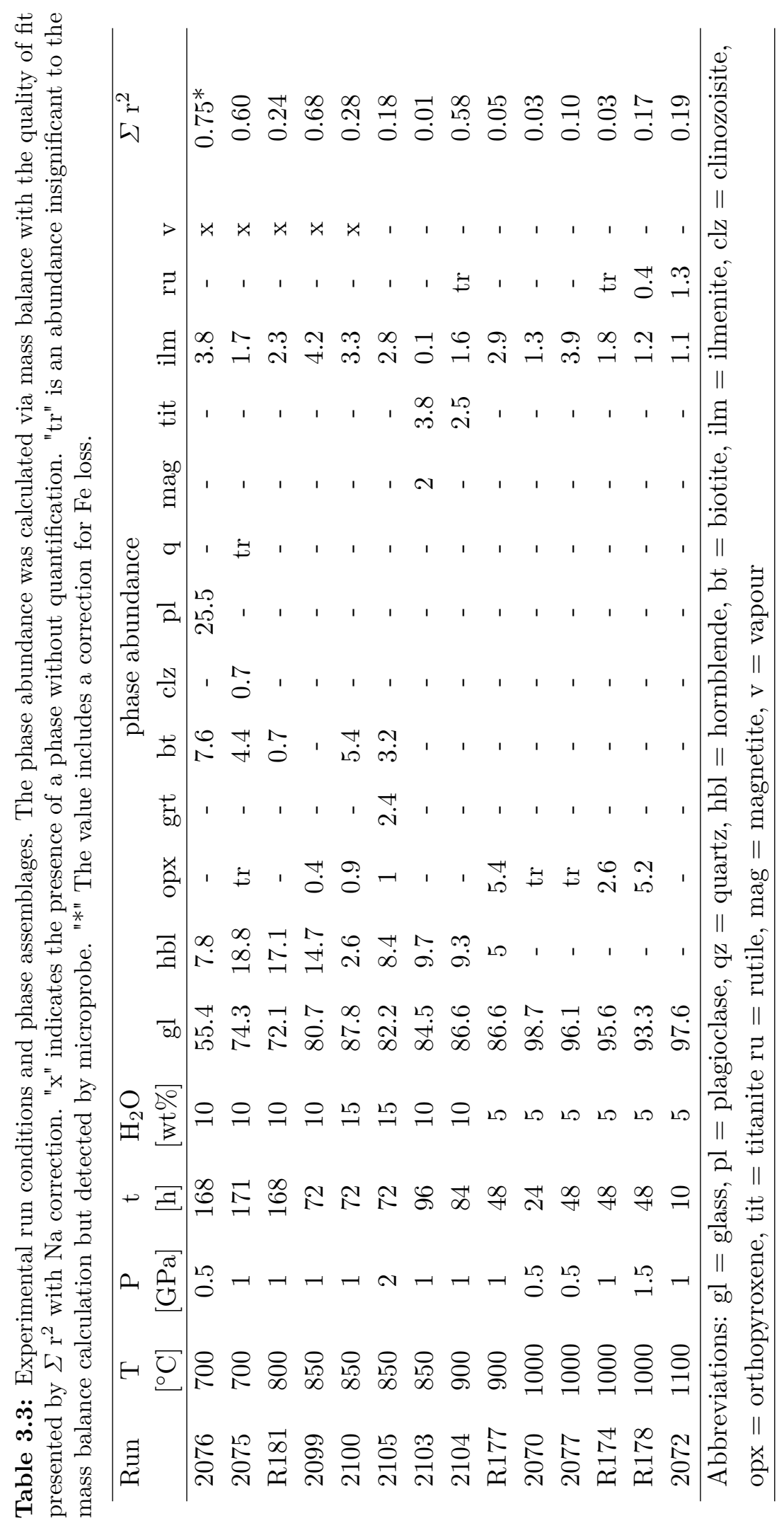


time as well as with smaller beam diameter. The counts per second (cps) are averages for 10 second intervals. Na loss during glass analyses was also assessed via mass-balances calculated between run products and starting compositions. Measured and corrected $\mathrm{Na}_{2} \mathrm{O}$ concentrations are presented in table 3.4. The corrected $\mathrm{Na}_{2} \mathrm{O}$ concentrations are indicated with an *
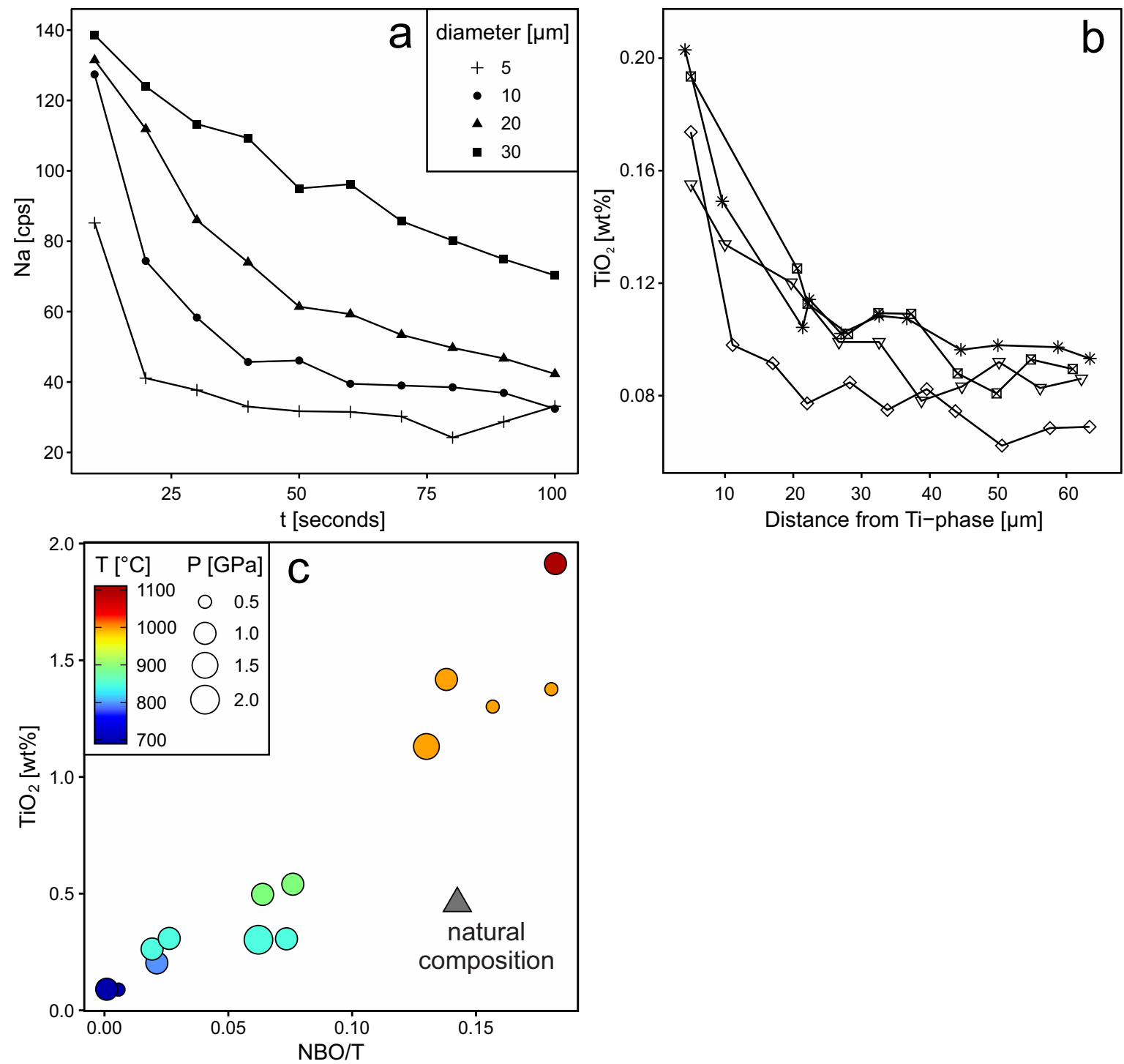

Figure 3.5: a: Na loss over time during analysis at different beam diameters. The cps is a 10 second average. b: Effect of secondary Ti-fluorescence in glass close to Ti phases. Profiles were measured in sample 2075 adjacent to ilmenite. c: $\mathrm{TiO}_{2}$ content of melts produced in experiments on tonalite PC-103. The natural composition of PC-103 is plotted as a the grey triangle.

The spots chosen for glass analyses were randomly distributed through sample capsules although care was taken to ensure that all spots were sufficiently distance from Ti-rich accessory phases to avoid the effects of secondary fluorescence on measured $\mathrm{TiO}_{2}$ (see Wark and Watson, 2006; Kronz et al., 2012). To assess the latter effect, we measured glass profiles 
with a $5 \mu \mathrm{m}$ diameter beam perpendicular to Ti phases. Results for Run 2075 are displayed in fig. 3.5b. At distances of $\geq 50 \mu \mathrm{m}$ from rutile or ilmenite we could not detect any effect of secondary fluorescence.

\subsubsection{Results}

A list of run products and matching experimental conditions is presented in table 3.3. Analyses of run products are given in table 3.4. Even though no reversal experiments were conducted we assume that equilibrium was approached in our experiments based on homogenous glass compositions and euhedral crystal shapes. All experiments produced Ti-rich accessory minerals with ilmenite present in all run products. Excepting runs 2070 and 2072, all experiments were saturated with more than one mineral phase (Runs 2070 and 2072 contained ilmenite only). Runs 2076, R174, R178 and 2104 were additionally saturated in rutile. The titanite-doped runs 2103 and 2104 were both saturated in titanite together with ilmenite. Run 2104 also produced rutile. Runs 2076, 2075, R181, 2099 and 2100 contained a vapour phase, as demonstrated by the presence of vesicles in glasses. The $\mathrm{TiO}_{2}$ concentrations of the experimentally produced glasses are positively correlated with $\mathrm{NBO} / \mathrm{T}$ and temperature (fig. 3.5c). Glasses from near-liquidus experiments at around $1000{ }^{\circ} \mathrm{C}$ and with 5 wt $\% \mathrm{H}_{2} \mathrm{O}$ contain over twice the $\mathrm{TiO}_{2}$ concentration present in the natural tonalite. Regardless of temperature, pressure and dissolved $\mathrm{H}_{2} \mathrm{O}$ concentration, the $\mathrm{TiO}_{2}$ concentration of the natural rock was not reproduced or even closely approached under near-liquidus conditions.

The Fe-loss resulting from experiments was calculated from mass-balances and varied from $0.1-9.8 \%$ of the total Fe initially present in starting materials (table 3.4). Run 2076 experienced significant more Fe loss with $33.8 \%$. The low loss of run 2103 might be due to an underestimation of $\mathrm{FeO}$ of magnetite in the mass-balance calculation. 


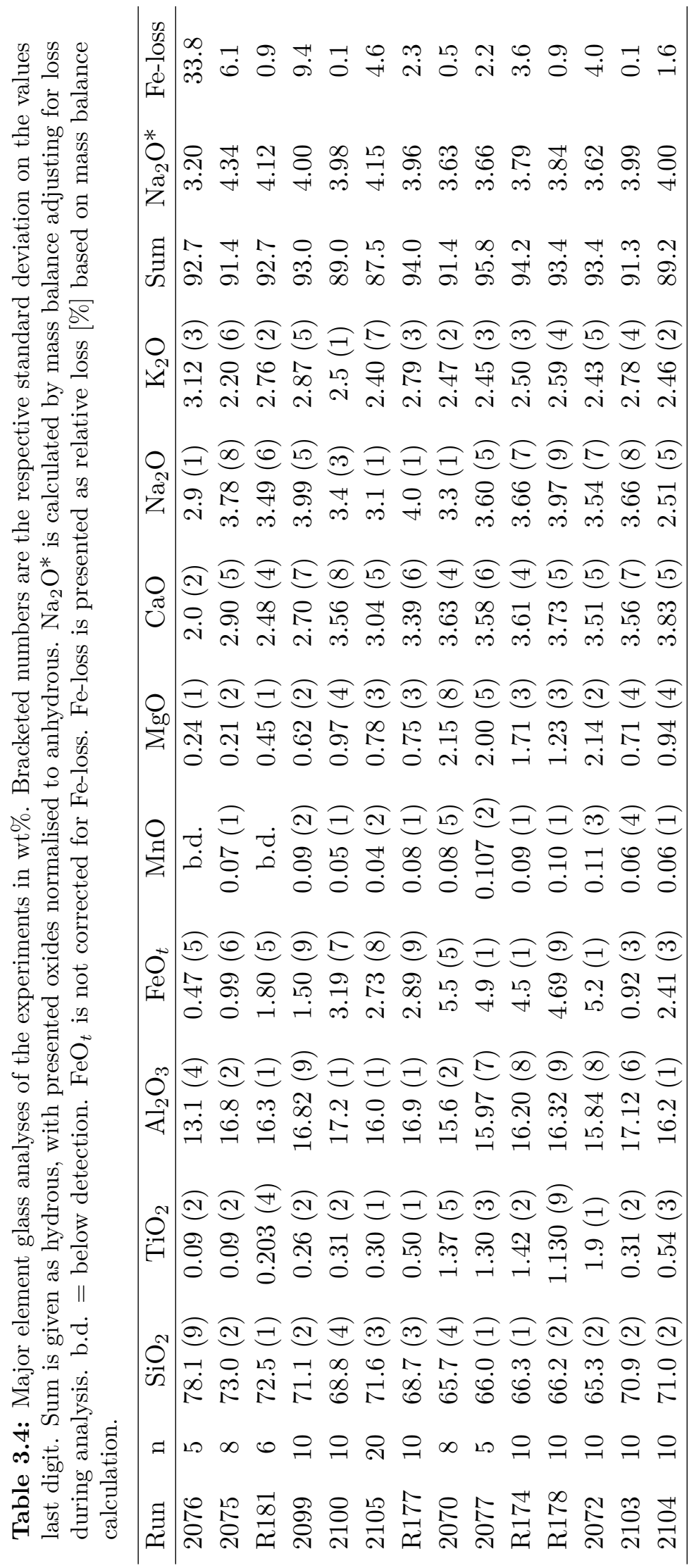




\subsection{Application of the new Ti-solubility model to the experimental results for PC-103}

To test the accuracy of our new Ti solubility model (table 3.2, eq. (3.4)), including its applicability to melts of TTG composition, we applied it to the glass compositions given in table 3.4 of this study. The results (fig. 3.6) justify our strategy of sample filtering and noise-reduction. Whereas calibrations based on the modified and unmodified datasets give similar results for the temperature range $800-900{ }^{\circ} \mathrm{C}$, the calibration on the unmodified dataset underestimates lower temperatures and overestimates higher temperatures. In contrast to this, the calibration on the modified dataset returns good results for both high and low temperatures with all temperatures estimated within the $1 \sigma$ uncertainty. The results are of similar accuracy to those returned by Xiong et al. (2009) but without the use of unconstrained parameters. A single exception is produced by estimates for Run R174 where both models overestimate the run temperature by $50{ }^{\circ} \mathrm{C}$. Both models return a temperature for PC-103 of around $850{ }^{\circ} \mathrm{C}$. As previously commented on, this is significantly less than possible liquidus temperatures as constrained by the composition of the bulk rock. The Fe-loss (table 3.4) results in lower Ti solubility but does not result in a bias of the model as the amount of Fe is accounted for in our regression. 


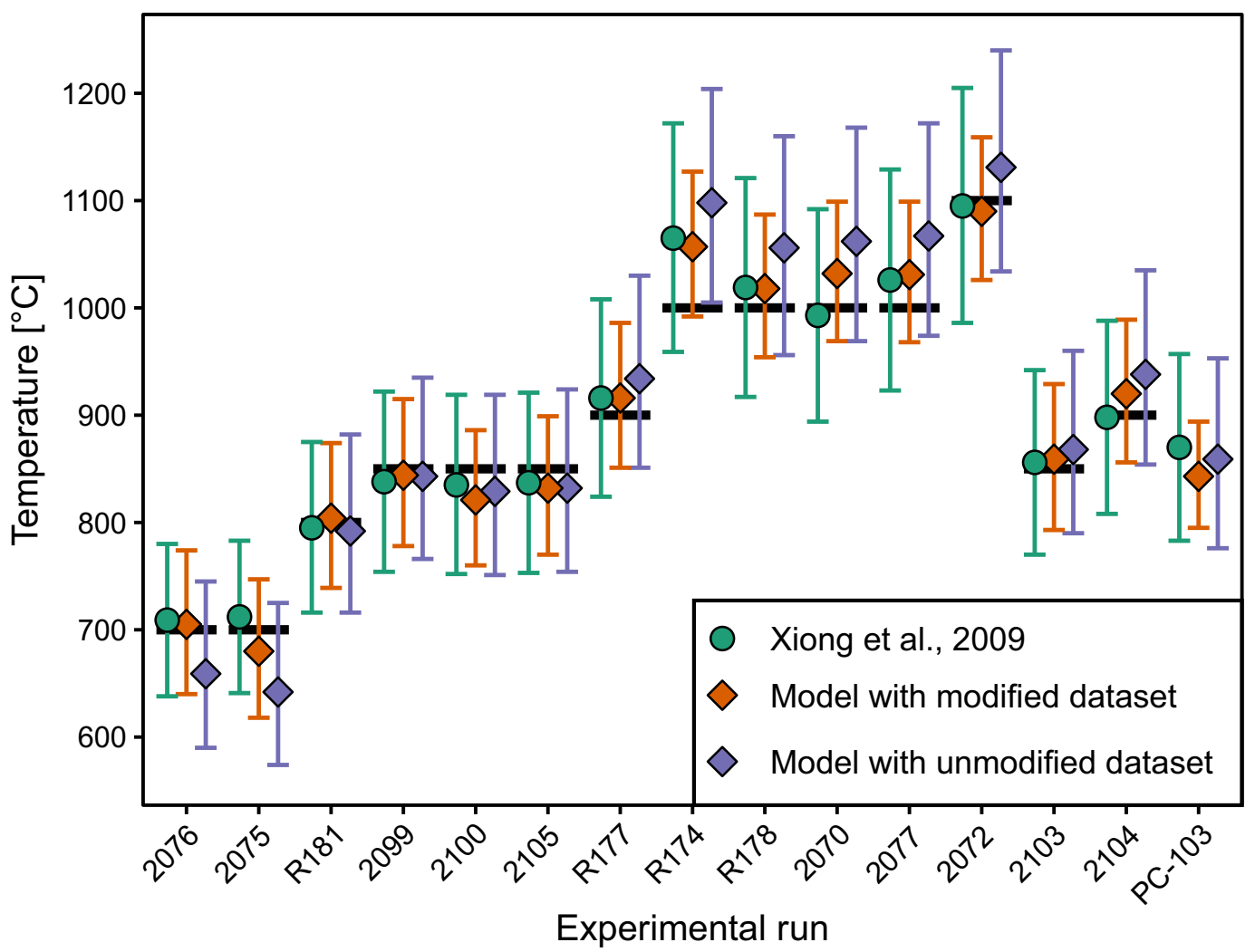

Figure 3.6: Calculated temperatures compared to actual conditions for PC-103 experiments (black bars) using the calibration model based on the modified and unmodified dataset. The modified dataset has reduced bias and scatter due to statistical operations explained in Section 3.5. Temperatures using the Xiong et al. (2009) calibration are given for comparison. 2103 and 2104 are doped with titanite. PC-103 is the natural composition. Uncertainty for Xiong et al. (2009) is a $10 \%$ interval as given in their paper. Calculation of the natural rock PC-103 Ti-saturation temperature with Xiong et al. (2009) is based on a $1 \mathrm{GPa}$ and a $5 \mathrm{wt} \% \mathrm{H}_{2} \mathrm{O}$ estimate.

\subsection{Application of the new thermometer to Archean TTGs}

Two datasets for Archean TTGs (Moyen, 2011; Johnson et al., 2019) were complemented here with data from Nutman et al. (1999) Huang et al. (2013), Laurent et al. (2014) and O'Neil and Carlson (2017). Samples appearing twice were identified and removed. The resulting dataset includes analyses for 1860 samples. This was filtered using the GCDkit of Janoušek et al. (2006) to include only samples with CIPW-norms conforming to the definition of either tonalite, trondhjemite or granodiorite. We further selected compositions with La $>10 \mathrm{ppm}$, $\mathrm{Yb}<2 \mathrm{ppm}$ and an Eu anomaly below 1.1 to assure the characteristic HREE depletions that define TTGs. Compositions with $<64 \mathrm{wt} \% \mathrm{SiO}_{2}$ (28 samples) were intentionally kept since they are potential parents to the more evolved granitoids. The filtered TTG dataset contains 359 samples. 


\subsubsection{Calculated Ti-saturation temperatures for TTGs}

Applying our model to Archaean TTGs produces a generally positive correlation between temperature and $\mathrm{NBO} / \mathrm{T}$ for a temperature range of 750 to $900{ }^{\circ} \mathrm{C}$ (fig. 3.7a). Based on the overlap with experimental data for Ti-saturated melts (fig. 3.7a), we can also distinguish between TTGs that could have been saturated (above the red line) and the ones that could not have been saturated (below the red line) in a Ti-rich accessory mineral. Many TTGs simply do not contain enough Ti to be in equilibrium with a Ti-rich accessory mineral at their expected liquidus temperatures. In any case, the calculated temperatures must be regarded as minimum estimates of potential liquidus temperatures. This is because TTG magmas may have evolved at higher temperatures where the behaviour of $\mathrm{Ti}$ was governed by the crystallisation of common Ti-bearing silicates, such as amphibole, pyroxene, garnet or mica. This is borne out by the consistent negative correlation between $\mathrm{Ti}$ and indices of fractionation in TTGs, irrespective of whether they were potentially saturated or under-saturated in a Ti-rich accessory phase.

The maximum Ti-saturation temperatures $\left(\sim 960{ }^{\circ} \mathrm{C}\right)$ calculated for Archaean TTGs are at
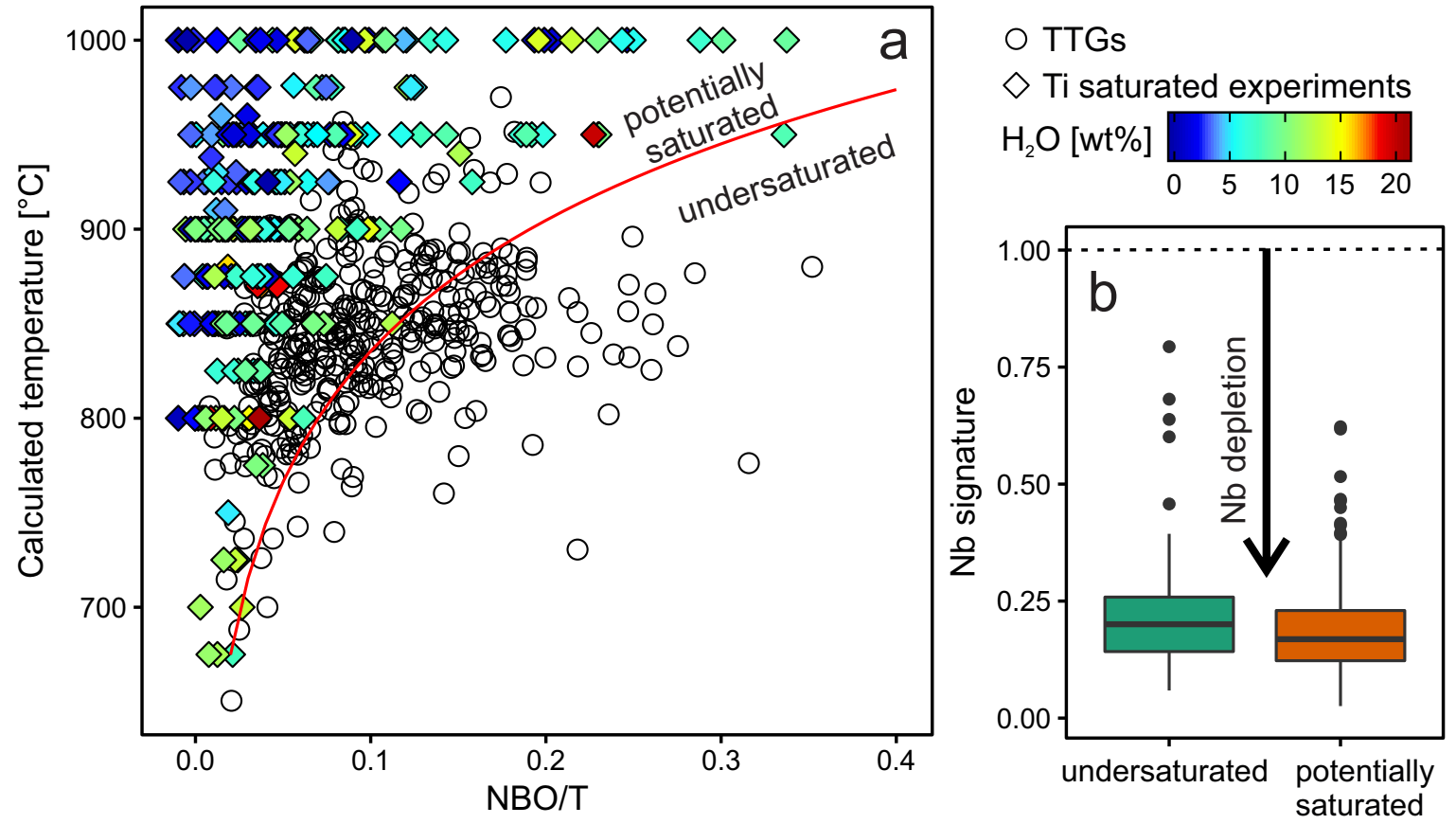

Figure 3.7: a) Ti saturated liquidus temperatures calculated from with our model for the natural TTG dataset. The Ti saturated experimental melts are plotted with colour-coded $\mathrm{H}_{2} \mathrm{O}$. The red line separates potentially saturated from undersaturated TTG compositions based on the extend of experimental data. b) Box plot of the $\mathrm{Nb}$ depletion for Ti excess phase saturated and undersaturated TTGs in comparison. Y-axis is a $\log _{10}$ scale. The $\mathrm{Nb}$ signature is calculated as $N b / N b^{*}=N b_{P M} / \sqrt{\left(U_{P M} * L a_{P M}\right)}$. The decision of saturation is based on the red line in fig. 3.7a. PM is from McDonough and Sun (1995).

NBO/T between 0.09 and 0.125 (fig. 3.7a). Less evolved compositions (higher NBO/T) have 
lower calculated temperatures. We interpret this to be the point where more evolved TTG melts became saturated with a Ti-rich accessory mineral. More primitive compositions with $\mathrm{NBO} / \mathrm{T}>0.2$ cannot have been saturated in Ti-rich accessory minerals at their expected liquidus temperatures. This has significant relevance for the role of Ti-rich accessory minerals in controlling high field strenght element (HFSE) abundances in TTGs, as will be discussed the next section.

\subsubsection{The controls on Nb-depletions in TTGs}

To assess the relationship between Nb depletions in TTGs and saturation in a Ti-rich accessory phases, we calculated a $\mathrm{Nb} / \mathrm{Nb}^{*}$ signature for the 265 samples of the dataset that contain data for $\mathrm{Nb}$, La and $\mathrm{U}$. This was done using the relationship

$$
N b / N b^{*}=N b_{P M} / \sqrt{\left(U_{P M} * L a_{P M}\right)}
$$

and mantle-normalized concentrations based on the primitive mantle of McDonough and Sun (1995). As shown in fig. 3.7b, potentially saturated as well as undersaturated TTGs both show relative $\mathrm{Nb}$ depletions, although the former are typically more depleted than the latter. This is consistent with a limited role for Ti-rich accessory phases in evolved TTGs magmas, but also requires a more general explanation for the Nb depletions in TTGs. This could be linked to magmas mixing whereby TTG melts that were initially saturated in a Ti-rich accessory phase mixed with Ti-undersaturated melts. Alternatively, the Nb depletions may have been inherited from source materials that were themselves already depleted in $\mathrm{Nb}$.

In whatever case, it appears that earlier magmatic processes pre-dating TTG formation must be responsible for the Nb depletions in TTGs. Such an idea has already been debated in the literature. For example, Smithies et al. (2009) noted Nb depletions in the Archaean-aged Coucal basalts of the East Pilbara Terrane, which were considered by them as potential source material for TTGs. However, modelling by Johnson et al. (2017) showed that in this case rutile is still needed to explain observed $\mathrm{Nb}$ depletion in TTGs. Nb depletions similar to those found in the Coucal Formation are also present in other cratons (Thurston and Fryer, 1983; Crow and Condie, 1987; Puchtel et al., 1997; Jenner et al., 2009; Hoffmann et al., 2011b; Adam et al., 2012; Parks et al., 2014) and so similar arguments might be expected to apply. However, because the difference in Nb-depletions is small between Ti-saturated and undersaturated TTGs, the role of Ti-rich accessory phases would have to be limited making it likely that other phases that also fractionate $\mathrm{Nb}$ from La are involved. These include amphibole and mica (Foley et al., 2002; Stepanov and Hermann, 2013).

\subsubsection{Implications for the evolution of TTG magmas}

A corollary of low magmatic temperatures for TTGs is that their magmas can be expected to have been water-rich with between 8 to 12 wt $\%$ of dissolved $\mathrm{H}_{2} \mathrm{O}$ (fig. 3.7). This has 
significant implications for potential TTG sources and settings of origin. Thus a comparison of our estimates with those of other studies is warranted. Our estimated liquidus temperatures of 750 and $900{ }^{\circ} \mathrm{C}$ are lower than those $\left(900-1100{ }^{\circ} \mathrm{C}\right)$ suggested by Moyen and Stevens (2006) on the basis of melting experiments on dry basaltic starting materials. They are also lower than the temperatures suggested by Wyllie et al. (1997) for tonalitic and trondhjemitic melts under eclogite facies conditions. However, under amphibolite facies conditions TTG melts can be produced at a much lower temperatures $\left(750-900{ }^{\circ} \mathrm{C}\right.$, see Wyllie et al., 1997). These conditions are comparable to estimates based on both mineral thermometry for TTGs (Bédard, 2003) and thermodynamic modelling (Palin et al., 2016; Johnson et al., 2017).

Low magmatic temperatures may reflect low degrees of melting, the presence of an aqueousfluid phase during melting, evolution from hydrous parent magmas, or some combination of these factors. In the case of the first option, it can be shown that low degree melts produced by fluid-absent melting of amphibolite (Clemens and Vielzeuf, 1987; Rushmer, 1991) contain comparatively modest $\mathrm{H}_{2} \mathrm{O}$ concentrations (4.6-6.5 wt\%). This objection can be removed if melting occurred in a fluid-saturated environment, as in a lower crustal setting affected by underthrusting of hydrated oceanic crust. Such an option was favoured by Hastie et al. (2016) who argued for fluid involvement arising from the dehydration of oceanic basalt involved in the basal melting of oceanic plateaus.

\subsection{Summary and conclusions}

We have formulated a new thermometer for silicate melts based on the solubility of Ti-rich accessory minerals (rutile and ilmenite). This is based on an extensive experimental dataset and constrains temperature as a function of $\mathrm{Ti}, \mathrm{NBO} / \mathrm{T}$ and $(\mathrm{Na}+\mathrm{K}) /(\mathrm{Fe}+\mathrm{Mg}+\mathrm{Ca})$. Application of our thermometer to Archaean TTGs produces temperature estimates that are generally between 750 and $900{ }^{\circ} \mathrm{C}$. We note that for many TTGs these temperatures are significantly less than expected liquidus temperatures and that consequently liquids of this composition are unlikely to have been saturated in either rutile or ilmenite. This has implications for the role of Ti-rich accessory phases in the production of $\mathrm{Nb}$ depletions in TTGs. These must be ascribed to either inheritance and/or the role of Ti-bearing silicate minerals, such as amphibole and mica. Another corollary of low magmatic temperatures is that they can only be achieved if TTG magmas were relatively hydrous, with 8-12 wt\% of dissolved $\mathrm{H}_{2} \mathrm{O}$. This cannot be accounted for by low degrees of melting alone and favours the presence of a fluid.

\subsection{Remarks and usage of the model}

There are several things to consider with regard to the applicability of the Ti solubility model. One is that the model does not answer the question of whether the liquidus of a particular sample was ever saturated in either rutile or ilmenite. It only returns an expected saturation temperature. In addition, the thermometer is not calibrated for titanite. Furthermore, the 
model assumes that whole rocks are representative of original melts and is not suitable for rocks influenced by cumulate processes. Whether or not a sample was potentially saturated in either rutile and/or ilmenite can be assessed by comparing it to the experimental range shown in fig. 3.7a. If the sample lies within the covered range of experimental compositions, the Ti-saturated liquidus can be calculated and the result treated as a minimum temperature estimate. The thermometer is not recommended for samples that lie outside of this range.

$\mathrm{NBO} / \mathrm{T}$ is calculated after Mysen (1990) as (eq. (3.3)):

$$
\frac{N B O}{T}=\frac{2 *(2 * S i+1.5 * A l+F e+M g+C a+0.5 *(N a+K))-4 *(S i+A l)}{S i+A l}
$$

All elements in the equation are in mol\%. The Ti saturated liquidus temperature is calculated as (eq. (3.4)):

$$
\log _{10}(T i)=-2.63+0.00248 * T+0.8 * \frac{N B O}{T}-0.097 * \frac{N a+K}{F e+M g+C a}
$$

Temperature in eq. (3.4) is given in ${ }^{\circ} \mathrm{C}$, $\mathrm{Ti}$ and the cation ratio are in mol\%. The 1 $\sigma$ uncertainty the model is at $11 \%$ based on the comparison of calculated and recorded temperatures. 
Table 3.5: List of studies containing Ti phase saturated experiments. $\mathrm{H}_{2} \mathrm{O}$ is the amount dissolved in the melt, either given or estimated by the difference to $100 \%$ total of the analyses.

\begin{tabular}{|c|c|c|c|c|c|c|}
\hline study & $\mathrm{n}$ & $\mathrm{T}\left[{ }^{\circ} \mathrm{C}\right]$ & $\mathrm{P}[\mathrm{GPa}]$ & $\mathrm{H}_{2} \mathrm{O}[\mathrm{wt} \%]$ & $\mathrm{TiO}_{2}[\mathrm{wt} \%]$ & $\mathrm{NBO} / \mathrm{T}$ \\
\hline Alonso-Perez et al. (2009) & 16 & $800-1000$ & $0.8-1.2$ & $4-15$ & $0.13-0.86$ & $-0.01-0.32$ \\
\hline Beard and Lofgren (1991) & 59 & $800-1000$ & $0.1-0.69$ & $1-12$ & $0.12-1.60$ & $-0.04-0.25$ \\
\hline Castro et al. (1999) & 3 & $800-900$ & $0.6-1.0$ & $9-11$ & $0.17-0.19$ & $-0.03-(-0.01)$ \\
\hline Conrad et al. (1988) & 19 & $675-925$ & 1.0 & $5-13$ & $0.10-0.66$ & 0.00-0.08 \\
\hline Gaetani et al. (2008) & 22 & $1150-1450$ & $0.0001-3.5$ & 0 & $2.07-38.9$ & $-0.02-0.80$ \\
\hline García-Arias et al. (2012) & 8 & $800-900$ & $0.6-1.0$ & $10-12$ & $0.11-0.42$ & $0.00-0.06$ \\
\hline Gardien et al. (1995) & 4 & $750-950$ & 1.0 & $5-15$ & $0.06-0.37$ & $-0.06-0.05$ \\
\hline Getsinger et al. (2009) & 6 & $925-1000$ & 1.4 & $4-6$ & $0.13-0.54$ & $0.01-0.08$ \\
\hline Green and Pearson (1986), & 114 & $900-1080$ & $0.75-3.0$ & $2-16$ & $0.29-4.42$ & $0.00-0.55$ \\
\hline Hayden and Watson (2007) & 13 & $700-1000$ & 1.0 & $6-10$ & $0.10-1.09$ & $-0.06-0.06$ \\
\hline Klemme et al. (2002) & 2 & $1200-1300$ & 3.0 & 0 & $2.00-4.22$ & $0.10-0.14$ \\
\hline Laurie and Stevens (2012) & 6 & $870-900$ & $1.9-3.0$ & $16-19$ & $0.10-0.50$ & $0.02-0.05$ \\
\hline Patiño Douce and Beard (1996) & 33 & $840-950$ & $0.3-1.5$ & $1-6$ & $0.07-0.47$ & $-0.02-0.05$ \\
\hline Patiño Douce and Johnston (1991) & 18 & $825-1075$ & $0.7-1.3$ & $0-4$ & $0.02-0.77$ & $-0.03-0.03$ \\
\hline Patiño Douce (2005) & 6 & $975-1150$ & $2.7-3.0$ & $2-8$ & $0.17-0.59$ & $-0.08-0.01$ \\
\hline Patiño Douce and Beard (1995) & 44 & $875-1000$ & $0.3-1.5$ & $1-7$ & $0.16-1.26$ & $-0.03-0.12$ \\
\hline Pertermann and Hirschmann (2003) & 4 & $1250-1335$ & $2.0-3.0$ & 0 & $6.07-6.66$ & $0.35-0.51$ \\
\hline Pickering and Johnston (1998) & 3 & $812-900$ & 1.0 & $4-6$ & $0.13-0.20$ & $-0.06-(-0.01)$ \\
\hline Qian and Hermann (2013) & 8 & $800-1000$ & $1.0-1.5$ & $6-21$ & $0.23-1.66$ & 0.01-0.14 \\
\hline Rapp and Watson (1995) & 11 & $1000-1150$ & $0.8-3.2$ & $5-15$ & $0.36-2.31$ & $0.05-0.43$ \\
\hline Rapp et al. (1991) & 6 & $1000-1150$ & $1.6-3.2$ & $6-9$ & $0.85-2.23$ & $0.05-1.18$ \\
\hline Ryerson and Watson (1987) & 10 & $1000-1350$ & $0.6-3.0$ & $1-14$ & $1.42-9.57$ & $0.03-0.57$ \\
\hline Sen and Dunn (1994) & 13 & $900-1150$ & $1.5-2.0$ & $6-9$ & $0.26-2.29$ & $0.03-0.32$ \\
\hline Sisson et al. (2005) & 22 & $825-925$ & 0.7 & $5-9$ & $0.06-0.78$ & $0.01-0.16$ \\
\hline Skjerlie and Johnston (1992) & 2 & $1000-1050$ & 1.0 & 3 & $0.28-0.31$ & $0.06-0.08$ \\
\hline Skjerlie and Johnston (1993) & 9 & $875-1075$ & 1.0 & $2-7$ & $0.07-0.74$ & $0.00-0.22$ \\
\hline Skjerlie and Johnston (1996) & 16 & $850-1000$ & $1.0-2.0$ & $2-7$ & $0.11-0.72$ & $-0.08-0.05$ \\
\hline Skjerlie and Patiño Douce (1995) & 3 & $900-950$ & 1.0 & $4-7$ & $0.40-0.64$ & $0.02-0.08$ \\
\hline Spandler et al. (2008) & 4 & $1240-1350$ & $3.0-5.0$ & 0 & $2.56-5.68$ & $0.15-0.26$ \\
\hline Spicer et al. (2004) & 16 & $800-1000$ & $0.3-0.32$ & $0-4$ & $0.11-0.71$ & $-0.01-0.04$ \\
\hline Springer and Seck (1997) & 3 & $940-1115$ & 0.5 & $5-13$ & $0.34-2.91$ & $0.06-0.34$ \\
\hline Xiong et al. (2009) & 36 & $750-1250$ & $1.5-3.5$ & $8-14$ & $0.11-2.44$ & $-0.01-0.12$ \\
\hline Xiong et al. (2011) & 3 & $900-1350$ & 2.0 & $6-11$ & $0.30-3.80$ & $0.02-0.05$ \\
\hline Yearron (2003) & 2 & $925-1000$ & 1.6 & - & $0.57-0.75$ & 0.04-0.09 \\
\hline
\end{tabular}




\subsection{Acknowledgements}

A. Wellhäuser is supported by an iMQRES from Macquarie University. T. Rushmer and J. Adam acknowledge the support from Macquarie University. We gratefully thank A. Silbersdorf for statistical advice, A. Kronz for analytical assistance, S. Turner for valuable discussion and suggestions, J. O'Neil for providing the sample PC-103 and T. Green for remarks on the manuscript and providing an extensive experimental dataset. A. Audédat is thanked for comments on an earlier version of the manuscript. 



\section{CHAPTER 4}

\section{TTG suite differentiation paths as a function of water availability}

\subsection{Preface}

This study was initially intended to be the main task of the thesis which, however shifted in focus while progressing. The original plan was to connect greenstone melting experiments from Adam et al. (2012), conducted on samples from the Nuvvuagittuq greenstone belt with a liquidus study on surrounding felsic granitoids. Thereby fields of matching residual and liquidus saturating phases should have been identified. The goal shifted due to acknowledging the study of Wyllie et al. (1997) who had the same study design with a far broader extend as possible for this thesis.

The original scope of the manuscript was designed by John Adam and Tracy Rushmer, the shift in focus was done by myself. Experiments were conducted by John Adam and myself. The discussion and interpretation of experimental results involved Tracy Rushmer, John Adam and me. I wrote the first draft of the manuscript. Subsequently the manuscript was reviewed by John Adam and Tracy Rushmer.

\subsection{Abstract}

We investigated the saturated liquidus of an Eoarchean granodiorite from the Nuvvuagittuq belt with crystallisation experiments and thermodynamic modelling to identify potential paths of differentiation. With piston cylinder experiments varying in pressure (0.5-2.0 GPa) and initial $\mathrm{H}_{2} \mathrm{O}$ (5 and $10 \mathrm{wt} \%$ ), we found several points of multiple saturation from which the granodiorite can further differentiate. We constructed P-T sections via THERMOCALC for 2, 5 and $10 \mathrm{wt} \% \mathrm{H}_{2} \mathrm{O}$ and extracted isobaric profiles at 0.5, 1.0, 1.5 and 2.0 GPa. No experimentally defined cotectic path or isobaric profile can retrace the observed geochemical variability of the Nuvvuagittuq tonalite-trondhjemite-granodiorite (TTG) suite, especially in respect to the alkali elements. However, we have identified a critical dependence of the differentiation path on $\mathrm{H}_{2} \mathrm{O}$. The suppression of plagioclase crystallisation in liquidus proximity under hydrous conditions at elevated pressure $(\geq 1.0 \mathrm{GPa})$ is essential to produce trondhjemitic compositions by crystal fractionation along a cotectic path involving hornblende/clinopyroxene (cpx) and orthopyroxene (opx)/garnet. At low pressure, or dry conditions, melt evolves towards a granodioritic composition by fractionating plagioclase and hornblende/opx.

A large literature compilation of natural TTGs is difficult to describe by a single cotectic 
path not involving plagioclase due to a parallel alignment of the data to the An-Qtz plane in the CMAS recalculated Qtz-Fo-An ternary diagram. As the lack of an Eu-anomaly, which rules out the involvement of plagioclase, is one of the TTG suite's distinct features, contrary to post-Archean granites, TTGs most likely do not align on a liquid line of descent. Instead, they formed at varying $\mathrm{H}_{2} \mathrm{O}$ and pressure conditions outside of the plagioclase stability field.

\subsection{Introduction}

The possible formation mechanism(s) of tonalite-trondhjemite-granodiorite suites (TTG, Jahn et al., 1981) are yet to be resolved even though they are the major component of Archean continental crust (Martin et al., 2005). Their composition $\left(\mathrm{K}_{2} \mathrm{O}\right.$ poor while being enriched in large ion lithophile elements (LILEs), depleted in heavy rare earth elements (HREEs), $\mathrm{Nb} \mathrm{Ta}$ and Ti, no Eu-anomaly and high Sr/Y ratios (Moyen and Martin, 2012)) is distinct from rocks that are associated with modern continent formation processes. Understanding the formation of TTGs provides an essential insight into the unknown Archean geodynamic environment(s) and addresses the major question at what point modern style plate tectonics started operating (Laurent et al., 2014; Turner et al., 2014; Hastie et al., 2016; Tang et al., 2016).

In general, there is agreement that TTGs formed from partial melting of hydrated basalt (Moyen and Stevens, 2006). The depletion in HREEs and high Sr/Y ratios are generally associated with the presence of garnet during their formation and/or evolution, directly connected to crustal depth. Furthermore, high Sr/Y ratios point to the absence of plagioclase contiguous to the lacking Eu-anomaly. Low $\mathrm{K}_{2} \mathrm{O}$ concentration, the crucial major element feature of TTGs, can be linked to either high degree melting, low $\mathrm{K}_{2} \mathrm{O}$ in the source, or the fractionation of a $\mathrm{K}_{2} \mathrm{O}$ bearing phase. The enrichment in LILE is attributed to the source rock (Martin et al., 2014) or the involvement of fluid (Hastie et al., 2016). The depletion of $\mathrm{Nb}$, Ta and $\mathrm{Ti}$ is associated with the presence of a Ti phase during melt formation/evolution (chapter 3).

Several geodynamic scenarios have been proposed in which TTGs could have been generated. These include (i) steep subduction with slab melting (Martin et al., 2005; Laurie and Stevens, 2012) as thought for modern adakites (Martin et al., 2005; Castillo, 2012); (ii) shallow subduction/underthrusting/stacking of oceanic crust with melt formation in the garnet stability field (Nagel et al., 2012; Nutman et al., 2015; Hastie et al., 2016) and (iii) basal melting of a thick oceanic plateau at high pressure with possible interplay with mantle plumes, resulting in crustal overturns (Collins et al., 1998; Bédard, 2006a; Smithies et al., 2009; Bédard, 2018; Wiemer et al., 2018).

Aside the uncertain Archean geodynamic environment, the mechanisms resulting in jointly occurring tonalites, trondhjemites and granodiorites are uncertain as well. A generally accepted model is that they formed at different depths (Moyen, 2011; Hoffmann et al., 2011a; Moyen and Martin, 2012) based on their trace element signature and in case of $\mathrm{K}_{2} \mathrm{O}$-richer 
granitoids, by remelting of older TTG intrusions (Watkins et al., 2007). The formation of TTGs by crystal fractionation is generally discarded as no continuous trends from parental melts to TTGs are observed (Moyen and Martin, 2012). However, in numerous experimental basalt melting studies only few experiments resulted in glass compositions that resemble TTG. This is contrary to their common occurrence in Archean cratons, implying that it should be fairly easy to produce them. Either they must have formed under very specific conditions, spatially and temporarily separated during the Archean, or other magmatic processes as crystal fractionation, accumulation or magma mixing were involved. Several studies suggest that crystal fractionation and accumulation could be relevant to TTG formation (Arth et al., 1978; Martin, 1993; Kamber et al., 2002; Bédard, 2006a; Hoffmann et al., 2014). Proposed scenarios are high pressure fractionation of mantle wedge derived melts (Kleinhanns et al., 2003), a scenario similar as proposed for modern adakites (Macpherson et al., 2006; Coldwell et al., 2011), and mid to upper crustal fractionation / accumulation of feldspar and hornblende (Liou and Guo, 2019; Smithies et al., 2019; Laurent et al., 2020) alike observed by Jagoutz et al. (2013) in a recent arc system.

In this study, we examine the liquidus conditions of the Archean granodiorite PC-103 (O'Neil et al., 2008; Adam et al., 2012) by crystallisation experiments and petrological modelling to show that the amount of $\mathrm{H}_{2} \mathrm{O}$ is critical for the differentiation of TTG suites and test how they can differentiate by crystal fractionation.

\subsubsection{Formation conditions for TTGs}

Out of a vast range of experimental studies, TTG-like compositions (as defined in Moyen and Martin, 2012) have been produced in only few melting experiments (Rapp and Watson, 1995; Winther, 1996; Skjerlie and Patiño Douce, 2002; Adam et al., 2012; Laurie and Stevens, 2012; Hastie et al., 2016) on mostly basaltic compositions between 1.5-3.0 GPa, 800-1050 ${ }^{\circ} \mathrm{C}$, by both dehydration and fluid-present melting (Figure 4.1, Table 4.1). Notably, no TTG-like melt was produced at lower pressure conditions. A major factor for the experiments to result in glasses of TTG composition is the low $\mathrm{K}_{2} \mathrm{O}$ content of their starting materials (0.08 - 0.17 wt\%). The experimental melts of Laurie and Stevens (2012) and Hastie et al. (2016) do not match the field of TTGs (natural data from Nutman et al. (1999), Moyen (2011), Huang et al. (2013), Laurent et al. (2014), O'Neil and Carlson (2017), and Johnson et al. (2019), filtered for $\mathrm{La}>10, \mathrm{Yb}<2$ and an Eu-anomaly in between 0.9 and 1.1) because they do not contain enough $\mathrm{K}_{2} \mathrm{O}$ as shown in fig. 4.1a. As observed by Wyllie et al. (1997) and visible in fig. 4.1b, tonalites tend to form at higher- and trondhjemites at lower temperature.

In the Qtz-Fo-An plane based on compositions being recalculated by CMAS (O'Hara, 1968), most experiments only marginally overlap with TTG compositions (fig. 4.1b) that could be primary liquids due to the absence of an Eu anomaly. Especially in some of the experiments of Laurie and Stevens (2012) and Hastie et al. (2016) the Qtz component is too large. The experimental melts of Skjerlie and Patiño Douce (2002) contain the least Qtz component and 
match well. However, their melts are in equilibrium with quartz, which shifts the melt composition away from the Qtz corner. Rapp and Watson (1995) produce a TTG composition at 1.6 GPa and it is possible to infer the cotectic path based on their comprehensive melting study for this pressure (fig. 4.1d). The interpreted cotectic path matches the array of TTGs, falling on a plag - hbl/cpx/grt controlled cotectic. However, the involvement of plagioclase will result in a negative Eu anomaly, which is generally not observed in TTGs (Moyen and Martin, 2012).

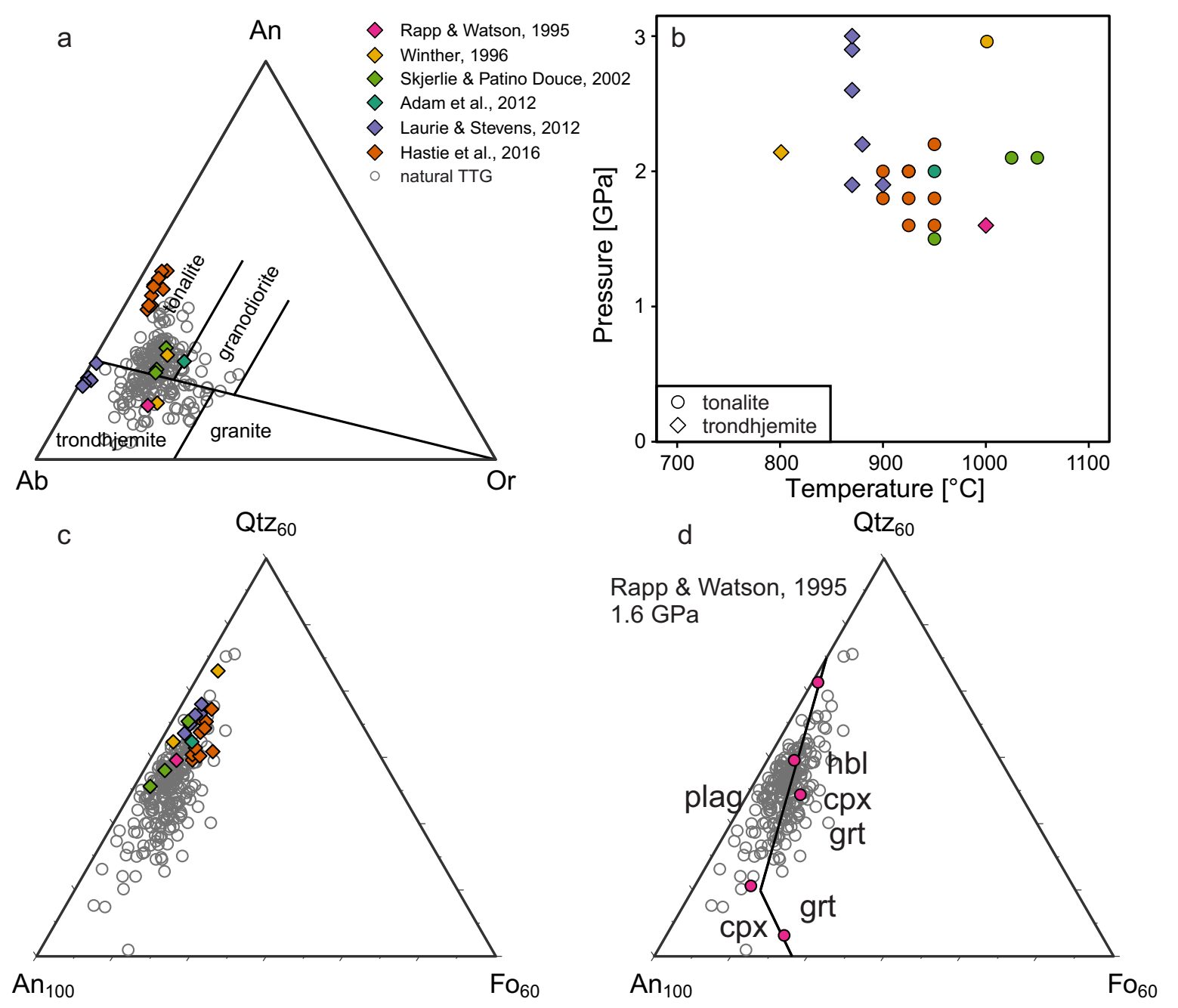

Figure 4.1: a: Feldspar diagram of O'Connor (1965) with experimental melt compositions from Rapp and Watson (1995), Winther (1996), Skjerlie and Patiño Douce (2002), Adam et al. (2012), Laurie and Stevens (2012), and Hastie et al. (2016) plotted together with natural TTG data from Nutman et al. (1999), Moyen (2011), Huang et al. (2013), Laurent et al. (2014), and O'Neil and Carlson (2017) and Johnson et al. (2019). The compilation is filtered for samples only containing tonalites, trondhjemites and granodiorites; $\mathrm{La}>10, \mathrm{Yb}<2$ and an Eu-anomaly in between 0.9 and 1.1. By this procedure, compositions not being TTG and affected by fractionation or accumulation are avoided. b: P-T condition plot of the experimental melts that match TTG composition. c: Qtz-Fo-An plot with the same data as in fig. 4.1a, recalculated as CMAS (O'Hara, 1968) d: Experiments by Rapp and Watson (1995) on an migmatic amphibolite at 1.6 GPa with interpreted cotectic path. 
TTG like compositions were also produced by direct melting in several petrological modelling studies (Nagel et al., 2012; Palin et al., 2016; Johnson et al., 2017). The TTG melt production conditions were determined to be between 1.0-1.8 GPa and below $1000{ }^{\circ} \mathrm{C}$. This is in contrast to most experimentally produced TTG melts, which were produced at higher pressures. The differentiation of TTGs by crystal fractionation is not covered by experimental work or modelling.

In this study, we examine the crystallisation sequence of an Archean granodiorite from the Nuvvuagittuq Greenstone Belt (NGB) experimentally by piston cylinder and rapid quench autoclave experiments as well as calculated P-T pseudosections using THERMOCALC (Powell et al., 1998). From that we can identify points of multiple saturation in liquidus proximity as origin for differentiation paths that lead to the compositional diversity of TTG suites. We use the 3.66 Ga granodiorite PC-103 (O'Neil et al., 2008, 2012; Adam et al., 2012) from the Hadean to Eoarchean NGB, Northeastern Superior Province (NESP) in Canada. The major element composition of PC-103 is displayed in table 4.2. The NGB major components are mafic to ultramafic rocks, chemical sediments and a minor fraction of felsic compositions. The whole belt is highly deformed and metamorphosed under at least upper greenschist facies conditions. The felsic rocks comprise the $3.66 \mathrm{Ga}$ tonalites and granodiorites that enclose and partially intruded the NGB and scarce 3.82 Ga trondhjemite veins. The felsic rocks are interpreted to have formed from melting of the surrounding Hadean mafic lithologies (O'Neil et al., 2012).

Table 4.2: Major element composition of the sample PC-103 from O'Neil et al. (2012) in wt\%.

\begin{tabular}{ccccccccccc}
\hline $\mathrm{SiO}_{2}$ & $\mathrm{TiO}_{2}$ & $\mathrm{Al}_{2} \mathrm{O}_{3}$ & $\mathrm{FeO}_{t}$ & $\mathrm{MnO}$ & $\mathrm{MgO}$ & $\mathrm{CaO}$ & $\mathrm{Na}_{2} \mathrm{O}$ & $\mathrm{K}_{2} \mathrm{O}$ & $\mathrm{P}_{2} \mathrm{O}_{5}$ & $\mathrm{LOI}$ \\
\hline 66.1 & 0.45 & 15.9 & 3.74 & 0.08 & 2.17 & 3.67 & 3.66 & 2.44 & 0.11 & 1.3 \\
\hline
\end{tabular}




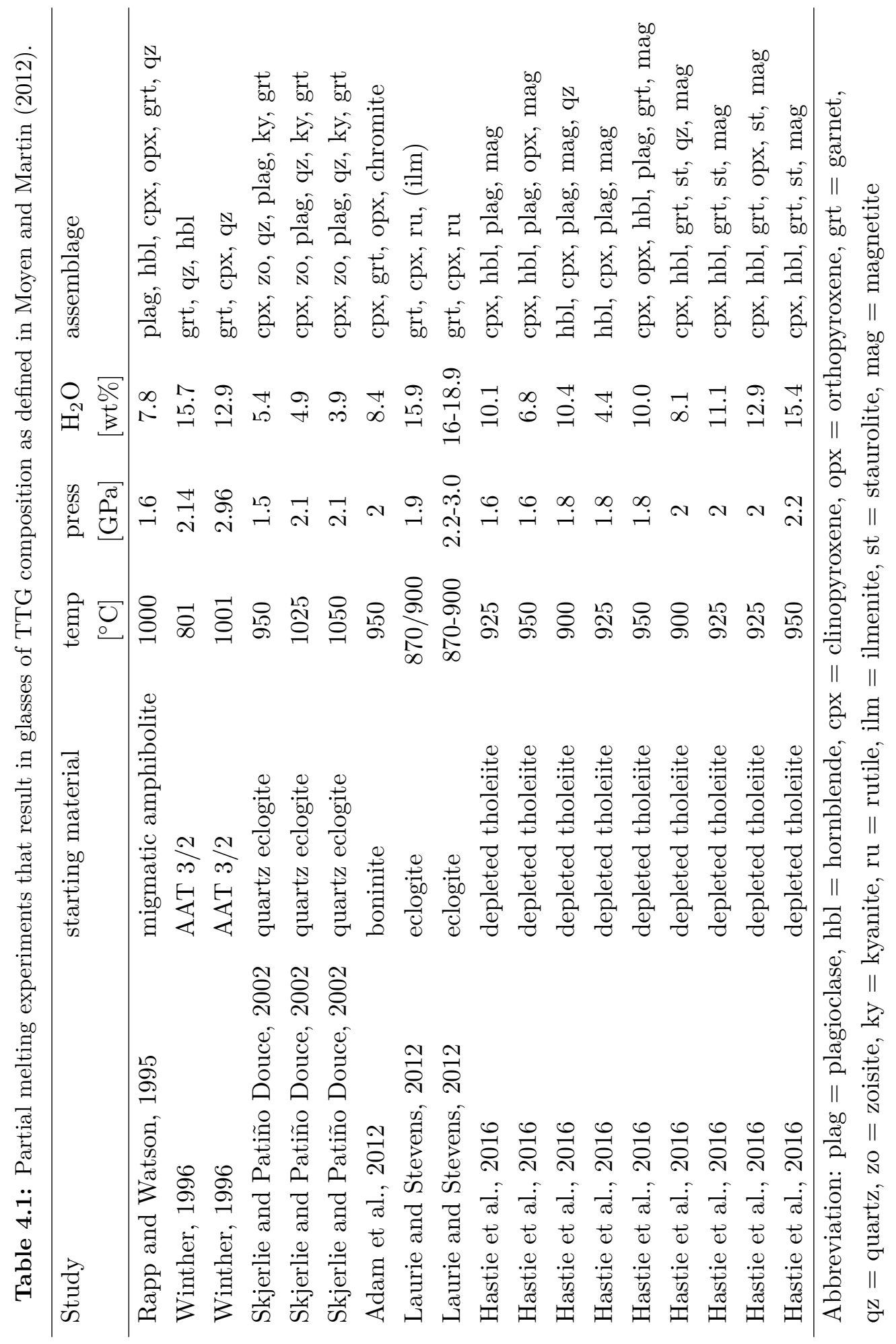




\subsection{Methods}

\subsubsection{Petrological modelling}

THERMOCALC (version 3.45, Powell et al., 1998) calculations where performed in the $\mathrm{Na}_{2} \mathrm{O}$ $\mathrm{CaO}-\mathrm{K}_{2} \mathrm{O}-\mathrm{FeO}-\mathrm{MgO}-\mathrm{Al}_{2} \mathrm{O}_{3}-\mathrm{SiO}_{2}-\mathrm{H}_{2} \mathrm{O}-\mathrm{TiO}_{2}-\mathrm{O}_{2}$ (NCKFMASHTO) system, using version 6 of the internally consistent Holland and Powell (2011) a-x models dataset. Amphibole, clinopyroxene and melt a-x relations are from Green et al. (2016), orthopyroxene, garnet, biotite, muscovite and ilmenite from White et al. (2014), K-feldspar and plagioclase from Holland (2003), spinel from White et al. (2002) and epidote from Holland and Powell (2011). A restraint in investigating liquidus conditions with THERMOCALC version 3.45 is that no mixing models for $\mathrm{TiO}_{2}$ and $\mathrm{Fe}^{3+}$ into the melt are present. Therefore a complete liquidus can not be reached, as there will always be a Ti-phase (ilmenite or rutile) present. The recently published expanded thermodynamic dataset from Holland et al. (2018) comprises a solution model for $\mathrm{TiO}_{2}$ into melt but does not return reasonable near-liquidus phase assemblages, most likely due to our PC-103 composition being outside of the calibration range because the model is only valid for tholeiitic to mildly alkalic melt compositions.

We calculated P-T sections with different amounts of $\mathrm{H}_{2} \mathrm{O}$ available (2, 5 and $10 \mathrm{wt} \%$ ) because the availability of water during TTG formation is a major uncertainty (see chapter 3 ). Relevant for high $\mathrm{H}_{2} \mathrm{O}$ calculations with the model is the limitation of $\mathrm{H}_{2} \mathrm{O}$ being a pure phase that does not dissolve any components. Hence, the melt composition in presence of free $\mathrm{H}_{2} \mathrm{O}$ would actually be different in a natural system or experiment. The THERMOCALC input for the different amounts of $\mathrm{H}_{2} \mathrm{O}$ is displayed in table 4.3.

Table 4.3: PC-103 input composition for THERMOCALC at different $\mathrm{H}_{2} \mathrm{O}$ contents displayed in $\mathrm{mol} \%$ if not indicated otherwise in the column head.

\begin{tabular}{ccccccccccc}
\hline $\mathrm{H}_{2} \mathrm{O}[\mathrm{wt} \%]$ & $\mathrm{H}_{2} \mathrm{O}$ & $\mathrm{SiO}_{2}$ & $\mathrm{Al}_{2} \mathrm{O}_{3}$ & $\mathrm{CaO}$ & $\mathrm{MgO}$ & $\mathrm{FeO}$ & $\mathrm{K}_{2} \mathrm{O}$ & $\mathrm{Na}_{2} \mathrm{O}$ & $\mathrm{TiO}_{2}$ & $\mathrm{O}$ \\
\hline 2 & 6.77 & 67.01 & 9.51 & 3.95 & 3.39 & 3.17 & 1.61 & 3.71 & 0.35 & 0.53 \\
5 & 15.37 & 60.83 & 8.64 & 3.59 & 3.08 & 2.88 & 1.46 & 3.37 & 0.32 & 0.48 \\
10 & 28.38 & 51.46 & 7.31 & 3.03 & 2.60 & 2.43 & 1.23 & 2.85 & 0.27 & 0.44 \\
\hline
\end{tabular}

\subsubsection{Experimental methods}

We conducted near liquidus experiments on a glass made from the Archean tonalite PC-103 (O'Neil et al., 2012; Adam et al., 2012). Experiments were conducted between 750 and $1100{ }^{\circ} \mathrm{C}$, pressure between 0.3 and $2.0 \mathrm{GPa}$ and $\mathrm{H}_{2} \mathrm{O}$ of either 5 or $10 \mathrm{wt} \%$.

The experiments $\geq 0.5 \mathrm{GPa}$ were conducted at Macquarie University on a piston cylinder apparatus as described by Boyd and England (1960) using a cold piston-in technique. A minus $10 \%$ pressure correction due to friction is applied (Green et al., 1966). For temperature adjustment and monitoring we used a $\mathrm{Pt}-\mathrm{Pt}_{90} \mathrm{Rh}_{10}$ thermocouple with a Leeds \& Northrup Electromax V temperature controller. The oxygen fugacity condition during the experiment was unbuffered but believed to be between fayalite-quartz-magnetite (FQM) and wüstite- 
magnetite (WM) based on the furnace type (Green, 1976).

In the furnace assembly $15 \mathrm{mg}$ of sample were sealed in $\mathrm{Ag}_{70} \mathrm{Pd}_{30}$ capsules via welding. Distilled water was inserted into the capsules before powder via micro-syringe. The capsule weight was carefully monitored after every step to guard against unwanted loss. To ensure leak tightness of the sealed capsule, it was heated to $100{ }^{\circ} \mathrm{C}$ for one hour and weighed subsequently. The furnace consists of an ALSIMG insert on both sides of the $\mathrm{Ag}_{70} \mathrm{Pd}_{30}$ capsule, inside a graphite tube surrounded by a Pyrex- and outermost talc sleeve.

Experiments at $0.3 \mathrm{GPa}$ were carried out at Nanjing University using a vertical, externally heated, cold seal rapid quench autoclave system with a setup as described in Matthews et al. (2003). Oxygen fugacity was controlled by Ni rods. For the experiments $30 \mathrm{mg}$ of sample, a mix of glass powder and distilled water, were sealed in gold capsules and heated subsequently to $110{ }^{\circ} \mathrm{C}$ for 2 hours to exclude pre-run leakage. The capsules were also weighed after the experiment.

\subsubsection{Analytical methods}

Major element composition of the experimentally produced glasses were analysed at Macquarie University using a Caméca SX100 and at Georg-August University using a JEOL JXA-8900RL. The analyses were conducted with an acceleration voltage of $15 \mathrm{kV}, 15$ to 20 $\mathrm{nA}$ beam current and beam diameters of either 20 or $30 \mu \mathrm{m}$. Acquisition times were $15 \mathrm{~s}$ for $\mathrm{Al}, \mathrm{Si}, \mathrm{Fe}, \mathrm{Mg}, \mathrm{Ca}, \mathrm{Na}$ and $\mathrm{K} ; 30 \mathrm{~s}$ for Ti, Mn and P.

The analytical loss of $\mathrm{Na}$ was assessed by exploring different beam diameters over time as described in chapter 3 and displayed by fig. 4.2a. To better constrain $\mathrm{H}_{2} \mathrm{O}$ dissolved in the melt we include $\mathrm{H}$ by difference into the matrix correction. It is peculiar for the JEOL software that including $\mathrm{H}$ into matrix correction only works for ZAF. Therefore we compare three different matrix corrections: (1) phi-rho-Z, (2) ZAF and (3) ZAF with H. The results are displayed in fig. $4.2 \mathrm{~b}$, for the glass analysis of R174 (see chapter 3 ). Whereas phi-rho-Z and $\mathrm{ZAF}$ are identical within error, including $\mathrm{H}$ into the matrix correction significantly increases the abundance of $\mathrm{Al}_{2} \mathrm{O}_{3}$ and $\mathrm{SiO}_{2}$. The total sum is increased by almost $2 \mathrm{wt} \%$. It can be concluded that the addition of $\mathrm{H}$ to the matrix correction improves the $\mathrm{H}_{2} \mathrm{O}$ estimate by difference. The ZAF + H correction was used for the experiments 191001, 193001 and 194001. 

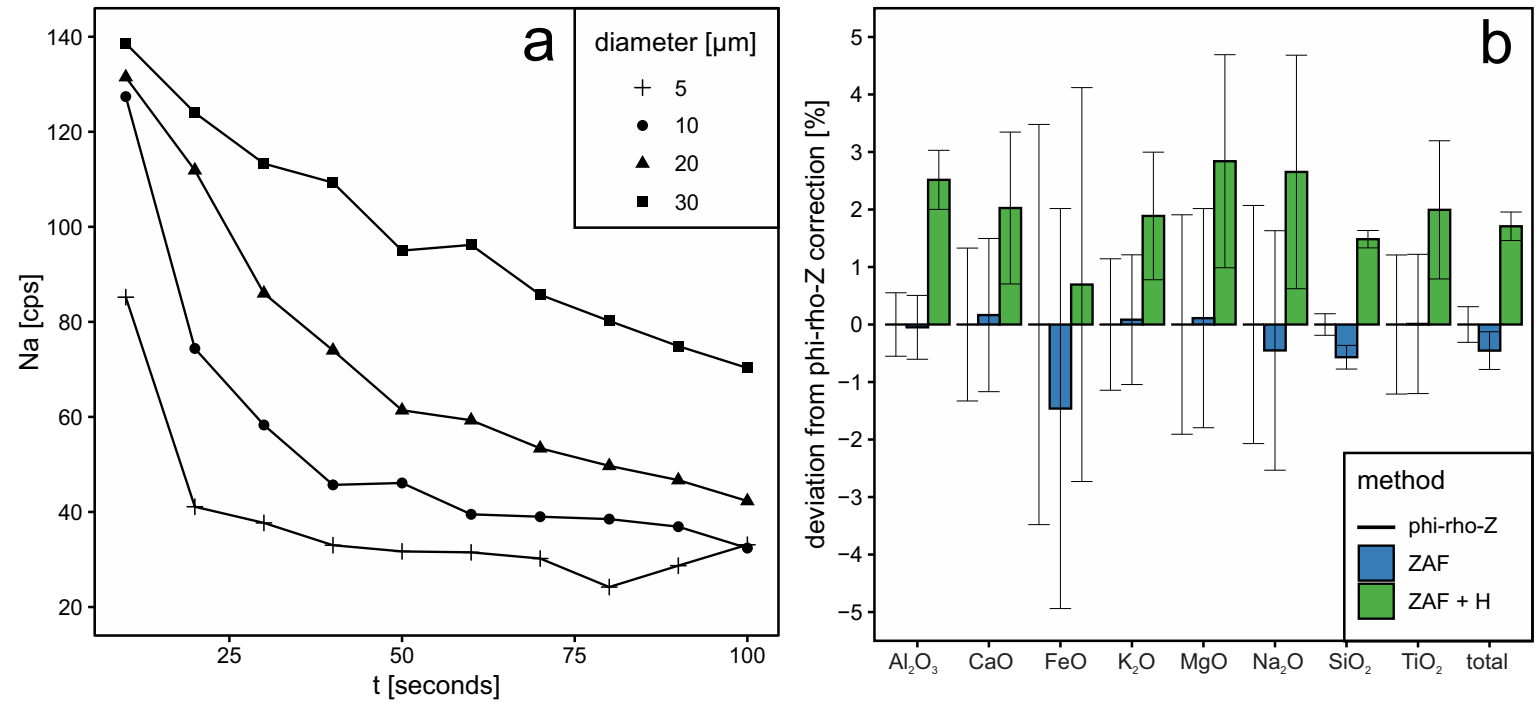

Figure 4.2: a: Na loss over time during analysis at different beam diameters. The cps is a 10 second average. b: Comparison of different matrix correction methods normalised to the values calculated from phi-rho-Z. The error bars are the $1 \sigma$ sd of 10 glass analysis in experiment R174 (chapter 3).

\subsection{Results}

\subsubsection{Experimentally determined saturated liquidus}

It is important to consider the potential source rock in context of the liquidus position in P-T space and saturation of phases in crystallisation experiments. As the source rock is unlikely to be mono-mineralic, it is expected that the liquidus would be multiply saturated.

The experimentally examined phase stabilities of PC-103 are displayed as a P-T sections in fig. 4.3 separated by initial $\mathrm{H}_{2} \mathrm{O}$ content. With $5 \mathrm{wt} \% \mathrm{H}_{2} \mathrm{O}$ present (fig. 4.3a), opx is the dominant liquidus phase from 0.5 to $1.5 \mathrm{GPa}$. The liquidus forms a positive slope from 950 to $1050{ }^{\circ} \mathrm{C}$. At $2 \mathrm{GPa}$ garnet and cpx both saturate the liquidus at $1050{ }^{\circ} \mathrm{C}$. Plagioclase crystallises pressure independent below $950{ }^{\circ} \mathrm{C}$. Amphibole is stable at $\leq 900{ }^{\circ} \mathrm{C}$.

For $10 \mathrm{wt} \% \mathrm{H}_{2} \mathrm{O}$ (fig. 4.3b) the liquidus was not reached with $10 \%$ of solid phase left at $900{ }^{\circ} \mathrm{C}$ and $1.5 \mathrm{GPa}$ (see table 4.4, run 2091). Directly compared with $5 \mathrm{wt} \% \mathrm{H}_{2} \mathrm{O}$ at the same conditions, the degree of melting is $5 \%$ higher with $10 \mathrm{wt} \% \mathrm{H}_{2} \mathrm{O}$ present. Hornblende is stable in all conducted experiments. Cpx stability is decreased by not being stable at $900{ }^{\circ} \mathrm{C}$ and 1.5 GPa. Garnet and opx have the same stability range as in the experiments with $5 \mathrm{wt} \%$ $\mathrm{H}_{2} \mathrm{O}$ at $900{ }^{\circ} \mathrm{C}$. An excess fluid phase is only present at $0.3 \mathrm{GPa}$.

In the two diagrams (fig. 4.3) several points of multiple saturation can be identified. At 5 wt $\% \mathrm{H}_{2} \mathrm{O}$, points of multiple saturation are at $0.5 \mathrm{GPa}, 925{ }^{\circ} \mathrm{C}$ (plagioclase and opx) and $2.0 \mathrm{GPa}, 1050{ }^{\circ} \mathrm{C}$ (garnet and cpx). With $10 \mathrm{wt} \% \mathrm{H}_{2} \mathrm{O}$ the liquidus is multiply saturated in hornblende, plagioclase and Fe-oxide at $0.3 \mathrm{GPa}, 800{ }^{\circ} \mathrm{C}$, hornblende, opx and Fe-oxide at 1.0 GPa, $900{ }^{\circ} \mathrm{C}$ and in hornblende, opx and garnet at $1.5 \mathrm{GPa}, 900{ }^{\circ} \mathrm{C}$.

The major element compositions of analysed glasses are presented in table 4.5. We report and 
use corrected $\mathrm{Na}_{2} \mathrm{O}$ concentrations based on mass balance calculations by $\mathrm{r}^{2}$ minimisation. Fe-loss is as well assessed by mass balance calculation and displayed in table 4.5. Harker diagrams for the analysed glasses are displayed in appendix fig. 4.7 and 4.8. The modes presented in table 4.4 are as well calculated by mass balance.
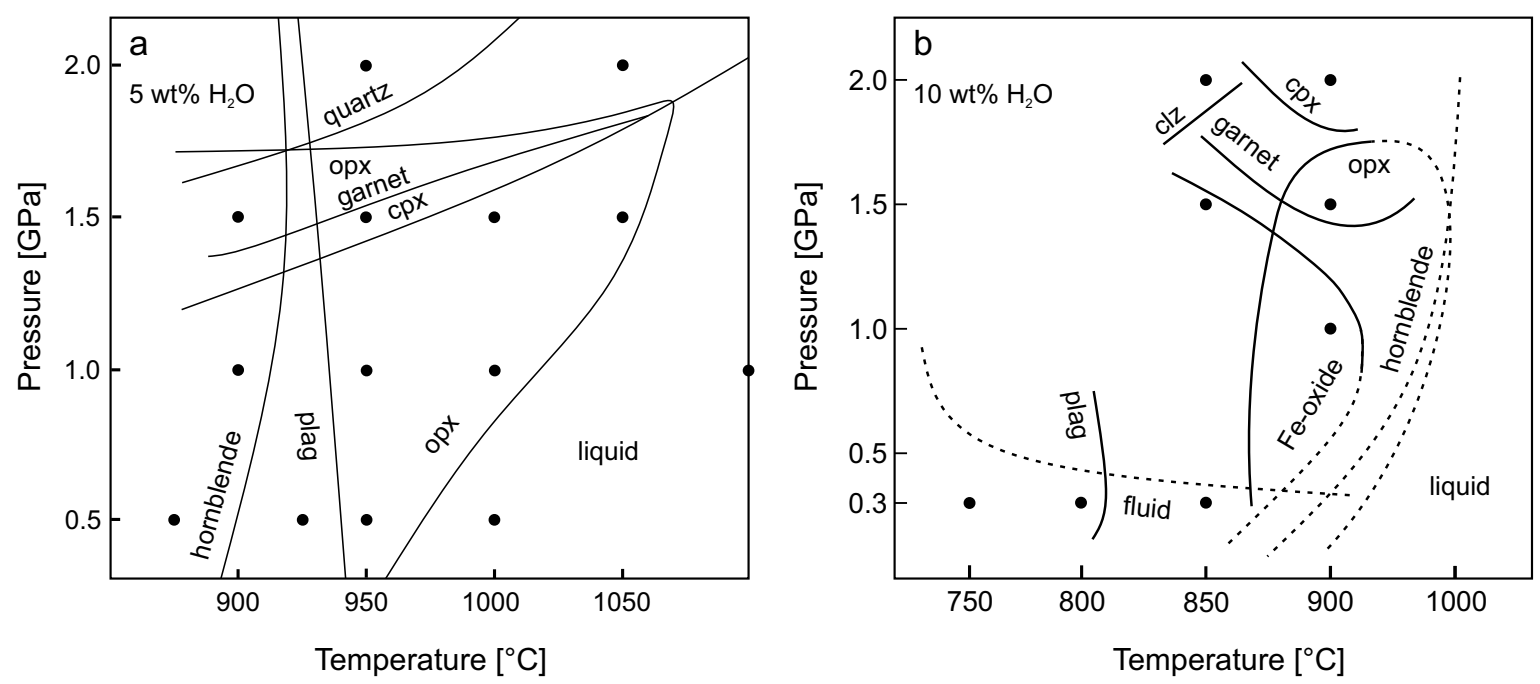

Figure 4.3: $\mathrm{P}-\mathrm{T}$ sections for $\mathrm{PC}-103$ based on crystallisation experiments with a: $5 \mathrm{wt} \% \mathrm{H}_{2} \mathrm{O}$ and $\mathbf{b}: 10$ wt $\% \mathrm{H}_{2} \mathrm{O}$ present. Black filled circles are the P-T conditions at which experiments were conducted. Abbreviations: $\mathrm{cpx}=$ clinopyroxene, $\mathrm{opx}=$ orthopyroxene, $\mathrm{plag}=$ plagioclase and $\mathrm{clz}=$ clino-zoisite.

\subsubsection{Calculated phase diagrams}

We calculated three pseudosections for PC-103 via THERMOCALC (Powell et al., 1998) with differing $\mathrm{H}_{2} \mathrm{O}$ content of 2,5 and $10 \mathrm{wt} \%$ and a $\mathrm{Fe}^{3+} / \mathrm{Fe}^{2+}$ ratio of 0.3 , displayed in fig. 4.4. For the section with $2 \mathrm{wt} \% \mathrm{H}_{2} \mathrm{O}$ (fig. 4.4a) the liquidus is not reached within the temperature interval between 700 and $1100{ }^{\circ} \mathrm{C}$. Phases stable at liquidus proximity are opx and plagioclase up to $1.3 \mathrm{GPa}$. An association of garnet, quartz, plagioclase and a minor amount of cpx are saturating phases above 1.5 GPa. Due to the high temperatures hornblende is not stable in liquidus proximity as the maximum temperature extend of its stability is $970{ }^{\circ} \mathrm{C}$ at $1.3 \mathrm{GPa}$. Modebox plots showing isobaric phase profiles through the diagram at 0.5, 1.0, 1.5 and $2.0 \mathrm{GPa}$ are displayed in appendix fig. 4.9. Major element melt compositions of the profiles are given in table 4.6.

The pseudosection with $5 \mathrm{wt} \% \mathrm{H}_{2} \mathrm{O}$ (fig. 4.4b) is calculated between 700 and $1100{ }^{\circ} \mathrm{C}$ and from 0.5 to $2.0 \mathrm{GPa}$. As for $2 \mathrm{wt} \% \mathrm{H}_{2} \mathrm{O}$, the liquidus is outside of the temperature range. Opx and hornblende are stable between 0.5 and $1.1 \mathrm{GPa}$ in proximity of the liquidus. At higher pressure cpx becomes stable. Garnet is stable in proximity of the liquidus at $1.2 \mathrm{GPa}$, above 1.6 GPa in association with quartz and cpx. Mode box plots showing isobaric phase profiles through the diagram at 0.5, 1.0, 1.5 and 2.0 GPa are displayed in fig. 4.10. 
루

낭. 음

总

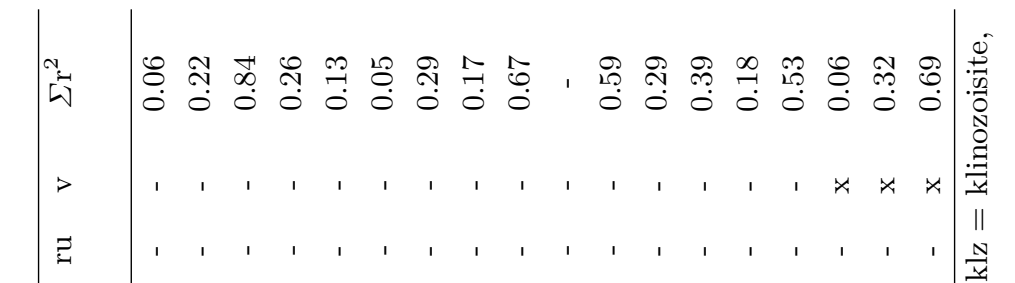

节

党

త్ర

劳

옹

节

零

ช.

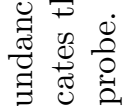

。.

政

竞 $=3$

正

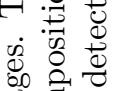

离

㤐范

㻤

है.

寻

웜

象总高

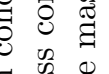

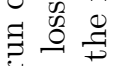

중ㅇ

氙学

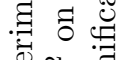

萬诘.

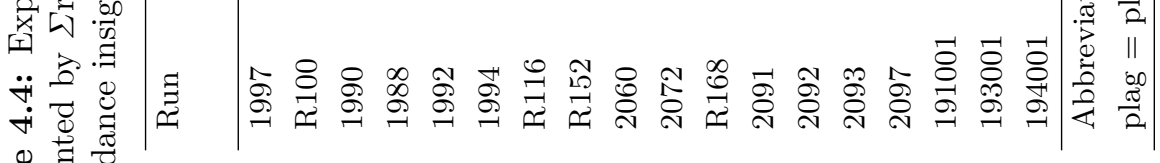

足苟 


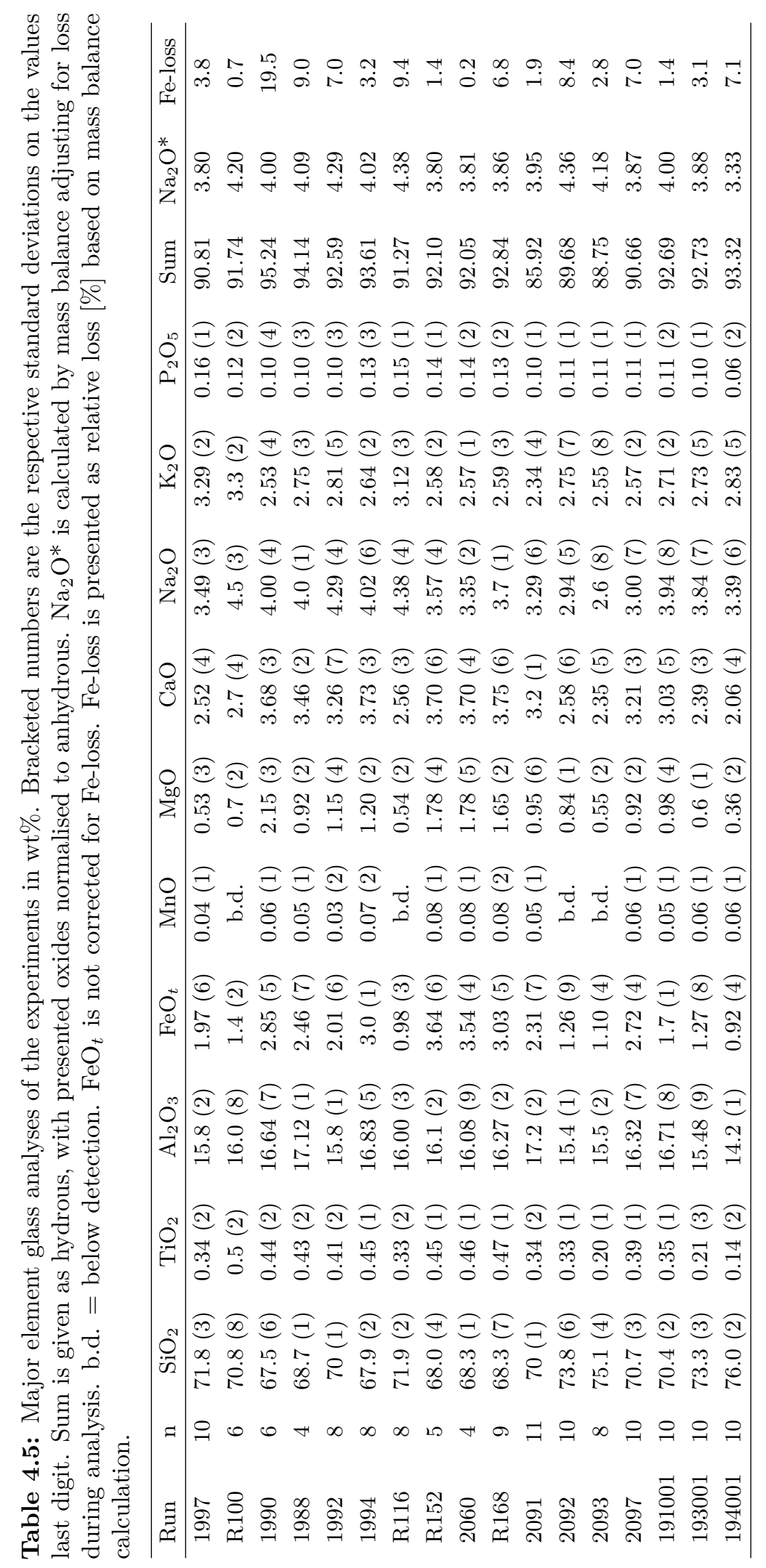




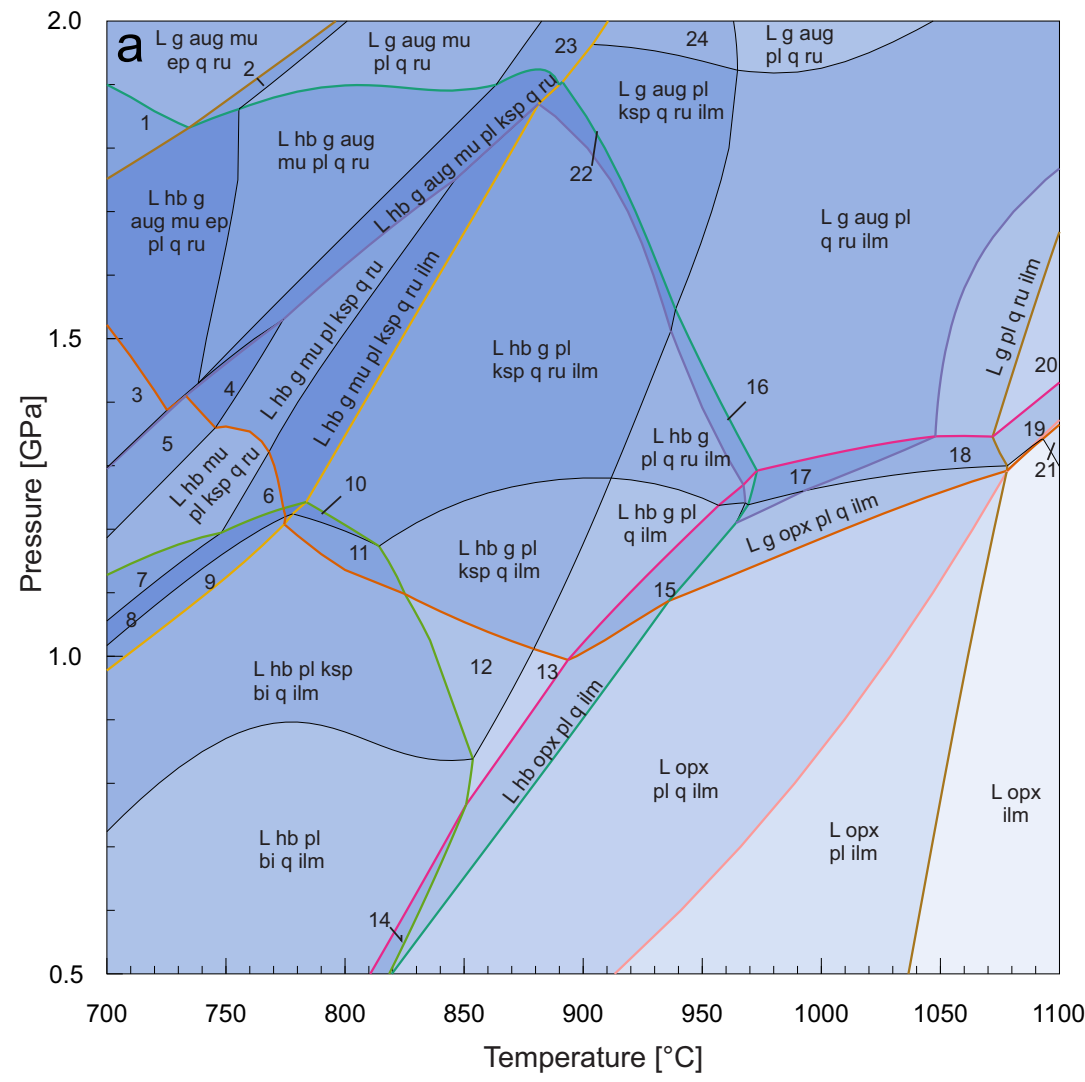

1) $L$ hb g aug mu ep q ru 2) L g aug mu ep pl q ru 3) L hb aug mu ep pl q ru 4) L hb g mu ep pl ksp q ru 5) L hb mu ep pl ksp q ru 6) L hb mu pl ksp q ru ilm 7) L hb mu bi pl ksp q ru 8) L hb mu bi pl ksp q ru ilm 9) L hb mu bi pl ksp q ilm 10) L hb g bi pl ksp q ru ilm 11) L hb g pl ksp bi q ilm 12) L hb pl ksp q ilm 13) L hb pl q ilm

14) L hb opx bi pl q ilm 15) L hb g opx pl q ilm 16) $L$ hb g aug pl q ru ilm 17) $\mathrm{Lg}$ aug opx pl q ru ilm 18) L g opx pl q ru ilm 19) $\mathrm{Lg}$ opx q ru ilm 20) L g q ru ilm 21) L opx ru ilm 22) L hb g aug pl ksp q ru ilm 23) L g aug mu pl ksp q ru 24) L g aug pl ksp q ru

\section{- hb - bi}

- $\mathrm{g} \quad-\mathrm{mu}$

- aug - p

- opx - q

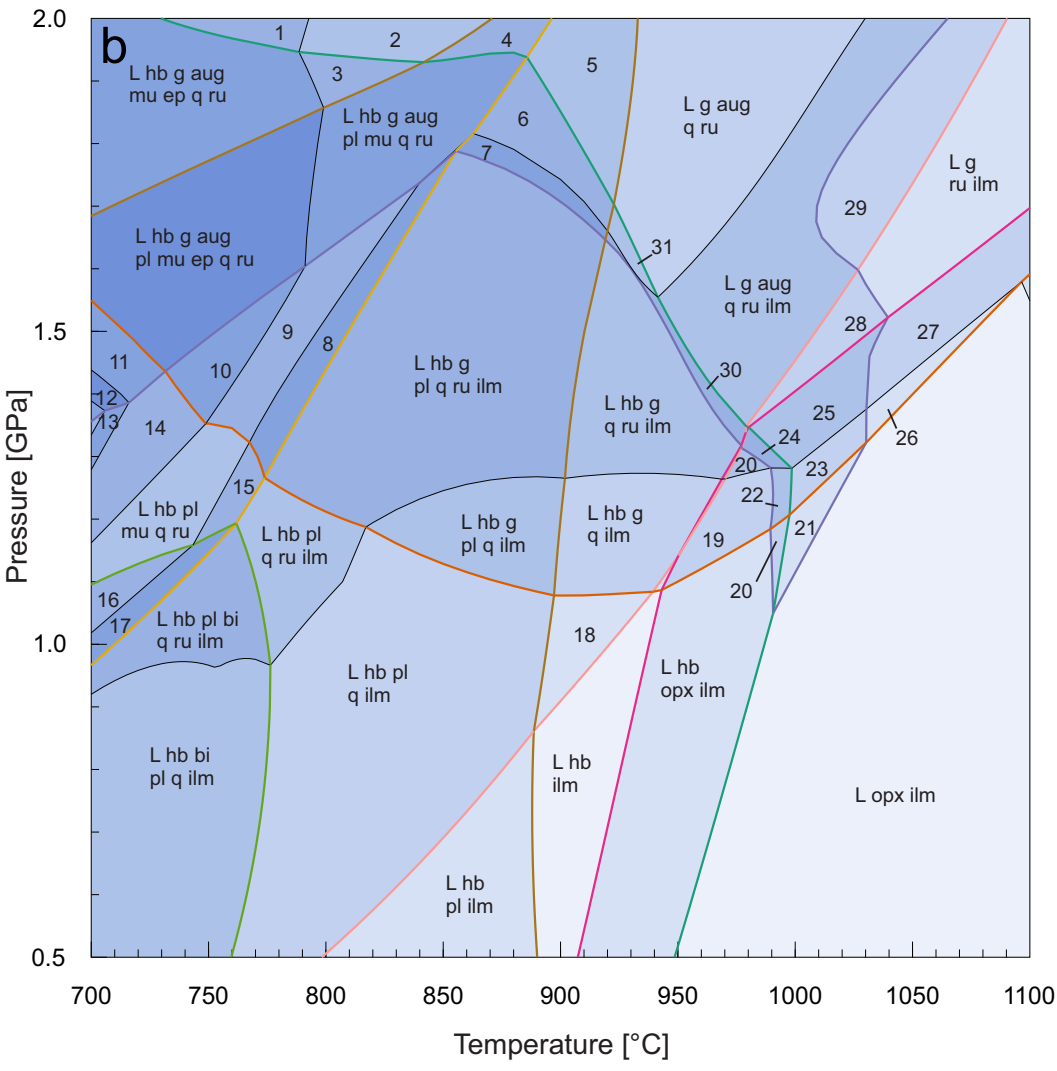

1) $L g$ aug mu ep q ru

2) $L g$ aug mu $q$ ru

3) L hb g aug mu q ru

4) L hb g aug pl mu q ru

5) $L \mathrm{~g}$ aug $\mathrm{pl} q \mathrm{ru}$

6) $L$ hb g aug pl q ru

7) L hb g aug pl q ru ilm

8) L hb g pl mu q ru ilm

9) L hb g pl mu q ru

10) $L$ hb g pl mu ep q ru

11) L hb aug pl mu ep q ru

12) L hb aug pl mu ep q sph ru

13) $L$ hb pl mu ep q sph ru

14) $L$ hb pl mu ep q ru

15) L hb pl mu q ru ilm

16) L hb bi pl mu q ru

17) L hb bi pl mu q ru ilm

18) L hb q ilm

19) L hb g opx ilm

20) L hb aug opx ilm

21) L aug opx ilm

22) $L$ hb g aug opx ilm

23) $L g$ aug opx ilm

24) L hb g aug opx ru ilm

25) $\mathrm{L} \mathrm{g}$ aug opx ru ilm

26) L g opx ilm

27) L g opx ru ilm

28) L g aug ru ilm

29) L g q ru ilm

30) $L \mathrm{hb} \mathrm{b}$ aug q ru ilm

31) L hb g aug q ru 


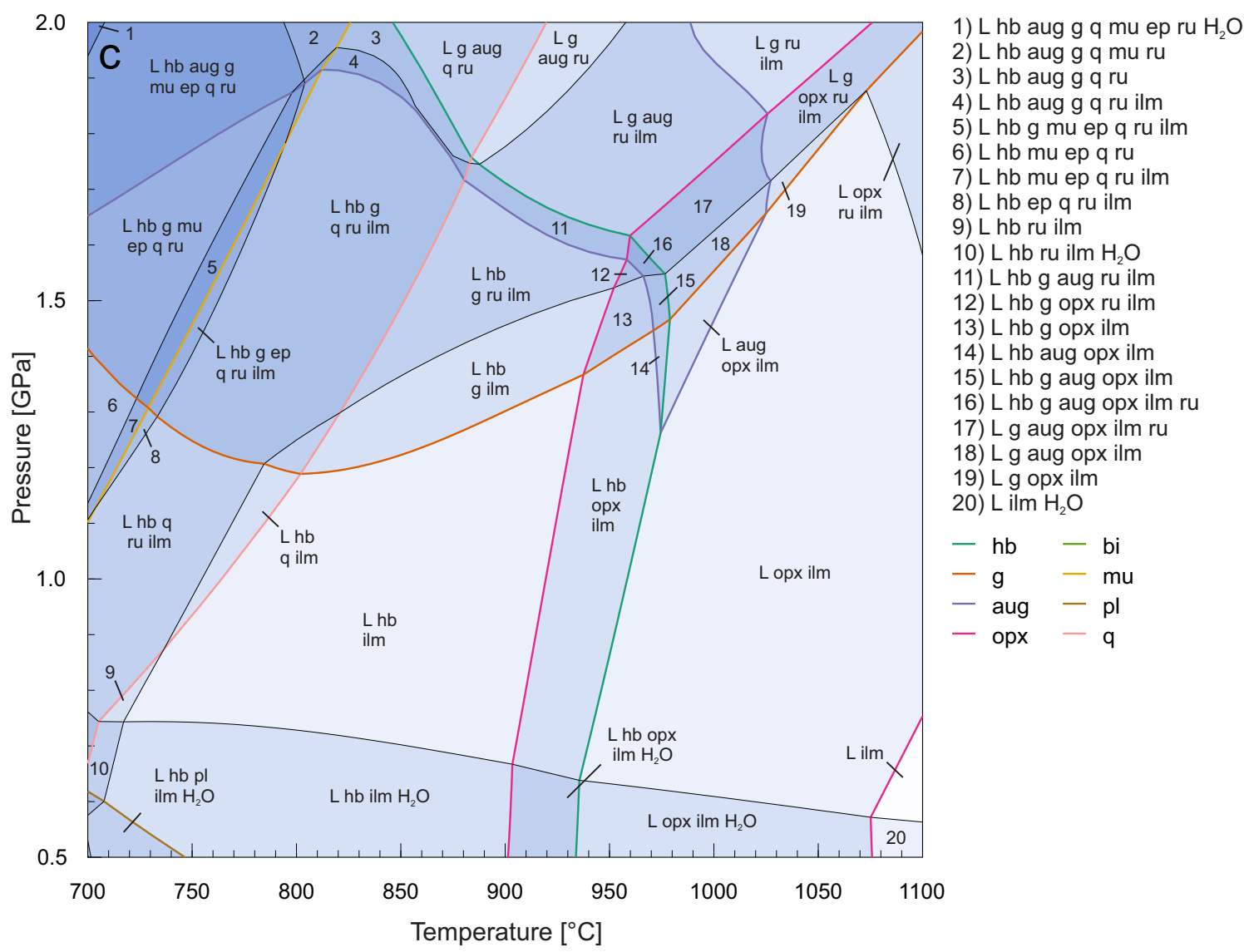

Figure 4.4: $\mathrm{P}-\mathrm{T}$ pseudosections of $\mathrm{PC}-103$ with $\mathrm{Fe}^{3+} / \mathrm{Fe}^{2+}$ ratio of 0.3 and $\mathbf{a}: 2, \mathbf{b}: 5$ and $\mathbf{c}: 10$ $\mathrm{wt} \% \mathrm{H}_{2} \mathrm{O}$. Abbreviations: $\mathrm{L}=$ liquid, $\mathrm{hb}=$ hornblende, $\mathrm{g}=$ garnet, aug = clinopyroxene, opx $=$ orthopyroxene, $\mathrm{mu}=$ muscovite, $\mathrm{bi}=$ biotite, $\mathrm{ep}=$ epidote, $\mathrm{pl}=$ plagioclase, $\mathrm{ksp}=$ alkali feldspar, $\mathrm{q}=$ quartz, $\mathrm{ru}=$ rutile, ilm $=$ ilmenite.

The pseudosection with $10 \mathrm{wt} \% \mathrm{H}_{2} \mathrm{O}$ (fig. 4.4c) is calculated between 700 and $1100{ }^{\circ} \mathrm{C}$ and from 0.5 to $2.0 \mathrm{GPa}$. In this section the true liquidus is present at $1075{ }^{\circ} \mathrm{C}$ and $0.5 \mathrm{GPa}$. The ilmenite stable under these conditions is an artefact of the missing mixing model of $\mathrm{TiO}_{2}$ and silicate melt. Due to the high water content there is free $\mathrm{H}_{2} \mathrm{O}$ present at pressures below $0.8 \mathrm{GPa}$. From 0.5 to $1.3 \mathrm{GPa}$ the liquidus is multiply saturated with hornblende and opx. Above $1.5 \mathrm{GPa}$ the stability of hornblende decreases to lower temperatures and the liquidus is saturated mainly in garnet and opx with a minor amount of cpx. The crystallisation of quartz and plagioclase is strongly suppressed. Mode box plots showing isobaric phase profiles through the diagram at 0.5, $1.0,1.5$ and 2.0 GPa are displayed in fig. 4.11.

\subsubsection{Comparison of experimental and calculated phase stabilities}

Phase stabilities in experiments and calculated sections are only partially consistent. Comparing the $5 \mathrm{wt} \% \mathrm{H}_{2} \mathrm{O}$ sections (4.3a and fig. 4.4b) shows that the stability of opx is increased in the calculated section by around $200{ }^{\circ} \mathrm{C}$ at $0.5 \mathrm{GPa}$. The stability of amphibole is $50{ }^{\circ} \mathrm{C}$ higher 
at $0.5 \mathrm{GPa}$ and the discrepancy increases at $1.0 \mathrm{GPa}$ to $100{ }^{\circ} \mathrm{C}$. Quartz has an increased stability field in the calculated section as well. Whereas it is only stable at $950{ }^{\circ} \mathrm{C}$ and $2 \mathrm{GPa}$ in the experiments, the calculated phase boundary reaches from $800{ }^{\circ} \mathrm{C}, 0.5 \mathrm{GPa}$ to $1075{ }^{\circ} \mathrm{C}$, $2 \mathrm{GPa}$. Garnet also has a greater stability field in the calculated section, extending to lower pressures at high temperatures. In contrast to the experiments, it is stable at 1000 and $1050{ }^{\circ} \mathrm{C}$ at $1.5 \mathrm{GPa}$. The plagioclase stability is similar for both methods.

Likewise is the case for $10 \mathrm{wt} \% \mathrm{H}_{2} \mathrm{O}$. Opx is stable at temperatures of $900{ }^{\circ} \mathrm{C}$ and below in both methods. Fluid saturation is similar in both methods, however the experimentally determined saturation boundary is not well defined. Epidote and cpx stability are similar as well, within deviation of $50{ }^{\circ} \mathrm{C}$. The stability field of garnet is larger in the calculated section as it did not occur experimentally at $850{ }^{\circ} \mathrm{C}$ and $1.5 \mathrm{GPa}$. Garnet precipitation can be kinetically inhibited in experiments, which could explain the difference. As for the other minerals, there might be differences in the experiments used to calibrate THERMOCALC and our experiments. The Fe loss observed in our experiments could contribute to the difference, however it is small for most of our experiments.

\subsection{Melt evolution via crystal fractionation}

For our interpretation we do not consider the age relations of the Nuvvuagittuq TTG suite, as the most differentiated trondhjemites bear the oldest ages. However, they must have differentiated and less evolved felsic compositions of similar age might not be disclosed or preserved.

To investigate the melt evolution of TTGs, we plot them together with our experimental $/$ modelling results in two different types of ternary diagrams. The feldspar triangle by O'Connor (1965), illustrates the change in alkalis, a crucial point for TTGs. The second diagram is the Qtz-Fo-An plane of CMAS re-calculated compositions (O'Hara, 1965) to display melt evolution in a higher dimensional system. The natural TTGs plotted into the diagrams are only filtered via the feldspar diagram (O'Connor, 1965), La $>10$ and $\mathrm{Y}<2$. Samples with Eu anomaly are intentionally kept, to include samples affected by fractionation or accumulation.

\subsubsection{The experimental system}

There are two distinct trends of melt differentiation for experimental glasses displayed in the normative feldspar diagram of O'Connor (1965) (fig. 4.5a and 4.5b). The first trend is a depletion of $\mathrm{CaO}$ without a change in the $\mathrm{K}_{2} \mathrm{O} / \mathrm{Na}_{2} \mathrm{O}$ ratio, visible for 5 and $10 \mathrm{wt} \% \mathrm{H}_{2} \mathrm{O}$. The trend is caused by the retardation of plagioclase crystallisation due to either high $\mathrm{H}_{2} \mathrm{O}$ or high temperature. This is most distinct at $2 \mathrm{GPa}$ where garnet and cpx are controlling the melt evolution, both not capable of fractionating $\mathrm{Na}_{2} \mathrm{O}$ and $\mathrm{K}_{2} \mathrm{O}$. Plagioclase crystallises at $5 \mathrm{wt} \% \mathrm{H}_{2} \mathrm{O}$, temperatures $<950{ }^{\circ} \mathrm{C}$ (fig. 4.3a) and shifts the trend towards a $\mathrm{K}_{2} \mathrm{O}$ enrichment. At $10 \mathrm{wt} \% \mathrm{H}_{2} \mathrm{O}$ plagioclase crystallises $\leq 800{ }^{\circ} \mathrm{C}$ which shifts the trend in the same way 
towards a $\mathrm{K}_{2} \mathrm{O}$ enrichment, observable in the $0.3 \mathrm{GPa}$ experiments.

We re-calculated the experiments and natural TTGs to CMAS components (CaO-MgO- $\mathrm{Al}_{2} \mathrm{O}_{3}-$ $\mathrm{SiO}_{2}$, O'Hara, 1968) and plot it in the Qtz-Fo-An plane (fig. 4.5c \& 4.5d), again separated by the initial water content. The diagrams are reduced in their size to $60 \%$ Qtz and Fo component for a more detailed presentation. In contrast to the feldspar diagrams, the TTGs from the Nuvvuagittuq plot on a narrow field around our starting material PC-103 with only 4 samples deviating from the field. Other natural TTG compositions trend almost parallel to the An - Qtz plane at Fo $\leq 10$.

At $5 \mathrm{wt} \% \mathrm{H}_{2} \mathrm{O}$ (fig. 4.5c) the melt is governed by an opx/cpx - hbl/grt cotectic, depending on pressure. The melt evolves almost straight towards the Qtz-An plane, perpendicular to the array formed by the Nuvvuagittuq TTGs. At 0.5 GPa plagioclase stability causes a cotectic path parallel to the Nuvvuagittuq TTG array. As the amount of crystals is below $20 \%$ in all experiments, the trends are not very distinct and plot close to each other.

At $10 \mathrm{wt} \% \mathrm{H}_{2} \mathrm{O}$ (fig. 4.5d) there is a distinct cotectic path governed by hornblende and plagioclase at $0.3 \mathrm{GPa}$ towards highly evolved compositions. This path resembles the differentiation trend seen in the Nuvvuagittuq TTGs, except for being offset towards a lower Fo component. The cotectic also fits well to the overall trend of the larger TTG dataset and is similar to the cotectic produced by Rapp and Watson (1995) displayed in fig. 4.1d. At higher pressure conditions, the number of experiments is insufficient to define cotectic paths. However, it is observable that at $2 \mathrm{GPa}$ the melt compositions evolves in a quite similar direction, in this case in presence of hornblende, clinozosisite and garnet. The difference between both melt evolution paths at 0.3 and $2 \mathrm{GPa}$ is more distinct in the feldspar diagram (fig. 4.3b).

The experiments show that the direction of differentiation within the feldspar diagram is strongly influenced by the amount of $\mathrm{H}_{2} \mathrm{O}$, however the trends are small and difficult to further quantify or generalise based on the amount of experiments. In the range of fractionation $(\leq 40 \%)$ seen in the experiments it is not possible to reproduce the natural rocks of the Nuvvuagittuq suite. On the one hand, due to mismatching alkalis (fig. 4.5a and 4.5b), and on the other, because of a lateral offset due to lacking the Fo component (fig. 4.5c and 4.5d). However, the general trend of TTGs can be retraced with both, a hornblende - feldspar cotectic at $0.5 \mathrm{GPa}$ and a high pressure trend comprising hornblende, garnet and clinozoisite at $2 \mathrm{GPa}$.

\subsubsection{The modelled system}

We extracted isobaric profiles from the the THERMOCALC P-T diagrams (fig. 4.4) containing modes and phase compositions for 0.5, 1.0, 1.5 and 2.0 GPa. The recalculated normative melt compositions are plotted in fig. $4.6 \mathrm{a}, 4.6 \mathrm{~b}$ and $4.6 \mathrm{c}$. The two trends seen in the experimental melts are also present in the calculated melt compositions at 5 and $10 \mathrm{wt} \% \mathrm{H}_{2} \mathrm{O}$. The modelling, which comprises higher degrees of fractionation at lower temperatures than our 


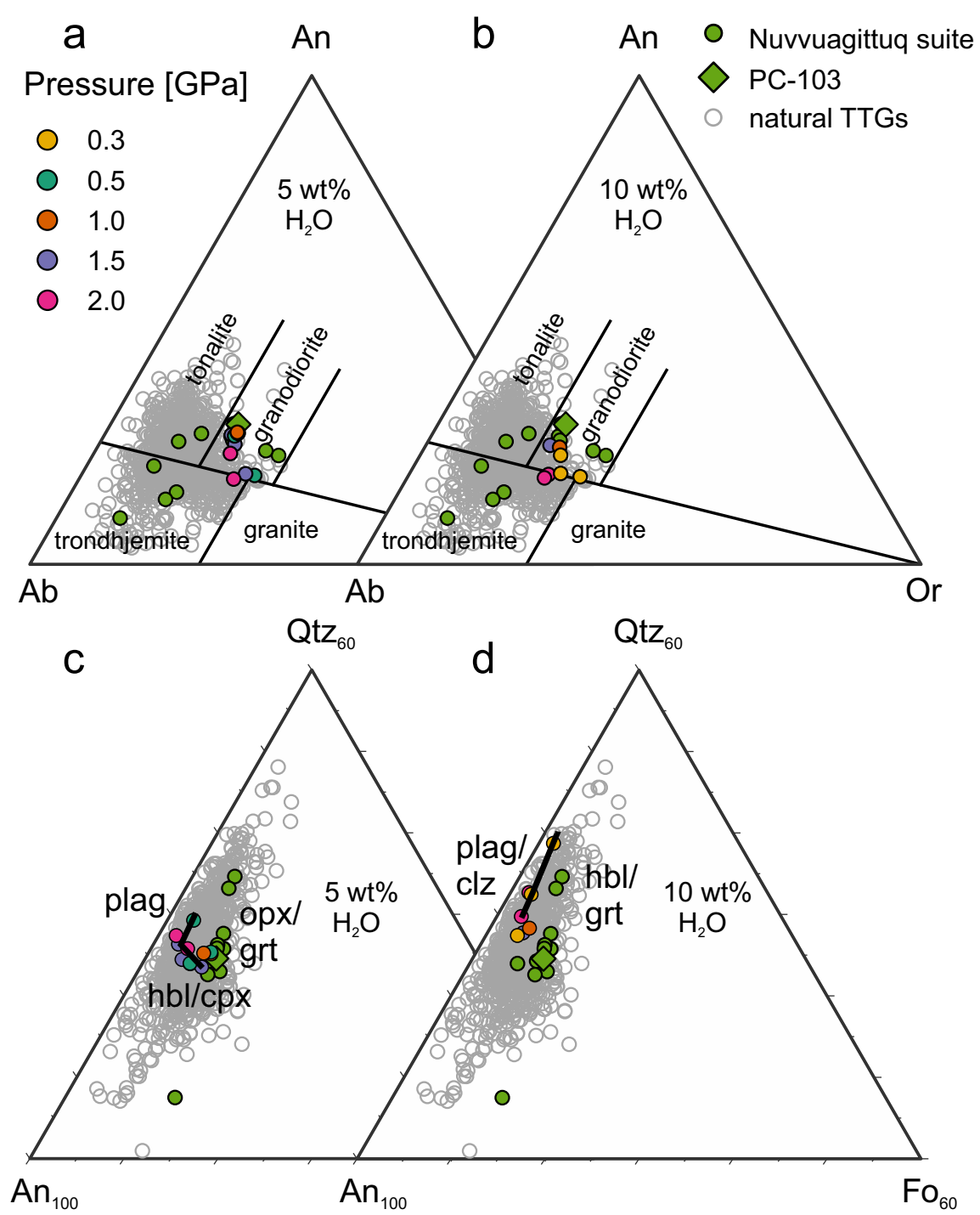

Figure 4.5: Feldspar diagram of O'Connor, 1965 with our experimental melts for a: 5 and $\mathbf{b}$ : $10 \mathrm{wt} \% \mathrm{H}_{2} \mathrm{O}$, Nuvvuagittuq TTGs (O'Neil et al., 2012) and other natural TTG data (Nutman et al., 1999; Moyen, 2011; Huang et al., 2013; Laurent et al., 2014; O'Neil and Carlson, 2017; Johnson et al., 2019). Diagrams $\mathbf{c}$ and $\mathbf{d}$ contain the same datasets as a \& b, recalculated to CMAS components (O'Hara, 1968) and projected in the Qtz-Fo-An plane. The diagrams are reduced in extend to $60 \%$ Qtz and Fo. Abbreviations: plag = plagioclase, opx = orthopyroxene, $\mathrm{cpx}=$ clinopyroxene, grt $=$ garnet, $\mathrm{hbl}=$ hornblende, $\mathrm{clz}=$ clinozoisite .

experiments, shows that the $\mathrm{K}_{2} \mathrm{O}$ enrichment trend shifts to a $\mathrm{K}_{2} \mathrm{O}$ depletion at pressures above $1 \mathrm{GPa}$, once mica becomes stable. The melt evolution at $2 \mathrm{wt} \% \mathrm{H}_{2} \mathrm{O}$ lacks the $\mathrm{CaO}$ depletion as plagioclase is already stable at $1050{ }^{\circ} \mathrm{C}$. The melt enriches in $\mathrm{K}_{2} \mathrm{O}$ until mica becomes a stable phase.

In contrast to the experimental melts, the calculated melts match several samples of the Nuvvuagittuq suite along their differentiation paths. Along the 1.0 GPa differentiation trend at $2 \mathrm{wt} \% \mathrm{H}_{2} \mathrm{O}$ the natural granodioritic compositions of the Nuvvuagittuq TTGs are matched. 
Furthermore, at 2.0 GPa high degrees of fractionation ( $50 \%$ for $10 \mathrm{wt} \% \mathrm{H}_{2} \mathrm{O}, 65 \%$ for 5 wt $\% \mathrm{H}_{2} \mathrm{O}$ and $90 \%$ for $2 \mathrm{wt} \% \mathrm{H}_{2} \mathrm{O}$ ), trondhjemitic compositions of the Nuvvuagittuq suite are similar. This match is only an artefact within the feldspar diagram, apparent by trends in the Qtz-Fo-An projection (fig. 4.6d, 4.6e and 4.6f) based on recalculated melt compositions in CMAS (O'Hara, 1968).

At low pressure, for 2 and $5 \mathrm{wt} \% \mathrm{H}_{2} \mathrm{O}$ (fig. 4.6d, 4.6e) a similar cotectic path as for the 0.3 $\mathrm{GPa}, 10 \mathrm{wt} \% \mathrm{H}_{2} \mathrm{O}$ experiments is present, however at $2 \mathrm{wt} \%$ it is governed by opx - plagioclase instead of hornblende - plagioclase. The melts at pressures $\geq 1 \mathrm{GPa}$ and $2 \mathrm{wt} \% \mathrm{H}_{2} \mathrm{O}$ evolve towards the An end-member due to the early presence of quartz within the crystallisation sequence. With $5 \mathrm{wt} \% \mathrm{H}_{2} \mathrm{O}$ present, quartz crystallisation is retained to lower temperatures wherefore the melt first evolves governed by either opx, garnet or hornblende towards the An-Qtz plane.

At $\mathrm{H}_{2} \mathrm{O}$ contents of $10 \mathrm{wt} \%$ (fig. 4.6f) with 0.5 and $1.0 \mathrm{GPa}$, the melt has no cotectic path until $750{ }^{\circ} \mathrm{C}$. The melt is evolving by the crystallisation of either opx or hornblende. At 1.5 GPa the melt is governed by a garnet - hornblende cotectic towards the An-Qtz plane until quartz crystallises at $850{ }^{\circ} \mathrm{C}$. At that point the Fo component of the system is already almost exhausted. For 2.0 GPa the cotectic control starts at $900{ }^{\circ} \mathrm{C}$ with garnet/cpx - quartz on the An - Qtz plane. Except for isobaric crystallisation paths that contain feldspar, neither the evolution of the Nuvvuagittuq TTGs, nor the array of other natural TTGs can be retraced. As we have already seen for the experimental melts, the melt evolution path is strongly dependent on the amount of $\mathrm{H}_{2} \mathrm{O}$ present. In the feldspar diagram, with 2 wt $\% \mathrm{H}_{2} \mathrm{O}$, the melt evolves towards $\mathrm{K}_{2} \mathrm{O}$ rich compositions, irrespective of pressure due to the presence of plagioclase. With $5 \mathrm{wt} \% \mathrm{H}_{2} \mathrm{O}$ the stability of plagioclase is already retarded by $150-200{ }^{\circ} \mathrm{C}$ and melt evolution in proximity of the liquidus is governed by either hornblende, garnet or cpx. Therefore, there is an initial depletion in $\mathrm{CaO}$ and once plagioclase crystallises the melt enriches in $\mathrm{K}_{2} \mathrm{O}$. The same is true for $10 \mathrm{wt} \% \mathrm{H}_{2} \mathrm{O}$ where plagioclase is almost completely suppressed. Irrespective of pressure, the melt evolves on a $\mathrm{CaO}$ depletion trend. Only once mica crystallises the melts are strongly depleted in $\mathrm{K}_{2} \mathrm{O}$.

\subsubsection{Was crystal fractionation involved?}

PC-103 cannot be the starting point of fractionation to produce the Nuvvuagittuq TTG suite. It is furthermore questionable that crystal fractionation shaped the majority of the suite as the individual samples differ in their alkali content but behave similar in regard to their decrease of $\mathrm{Al}_{2} \mathrm{O}_{3}, \mathrm{FeO}_{t}$ and $\mathrm{MgO}$ along differentiation paths (appendix fig. 4.7). It is further reasonable to assume that the differences in $\mathrm{K}_{2} \mathrm{O} / \mathrm{Na}_{2} \mathrm{O}$ within the suite are not the result of internal crystal fractionation. Alternatives are the fractionation of a less evolved parental magma under differing conditions or different degrees of melting. Accumulation of plagioclase can also lead to low $\mathrm{K}_{2} \mathrm{O} / \mathrm{Na}_{2} \mathrm{O}$ ratios, however there is no positive Eu-anomaly present in 


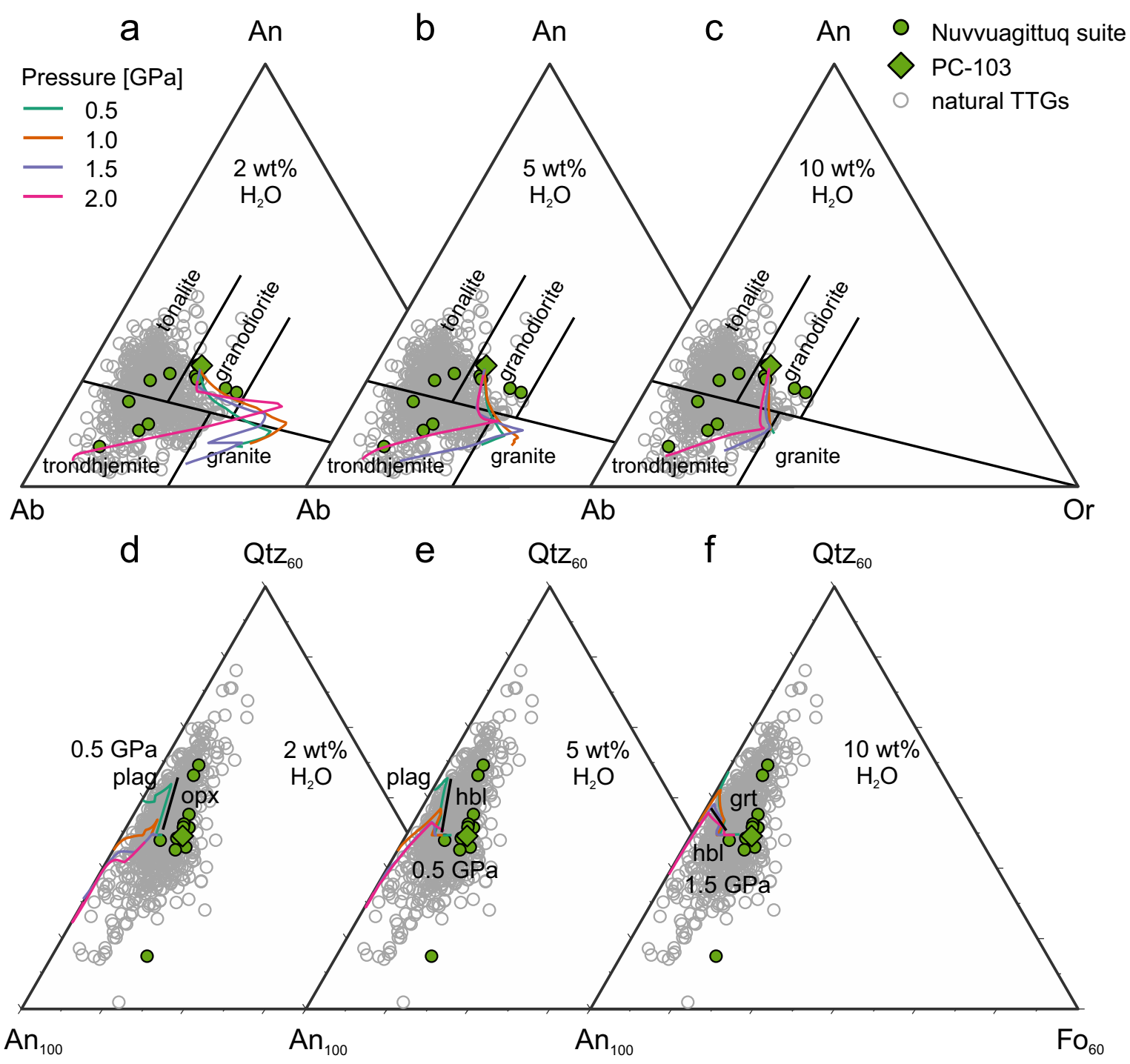

Figure 4.6: Feldspar diagram (O'Connor, 1965) with isobaric melt compositions profiles for a: 2 , b: 5 and c: $10 \mathrm{wt} \% \mathrm{H}_{2} \mathrm{O}$ calculated with THERMOCALC for different $\mathrm{H}_{2} \mathrm{O}$ contents with $\mathrm{Fe}^{3+} / \mathrm{Fe}^{2+}$ ratio of 0.3. Natural TTG data is from Nutman et al. (1999), Moyen (2011), Huang et al. (2013), Laurent et al. (2014), and O'Neil and Carlson (2017) and Johnson et al. (2019). The sub-figures d, e \& f display the same data recalculated as CMAS (O'Hara, 1968) and plotted into the Qtz-Fo-An plane. The diagrams are reduced in extend to $60 \%$ Qtz and Fo. Modes of the isobaric profiles are in appendix fig. 4.9, $4.10 \& 4.11$. Abbreviations: plag = plagioclase, opx $=$ orthopyroxene, $\mathrm{hbl}=$ hornblende, grt $=$ garnet. 
the Nuvvuagittuq suite. This is the same predicament as for the 1.6 GPa cotectic path from Rapp and Watson (1995) in fig. 4.1d and our experiments. A high pressure cotectic path of clinozoisite - grt/hbl as in fig. $4.5 \mathrm{~d}$ might be an alternative, though clinozoisite drastically changes the trace element pattern (Bédard, 2006a), which is not observed. An option that avoids the presence of plagioclase is proposed by Adam et al. (2012). In their interpretation, TTGs can be formed along pressure dependent cotectic paths above 1.0 GPa, controlled by garnet and cpx/opx that lay perpendicular to the TTG array. Similar cotectic paths are present in fig. $4.5 \mathrm{c}$ where melt is controlled by garnet-cpx at $2 \mathrm{GPa}$ and in fig. $4.6 \mathrm{f}$ with a hornblende - garnet cotectic at $1.5 \mathrm{GPa}$.

It was remarked by Kleinhanns et al. (2003) that $\mathrm{H}_{2} \mathrm{O}$ is of significant importance in the differentiation/formation of TTGs by determining the path of fractionation by controlling plagioclase crystallisation. Starting from a tonalitic or less evolved composition (Liou and Guo, 2019), crystal fractionation under hydrous conditions involving garnet, hornblende or pyroxene will produce trondhjemitic compositions, whereas $\mathrm{H}_{2} \mathrm{O}$ poor melts will produce granodioritic compositions as observable in fig. 4.6. Very hydrous conditions for TTG formation are favoured by Laurie and Stevens (2012) who explain trondhjemite formation by fluid present slab melting.

An option we did not explore in our experiments and modelling is the absence of plagioclase due to high pressure $(>2 \mathrm{GPa})$. This might also be a suitable environment to produce trondhjemitic compositions.

\subsection{Conclusions}

From our experiments and modelling we can conclude that the internal differentiation of TTGs is strongly dependent on the presence of $\mathrm{H}_{2} \mathrm{O}$. Water rich systems will trend towards tonalitic to trondhjemitic compositions along a cotectic path governed by hornblende, garnet and opx/cpx. Under dryer conditions the system will evolve towards granodioritic to granitic compositions due to plagioclase crystallisation.

It is difficult to retrace the array of Eu anomaly free TTGs without plagioclase involved in governing the cotectic. Therefore this array is most likely not a liquid line of descent. It rather seems that TTGs where formed along hbl/cpx - grt/opx controlled cotectic paths perpendicular to the array at different pressure conditions and/or elevated $\mathrm{H}_{2} \mathrm{O}$ content. TTGs containing an Eu anomaly could likely have formed along a lower pressure plagioclase hornblende/opx cotectic path. We were not able to experimentally reproduce the compositional diversity of the Nuvvuagittuq TTGs, however identified the required differentiation paths to do so. Starting with a $\mathrm{K}_{2} \mathrm{O}$ poorer composition than PC-103 should enable the evolution towards the trondhjemite members of the suite. 


\subsection{Acknowledgements}

A. Wellhäuser is supported by an iMQRES from Macquarie University. The experimental work at Nanjing University was supported by the fund number 2019-LAMD-K02 granted from the State Key Laboratory of Mineral Deposits Research of Nanjing University.

\subsection{Appendix}
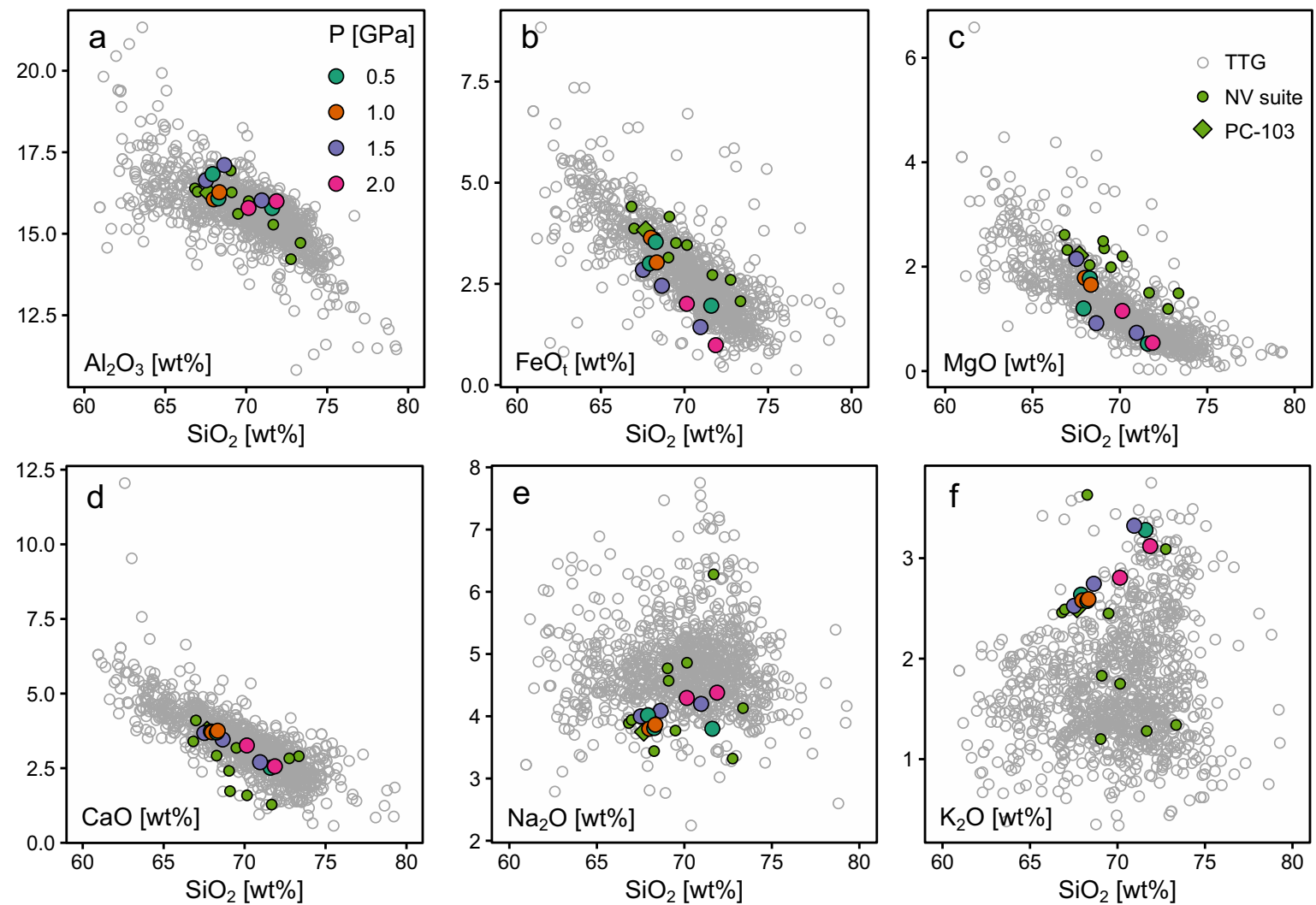

Figure 4.7: Major element scatter plots for glass compositions from PC-103 experiments with 5 wt $\% \mathrm{H}_{2} \mathrm{O}$, the Nuvvuagittuq Suite (O'Neil et al., 2012) and other natural TTGs (Nutman et al., 1999; Moyen, 2011; Huang et al., 2013; Laurent et al., 2014; O'Neil and Carlson, 2017; Johnson et al., 2019). 

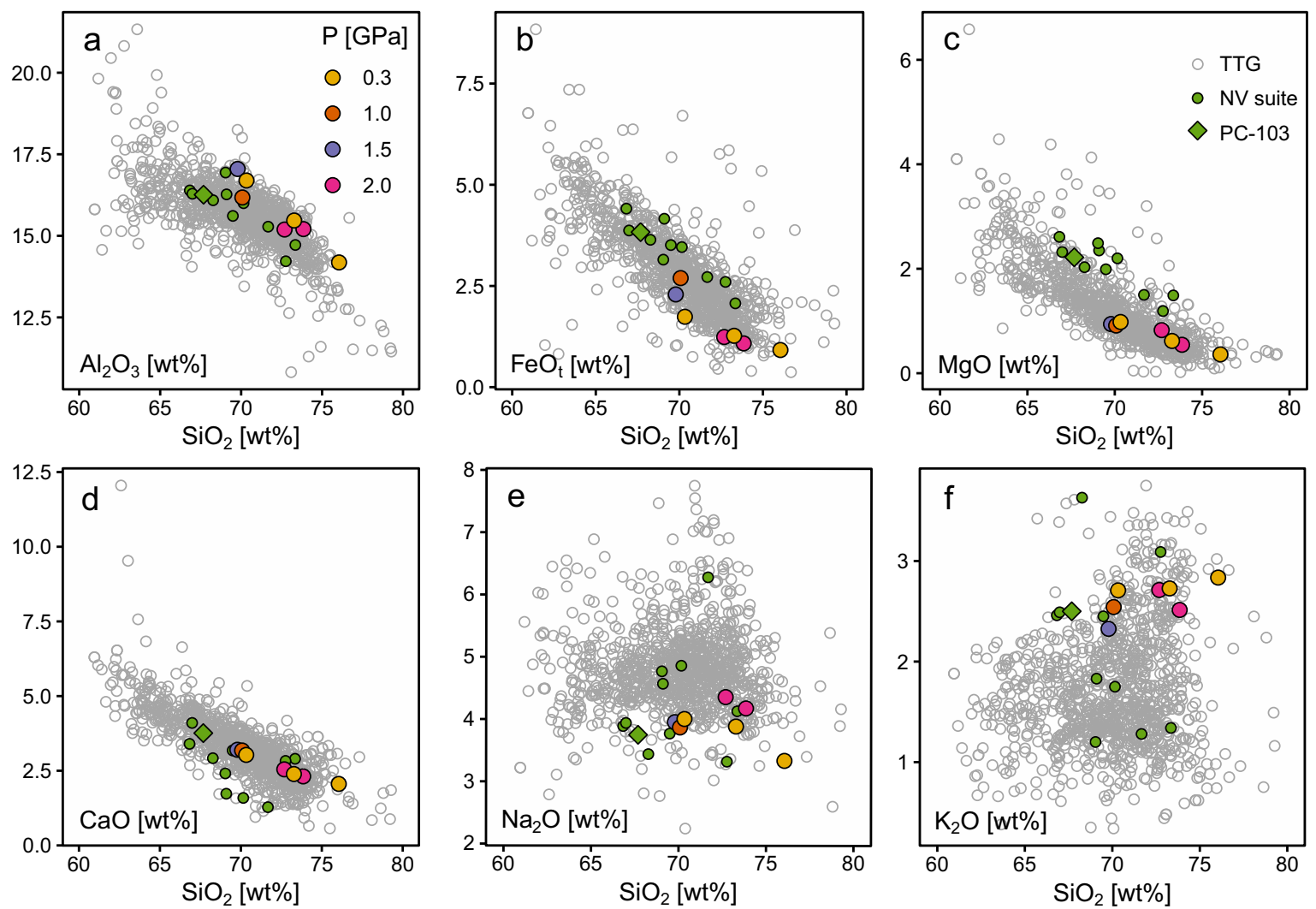

Figure 4.8: Major element scatter plots for glass compositions from PC-103 experiments with 10 wt\% $\mathrm{H}_{2} \mathrm{O}$,the Nuvvuagittuq Suite (O'Neil et al., 2012) and other natural TTGs (Nutman et al., 1999; Moyen, 2011; Huang et al., 2013; Laurent et al., 2014; O’Neil and Carlson, 2017; Johnson et al., 2019). 

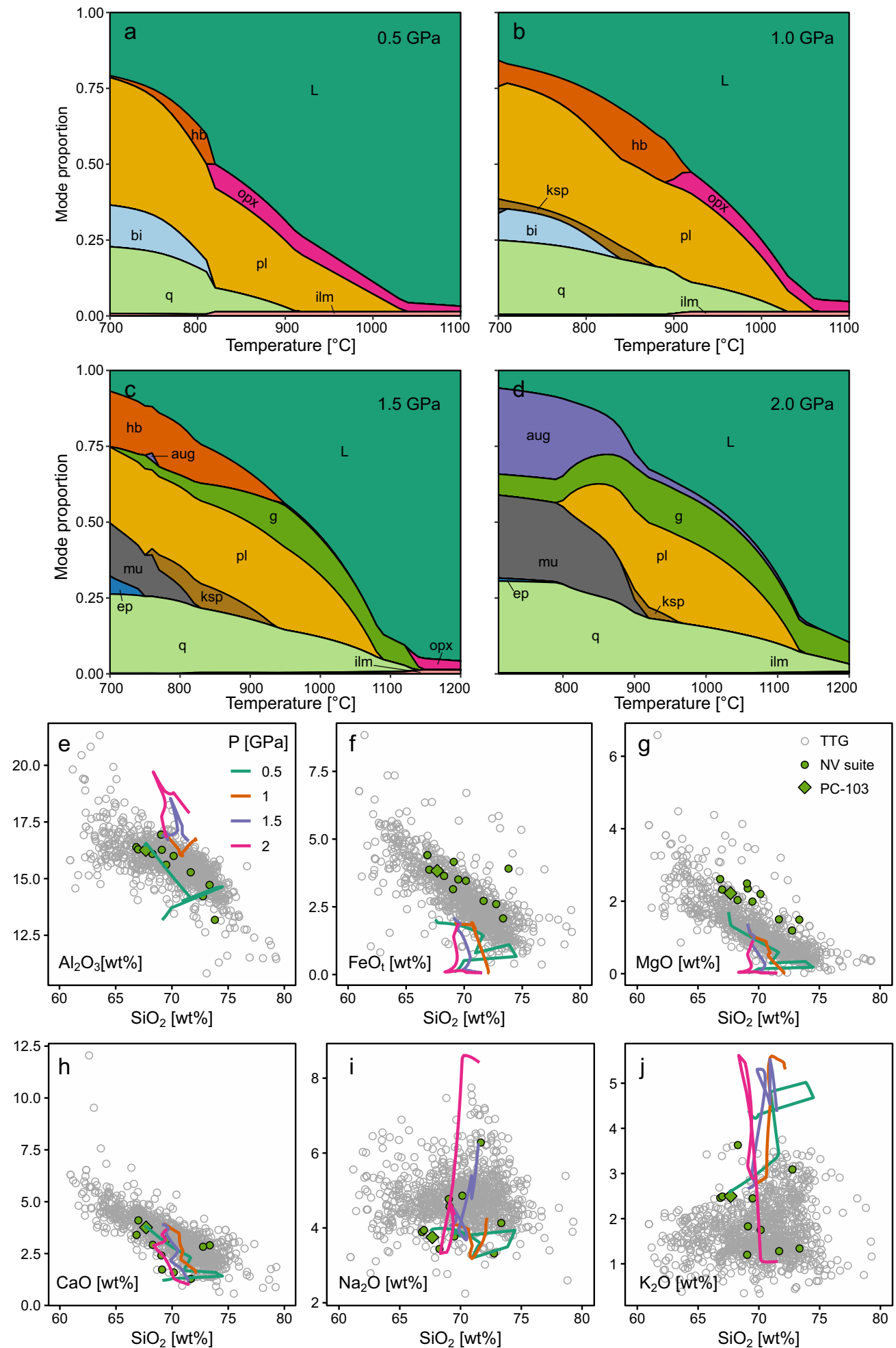

Figure 4.9: a-d: Modes for different pressure sections through the P-T pseudosection of PC-103 calculated with $2 \mathrm{wt} \%$ of $\mathrm{H}_{2} \mathrm{O}$ (fig. 4.4a). Abbreviations : $\mathrm{L}=$ liquid, $\mathrm{hb}=$ hornblende, opx $=$ orthopyroxene, $\mathrm{pl}=$ plagioclase, $\mathrm{ilm}=$ ilmenite, $\mathrm{bi}=$ biotite, $\mathrm{q}=$ quartz, $\mathrm{ksp}=\mathrm{K}$-feldspar, aug $=$ augite, $\mathrm{mu}=$ muscovite, $\mathrm{ep}=$ epidote. $\mathbf{e}-\mathbf{j}$ : Harker diagrams for melt compositions based on the profiles of a-d plotted with the Nuvvuagittuq TTGs (O'Neil et al., 2012) and natural TTG (Nutman et al., 1999; Moyen, 2011; Huang et al., 2013; Laurent et al., 2014; O'Neil and Carlson, 2017; Johnson et al., 2019). 

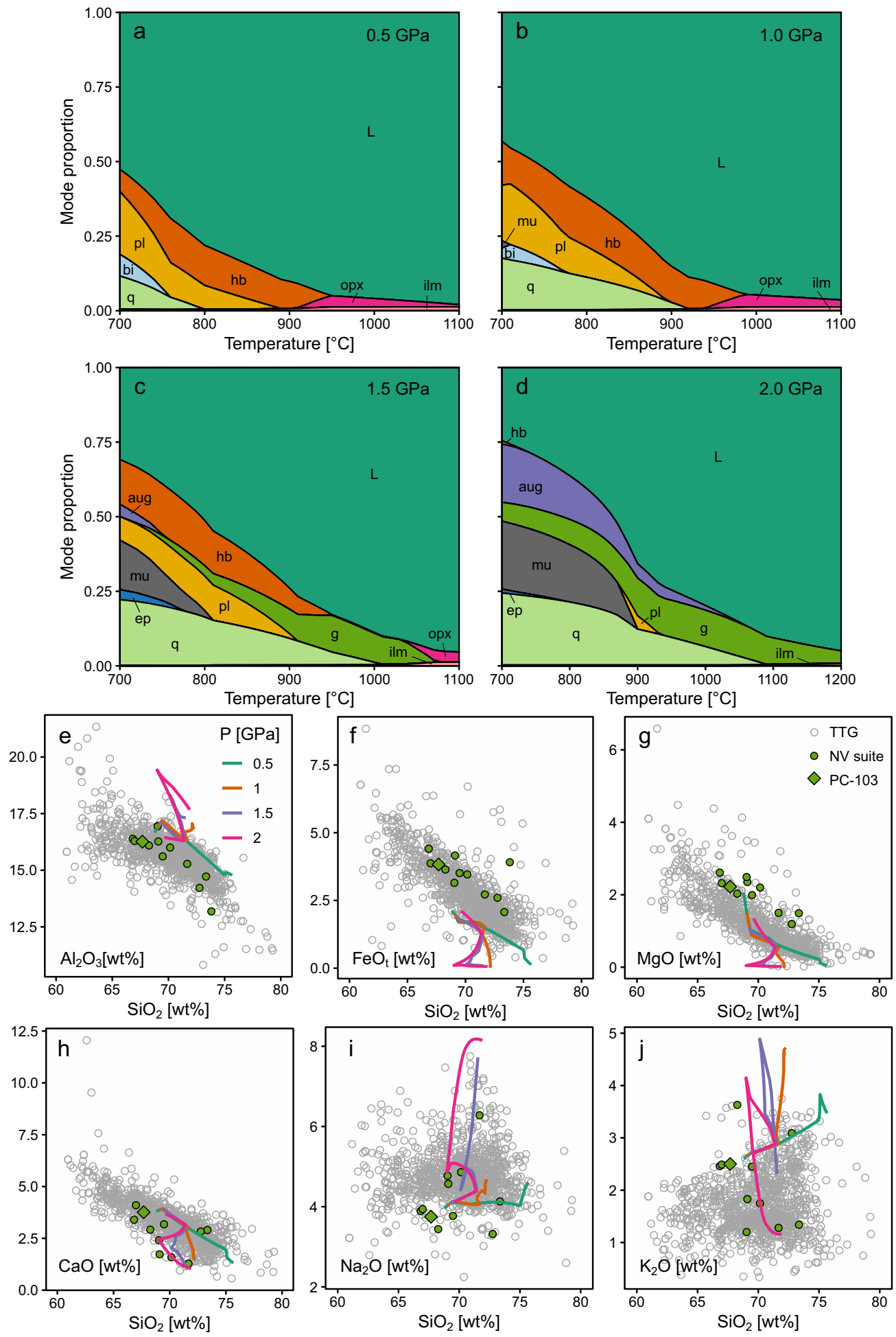

Figure 4.10: a-d: Modes for different pressure sections through the P-T pseudosection of PC-103 calculated with $5 \mathrm{wt} \%$ of $\mathrm{H}_{2} \mathrm{O}$ (fig. 4.4b). Abbreviations : $\mathrm{L}=$ liquid, $\mathrm{hb}=$ hornblende, opx $=$ orthopyroxene, $\mathrm{pl}=$ plagioclase, $\mathrm{ilm}=$ ilmenite, $\mathrm{bi}=$ biotite, $\mathrm{q}=$ quartz, aug $=$ augite, $\mathrm{mu}=$ muscovite, ep = epidote. e-j: Harker diagrams for melt compositions based on the profiles of a-d plotted with the Nuvvuagittuq TTGs and natural TTG (Nutman et al., 1999; Moyen, 2011; Huang et al., 2013; Laurent et al., 2014; O'Neil and Carlson, 2017; Johnson et al., 2019) 

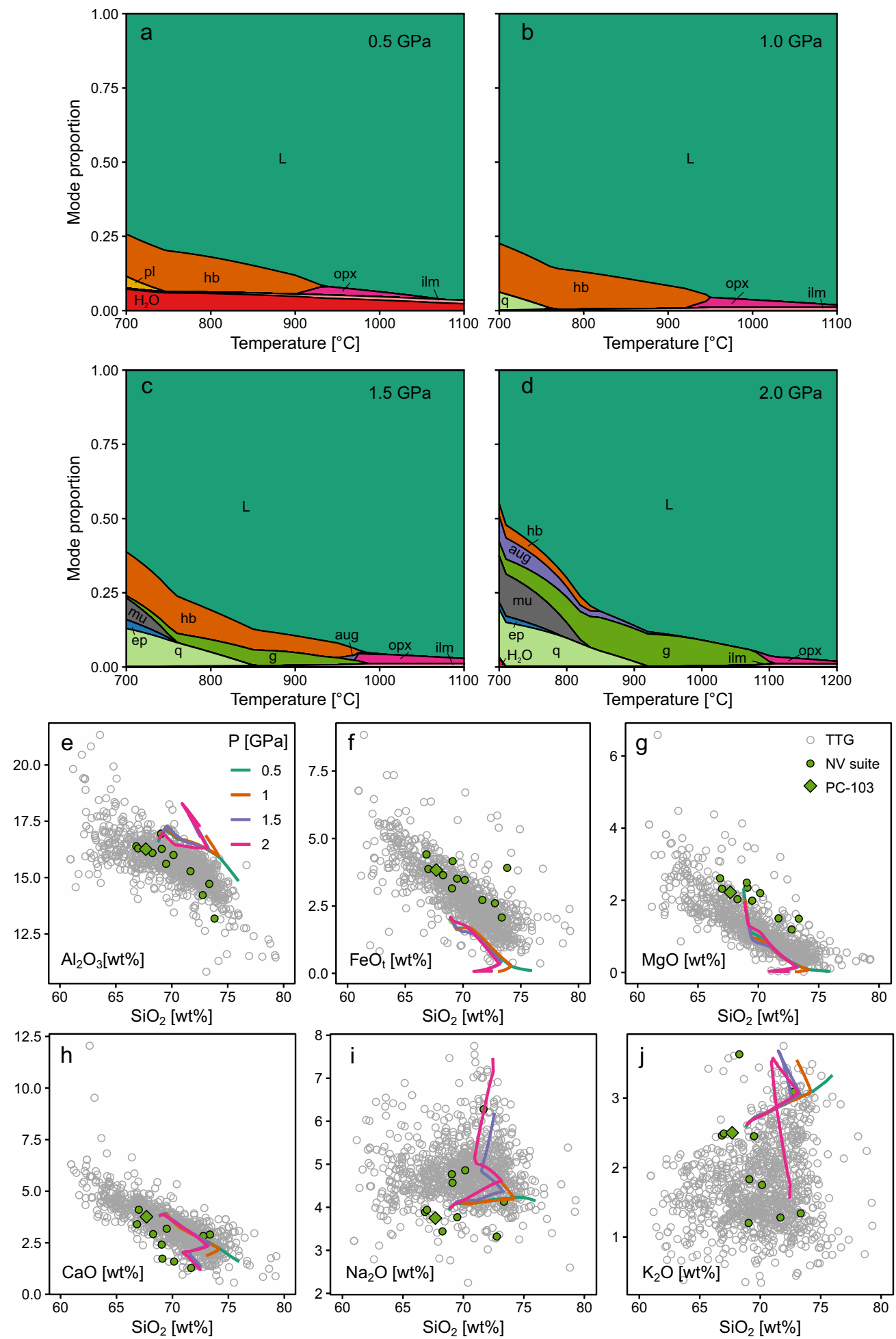

Figure 4.11: a-d: Modes for different pressure sections through the P-T pseudosection of PC-103 calculated with $10 \mathrm{wt} \%$ of $\mathrm{H}_{2} \mathrm{O}$ (fig. 4.4c). Abbreviations : $\mathrm{L}=$ liquid, $\mathrm{hb}=$ hornblende, opx $=$ orthopyroxene, $\mathrm{pl}=$ plagioclase, $\mathrm{ilm}=$ ilmenite, $\mathrm{bi}=$ biotite, $\mathrm{q}=$ quartz, aug $=$ augite, $\mathrm{mu}=$ muscovite, ep = epidote. $\mathbf{e - j}$ : Harker diagrams for melt compositions based on the profiles of a-d plotted with the Nuvvuagittuq TTGs and natural TTG (Nutman et al., 1999; Moyen, 2011; Huang et al., 2013; Laurent et al., 2014; O'Neil and Carlson, 2017; Johnson et al., 2019) 
Table 4.6: Melt compositions extracted from isobaric profiles of the calculated P-T sections (fig. 4.4) $\mathrm{H}_{2} \mathrm{O}^{i}$ is the water content in the system, $\mathrm{H}_{2} \mathrm{O}^{m}$ is dissolved in the melt. If not stated otherwise data is given in wt\%.

\begin{tabular}{|c|c|c|c|c|c|c|c|c|c|c|c|}
\hline $\mathrm{H}_{2} \mathrm{O}^{i}$ & $\begin{array}{c}\mathrm{P} \\
{\left[{ }^{\circ} \mathrm{C}\right]}\end{array}$ & $\begin{array}{c}\mathrm{T} \\
{[\mathrm{GPa}]}\end{array}$ & $\begin{array}{c}\text { melt } \\
{[\%]}\end{array}$ & $\mathrm{H}_{2} \mathrm{O}^{m}$ & $\mathrm{SiO}_{2}$ & $\mathrm{Al}_{2} \mathrm{O}_{3}$ & $\mathrm{MgO}$ & $\mathrm{FeO}_{t}$ & $\mathrm{CaO}$ & $\mathrm{Na}_{2} \mathrm{O}$ & $\mathrm{K}_{2} \mathrm{O}$ \\
\hline 2 & 0.5 & 1100 & 96.8 & 2.1 & 67.5 & 16.4 & 1.70 & 2.03 & 3.76 & 3.92 & 2.58 \\
\hline 2 & 0.5 & 1090 & 96.6 & 2.1 & 67.5 & 16.4 & 1.64 & 2.01 & 3.77 & 3.93 & 2.58 \\
\hline 2 & 0.5 & 1080 & 96.4 & 2.1 & 67.6 & 16.5 & 1.58 & 2.00 & 3.78 & 3.93 & 2.59 \\
\hline 2 & 0.5 & 1070 & 96.2 & 2.1 & 67.6 & 16.5 & 1.52 & 1.98 & 3.78 & 3.94 & 2.59 \\
\hline 2 & 0.5 & 1060 & 96.0 & 2.1 & 67.6 & 16.5 & 1.46 & 1.96 & 3.79 & 3.95 & 2.60 \\
\hline 2 & 0.5 & 1050 & 95.9 & 2.1 & 67.7 & 16.5 & 1.40 & 1.94 & 3.80 & 3.96 & 2.60 \\
\hline 2 & 0.5 & 1040 & 95.7 & 2.1 & 67.7 & 16.6 & 1.34 & 1.92 & 3.80 & 3.97 & 2.61 \\
\hline 2 & 0.5 & 1030 & 94.4 & 2.1 & 67.9 & 16.4 & 1.28 & 1.90 & 3.70 & 3.98 & 2.65 \\
\hline 2 & 0.5 & 1020 & 92.5 & 2.2 & 68.2 & 16.2 & 1.22 & 1.90 & 3.55 & 3.98 & 2.70 \\
\hline 2 & 0.5 & 1010 & 90.6 & 2.2 & 68.6 & 16.0 & 1.16 & 1.89 & 3.40 & 3.99 & 2.75 \\
\hline 2 & 0.5 & 1000 & 88.8 & 2.3 & 68.9 & 15.8 & 1.10 & 1.87 & 3.26 & 3.98 & 2.81 \\
\hline 2 & 0.5 & 990 & 86.9 & 2.3 & 69.2 & 15.6 & 1.04 & 1.85 & 3.13 & 3.96 & 2.87 \\
\hline 2 & 0.5 & 980 & 85.1 & 2.4 & 69.5 & 15.4 & 0.98 & 1.82 & 3.00 & 3.94 & 2.93 \\
\hline 2 & 0.5 & 970 & 83.2 & 2.4 & 69.8 & 15.2 & 0.92 & 1.78 & 2.88 & 3.91 & 3.00 \\
\hline 2 & 0.5 & 960 & 81.3 & 2.5 & 70.2 & 15.0 & 0.86 & 1.74 & 2.77 & 3.87 & 3.06 \\
\hline 2 & 0.5 & 950 & 79.5 & 2.6 & 70.5 & 14.8 & 0.80 & 1.69 & 2.66 & 3.83 & 3.13 \\
\hline 2 & 0.5 & 940 & 77.6 & 2.6 & 70.8 & 14.6 & 0.74 & 1.63 & 2.56 & 3.77 & 3.20 \\
\hline 2 & 0.5 & 930 & 75.8 & 2.7 & 71.1 & 14.5 & 0.69 & 1.57 & 2.47 & 3.71 & 3.27 \\
\hline 2 & 0.5 & 920 & 73.9 & 2.8 & 71.5 & 14.3 & 0.63 & 1.50 & 2.39 & 3.64 & 3.35 \\
\hline 2 & 0.5 & 910 & 71.7 & 2.9 & 71.6 & 14.1 & 0.58 & 1.43 & 2.30 & 3.58 & 3.45 \\
\hline 2 & 0.5 & 900 & 68.6 & 3.0 & 71.6 & 14.1 & 0.55 & 1.38 & 2.22 & 3.56 & 3.59 \\
\hline 2 & 0.5 & 890 & 65.7 & 3.1 & 71.5 & 14.1 & 0.52 & 1.33 & 2.14 & 3.53 & 3.74 \\
\hline 2 & 0.5 & 880 & 63.0 & 3.3 & 71.4 & 14.1 & 0.49 & 1.26 & 2.06 & 3.50 & 3.90 \\
\hline 2 & 0.5 & 870 & 60.4 & 3.4 & 71.3 & 14.1 & 0.45 & 1.19 & 1.99 & 3.46 & 4.05 \\
\hline 2 & 0.5 & 860 & 58.1 & 3.6 & 71.3 & 14.1 & 0.42 & 1.12 & 1.92 & 3.41 & 4.20 \\
\hline 2 & 0.5 & 850 & 55.8 & 3.8 & 71.2 & 14.1 & 0.39 & 1.04 & 1.85 & 3.36 & 4.35 \\
\hline 2 & 0.5 & 840 & 53.8 & 3.9 & 71.1 & 14.0 & 0.35 & 0.96 & 1.79 & 3.31 & 4.51 \\
\hline 2 & 0.5 & 830 & 51.8 & 4.1 & 71.1 & 14.0 & 0.32 & 0.88 & 1.73 & 3.26 & 4.66 \\
\hline 2 & 0.5 & 820 & 50.0 & 4.2 & 71.0 & 14.0 & 0.29 & 0.80 & 1.68 & 3.20 & 4.81 \\
\hline 2 & 0.5 & 810 & 40.1 & 4.6 & 73.9 & 14.6 & 0.34 & 1.10 & 1.59 & 3.49 & 5.02 \\
\hline 2 & 0.5 & 800 & 36.8 & 5.0 & 74.0 & 14.6 & 0.29 & 1.00 & 1.54 & 3.59 & 4.96 \\
\hline 2 & 0.5 & 790 & 33.8 & 5.4 & 74.2 & 14.6 & 0.25 & 0.90 & 1.50 & 3.70 & 4.88 \\
\hline 2 & 0.5 & 780 & 31.2 & 5.8 & 74.3 & 14.6 & 0.21 & 0.78 & 1.45 & 3.82 & 4.78 \\
\hline
\end{tabular}


Table 4.6 - Continued from previous page

\begin{tabular}{|c|c|c|c|c|c|c|c|c|c|c|c|}
\hline $\mathrm{H}_{2} \mathrm{O}^{i}$ & $\mathrm{P}$ & $\mathrm{T}$ & melt & $\mathrm{H}_{2} \mathrm{O}^{m}$ & $\mathrm{SiO}_{2}$ & $\mathrm{Al}_{2} \mathrm{O}_{3}$ & $\mathrm{MgO}$ & $\mathrm{FeO}_{t}$ & $\mathrm{CaO}$ & $\mathrm{Na}_{2} \mathrm{O}$ & $\mathrm{K}_{2} \mathrm{O}$ \\
\hline 2 & 0.5 & 770 & 28.9 & 6.2 & 74.5 & 14.6 & 0.18 & 0.67 & 1.41 & 3.93 & 4.68 \\
\hline 2 & 0.5 & 760 & 27.0 & 6.3 & 70.0 & 13.7 & 0.14 & 0.52 & 1.29 & 3.79 & 4.31 \\
\hline 2 & 0.5 & 750 & 25.4 & 6.6 & 69.9 & 13.6 & 0.11 & 0.41 & 1.27 & 3.84 & 4.24 \\
\hline 2 & 0.5 & 740 & 24.1 & 7.0 & 69.7 & 13.5 & 0.09 & 0.32 & 1.25 & 3.87 & 4.22 \\
\hline 2 & 0.5 & 730 & 23.1 & 7.3 & 69.6 & 13.5 & 0.07 & 0.24 & 1.24 & 3.87 & 4.23 \\
\hline 2 & 0.5 & 720 & 22.2 & 7.6 & 69.5 & 13.4 & 0.05 & 0.18 & 1.23 & 3.85 & 4.27 \\
\hline 2 & 0.5 & 710 & 21.5 & 7.9 & 69.3 & 13.3 & 0.04 & 0.13 & 1.22 & 3.81 & 4.33 \\
\hline 2 & 0.5 & 700 & 20.8 & 8.2 & 69.1 & 13.2 & 0.03 & 0.10 & 1.21 & 3.76 & 4.39 \\
\hline 2 & 1.0 & 1100 & 95.3 & 2.2 & 69.2 & 16.9 & 1.23 & 1.95 & 3.90 & 4.07 & 2.68 \\
\hline 2 & 1.0 & 1090 & 95.1 & 2.2 & 69.3 & 17.0 & 1.18 & 1.93 & 3.90 & 4.08 & 2.68 \\
\hline 2 & 1.0 & 1080 & 94.9 & 2.2 & 69.3 & 17.0 & 1.14 & 1.90 & 3.91 & 4.09 & 2.69 \\
\hline 2 & 1.0 & 1070 & 94.8 & 2.2 & 69.3 & 17.0 & 1.09 & 1.88 & 3.91 & 4.09 & 2.69 \\
\hline 2 & 1.0 & 1060 & 94.3 & 2.2 & 69.4 & 17.0 & 1.04 & 1.85 & 3.89 & 4.10 & 2.71 \\
\hline 2 & 1.0 & 1050 & 91.8 & 2.2 & 69.8 & 16.7 & 0.99 & 1.85 & 3.75 & 4.07 & 2.78 \\
\hline 2 & 1.0 & 1040 & 89.4 & 2.3 & 70.2 & 16.5 & 0.94 & 1.85 & 3.61 & 4.03 & 2.85 \\
\hline 2 & 1.0 & 1030 & 86.9 & 2.4 & 70.6 & 16.3 & 0.89 & 1.83 & 3.48 & 3.98 & 2.92 \\
\hline 2 & 1.0 & 1020 & 82.8 & 2.5 & 70.6 & 16.2 & 0.87 & 1.86 & 3.37 & 3.97 & 3.06 \\
\hline 2 & 1.0 & 1010 & 78.7 & 2.7 & 70.6 & 16.2 & 0.85 & 1.89 & 3.27 & 3.95 & 3.21 \\
\hline 2 & 1.0 & 1000 & 75.0 & 2.8 & 70.7 & 16.1 & 0.83 & 1.91 & 3.18 & 3.93 & 3.35 \\
\hline 2 & 1.0 & 990 & 71.5 & 2.9 & 70.7 & 16.1 & 0.81 & 1.92 & 3.09 & 3.90 & 3.51 \\
\hline 2 & 1.0 & 980 & 68.2 & 3.1 & 70.7 & 16.1 & 0.78 & 1.91 & 3.01 & 3.86 & 3.66 \\
\hline 2 & 1.0 & 970 & 65.2 & 3.3 & 70.7 & & 0.75 & 1.90 & 2.94 & 3.81 & 3.81 \\
\hline 2 & 1.0 & 960 & 62.3 & 3.4 & 70.8 & 16.0 & 0.72 & 1.87 & 2.87 & 3.76 & 3.97 \\
\hline 2 & 1.0 & 950 & 59.7 & 3.6 & 70.8 & 16.0 & 0.68 & 1.84 & 2.81 & 3.71 & 4.13 \\
\hline 2 & 1.0 & 940 & 57.2 & 3.8 & 70.9 & 16.0 & 0.65 & 1.79 & 2.75 & 3.65 & 4.29 \\
\hline 2 & 1.0 & 930 & 54.8 & 4.0 & 70.9 & 16.0 & 0.61 & 1.73 & 2.69 & 3.59 & 4.46 \\
\hline 2 & 1.0 & 920 & 52.7 & 4.1 & 71.0 & 16.0 & 0.58 & 1.66 & 2.64 & 3.53 & 4.62 \\
\hline 2 & 1.0 & 910 & 49.4 & 4.3 & 70.9 & 16.1 & 0.55 & 1.69 & 2.48 & 3.45 & 4.85 \\
\hline 2 & 1.0 & 900 & 45.4 & 4.4 & 70.8 & 16.1 & 0.54 & 1.77 & 2.31 & 3.34 & 5.12 \\
\hline 2 & 1.0 & 890 & 42.0 & 4.5 & 70.8 & 16.1 & 0.50 & 1.76 & 2.21 & 3.25 & 5.38 \\
\hline 2 & 1.0 & 880 & 40.1 & 4.7 & 70.9 & 16.1 & 0.44 & 1.59 & 2.15 & 3.18 & 5.57 \\
\hline 2 & 1.0 & 870 & 37.8 & 5.0 & 71.1 & 16.2 & 0.38 & 1.41 & 2.10 & 3.21 & 5.60 \\
\hline 2 & 1.0 & 860 & 35.6 & 5.4 & 71.2 & 16.3 & 0.33 & 1.24 & 2.04 & 3.28 & 5.59 \\
\hline 2 & 1.0 & 850 & 33.6 & 5.7 & 71.4 & 16.4 & 0.29 & 1.08 & 1.98 & 3.36 & 5.57 \\
\hline 2 & 1.0 & 840 & 31.8 & 6.1 & 71.5 & 16.5 & 0.25 & 0.93 & 1.92 & 3.43 & 5.54 \\
\hline 2 & 1.0 & 830 & 29.9 & 6.4 & 71.6 & 16.5 & 0.21 & 0.81 & 1.88 & 3.49 & 5.53 \\
\hline
\end{tabular}


Table 4.6 - Continued from previous page

\begin{tabular}{|c|c|c|c|c|c|c|c|c|c|c|c|}
\hline $\mathrm{H}_{2} \mathrm{O}^{i}$ & $\mathrm{P}$ & $\mathrm{T}$ & melt & $\mathrm{H}_{2} \mathrm{O}^{m}$ & $\mathrm{SiO}_{2}$ & $\mathrm{Al}_{2} \mathrm{O}_{3}$ & $\mathrm{MgO}$ & $\mathrm{FeO}_{t}$ & $\mathrm{CaO}$ & $\mathrm{Na}_{2} \mathrm{O}$ & $\mathrm{K}_{2} \mathrm{O}$ \\
\hline 2 & 1.0 & 820 & 28.2 & 6.8 & 71.7 & 16.6 & 0.18 & 0.70 & 1.84 & 3.54 & 5.52 \\
\hline 2 & 1.0 & 810 & 26.6 & 7.2 & 71.8 & 16.6 & 0.15 & 0.60 & 1.81 & 3.58 & 5.51 \\
\hline 2 & 1.0 & 800 & 25.1 & 7.6 & 71.8 & 16.6 & 0.12 & 0.51 & 1.78 & 3.64 & 5.50 \\
\hline 2 & 1.0 & 790 & 23.8 & 8.0 & 71.9 & 16.7 & 0.10 & 0.42 & 1.75 & 3.69 & 5.49 \\
\hline 2 & 1.0 & 780 & 22.6 & 8.4 & 71.9 & 16.7 & 0.08 & 0.34 & 1.73 & 3.74 & 5.48 \\
\hline 2 & 1.0 & 770 & 21.5 & 8.9 & 72.0 & 16.7 & 0.07 & 0.28 & 1.71 & 3.79 & 5.47 \\
\hline 2 & 1.0 & 760 & 20.6 & 9.3 & 72.0 & 16.7 & 0.05 & 0.22 & 1.69 & 3.85 & 5.46 \\
\hline 2 & 1.0 & 750 & 19.7 & 9.8 & 72.1 & 16.7 & 0.04 & 0.17 & 1.67 & 3.90 & 5.44 \\
\hline 2 & 1.0 & 740 & 18.9 & 10.3 & 72.1 & 16.7 & 0.03 & 0.13 & 1.65 & 3.95 & 5.43 \\
\hline 2 & 1.0 & 730 & 18.2 & 10.8 & 72.1 & 16.7 & 0.03 & 0.10 & 1.63 & 4.00 & 5.42 \\
\hline 2 & 1.0 & 720 & 17.6 & 11.3 & 72.1 & 16.7 & 0.02 & 0.08 & 1.61 & 4.05 & 5.40 \\
\hline 2 & 1.0 & 710 & 16.9 & 11.9 & 72.1 & 16.8 & 0.02 & 0.06 & 1.59 & 4.10 & 5.39 \\
\hline 2 & 1.0 & 700 & 15.8 & 12.5 & 72.2 & 16.6 & 0.01 & 0.05 & 1.54 & 4.27 & 5.31 \\
\hline 2 & 1.5 & 1200 & 95.8 & 2.1 & 69.1 & 16.8 & 1.38 & 2.11 & 3.87 & 4.04 & 2.66 \\
\hline 2 & 1.5 & 1190 & 95.6 & 2.1 & 69.1 & 16.9 & 1.32 & 2.09 & 3.88 & 4.05 & 2.67 \\
\hline 2 & 1.5 & 1180 & 95.4 & 2.2 & 69.2 & 16.9 & 1.27 & 2.06 & 3.89 & 4.06 & 2.67 \\
\hline 2 & 1.5 & 1170 & 95.3 & 2.2 & 69.2 & 16.9 & 1.22 & 2.04 & 3.89 & 4.07 & 2.68 \\
\hline 2 & 1.5 & 1160 & 95.1 & 2.2 & 69.2 & 16.9 & 1.18 & 2.02 & 3.90 & 4.08 & 2.68 \\
\hline 2 & 1.5 & 1150 & 95.0 & 2.2 & 69.3 & 16.9 & 1.13 & 1.99 & 3.90 & 4.08 & 2.69 \\
\hline 2 & 1.5 & 1140 & 94.5 & 2.2 & 69.4 & 16.9 & 1.08 & 1.95 & 3.86 & 4.11 & 2.70 \\
\hline 2 & 1.5 & 1130 & 92.8 & 2.2 & 69.6 & 16.7 & 1.04 & 1.90 & 3.75 & 4.19 & 2.76 \\
\hline 2 & 1.5 & 1120 & 90.6 & 2.3 & 69.6 & 16.7 & 1.01 & 1.86 & 3.65 & 4.30 & 2.83 \\
\hline 2 & 1.5 & 1110 & 89.4 & 2.3 & 69.6 & 16.8 & 0.95 & 1.80 & 3.63 & 4.36 & 2.87 \\
\hline 2 & 1.5 & 1100 & 88.3 & 2.3 & 69.5 & 16.9 & 0.89 & 1.74 & 3.61 & 4.42 & 2.91 \\
\hline 2 & 1.5 & 1090 & 87.1 & 2.4 & 69.4 & 17.1 & 0.83 & 1.67 & 3.58 & 4.49 & 2.95 \\
\hline 2 & 1.5 & 1080 & 84.0 & 2.5 & 69.4 & 17.1 & 0.79 & 1.63 & 3.51 & 4.51 & 3.05 \\
\hline 2 & 1.5 & 1070 & 79.2 & 2.6 & 69.5 & 17.0 & 0.76 & 1.62 & 3.42 & 4.48 & 3.19 \\
\hline 2 & 1.5 & 1060 & 74.8 & 2.8 & 69.6 & 17.0 & 0.73 & 1.59 & 3.34 & 4.44 & 3.34 \\
\hline 2 & 1.5 & 1050 & 70.7 & 3.0 & 69.7 & 16.9 & 0.69 & 1.55 & 3.27 & 4.40 & 3.48 \\
\hline 2 & 1.5 & 1040 & 66.9 & 3.2 & 69.8 & 16.9 & 0.65 & 1.50 & 3.19 & 4.34 & 3.63 \\
\hline 2 & 1.5 & 1030 & 63.5 & 3.4 & 69.9 & 16.9 & 0.61 & 1.43 & 3.12 & 4.29 & 3.77 \\
\hline 2 & 1.5 & 1020 & 60.3 & 3.6 & 69.9 & 16.9 & 0.56 & 1.35 & 3.06 & 4.24 & 3.92 \\
\hline 2 & 1.5 & 1010 & 57.4 & 3.8 & 70.0 & 16.9 & 0.52 & 1.26 & 2.99 & 4.18 & 4.06 \\
\hline 2 & 1.5 & 1000 & 54.7 & 4.0 & 70.1 & 17.0 & 0.47 & 1.16 & 2.94 & 4.13 & 4.21 \\
\hline 2 & 1.5 & 990 & 52.2 & 4.2 & 70.2 & 17.0 & 0.43 & 1.06 & 2.88 & 4.07 & 4.35 \\
\hline 2 & 1.5 & 980 & 49.9 & 4.4 & 70.3 & 17.0 & 0.39 & 0.96 & 2.82 & 4.02 & 4.50 \\
\hline
\end{tabular}


Table 4.6 - Continued from previous page

\begin{tabular}{|c|c|c|c|c|c|c|c|c|c|c|c|}
\hline $\mathrm{H}_{2} \mathrm{O}^{i}$ & $\mathrm{P}$ & $\mathrm{T}$ & melt & $\mathrm{H}_{2} \mathrm{O}^{m}$ & $\mathrm{SiO}_{2}$ & $\mathrm{Al}_{2} \mathrm{O}_{3}$ & $\mathrm{MgO}$ & $\mathrm{FeO}_{t}$ & $\mathrm{CaO}$ & $\mathrm{Na}_{2} \mathrm{O}$ & $\mathrm{K}_{2} \mathrm{O}$ \\
\hline 2 & 1.5 & 970 & 47.7 & 4.7 & 70.4 & 17.0 & 0.35 & 0.86 & 2.77 & 3.96 & 4.64 \\
\hline 2 & 1.5 & 960 & 45.8 & 4.9 & 70.5 & 17.1 & 0.31 & 0.76 & 2.72 & 3.90 & 4.78 \\
\hline 2 & 1.5 & 950 & 44.0 & 5.1 & 70.5 & 17.1 & 0.27 & 0.67 & 2.67 & 3.84 & 4.92 \\
\hline 2 & 1.5 & 940 & 41.8 & 5.3 & 70.5 & 17.1 & 0.25 & 0.62 & 2.65 & 3.75 & 5.09 \\
\hline 2 & 1.5 & 930 & 39.6 & 5.6 & 70.5 & 17.2 & 0.22 & 0.57 & 2.62 & 3.68 & 5.20 \\
\hline 2 & 1.5 & 920 & 37.5 & 5.9 & 70.5 & 17.3 & 0.19 & 0.52 & 2.58 & 3.68 & 5.24 \\
\hline 2 & 1.5 & 910 & 35.6 & 6.2 & 70.4 & 17.5 & 0.17 & 0.47 & 2.54 & 3.68 & 5.26 \\
\hline 2 & 1.5 & 900 & 33.8 & 6.5 & 70.4 & 17.6 & 0.15 & 0.42 & 2.49 & 3.70 & 5.28 \\
\hline 2 & 1.5 & 890 & 32.2 & 6.8 & 70.3 & 17.7 & 0.13 & 0.38 & 2.45 & 3.71 & 5.29 \\
\hline 2 & 1.5 & 880 & 30.7 & 7.1 & 70.3 & 17.8 & 0.11 & 0.33 & 2.41 & 3.74 & 5.30 \\
\hline 2 & 1.5 & 870 & 29.2 & 7.5 & 70.2 & 18.0 & 0.10 & 0.30 & 2.36 & 3.76 & 5.31 \\
\hline 2 & 1.5 & 860 & 27.9 & 7.8 & 70.1 & 18.1 & 0.08 & 0.26 & 2.32 & 3.79 & 5.31 \\
\hline 2 & 1.5 & 850 & 26.6 & 8.2 & 70.0 & 18.3 & 0.07 & 0.23 & 2.27 & 3.82 & 5.31 \\
\hline 2 & 1.5 & 840 & 25.5 & 8.6 & 70.0 & 18.4 & 0.06 & 0.20 & 2.23 & 3.85 & 5.31 \\
\hline 2 & 1.5 & 830 & 24.4 & 8.9 & 69.9 & 18.5 & 0.05 & 0.17 & 2.19 & 3.88 & 5.31 \\
\hline 2 & 1.5 & 820 & 22.6 & 9.4 & 69.9 & 18.5 & 0.05 & 0.16 & 2.12 & 4.01 & 5.24 \\
\hline 2 & 1.5 & 810 & 20.1 & 10.0 & 70.1 & 18.2 & 0.04 & 0.16 & 2.04 & 4.29 & 5.09 \\
\hline 2 & 1.5 & 800 & 18.0 & 10.5 & 70.3 & 18.0 & 0.04 & 0.15 & 1.96 & 4.55 & 4.95 \\
\hline 2 & 1.5 & 790 & 16.4 & 11.0 & 70.5 & 17.8 & 0.04 & 0.14 & 1.90 & 4.76 & 4.85 \\
\hline 2 & 1.5 & 780 & 15.1 & 11.6 & 70.6 & 17.6 & 0.03 & 0.13 & 1.85 & 4.95 & 4.77 \\
\hline 2 & 1.5 & 770 & 14.0 & 12.1 & 70.8 & 17.5 & 0.03 & 0.11 & 1.80 & 5.13 & 4.68 \\
\hline 2 & 1.5 & 760 & 11.9 & 12.7 & 70.9 & & 0.03 & 0.11 & 1.68 & 5.40 & 4.54 \\
\hline 2 & 1.5 & 750 & 11.7 & 12.7 & 70.9 & 17.0 & 0.02 & 0.07 & 1.71 & 4.78 & 5.53 \\
\hline 2 & 1.5 & 740 & 10.2 & 13.4 & 71.1 & 16.8 & 0.02 & 0.09 & 1.51 & 5.17 & 5.25 \\
\hline 2 & 1.5 & 730 & 9.3 & 14.1 & 71.2 & 16.8 & 0.02 & 0.08 & 1.40 & 5.49 & 5.00 \\
\hline 2 & 1.5 & 720 & 8.4 & 14.8 & 71.3 & 16.7 & 0.02 & 0.08 & 1.30 & 5.78 & 4.76 \\
\hline 2 & 1.5 & 710 & 7.6 & 15.6 & 71.4 & 16.7 & 0.02 & 0.07 & 1.21 & 6.05 & 4.54 \\
\hline 2 & 1.5 & 700 & 6.8 & 16.3 & 71.5 & 16.7 & 0.01 & 0.07 & 1.14 & 6.27 & 4.36 \\
\hline 2 & 2.0 & 1200 & 89.6 & 2.3 & 69.5 & 16.8 & 0.91 & 1.89 & 3.65 & 4.35 & 2.86 \\
\hline 2 & 2.0 & 1190 & 88.6 & 2.3 & 69.5 & 16.9 & 0.86 & 1.84 & 3.63 & 4.40 & 2.90 \\
\hline 2 & 2.0 & 1180 & 87.5 & 2.4 & 69.4 & 17.0 & 0.80 & 1.77 & 3.61 & 4.46 & 2.94 \\
\hline 2 & 2.0 & 1170 & 86.5 & 2.4 & 69.3 & 17.1 & 0.75 & 1.70 & 3.58 & 4.52 & 2.97 \\
\hline 2 & 2.0 & 1160 & 85.4 & 2.4 & 69.3 & 17.3 & 0.70 & 1.63 & 3.55 & 4.58 & 3.02 \\
\hline 2 & 2.0 & 1150 & 84.2 & 2.5 & 69.2 & 17.4 & 0.64 & 1.55 & 3.50 & 4.62 & 3.06 \\
\hline 2 & 2.0 & 1140 & 83.0 & 2.5 & 69.1 & 17.6 & 0.59 & 1.47 & 3.45 & 4.66 & 3.11 \\
\hline 2 & 2.0 & 1130 & 81.0 & 2.6 & 69.1 & 17.7 & 0.53 & 1.39 & 3.41 & 4.68 & 3.17 \\
\hline
\end{tabular}


Table 4.6 - Continued from previous page

\begin{tabular}{|c|c|c|c|c|c|c|c|c|c|c|c|}
\hline $\mathrm{H}_{2} \mathrm{O}^{i}$ & $\mathrm{P}$ & $\mathrm{T}$ & melt & $\mathrm{H}_{2} \mathrm{O}^{m}$ & $\mathrm{SiO}_{2}$ & $\mathrm{Al}_{2} \mathrm{O}_{3}$ & $\mathrm{MgO}$ & $\mathrm{FeO}_{t}$ & $\mathrm{CaO}$ & $\mathrm{Na}_{2} \mathrm{O}$ & $\mathrm{K}_{2} \mathrm{O}$ \\
\hline 2 & 2.0 & 1120 & 76.0 & 2.8 & 69.1 & 17.8 & 0.49 & 1.33 & 3.39 & 4.63 & 3.25 \\
\hline 2 & 2.0 & 1110 & 71.6 & 3.0 & 69.2 & 17.8 & 0.45 & 1.26 & 3.37 & 4.58 & 3.34 \\
\hline 2 & 2.0 & 1100 & 67.5 & 3.1 & 69.2 & 17.9 & 0.41 & 1.17 & 3.34 & 4.52 & 3.44 \\
\hline 2 & 2.0 & 1090 & 63.9 & 3.3 & 69.2 & 18.0 & 0.37 & 1.08 & 3.32 & 4.46 & 3.55 \\
\hline 2 & 2.0 & 1080 & 60.6 & 3.6 & 69.3 & 18.0 & 0.34 & 0.99 & 3.28 & 4.40 & 3.66 \\
\hline 2 & 2.0 & 1070 & 57.6 & 3.8 & 69.3 & 18.1 & 0.30 & 0.90 & 3.25 & 4.33 & 3.78 \\
\hline 2 & 2.0 & 1060 & 54.9 & 4.0 & 69.4 & 18.2 & 0.27 & 0.80 & 3.22 & 4.26 & 3.91 \\
\hline 2 & 2.0 & 1050 & 52.4 & 4.2 & 69.4 & 18.2 & 0.24 & 0.71 & 3.19 & 4.18 & 4.04 \\
\hline 2 & 2.0 & 1040 & 50.1 & 4.4 & 69.4 & 18.3 & 0.21 & 0.63 & 3.16 & 4.11 & 4.18 \\
\hline 2 & 2.0 & 1030 & 48.1 & 4.6 & 69.4 & 18.4 & 0.19 & 0.56 & 3.14 & 4.02 & 4.33 \\
\hline 2 & 2.0 & 1020 & 46.1 & 4.8 & 69.4 & 18.5 & 0.16 & 0.49 & 3.11 & 3.93 & 4.48 \\
\hline 2 & 2.0 & 1010 & 44.4 & 5.1 & 69.3 & 18.6 & 0.14 & 0.42 & 3.09 & 3.84 & 4.63 \\
\hline 2 & 2.0 & 1000 & 42.7 & 5.3 & 69.3 & 18.6 & 0.12 & 0.37 & 3.07 & 3.74 & 4.79 \\
\hline 2 & 2.0 & 990 & 41.2 & 5.5 & 69.2 & 18.7 & 0.11 & 0.31 & 3.05 & 3.64 & 4.96 \\
\hline 2 & 2.0 & 980 & 39.8 & 5.8 & 69.1 & 18.9 & 0.09 & 0.27 & 3.03 & 3.54 & 5.14 \\
\hline 2 & 2.0 & 970 & 38.5 & 6.0 & 69.0 & 19.0 & 0.08 & 0.23 & 3.01 & 3.43 & 5.31 \\
\hline 2 & 2.0 & 960 & 37.3 & 6.2 & 68.9 & 19.1 & 0.07 & 0.19 & 2.99 & 3.35 & 5.45 \\
\hline 2 & 2.0 & 950 & 36.0 & 6.5 & 68.8 & 19.2 & 0.06 & 0.16 & 2.96 & 3.35 & 5.49 \\
\hline 2 & 2.0 & 940 & 34.8 & 6.8 & 68.6 & 19.4 & 0.05 & 0.14 & 2.93 & 3.34 & 5.53 \\
\hline 2 & 2.0 & 930 & 33.6 & 7.1 & 68.5 & 19.5 & 0.04 & 0.11 & 2.91 & 3.33 & 5.57 \\
\hline 2 & 2.0 & 920 & 32.6 & 7.4 & 68.3 & 19.7 & 0.04 & 0.10 & 2.89 & 3.32 & 5.61 \\
\hline 2 & 2.0 & 900 & 27.1 & 8.2 & 68.6 & 19.5 & 0.04 & 0.09 & 2.73 & 3.80 & 5.27 \\
\hline 2 & 2.0 & 890 & 22.7 & 8.8 & 69.0 & 19.1 & 0.04 & 0.11 & 2.52 & 4.40 & 4.79 \\
\hline 2 & 2.0 & 880 & 18.9 & 9.5 & 69.4 & 18.9 & 0.05 & 0.14 & 2.27 & 5.15 & 4.16 \\
\hline 2 & 2.0 & 870 & 16.4 & 10.1 & 69.6 & 18.8 & 0.05 & 0.15 & 2.02 & 6.07 & 3.30 \\
\hline 2 & 2.0 & 860 & 14.7 & 10.6 & 69.8 & 18.7 & 0.05 & 0.14 & 1.83 & 6.75 & 2.68 \\
\hline 2 & 2.0 & 850 & 13.5 & 11.1 & 69.9 & 18.7 & 0.04 & 0.14 & 1.69 & 7.25 & 2.23 \\
\hline 2 & 2.0 & 840 & 12.5 & 11.6 & 70.0 & 18.7 & 0.04 & 0.13 & 1.58 & 7.63 & 1.89 \\
\hline 2 & 2.0 & 830 & 11.6 & 12.2 & 70.0 & 18.8 & 0.04 & 0.12 & 1.50 & 7.93 & 1.62 \\
\hline 2 & 2.0 & 820 & 10.9 & 12.7 & 70.1 & 18.8 & 0.03 & 0.10 & 1.43 & 8.17 & 1.41 \\
\hline 2 & 2.0 & 810 & 10.1 & 13.2 & 70.1 & 18.8 & 0.03 & 0.09 & 1.37 & 8.36 & 1.24 \\
\hline 2 & 2.0 & 800 & 9.3 & 13.7 & 70.1 & 18.8 & 0.02 & 0.08 & 1.32 & 8.53 & 1.11 \\
\hline 2 & 2.0 & 790 & 8.7 & 14.5 & 70.3 & 18.7 & 0.02 & 0.08 & 1.26 & 8.61 & 1.05 \\
\hline 2 & 2.0 & 780 & 8.2 & 15.5 & 70.4 & 18.6 & 0.02 & 0.08 & 1.22 & 8.60 & 1.05 \\
\hline 2 & 2.0 & 770 & 7.8 & 16.5 & 70.6 & 18.5 & 0.02 & 0.07 & 1.18 & 8.60 & 1.04 \\
\hline 2 & 2.0 & 760 & 7.4 & 17.6 & 70.7 & 18.4 & 0.02 & 0.07 & 1.15 & 8.58 & 1.04 \\
\hline
\end{tabular}


Table 4.6 - Continued from previous page

\begin{tabular}{|c|c|c|c|c|c|c|c|c|c|c|c|}
\hline $\mathrm{H}_{2} \mathrm{O}^{i}$ & $\mathrm{P}$ & $\mathrm{T}$ & melt & $\mathrm{H}_{2} \mathrm{O}^{m}$ & $\mathrm{SiO}_{2}$ & $\mathrm{Al}_{2} \mathrm{O}_{3}$ & $\mathrm{MgO}$ & $\mathrm{FeO}_{t}$ & $\mathrm{CaO}$ & $\mathrm{Na}_{2} \mathrm{O}$ & $\mathrm{K}_{2} \mathrm{O}$ \\
\hline 2 & 2.0 & 750 & 7.1 & 18.8 & 70.9 & 18.3 & 0.02 & 0.07 & 1.12 & 8.56 & 1.04 \\
\hline 2 & 2.0 & 740 & 6.7 & 20.0 & 71.0 & 18.2 & 0.02 & 0.07 & 1.09 & 8.53 & 1.04 \\
\hline 2 & 2.0 & 730 & 6.4 & 21.3 & 71.2 & 18.1 & 0.02 & 0.07 & 1.06 & 8.50 & 1.04 \\
\hline 2 & 2.0 & 720 & 6.1 & 22.7 & 71.4 & 18.0 & 0.02 & 0.06 & 1.04 & 8.46 & 1.05 \\
\hline 2 & 2.0 & 710 & 5.9 & 24.2 & 71.6 & 17.9 & 0.02 & 0.06 & 1.01 & 8.42 & 1.05 \\
\hline 5 & 0.5 & 1100 & 98.0 & 5.0 & 68.8 & 16.7 & 2.05 & 2.13 & 3.81 & 3.96 & 2.60 \\
\hline 5 & 0.5 & 1090 & 97.7 & 5.0 & 68.8 & 16.7 & 1.97 & 2.11 & 3.82 & 3.97 & 2.61 \\
\hline 5 & 0.5 & 1080 & 97.5 & 5.0 & 68.9 & 16.7 & 1.89 & 2.10 & 3.82 & 3.98 & 2.62 \\
\hline 5 & 0.5 & 1070 & 97.3 & 5.0 & 68.9 & 16.8 & 1.81 & 2.08 & 3.83 & 3.99 & 2.62 \\
\hline 5 & 0.5 & 1060 & 97.1 & 5.0 & 68.9 & 16.8 & 1.74 & 2.06 & 3.84 & 4.00 & 2.63 \\
\hline 5 & 0.5 & 1050 & 96.9 & 5.0 & 69.0 & 16.8 & 1.67 & 2.04 & 3.85 & 4.01 & 2.64 \\
\hline 5 & 0.5 & 1040 & 96.7 & 5.1 & 69.0 & 16.9 & 1.59 & 2.02 & 3.86 & 4.02 & 2.64 \\
\hline 5 & 0.5 & 1030 & 96.5 & 5.1 & 69.0 & 16.9 & 1.53 & 2.00 & 3.86 & 4.03 & 2.65 \\
\hline 5 & 0.5 & 1020 & 96.3 & 5.1 & 69.1 & 16.9 & 1.46 & 1.97 & 3.87 & 4.04 & 2.66 \\
\hline 5 & 0.5 & 1010 & 96.1 & 5.1 & 69.1 & 17.0 & 1.39 & 1.94 & 3.88 & 4.05 & 2.66 \\
\hline 5 & 0.5 & 1000 & 95.9 & 5.1 & 69.2 & 17.0 & 1.33 & 1.91 & 3.89 & 4.06 & 2.67 \\
\hline 5 & 0.5 & 990 & 95.7 & 5.1 & 69.2 & 17.0 & 1.27 & 1.88 & 3.90 & 4.07 & 2.68 \\
\hline 5 & 0.5 & 980 & 95.6 & 5.1 & 69.2 & 17.0 & 1.21 & 1.85 & 3.90 & 4.08 & 2.68 \\
\hline 5 & 0.5 & 970 & 95.4 & 5.1 & 69.3 & 17.1 & 1.15 & 1.81 & 3.91 & 4.09 & 2.69 \\
\hline 5 & 0.5 & 960 & 95.2 & 5.2 & 69.3 & 17.1 & 1.09 & 1.77 & 3.92 & 4.10 & 2.70 \\
\hline 5 & 0.5 & 950 & 95.0 & 5.2 & 69.4 & 17.1 & 1.03 & 1.72 & 3.92 & 4.11 & 2.70 \\
\hline 5 & 0.5 & 940 & 94.1 & 5.2 & 69.7 & & 0.98 & 1.72 & 3.77 & 4.10 & 2.73 \\
\hline 5 & 0.5 & 930 & 93.0 & 5.2 & 70.0 & 16.9 & 0.92 & 1.72 & 3.60 & 4.09 & 2.75 \\
\hline 5 & 0.5 & 920 & 92.0 & 5.2 & 70.4 & 16.7 & 0.86 & 1.71 & 3.42 & 4.08 & 2.78 \\
\hline 5 & 0.5 & 910 & 90.9 & 5.2 & 70.9 & 16.5 & 0.81 & 1.70 & 3.26 & 4.07 & 2.81 \\
\hline 5 & 0.5 & 900 & 90.2 & 5.2 & 71.1 & 16.4 & 0.73 & 1.63 & 3.17 & 4.07 & 2.83 \\
\hline 5 & 0.5 & 890 & 89.5 & 5.3 & 71.4 & 16.4 & 0.65 & 1.53 & 3.10 & 4.08 & 2.86 \\
\hline 5 & 0.5 & 880 & 88.2 & 5.3 & 71.8 & 16.2 & 0.59 & 1.45 & 2.95 & 4.09 & 2.90 \\
\hline 5 & 0.5 & 870 & 86.9 & 5.4 & 72.2 & 16.0 & 0.54 & 1.36 & 2.81 & 4.11 & 2.95 \\
\hline 5 & 0.5 & 860 & 85.6 & 5.5 & 72.6 & 15.8 & 0.48 & 1.27 & 2.67 & 4.11 & 3.01 \\
\hline 5 & 0.5 & 850 & 84.3 & 5.6 & 73.0 & 15.7 & 0.43 & 1.17 & 2.54 & 4.11 & 3.06 \\
\hline 5 & 0.5 & 840 & 83.1 & 5.7 & 73.4 & 15.5 & 0.39 & 1.07 & 2.41 & 4.11 & 3.11 \\
\hline 5 & 0.5 & 830 & 81.8 & 5.8 & 73.8 & 15.3 & 0.34 & 0.97 & 2.29 & 4.10 & 3.17 \\
\hline 5 & 0.5 & 820 & 80.6 & 5.9 & 74.2 & 15.1 & 0.30 & 0.87 & 2.18 & 4.08 & 3.22 \\
\hline 5 & 0.5 & 810 & 79.3 & 6.0 & 74.6 & 15.0 & 0.26 & 0.77 & 2.07 & 4.06 & 3.28 \\
\hline 5 & 0.5 & 800 & 78.1 & 6.1 & 75.0 & 14.8 & 0.23 & 0.68 & 1.97 & 4.02 & 3.34 \\
\hline
\end{tabular}


Table 4.6 - Continued from previous page

\begin{tabular}{|c|c|c|c|c|c|c|c|c|c|c|c|}
\hline $\mathrm{H}_{2} \mathrm{O}^{i}$ & $\mathrm{P}$ & $\mathrm{T}$ & melt & $\mathrm{H}_{2} \mathrm{O}^{m}$ & $\mathrm{SiO}_{2}$ & $\mathrm{Al}_{2} \mathrm{O}_{3}$ & $\mathrm{MgO}$ & $\mathrm{FeO}_{t}$ & $\mathrm{CaO}$ & $\mathrm{Na}_{2} \mathrm{O}$ & $\mathrm{K}_{2} \mathrm{O}$ \\
\hline 5 & 0.5 & 790 & 75.8 & 6.3 & 75.0 & 14.8 & 0.20 & 0.60 & 1.87 & 4.05 & 3.45 \\
\hline 5 & 0.5 & 780 & 73.4 & 6.5 & 75.1 & 14.8 & 0.17 & 0.51 & 1.77 & 4.08 & 3.58 \\
\hline 5 & 0.5 & 770 & 71.2 & 6.7 & 75.1 & 14.9 & 0.15 & 0.44 & 1.67 & 4.10 & 3.70 \\
\hline 5 & 0.5 & 760 & 69.1 & 6.9 & 75.1 & 14.9 & 0.12 & 0.37 & 1.58 & 4.11 & 3.83 \\
\hline 5 & 0.5 & 740 & 62.4 & 7.7 & 75.3 & 14.9 & 0.09 & 0.29 & 1.48 & 4.31 & 3.68 \\
\hline 5 & 0.5 & 730 & 59.6 & 8.1 & 75.4 & 14.9 & 0.08 & 0.24 & 1.43 & 4.40 & 3.62 \\
\hline 5 & 0.5 & 720 & 57.1 & 8.5 & 75.5 & 14.8 & 0.06 & 0.20 & 1.39 & 4.48 & 3.57 \\
\hline 5 & 0.5 & 710 & 54.7 & 8.9 & 75.6 & 14.8 & 0.05 & 0.16 & 1.35 & 4.55 & 3.51 \\
\hline 5 & 0.5 & 700 & 52.6 & 9.3 & 75.7 & 14.8 & 0.04 & 0.13 & 1.31 & 4.61 & 3.47 \\
\hline 5 & 1.0 & 1100 & 96.4 & 5.1 & 69.1 & 16.9 & 1.48 & 2.02 & 3.87 & 4.03 & 2.65 \\
\hline 5 & 1.0 & 1090 & 96.3 & 5.1 & 69.1 & 16.9 & 1.42 & 2.00 & 3.87 & 4.04 & 2.66 \\
\hline 5 & 1.0 & 1070 & 95.9 & 5.1 & 69.2 & 17.0 & 1.30 & 1.96 & 3.89 & 4.06 & 2.67 \\
\hline 5 & 1.0 & 1050 & 95.6 & 5.1 & 69.2 & 17.0 & 1.19 & 1.90 & 3.90 & 4.08 & 2.68 \\
\hline 5 & 1.0 & 1030 & 95.2 & 5.1 & 69.3 & 17.1 & 1.09 & 1.84 & 3.91 & 4.10 & 2.69 \\
\hline 5 & 1.0 & 1010 & 94.9 & 5.2 & 69.4 & 17.1 & 0.98 & 1.77 & 3.92 & 4.11 & 2.71 \\
\hline 5 & 1.0 & 990 & 94.6 & 5.2 & 69.4 & 17.2 & 0.89 & 1.69 & 3.93 & 4.13 & 2.72 \\
\hline 5 & 1.0 & 980 & 93.9 & 5.2 & 69.7 & 17.1 & 0.84 & 1.69 & 3.82 & 4.12 & 2.74 \\
\hline 5 & 1.0 & 960 & 92.0 & 5.2 & 70.4 & 16.8 & 0.75 & 1.69 & 3.50 & 4.09 & 2.78 \\
\hline 5 & 1.0 & 940 & 90.0 & 5.3 & 71.2 & 16.4 & 0.66 & 1.67 & 3.18 & 4.05 & 2.84 \\
\hline 5 & 1.0 & 930 & 89.3 & 5.3 & 71.4 & 16.3 & 0.60 & 1.61 & 3.10 & 4.05 & 2.86 \\
\hline 5 & 1.0 & 920 & 88.7 & 5.3 & 71.7 & 16.3 & 0.54 & 1.52 & 3.04 & 4.05 & 2.88 \\
\hline 5 & 1.0 & 910 & 86.9 & 5.4 & 71.6 & 16.5 & 0.48 & 1.43 & 3.00 & 4.12 & 2.95 \\
\hline 5 & 1.0 & 900 & 85.1 & 5.5 & 71.5 & 16.6 & 0.42 & 1.33 & 2.95 & 4.18 & 3.01 \\
\hline 5 & 1.0 & 890 & 82.9 & 5.7 & 71.5 & 16.7 & 0.38 & 1.24 & 2.86 & 4.24 & 3.11 \\
\hline 5 & 1.0 & 880 & 80.0 & 5.9 & 71.6 & 16.7 & 0.34 & 1.16 & 2.72 & 4.29 & 3.23 \\
\hline 5 & 1.0 & 860 & 74.7 & 6.3 & 71.7 & 16.7 & 0.27 & 0.97 & 2.47 & 4.36 & 3.48 \\
\hline 5 & 1.0 & 840 & 70.0 & 6.8 & 71.9 & 16.7 & 0.21 & 0.78 & 2.25 & 4.39 & 3.74 \\
\hline 5 & 1.0 & 820 & 65.8 & 7.3 & 72.0 & 16.8 & 0.16 & 0.60 & 2.05 & 4.40 & 4.01 \\
\hline 5 & 1.0 & 800 & 62.0 & 7.8 & 72.1 & 16.8 & 0.12 & 0.44 & 1.88 & 4.38 & 4.28 \\
\hline 5 & 1.0 & 780 & 58.5 & 8.3 & 72.1 & 16.9 & 0.08 & 0.31 & 1.73 & 4.33 & 4.57 \\
\hline 5 & 1.0 & 770 & 56.4 & 8.7 & 72.1 & 16.9 & 0.07 & 0.26 & 1.68 & 4.35 & 4.62 \\
\hline 5 & 1.0 & 760 & 54.2 & 9.0 & 72.1 & 16.9 & 0.06 & 0.22 & 1.66 & 4.39 & 4.60 \\
\hline 5 & 1.0 & 750 & 52.2 & 9.4 & 72.1 & 17.0 & 0.05 & 0.17 & 1.64 & 4.43 & 4.59 \\
\hline 5 & 1.0 & 740 & 50.3 & 9.8 & 72.1 & 17.0 & 0.04 & 0.14 & 1.62 & 4.47 & 4.60 \\
\hline 5 & 1.0 & 730 & 48.5 & 10.3 & 72.1 & 17.0 & 0.03 & 0.11 & 1.60 & 4.49 & 4.61 \\
\hline 5 & 1.0 & 720 & 46.9 & 10.7 & 72.1 & 17.0 & 0.02 & 0.08 & 1.58 & 4.51 & 4.64 \\
\hline
\end{tabular}


Table 4.6 - Continued from previous page

\begin{tabular}{|c|c|c|c|c|c|c|c|c|c|c|c|}
\hline $\mathrm{H}_{2} \mathrm{O}^{i}$ & $\mathrm{P}$ & $\mathrm{T}$ & melt & $\mathrm{H}_{2} \mathrm{O}^{m}$ & $\mathrm{SiO}_{2}$ & $\mathrm{Al}_{2} \mathrm{O}_{3}$ & $\mathrm{MgO}$ & $\mathrm{FeO}_{t}$ & $\mathrm{CaO}$ & $\mathrm{Na}_{2} \mathrm{O}$ & $\mathrm{K}_{2} \mathrm{O}$ \\
\hline 5 & 1.0 & 710 & 45.5 & 11.1 & 72.1 & 17.1 & 0.02 & 0.07 & 1.56 & 4.52 & 4.67 \\
\hline 5 & 1.0 & 700 & 43.2 & 11.5 & 72.3 & 16.8 & 0.01 & 0.06 & 1.46 & 4.68 & 4.72 \\
\hline 5 & 1.5 & 1100 & 95.4 & 5.1 & 69.3 & 17.0 & 1.12 & 1.92 & 3.90 & 4.09 & 2.69 \\
\hline 5 & 1.5 & 1080 & 95.1 & 5.2 & 69.3 & 17.1 & 1.03 & 1.87 & 3.91 & 4.10 & 2.70 \\
\hline 5 & 1.5 & 1070 & 94.7 & 5.2 & 69.5 & 17.0 & 0.97 & 1.80 & 3.86 & 4.13 & 2.71 \\
\hline 5 & 1.5 & 1060 & 93.7 & 5.2 & 69.9 & 16.8 & 0.91 & 1.72 & 3.71 & 4.18 & 2.75 \\
\hline 5 & 1.5 & 1040 & 91.9 & 5.4 & 70.7 & 16.5 & 0.78 & 1.54 & 3.41 & 4.28 & 2.82 \\
\hline 5 & 1.5 & 1030 & 91.1 & 5.4 & 71.1 & 16.3 & 0.72 & 1.44 & 3.27 & 4.33 & 2.85 \\
\hline 5 & 1.5 & 1010 & 90.0 & 5.5 & 71.5 & 16.3 & 0.58 & 1.23 & 3.13 & 4.39 & 2.89 \\
\hline 5 & 1.5 & 1000 & 88.8 & 5.6 & 71.4 & 16.4 & 0.52 & 1.13 & 3.07 & 4.46 & 2.94 \\
\hline 5 & 1.5 & 990 & 87.5 & 5.7 & 71.4 & 16.6 & 0.47 & 1.03 & 3.02 & 4.54 & 3.00 \\
\hline 5 & 1.5 & 970 & 85.1 & 5.9 & 71.3 & 16.9 & 0.37 & 0.82 & 2.89 & 4.70 & 3.10 \\
\hline 5 & 1.5 & 950 & 82.8 & 6.1 & 71.1 & 17.1 & 0.28 & 0.62 & 2.76 & 4.86 & 3.21 \\
\hline 5 & 1.5 & 940 & 81.2 & 6.2 & 71.0 & 17.3 & 0.25 & 0. & 2.73 & 4.89 & 3.27 \\
\hline 5 & 1.5 & 930 & 79.7 & 6.2 & 70.8 & 17.5 & 0.22 & 0.53 & 2.68 & 4.92 & 3.34 \\
\hline 5 & 1.5 & 910 & 76.8 & 6.4 & 70.5 & 17.8 & 0.16 & 0.43 & 2.60 & 4.98 & 3.47 \\
\hline 5 & 1.5 & 900 & 73.9 & 6.7 & 70.5 & 17.8 & 0.15 & 0.40 & 2.53 & 4.94 & 3.60 \\
\hline 5 & 1.5 & 890 & 71.3 & 6.9 & 70.5 & 17.9 & 0.13 & 0.38 & 2.46 & 4.89 & 3.74 \\
\hline 5 & 1.5 & 870 & 66.4 & 7.5 & 70.5 & 18.0 & 0.10 & 0.32 & 2.34 & 4.79 & 4.01 \\
\hline 5 & 1.5 & 850 & 62.1 & 8.0 & 70.4 & 18.1 & 0.08 & 0.26 & 2.23 & 4.68 & 4.29 \\
\hline 5 & 1.5 & 830 & 58.2 & 8.6 & 70.3 & 18.2 & 0.06 & 0.20 & 2.13 & 4.56 & 4.58 \\
\hline 5 & 1.5 & 810 & 54.8 & 9.1 & 70.1 & & 0.04 & 0.16 & 2.05 & 4.42 & 4.89 \\
\hline 5 & 1.5 & 800 & 51.2 & 9.6 & 70.3 & 18.1 & 0.04 & 0.14 & 1.98 & 4.68 & 4.72 \\
\hline 5 & 1.5 & 790 & 48.3 & 10.1 & 70.5 & 17.9 & 0.03 & 0.13 & 1.93 & 4.92 & 4.57 \\
\hline 5 & 1.5 & 780 & 45.8 & 10.5 & 70.6 & 17.8 & 0.03 & 0.12 & 1.88 & 5.15 & 4.43 \\
\hline 5 & 1.5 & 770 & 43.4 & 11.0 & 70.8 & 17.6 & 0.03 & 0.11 & 1.78 & 5.41 & 4.27 \\
\hline 5 & 1.5 & 760 & 41.2 & 11.5 & 70.9 & 17.5 & 0.03 & 0.11 & 1.65 & 5.71 & 4.11 \\
\hline 5 & 1.5 & 750 & 39.0 & 12.0 & 71.1 & 17.4 & 0.03 & 0.11 & 1.52 & 6.05 & 3.86 \\
\hline 5 & 1.5 & 735 & 35.9 & 12.8 & 71.2 & 17.3 & 0.02 & 0.10 & 1.35 & 6.67 & 3.27 \\
\hline 5 & 1.5 & 720 & 33.4 & 13.6 & 71.4 & 17.3 & 0.02 & 0.10 & 1.20 & 7.18 & 2.80 \\
\hline 5 & 1.5 & 700 & 30.8 & 14.8 & 71.5 & 17.3 & 0.02 & 0.08 & 1.02 & 7.72 & 2.31 \\
\hline 5 & 2.0 & 1200 & 95.0 & 5.2 & 69.6 & 16.4 & 1.35 & 2.11 & 3.67 & 4.11 & 2.70 \\
\hline 5 & 2.0 & 1180 & 94.2 & 5.2 & 69.9 & 16.4 & 1.18 & 2.02 & 3.62 & 4.15 & 2.73 \\
\hline 5 & 2.0 & 1160 & 93.4 & 5.3 & 70.2 & 16.4 & 1.03 & 1.91 & 3.55 & 4.19 & 2.76 \\
\hline 5 & 2.0 & 1140 & 92.5 & 5.3 & 70.5 & 16.4 & 0.88 & 1.78 & 3.46 & 4.25 & 2.79 \\
\hline 5 & 2.0 & 1120 & 91.6 & 5.4 & 70.8 & 16.3 & 0.74 & 1.61 & 3.35 & 4.30 & 2.83 \\
\hline
\end{tabular}


Table 4.6 - Continued from previous page

\begin{tabular}{|c|c|c|c|c|c|c|c|c|c|c|c|}
\hline $\mathrm{H}_{2} \mathrm{O}^{i}$ & $\mathrm{P}$ & $\mathrm{T}$ & melt & $\mathrm{H}_{2} \mathrm{O}^{m}$ & $\mathrm{SiO}_{2}$ & $\mathrm{Al}_{2} \mathrm{O}_{3}$ & $\mathrm{MgO}$ & $\mathrm{FeO}_{t}$ & $\mathrm{CaO}$ & $\mathrm{Na}_{2} \mathrm{O}$ & $\mathrm{K}_{2} \mathrm{O}$ \\
\hline 5 & 2.0 & 1100 & 90.6 & 5.5 & 71.2 & 16.3 & 0.61 & 1.42 & 3.23 & 4.36 & 2.87 \\
\hline 5 & 2.0 & 1090 & 90.1 & 5.5 & 71.4 & 16.3 & 0.55 & 1.32 & 3.16 & 4.39 & 2.89 \\
\hline 5 & 2.0 & 1080 & 88.9 & 5.6 & 71.3 & 16.4 & 0.50 & 1.23 & 3.11 & 4.47 & 2.94 \\
\hline 5 & 2.0 & 1070 & 87.7 & 5.7 & 71.3 & 16.6 & 0.45 & 1.13 & 3.06 & 4.54 & 2.99 \\
\hline 5 & 2.0 & 1060 & 86.5 & 5.8 & 71.2 & 16.7 & 0.41 & 1.03 & 3.00 & 4.61 & 3.04 \\
\hline 5 & 2.0 & 1045 & 84.8 & 5.9 & 71.1 & 17.0 & 0.34 & 0.88 & 2.91 & 4.71 & 3.11 \\
\hline 5 & 2.0 & 1030 & 83.1 & 6.0 & 70.9 & 17.2 & 0.28 & 0.74 & 2.82 & 4.80 & 3.20 \\
\hline 5 & 2.0 & 1020 & 81.9 & 6.1 & 70.8 & 17.4 & 0.25 & 0.66 & 2.78 & 4.85 & 3.25 \\
\hline 5 & 2.0 & 1000 & 79.8 & 6.3 & 70.5 & 17.8 & 0.19 & 0.50 & 2.69 & 4.94 & 3.36 \\
\hline 5 & 2.0 & 980 & 77.7 & 6.5 & 70.2 & 18.2 & 0.14 & 0.38 & 2.61 & 5.01 & 3.47 \\
\hline 5 & 2.0 & 960 & 75.6 & 6.7 & 69.8 & 18.6 & 0.11 & 0.28 & 2.55 & 5.06 & 3.59 \\
\hline 5 & 2.0 & 940 & 73.6 & 7.0 & 69.5 & 19.0 & 0.08 & 0.20 & 2.50 & 5.09 & 3.72 \\
\hline 5 & 2.0 & 930 & 72.1 & 7.1 & 69.3 & 19.1 & 0.07 & 0.17 & 2.48 & 5.07 & 3.80 \\
\hline 5 & 2.0 & 915 & 68.8 & 7.5 & 69.2 & 19.3 & 0.05 & 0.13 & 2.45 & 4.97 & 3.97 \\
\hline 5 & 2.0 & 900 & 65.8 & 7.9 & 69.0 & 19.4 & 0.04 & 0.11 & 2.42 & 4.86 & 4.15 \\
\hline 5 & 2.0 & 885 & 58.7 & 8.6 & 69.2 & 19.2 & 0.04 & 0.11 & 2.26 & 5.52 & 3.59 \\
\hline 5 & 2.0 & 870 & 52.2 & 9.2 & 69.5 & 19.1 & 0.04 & 0.11 & 2.04 & 6.40 & 2.80 \\
\hline 5 & 2.0 & 860 & 48.9 & 9.8 & 69.7 & 19.0 & 0.04 & 0.11 & 1.94 & 6.73 & 2.51 \\
\hline 5 & 2.0 & 850 & 46.1 & 10.3 & 69.8 & 18.9 & 0.04 & 0.11 & 1.84 & 7.01 & 2.25 \\
\hline 5 & 2.0 & 840 & 43.7 & 10.8 & 70.0 & 18.9 & 0.04 & 0.10 & 1.75 & 7.25 & 2.04 \\
\hline 5 & 2.0 & 830 & 41.6 & 11.4 & 70.1 & 18.8 & 0.04 & 0.10 & 1.68 & 7.45 & 1.86 \\
\hline 5 & 2.0 & 820 & 39.7 & 11.9 & 70.2 & 18.8 & 0.03 & 0.09 & 1.61 & 7.61 & 1.71 \\
\hline 5 & 2.0 & 810 & 37.9 & 12.5 & 70.3 & 18.7 & 0.03 & 0.09 & 1.55 & 7.75 & 1.59 \\
\hline 5 & 2.0 & 800 & 36.3 & 13.1 & 70.4 & 18.7 & 0.03 & 0.08 & 1.49 & 7.86 & 1.49 \\
\hline 5 & 2.0 & 790 & 34.8 & 13.7 & 70.5 & 18.6 & 0.03 & 0.08 & 1.43 & 7.95 & 1.41 \\
\hline 5 & 2.0 & 780 & 33.4 & 14.4 & 70.7 & 18.5 & 0.03 & 0.08 & 1.37 & 8.03 & 1.35 \\
\hline 5 & 2.0 & 770 & 32.0 & 15.1 & 70.8 & 18.4 & 0.03 & 0.08 & 1.31 & 8.09 & 1.29 \\
\hline 5 & 2.0 & 760 & 30.8 & 15.8 & 70.9 & 18.3 & 0.02 & 0.07 & 1.26 & 8.13 & 1.25 \\
\hline 5 & 2.0 & 750 & 29.6 & 16.6 & 71.1 & 18.2 & 0.02 & 0.07 & 1.21 & 8.16 & 1.22 \\
\hline 5 & 2.0 & 740 & 28.4 & 17.4 & 71.2 & 18.1 & 0.02 & 0.07 & 1.17 & 8.18 & 1.19 \\
\hline 5 & 2.0 & 720 & 26.4 & 19.1 & 71.6 & 17.9 & 0.02 & 0.07 & 1.10 & 8.18 & 1.16 \\
\hline 5 & 2.0 & 710 & 25.4 & 20.1 & 71.7 & 17.8 & 0.02 & 0.06 & 1.07 & 8.17 & 1.16 \\
\hline 5 & 2.0 & 700 & 24.5 & 21.0 & 71.9 & 17.7 & 0.02 & 0.06 & 1.04 & 8.15 & 1.16 \\
\hline 10 & 0.5 & 1100 & 96.5 & 10.4 & 68.8 & 16.6 & 2.33 & 2.04 & 3.78 & 3.93 & 2.58 \\
\hline 10 & 0.5 & 1095 & 96.5 & 10.4 & 68.8 & 16.6 & 2.33 & 2.04 & 3.78 & 3.93 & 2.58 \\
\hline 10 & 0.5 & 1085 & 96.4 & 10.4 & 68.8 & 16.6 & 2.33 & 2.04 & 3.78 & 3.93 & 2.58 \\
\hline
\end{tabular}


Table 4.6 - Continued from previous page

\begin{tabular}{|c|c|c|c|c|c|c|c|c|c|c|c|}
\hline $\mathrm{H}_{2} \mathrm{O}^{i}$ & $\mathrm{P}$ & $\mathrm{T}$ & melt & $\mathrm{H}_{2} \mathrm{O}^{m}$ & $\mathrm{SiO}_{2}$ & $\mathrm{Al}_{2} \mathrm{O}_{3}$ & $\mathrm{MgO}$ & $\mathrm{FeO}_{t}$ & $\mathrm{CaO}$ & $\mathrm{Na}_{2} \mathrm{O}$ & $\mathrm{K}_{2} \mathrm{O}$ \\
\hline 10 & 0.5 & 1075 & 96.3 & 10.3 & 68.8 & 16.6 & 2.33 & 2.04 & 3.78 & 3.93 & 2.58 \\
\hline 10 & 0.5 & 1065 & 95.9 & 10.3 & 68.8 & 16.6 & 2.22 & 2.03 & 3.79 & 3.94 & 2.59 \\
\hline 10 & 0.5 & 1040 & 95.0 & 10.2 & 68.9 & 16.7 & 1.97 & 1.99 & 3.82 & 3.97 & 2.61 \\
\hline 10 & 0.5 & 1015 & 94.1 & 10.2 & 69.0 & 16.8 & 1.74 & 1.94 & 3.84 & 4.00 & 2.63 \\
\hline 10 & 0.5 & 990 & 93.4 & 10.1 & 69.1 & 16.9 & 1.54 & 1.88 & 3.87 & 4.03 & 2.65 \\
\hline 10 & 0.5 & 965 & 92.7 & & 69.2 & 17.0 & 1.34 & 1.80 & 3.89 & 4.06 & 2.67 \\
\hline 10 & 0.5 & 940 & 92.0 & 10.1 & 69.3 & 17.1 & 1.17 & 1.70 & 3.91 & 4.09 & 2.69 \\
\hline 10 & 0.5 & 930 & 91.4 & 10.1 & 69.5 & 17.1 & 1.10 & 1.68 & 3.84 & 4.09 & 2.70 \\
\hline 10 & 0.5 & 915 & 89.7 & 10.1 & 70.0 & 16.9 & 1.01 & 1.69 & 3.54 & 4.09 & 2.74 \\
\hline 10 & 0.5 & 900 & 88.1 & 10.1 & 70.6 & 16.7 & 0.91 & 1.67 & 3.28 & 4.08 & 2.78 \\
\hline 10 & 0.5 & 885 & 87.1 & 10.1 & 70.9 & 16.7 & 0.77 & 1.55 & 3.18 & 4.10 & 2.82 \\
\hline 10 & 0.5 & 870 & 86.1 & 10.1 & 71.3 & 16.6 & 0.64 & 1.41 & 3.08 & 4.12 & 2.85 \\
\hline 10 & 0.5 & 855 & 85.1 & & 71.7 & 16.6 & 0.53 & 1.25 & 2.97 & 4.14 & 2.88 \\
\hline 10 & 0.5 & 840 & 84.2 & 10. & 72. & & 0.43 & 1.09 & 2.86 & 4.16 & 2.91 \\
\hline 10 & 0.5 & 825 & 83.3 & 10.2 & 72.5 & 16.4 & 0.34 & 0.92 & 2.75 & 4.18 & 2.95 \\
\hline 10 & 0.5 & 810 & 82.5 & 10.2 & 72.8 & 16.3 & 0.27 & 0.75 & 2.64 & 4.19 & 2.98 \\
\hline 10 & 0.5 & 795 & 81.7 & 10.3 & 73.2 & 16.2 & 0.21 & 0.60 & 2.53 & 4.20 & 3.01 \\
\hline 10 & 0.5 & 780 & 81.0 & 10.3 & 73.6 & 16.1 & 0.15 & 0.46 & 2.42 & 4.21 & 3.04 \\
\hline 10 & 0.5 & 765 & 80.4 & 10.4 & 73.9 & 16.0 & 0.11 & 0.34 & 2.31 & 4.22 & 3.06 \\
\hline 10 & 0.5 & 750 & 79.9 & 10.4 & 74.3 & 15.9 & 0.08 & 0.25 & 2.21 & 4.23 & 3.09 \\
\hline 10 & 0.5 & 745 & 79.6 & & 74.4 & 15.8 & 0.07 & 0.23 & 2.16 & & 3.10 \\
\hline 10 & 0.5 & 730 & 78.0 & & 74.9 & & 0.06 & & 1.95 & 4.23 & 3.17 \\
\hline 10 & 0.5 & 715 & 76.2 & 10.5 & 75.4 & 15.2 & 0.04 & 0.13 & 1.76 & 4.20 & 3.24 \\
\hline 10 & 0.5 & 700 & 74.3 & 10.6 & 76.0 & 14.8 & 0.03 & 0.10 & 1.58 & 4.15 & 3.33 \\
\hline 10 & 1.0 & 1100 & 98.1 & 11.5 & 68.9 & 16.7 & 2.02 & 2.01 & 3.81 & 3.97 & 2.61 \\
\hline 10 & 1.0 & 1075 & 97.7 & 11.6 & 69.0 & 16.8 & 1.81 & 1.98 & 3.84 & 3.99 & 2.63 \\
\hline 10 & 1.0 & 1050 & 97.2 & 11.6 & 69.1 & 16.9 & 1.61 & 1.93 & 3.86 & 4.02 & 2.64 \\
\hline 10 & 1.0 & 1025 & 96.8 & 11.7 & 69.2 & 17.0 & 1.43 & 1.88 & 3.87 & 4.04 & 2.66 \\
\hline 10 & 1.0 & 1000 & 96.4 & 11.8 & 69.2 & 17.1 & 1.26 & 1.81 & 3.89 & 4.07 & 2.68 \\
\hline 10 & 1.0 & 975 & 96.0 & 11.8 & 69.3 & 17.1 & 1.11 & 1.72 & 3.91 & 4.09 & 2.69 \\
\hline 10 & 1.0 & 950 & 95.6 & 11.9 & 69.4 & 17.2 & 0.96 & 1.62 & 3.93 & 4.12 & 2.71 \\
\hline 10 & 1.0 & 945 & 94.6 & 12.0 & 69.8 & 17.1 & 0.94 & 1.67 & 3.67 & 4.10 & 2.73 \\
\hline 10 & 1.0 & 930 & 93.4 & 12.1 & 70.3 & 16.9 & 0.87 & 1.69 & 3.41 & 4.09 & 2.77 \\
\hline 10 & 1.0 & 920 & 92.5 & 12.2 & 70.7 & 16.7 & 0.83 & 1.69 & 3.23 & 4.08 & 2.79 \\
\hline 10 & 1.0 & 895 & 91.4 & 12.4 & 71.2 & 16.7 & 0.64 & 1.51 & 3.08 & 4.11 & 2.84 \\
\hline 10 & 1.0 & 870 & 90.2 & 12.6 & 71.7 & 16.6 & 0.48 & 1.28 & 2.92 & 4.13 & 2.89 \\
\hline
\end{tabular}


Table 4.6 - Continued from previous page

\begin{tabular}{|c|c|c|c|c|c|c|c|c|c|c|c|}
\hline $\mathrm{H}_{2} \mathrm{O}^{i}$ & $\mathrm{P}$ & $\mathrm{T}$ & melt & $\mathrm{H}_{2} \mathrm{O}^{m}$ & $\mathrm{SiO}_{2}$ & $\mathrm{Al}_{2} \mathrm{O}_{3}$ & $\mathrm{MgO}$ & $\mathrm{FeO}_{t}$ & $\mathrm{CaO}$ & $\mathrm{Na}_{2} \mathrm{O}$ & $\mathrm{K}_{2} \mathrm{O}$ \\
\hline 10 & 1.0 & 845 & 89.0 & 12.8 & 72.3 & 16.5 & 0.34 & 1.02 & 2.75 & 4.15 & 2.94 \\
\hline 10 & 1.0 & 820 & 87.8 & 13.0 & 73.0 & 16.3 & 0.23 & 0.75 & 2.58 & 4.17 & 2.98 \\
\hline 10 & 1.0 & 795 & 86.8 & 13.2 & 73.6 & 16.2 & 0.15 & 0.51 & 2.40 & 4.19 & 3.03 \\
\hline 10 & 1.0 & 770 & 85.9 & 13.4 & 74.1 & 16.0 & 0.09 & 0.32 & 2.24 & 4.19 & 3.07 \\
\hline 10 & 1.0 & 760 & 85.1 & 13.5 & 74.2 & 16.0 & 0.07 & 0.26 & 2.18 & 4.22 & 3.11 \\
\hline 10 & 1.0 & 750 & 83.7 & 13.8 & 74.0 & 16.1 & 0.06 & 0.21 & 2.12 & 4.29 & 3.19 \\
\hline 10 & 1.0 & 745 & 83.0 & 14.0 & 73.9 & 16.2 & 0.05 & 0.19 & 2.09 & 4.32 & 3.22 \\
\hline 10 & 1.0 & 730 & 81.0 & 14.5 & 73.6 & 16.4 & 0.04 & 0.13 & 2.01 & 4.42 & 3.33 \\
\hline 10 & 1.0 & 715 & 79.1 & 15.0 & 73.3 & 16.7 & 0.02 & 0.09 & 1.94 & 4.52 & 3.44 \\
\hline 10 & 1.0 & 700 & 77.4 & 15.4 & 73.0 & 16.9 & 0.02 & 0.06 & 1.86 & 4.62 & 3.55 \\
\hline 10 & 1.5 & 1100 & 97.1 & 11.6 & 69.1 & 16.9 & 1.56 & 1.95 & 3.86 & 4.02 & 2.65 \\
\hline 10 & 1.5 & 1085 & 96.9 & 11.7 & 69.1 & 16.9 & 1.46 & 1.92 & 3.87 & 4.04 & 2.66 \\
\hline 10 & 1.5 & 1070 & 96.7 & 11.7 & 69.2 & 17.0 & 1.37 & 1.89 & 3.88 & 4.05 & 2.66 \\
\hline 10 & 1.5 & 1055 & 96.4 & 11.8 & 69.2 & 17.0 & 1.27 & 1.86 & 3.89 & 4.06 & 2.67 \\
\hline 10 & 1.5 & 1040 & 96.2 & 11.8 & 69.3 & 17.1 & 1.18 & 1.82 & 3.90 & 4.08 & 2.68 \\
\hline 10 & 1.5 & 1025 & 96.0 & 11.8 & 69.3 & 17.1 & 1.10 & 1.78 & 3.90 & 4.09 & 2.69 \\
\hline 10 & 1.5 & 1010 & 95.8 & 11.9 & 69.4 & 17.2 & 1.02 & 1.73 & 3.91 & 4.11 & 2.70 \\
\hline 10 & 1.5 & 990 & 95.3 & 12.0 & 69.5 & 17.3 & 0.92 & 1.66 & 3.81 & 4.13 & 2.72 \\
\hline 10 & 1.5 & 985 & 95.1 & 12.0 & 69.6 & 17.3 & 0.89 & 1.63 & 3.76 & 4.14 & 2.73 \\
\hline 10 & 1.5 & 975 & 94.3 & 12.1 & 70.0 & 17.1 & 0.82 & 1.54 & 3.63 & 4.16 & 2.76 \\
\hline 10 & 1.5 & 970 & 93.7 & 12.2 & 70.2 & 16.9 & 0.80 & 1.55 & 3.54 & 4.15 & 2.77 \\
\hline 10 & 1.5 & 960 & 92.8 & 12.3 & 70.7 & 16.8 & 0.75 & 1.49 & 3.36 & 4.16 & 2.80 \\
\hline 10 & 1.5 & 950 & 91.9 & 12.4 & 71.1 & 16.6 & 0.70 & 1.44 & 3.18 & 4.16 & 2.83 \\
\hline 10 & 1.5 & 940 & 91.4 & 12.5 & 71.3 & 16.6 & 0.62 & 1.33 & 3.11 & 4.19 & 2.86 \\
\hline 10 & 1.5 & 930 & 90.9 & 12.6 & 71.5 & 16.6 & 0.55 & 1.23 & 3.04 & 4.21 & 2.88 \\
\hline 10 & 1.5 & 920 & 90.4 & 12.7 & 71.8 & 16.5 & 0.48 & 1.11 & 2.96 & 4.24 & 2.90 \\
\hline 10 & 1.5 & 905 & 89.7 & 12.9 & 72.2 & 16.5 & 0.39 & 0.93 & 2.84 & 4.28 & 2.94 \\
\hline 10 & 1.5 & 890 & 89.0 & 13.0 & 72.5 & 16.4 & 0.31 & 0.77 & 2.72 & 4.32 & 2.97 \\
\hline 10 & 1.5 & 875 & 88.4 & 13.2 & 72.9 & 16.3 & 0.24 & 0.62 & 2.60 & 4.34 & 3.01 \\
\hline 10 & 1.5 & 860 & 87.8 & 13.3 & 73.2 & 16.3 & 0.19 & 0.49 & 2.49 & 4.36 & 3.03 \\
\hline 10 & 1.5 & 850 & 87.3 & 13.4 & 73.3 & 16.3 & 0.16 & 0.42 & 2.43 & 4.37 & 3.06 \\
\hline 10 & 1.5 & 845 & 86.6 & 13.5 & 73.2 & 16.4 & 0.14 & 0.39 & 2.40 & 4.40 & 3.09 \\
\hline 10 & 1.5 & 830 & 84.6 & 13.9 & 72.9 & 16.6 & 0.11 & 0.32 & 2.34 & 4.49 & 3.19 \\
\hline 10 & 1.5 & 815 & 82.7 & 14.4 & 72.6 & 16.9 & 0.09 & 0.25 & 2.27 & 4.58 & 3.29 \\
\hline 10 & 1.5 & 800 & 80.8 & 14.8 & 72.3 & 17.2 & 0.07 & 0.20 & 2.21 & 4.65 & 3.39 \\
\hline 10 & 1.5 & 785 & 79.0 & 15.3 & 72.0 & 17.4 & 0.05 & 0.15 & 2.16 & 4.73 & 3.50 \\
\hline
\end{tabular}


Table 4.6 - Continued from previous page

\begin{tabular}{|c|c|c|c|c|c|c|c|c|c|c|c|}
\hline $\mathrm{H}_{2} \mathrm{O}^{i}$ & $\mathrm{P}$ & $\mathrm{T}$ & melt & $\mathrm{H}_{2} \mathrm{O}^{m}$ & $\mathrm{SiO}_{2}$ & $\mathrm{Al}_{2} \mathrm{O}_{3}$ & $\mathrm{MgO}$ & $\mathrm{FeO}_{t}$ & $\mathrm{CaO}$ & $\mathrm{Na}_{2} \mathrm{O}$ & $\mathrm{K}_{2} \mathrm{O}$ \\
\hline 10 & 1.5 & 770 & 77.3 & 15.7 & 71.7 & 17.7 & 0.04 & 0.11 & 2.10 & 4.79 & 3.61 \\
\hline 10 & 1.5 & 760 & 76.1 & 16.1 & 71.5 & 17.8 & 0.03 & 0.10 & 2.04 & 4.84 & 3.68 \\
\hline 10 & 1.5 & 750 & 73.4 & 16.8 & 71.6 & 17.7 & 0.03 & 0.10 & 1.88 & 5.03 & 3.64 \\
\hline 10 & 1.5 & 740 & 70.4 & 17.6 & 71.9 & 17.5 & 0.03 & 0.10 & 1.74 & 5.29 & 3.51 \\
\hline 10 & 1.5 & 730 & 67.8 & 18.5 & 72.1 & 17.3 & 0.03 & 0.10 & 1.62 & 5.52 & 3.39 \\
\hline 10 & 1.5 & 720 & 65.4 & 19.3 & 72.3 & 17.1 & 0.03 & 0.10 & 1.51 & 5.76 & 3.26 \\
\hline 10 & 1.5 & 710 & 63.2 & 20.2 & 72.4 & 16.9 & 0.02 & 0.10 & 1.40 & 5.98 & 3.14 \\
\hline 10 & 1.5 & 00 & 61.2 & 21.1 & 72.6 & 16.8 & 0.02 & 0.09 & 1.31 & 6.20 & 3.01 \\
\hline 10 & 2.0 & 1200 & 98.1 & 11.5 & 68.8 & 16.7 & 1.97 & 2.12 & 3.81 & 3.97 & 2.61 \\
\hline 10 & 2.0 & 185 & 97.8 & 11.5 & 68.9 & 16.7 & 1.85 & 2.10 & 3.83 & 3.98 & 2.62 \\
\hline 10 & 2.0 & 1160 & 97.4 & 11.6 & 69.0 & 16.8 & 1.66 & 2.05 & 3.84 & 4.01 & 2.64 \\
\hline 10 & 2.0 & 1135 & 97.0 & 11.7 & 69.1 & 16.9 & 1.49 & 2.00 & 3.86 & 4.03 & 2.65 \\
\hline 10 & 2.0 & 1110 & 96.6 & 11.7 & 69.2 & 17.0 & 1.33 & 1.94 & 3.88 & 4.05 & 2.67 \\
\hline 10 & 2.0 & 1100 & 96.2 & 11.8 & 69.3 & 16.9 & 1.26 & 1.91 & 3.82 & 4.08 & 2.68 \\
\hline 10 & 2.0 & 1080 & 94.7 & 12.1 & 70.1 & 16.5 & 1.13 & 1.80 & 3.54 & 4.17 & 2.75 \\
\hline 10 & 2.0 & 1070 & 94.2 & 12.2 & 70.3 & 16.5 & 1.05 & 1.73 & 3.45 & 4.21 & 2.77 \\
\hline 10 & 2.0 & 1065 & 93.9 & 12.2 & 70.4 & 16.4 & 1.01 & 1.69 & 3.42 & 4.23 & 2.78 \\
\hline 10 & 2.0 & 1050 & 93.3 & 12.4 & 70.7 & 16.4 & 0.88 & 1.57 & 3.33 & 4.27 & 2.81 \\
\hline 10 & 2.0 & 1035 & 92.6 & 12.5 & 71.0 & 16.4 & 0.76 & 1.43 & 3.22 & 4.32 & 2.84 \\
\hline 10 & 2.0 & 1020 & 91.9 & 12.7 & 71.3 & 16.4 & 0.65 & 1.28 & 3.10 & 4.37 & 2.88 \\
\hline 10 & 2.0 & 1005 & 91.2 & 12.8 & 71.7 & & 0.54 & 1.11 & 2.98 & 4.43 & 2.91 \\
\hline 10 & 2.0 & & 90.5 & & 72.0 & & 0.45 & & 2.86 & 4. & 2.94 \\
\hline 10 & 2.0 & 980 & 90.1 & 13.0 & 72.2 & 16.3 & 0.39 & 0.84 & 2.77 & 4.51 & 2.97 \\
\hline 10 & 2.0 & 960 & 89.3 & 13.2 & 72.6 & 16.3 & 0.29 & 0.64 & 2.61 & 4.56 & 3.01 \\
\hline 10 & 2.0 & 950 & 89.0 & 13.3 & 72.7 & 16.3 & 0.25 & 0.56 & 2.53 & 4.58 & 3.02 \\
\hline 10 & 2.0 & 935 & 88.6 & 13.4 & 73.0 & 16.3 & 0.20 & 0.44 & 2.43 & 4.60 & 3.05 \\
\hline 10 & 2.0 & 920 & 88.1 & 13.5 & 73.2 & 16.3 & 0.16 & 0.34 & 2.33 & 4.61 & 3.07 \\
\hline 10 & 2.0 & 910 & 87.1 & 13.8 & 72.9 & 16.5 & 0.13 & 0.29 & 2.29 & 4.68 & 3.13 \\
\hline 10 & 2.0 & 895 & 85.6 & 14.1 & 72.6 & 16.9 & 0.11 & 0.23 & 2.23 & 4.78 & 3.21 \\
\hline 10 & 2.0 & 880 & 84.1 & 14.5 & 72.2 & 17.2 & 0.08 & 0.18 & 2.17 & 4.86 & 3.29 \\
\hline 10 & 2.0 & 865 & 82.7 & 14.9 & 71.8 & 17.5 & 0.07 & 0.13 & 2.12 & 4.94 & 3.38 \\
\hline 10 & 2.0 & 850 & 81.3 & 15.2 & 71.4 & 17.9 & 0.05 & 0.10 & 2.08 & 4.99 & 3.47 \\
\hline 10 & 2.0 & 835 & 79.4 & 15.7 & 71.1 & 18.2 & 0.04 & 0.08 & 2.05 & 5.02 & 3.57 \\
\hline 10 & 2.0 & 820 & 76.2 & 16.5 & 70.9 & 18.3 & 0.03 & 0.07 & 2.02 & 5.15 & 3.52 \\
\hline 10 & 2.0 & 800 & 70.0 & 18.3 & 71.2 & 18.1 & 0.03 & 0.07 & 1.93 & 5.57 & 3.07 \\
\hline 10 & 2.0 & 790 & 67.3 & 19.2 & 71.3 & 18.0 & 0.03 & 0.07 & 1.86 & 5.79 & 2.86 \\
\hline
\end{tabular}


Table 4.6 - Continued from previous page

\begin{tabular}{cccccccccccc}
\hline $\mathrm{H}_{2} \mathrm{O}^{i}$ & $\mathrm{P}$ & $\mathrm{T}$ & melt & $\mathrm{H}_{2} \mathrm{O}^{m}$ & $\mathrm{SiO}_{2}$ & $\mathrm{Al}_{2} \mathrm{O}_{3}$ & $\mathrm{MgO}$ & $\mathrm{FeO}$ & $\mathrm{CaO}$ & $\mathrm{Na}_{2} \mathrm{O}$ & $\mathrm{K}_{2} \mathrm{O}$ \\
\hline 10 & 2.0 & 785 & 66.0 & 19.7 & 71.4 & 18.0 & 0.03 & 0.07 & 1.81 & 5.90 & 2.77 \\
10 & 2.0 & 770 & 62.6 & 21.2 & 71.7 & 17.8 & 0.03 & 0.08 & 1.67 & 6.21 & 2.51 \\
10 & 2.0 & 755 & 59.5 & 22.8 & 71.9 & 17.7 & 0.03 & 0.08 & 1.54 & 6.50 & 2.28 \\
10 & 2.0 & 740 & 56.9 & 24.4 & 72.1 & 17.6 & 0.03 & 0.08 & 1.43 & 6.75 & 2.07 \\
10 & 2.0 & 725 & 54.4 & 26.1 & 72.3 & 17.4 & 0.03 & 0.08 & 1.32 & 6.97 & 1.90 \\
10 & 2.0 & 710 & 52.2 & 27.9 & 72.5 & 17.3 & 0.03 & 0.07 & 1.23 & 7.15 & 1.76 \\
10 & 2.0 & 700 & 45.0 & 28.6 & 72.4 & 17.3 & 0.02 & 0.07 & 1.14 & 7.47 & 1.55 \\
& & & & & & & & & & & \\
\hline
\end{tabular}




\section{CHAPTER 5}

\section{Empirical estimate of temperature, pressure and $\mathrm{H}_{2} \mathrm{O}$ at liquidus conditions in silicic melt based on major element chemistry via support vector machine regression}

\subsection{Preface}

The impetus for this study is the question at which conditions the liquidus of Archean tonalites-trondhjemites-granodiorites (TTG) is located under different variables of $\mathrm{P}-\mathrm{T}-\mathrm{H}_{2} \mathrm{O}$. This study emerged as a side track project while visiting Nanjing University during my final year. After I was not able to finish my experimental work at Macquarie University due to the piston cylinder laboratory not being fully operational, I was discontent as the liquidus of PC-103 was not fully explored for $10 \mathrm{wt} \% \mathrm{H}_{2} \mathrm{O}$ and experiments on a second sample of the suite, the trondhjemite PC-187 were insufficient to construct a PT diagram. Therefore I had to find an alternative way to investigate TTG formation conditions, which resulted in using the experimental data of published studies to calibrate a model that estimates liquidus conditions based on the equilibrium major element composition of experimental melts.

The whole research until finishing the first manuscript draft was done by myself. Gerhard Wörner and Tracy Rushmer reviewed the manuscript.

\subsection{Abstract}

I calibrated a statistical model via a support vector machine regression (SVR) based on a large dataset $(\mathrm{n}=740)$ comprising major element compositions of glasses produced in hydrous melting experiments to predict temperature, pressure and dissolved $\mathrm{H}_{2} \mathrm{O}$ at liquidus conditions of a silicate melt. The goal is to construct a model where temperature, pressure and $\mathrm{H}_{2} \mathrm{O}$ are estimated simultaneously and interdependent, by iteratively calculating the most likely conditions of the liquidus.

However, the model setup contains several flaws that prevents it from reliably functioning: (i) an artificial correlation of pressure and temperature in the input dataset due to the general experimental design of individual studies, (ii) an uncertainty of the $\mathrm{H}_{2} \mathrm{O}$ dissolved into experimental melts and (iii) the interference of major element features resulting from pressure and $\mathrm{H}_{2} \mathrm{O}$ by the diversity of starting materials used for the experiments. A statistical model as calibrated here is not able to resolve these issues. 
Despite that, individual calibrations within the model return reliable results. Therefore I calculated a liquidus temperature range for Archean tonalite-trondhjemite-granodiorite (TTG) to be $850-1050{ }^{\circ} \mathrm{C}$ solely based on major element compositions. Based on a $\mathrm{H}_{2} \mathrm{O}$ dependent calibration approximately $8 \mathrm{wt} \%$ of $\mathrm{H}_{2} \mathrm{O}$ dissolved are required for this temperature range. Furthermore I calculated the $\mathrm{H}_{2} \mathrm{O}$ content and pressure conditions for Ti saturated liquidus temperatures of TTGs from chapter 3. As independently predicted in the previous chapter, the amount of $\mathrm{H}_{2} \mathrm{O}$ required is between 9-12 wt\%. Pressure conditions for the liquidus give a broad span from 0.5-2.0 GPa.

\subsection{Introduction}

The physical conditions of formation of silicate melts can only be indirectly inferred from petrography, chemical and isotopic analysis of magmatic rocks. The simulation of magmatic processes under laboratory conditions by melting experiments also provides an important reference frame to understand magmatic systems. To compare experiments and natural rocks and to understand the underlying processes, graphical systems like the Qtz-Fo-An-Di tetrahedron and the granite system (Tuttle and Bowen, 1958; Yoder and Tilley, 1962) have been established. Within these simplified compositional spaces, experimental results are schematised into vectors displaying the chemical evolution of melts governed by equilibrium phases. The position of the vectors, called cotectic paths, depend on extrinsic factors as temperature, pressure, available volatiles, oxygen fugacity and source rock composition (Adam et al., 2016; Gao et al., 2016). By comparing natural magmatic rock suites and experimentally determined cotectic paths, inferences about the extrinsic parameters that shaped the natural rock suite are possible.

In this study, I test modern data analysis on an experimental dataset of hydrous melting experiments comprising 36 different studies. The aim is to examine the entity of the data and develop a model capable of estimating the liquidus conditions in respect to T-P- $\mathrm{H}_{2} \mathrm{O}$. A large focus in doing so is on the statistical robustness of the model to support these predictions. For the statistic evaluation of the data, I use a support vector machine (SVM) algorithm (Noble, 2006). SVM can be applied as a tool for regression (support vector machine regression (SVR) Vapnik, 1995; Smola and Schölkopf, 2004) and classification (Kowalczyk, 2017) that has been successfully applied in the field of medical science (Kourou et al., 2015) and was introduced for petrological applications by Petrelli and Perugini (2016).

I apply the model to natural felsic compositions of Archean cratons. The mechanisms of continental crust production during the Archean are proposed to have been different to the recent, globally operating plate tectonic system (Moyen and Martin, 2012), where magmatic felsic rocks are dominantly formed in convergent plate settings. The zircon record suggests that $60 \%$ of the current continental crust was already stable by the end of the Archean (Belousova et al., 2010; Hawkesworth et al., 2019). Granitoid rocks, characteristic for Archean continental crust, differ significantly from rocks that are produced in modern continental growth settings. 
The dominant rock types are an association of tonalite-trondhjemite-granodiorite (TTG). Their distinct characteristics are a depletion in heavy rare earth element (HREE) and a high $\mathrm{Sr} / \mathrm{Y}$ ratio, interpreted as the involvement of garnet during formation, a depletion in $\mathrm{Nb}-\mathrm{Ta}-\mathrm{Ti}$, no negative Eu-anomaly and low $\mathrm{K}_{2} \mathrm{O}$ concentrations (Moyen and Martin, 2012). The high $\mathrm{Sr} / \mathrm{Y}$ ratio, combined with no Eu anomaly and low- $\mathrm{K}_{2} \mathrm{O}$ differentiation trends favour the absence of plagioclase during their formation and evolution. These peculiarities of TTGs are the reason for a lack of knowledge regarding the predominant geodynamic environment during the Archean.

There are three commonly considered scenarios in which TTGs might have been formed (Palin et al., 2016). The first is a steep "modern style" subduction setting (Turner et al., 2014) with slab melting (Laurie et al., 2013), similar as what is proposed for the genesis of modern adakites (Martin et al., 2005). However, the formation of adakites does not seem to be limited to slab melting (Castillo, 2012). Another formation scenario is a setting of shallow subduction, respectively the stacking of oceanic crust by thrusting and subsequent melting within the garnet stability field (Foley et al., 2003; Nutman et al., 2015; Hastie et al., 2016). In a third scenario Archean crust is produced by the interplay of a "proto-crust" and mantle plumes (Bédard, 2006a; Van Kranendonk et al., 2007) producing and subsequently melting a thick oceanic plateau, accompanied by crustal overturns (Collins et al., 1998; Wiemer et al., 2018) and delamination of depleted eclogitised oceanic crust (Sizova et al., 2015; Johnson et al., 2014).

To discuss the origin of TTGs it is critical to decide which compositional signatures in TTGs are the result of their formation process, which were modified by subsequent magmatic differentiation and which are inherited from the source rock. Chapter 3 showed with the behaviour of $\mathrm{Nb}$, that $\mathrm{Ti}$ phases could only have had a minor role in shaping the trace element signature of TTGs and that most of the Nb depletion is caused by another mechanism, may it be another phase or inheritance. The major element composition on the other hand is the direct result of the underlying magmatic process. Understanding the major elements is inevitable for any further interpretation. Here, the calibrated model can provide an elementary framework for this.

\subsection{Methods}

For the regression in this study I use an $\epsilon$-SVR from the $R$ package e1071 (Meyer et al., 2018). A SVR is a supervised learning algorithm (Kowalczyk, 2017). In contrast to a normal regression method, that minimises the error, SVR allows deviation up to a definable threshold $(\epsilon)$ and the option to penalize outliers outside of the range between hyperplane and margin within a range of $\xi$. However, the largest advantage of SVR is the use of kernel functions. If data can not be described or separated by a linear function, a kernel function transforms it into a higher dimension to make it linearly describable. The aim is to find a function that deviates less than $\epsilon$ from all training data $\left\{\left(x_{1}, y_{1}\right), \ldots,\left(x_{n}, y_{n}\right)\right\} \in \mathbb{R}^{d}$, while still being as flat 
as possible (Smola and Schölkopf, 2004). In case of a function

$$
f(x)=\langle\omega, x\rangle+b \text { with } \omega \in \mathbb{R}^{d}, b \in \mathbb{R}
$$

where the hyperplane is described by the the dot product of the orthogonal vector $\omega$ and $x$, the optimal hyperplane describing the data is found via the minimisation of $\omega$. This is handled as a constrained convex optimisation problem minimising $\frac{1}{2}\|\omega\|^{2}$. Together with $\xi$ to penalise outliers, following formulation is used in Vapnik, 1995:

$$
\begin{aligned}
\operatorname{minimise} & \frac{1}{2}\|w\|^{2}+C \sum_{i=1}^{n}\left(\xi_{i}+\xi_{i}^{*}\right) \\
\text { subject to }= & \begin{cases}y_{i}-\left\langle w, x_{i}\right\rangle-b & \leq \epsilon+\xi_{i} \\
\left\langle w, x_{i}\right\rangle+b-y_{i} & \leq \epsilon+\xi_{i}^{*} \\
\xi_{i}, \xi_{i}^{*} & \geq 0\end{cases}
\end{aligned}
$$

$\xi$ is scaled by the constant $C>0$. A small $C$ does allow outliers to the expense of a large margin, whereas with a large $C$ the focus is on avoiding outliers with the risk to over determine the model. The constraints on equation 5.2 concern the margins with the distance $\epsilon$ to the hyperplane. Any support vector needs to be within $\epsilon+\xi_{i}$, respectively $\epsilon+\xi_{i}^{*}$. The desired model is found by constructing a Lagrange function (Smola and Schölkopf, 2004) that results in a linear SVR function

$$
f(x)=\sum_{i=1}^{n}\left(\alpha_{i}-\alpha_{i}^{*}\right)\left\langle x_{i}, x\right\rangle+b
$$

with $\alpha_{i}$ and $\alpha_{i}^{*}$ being Lagrange multipliers. For the application in this study I chose a radial basis function kernel

$$
k\left(x, x^{\prime}\right)=e^{\frac{\left\|x-x^{\prime}\right\|^{2}}{2 \sigma^{2}}}
$$

that replaces the dot product $\left\langle x_{i}, x\right\rangle$ in the linear SVR of eq. (5.3).

The optimisation of $\epsilon$ and $C$ is performed via a build in grid search of $R$ package $e 1071$ (Meyer et al., 2018) that identifies models with the lowest mean square error.

To test the SVR model, I use a k-fold cross-validation. The dataset is randomly divided 10,000 times into $75 \%$ training- and $25 \%$ test data. Each time the trained model is applied to the $25 \%$ test data. Based on approximately 2500 iterations per experiment, mean and uncertainty are calculated.

By comparing linear regression with SVR over the same set of data, the SVR outperforms the linear regression in precision and accuracy. This is exemplified in fig. 5.1, with the residuals for linear regression and SVR of temperature, pressure and $\mathrm{H}_{2} \mathrm{O}$ predictions on an experimental 
dataset described in section 5.5.1. The superior performance of the SVR is apparent for temperature and pressure with lower residuals, however in case of $\mathrm{H}_{2} \mathrm{O}$ the difference is not as incisive.
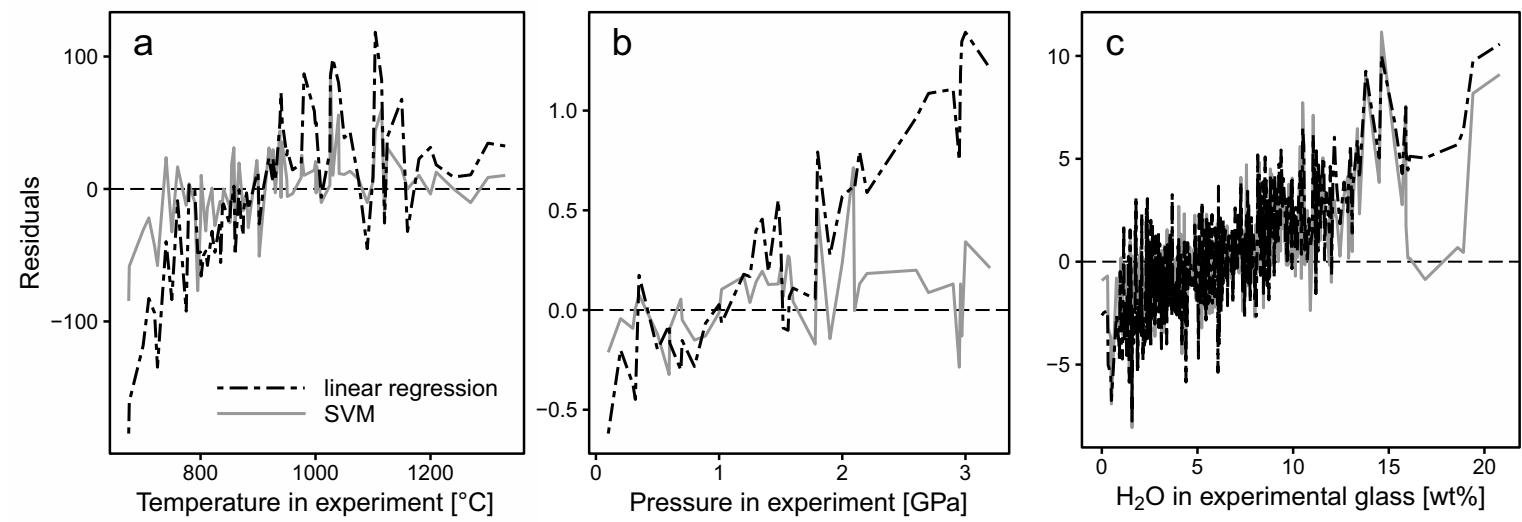

Figure 5.1: Residual plots for a linear regression and a SVR predicting temperature (a), pressure (b) and $\mathrm{H}_{2} \mathrm{O}$ (c) of an experimental data compilation described in section 5.5.1. These and all subsequent diagrams are made with ggplot2 (Wickham, 2016) in $R$ (R Core Team, 2017).

\subsection{Building the model}

It is not possible to construct a thermo(baro)meter without a basic supporting physical principle. Good examples are cation exchange thermometers (e.g. amphibole - plagioclase of Holland and Blundy, 1994) or saturation thermometers (Ti-solubility, see chapter 3). Using the experimental glass compositions to build a statistical model is rather like the construction of isotherms in the granite system (Yoder and Tilley, 1962), an empirical approach to compare experimental and natural data.

In a first step I evaluate the potential to estimate each of the unconstrained parameters (P-T$\mathrm{H}_{2} \mathrm{O}$ ) individually by training models to estimate them with the other two parameters being constrained. Furthermore I investigate the dependency and influence of the unconstrained parameters on each other by training several models that use different combinations of major elements and constrained parameters. As an example, temperature will be estimated by four different models: (i) major elements, (ii) pressure + major elements, (iii) $\mathrm{H}_{2} \mathrm{O}+$ major elements, (iv) pressure $+\mathrm{H}_{2} \mathrm{O}+$ major elements.

In the second step, I calibrate a self dependent model in which neither temperature, pressure or $\mathrm{H}_{2} \mathrm{O}$ content are constrained. I overcome this limitation by determining $\mathrm{T}, \mathrm{P}$ and $\mathrm{H}_{2} \mathrm{O}$ parameters as functions of each other, additional to the major element data. I calculate $\mathrm{T}$ in a $\mathrm{P}-\mathrm{H}_{2} \mathrm{O}$ matrix, $\mathrm{P}$ in a $\mathrm{T}-\mathrm{H}_{2} \mathrm{O}$ matrix and $\mathrm{H}_{2} \mathrm{O}$ in a $\mathrm{P}-\mathrm{T}$ matrix, each to the extend that is covered by the data used for calibration. Considered as planes, the three matrices intersect in a 3-dimensional T-P- $\mathrm{H}_{2} \mathrm{O}$ space, at which point the most likely liquidus condition is located. 


\subsubsection{The experimental dataset}

The dataset used to train the model contains glass analyses from 789 individual hydrous melting experiments from 36 different studies (Conrad et al., 1988; Vielzeuf and Holloway, 1988; Beard and Lofgren, 1991; Holtz and Johannes, 1991; Patiño Douce and Johnston, 1991; Rapp et al., 1991; Skjerlie and Johnston, 1992; Skjerlie and Johnston, 1993; Sen and Dunn, 1994; Vielzeuf and Montel, 1994; Wolf and Wyllie, 1994; Gardien et al., 1995; Patiño Douce and Beard, 1995; Rapp and Watson, 1995; Skjerlie and Patiño Douce, 1995; Patiño Douce and Beard, 1996; Skjerlie and Johnston, 1996; Winther, 1996; Springer and Seck, 1997; Patiño Douce and Harris, 1998; Pickering and Johnston, 1998; Castro et al., 1999, 2000; Gardien et al., 2000; Koester et al., 2002; Skjerlie and Patiño Douce, 2002; Grant, 2004; Spicer et al., 2004; López et al., 2005; Patiño Douce, 2005; Sisson et al., 2005; Xiong et al., 2005; Alonso-Perez et al., 2009; Getsinger et al., 2009; Adam et al., 2012; García-Arias et al., 2012; Laurie and Stevens, 2012; Qian and Hermann, 2013; Hastie et al., 2016). It comprises major element composition, temperature, pressure, $\mathrm{H}_{2} \mathrm{O}$ dissolved and the mode of the run products. The dataset covers an experimental temperature range from $675-1330{ }^{\circ} \mathrm{C}$, pressure from 0.1-3.2 GPa (fig. 5.2a) and basaltic to rhyolitic melt compositions.

In many studies the amount of water dissolved in the experimental glasses is based on the
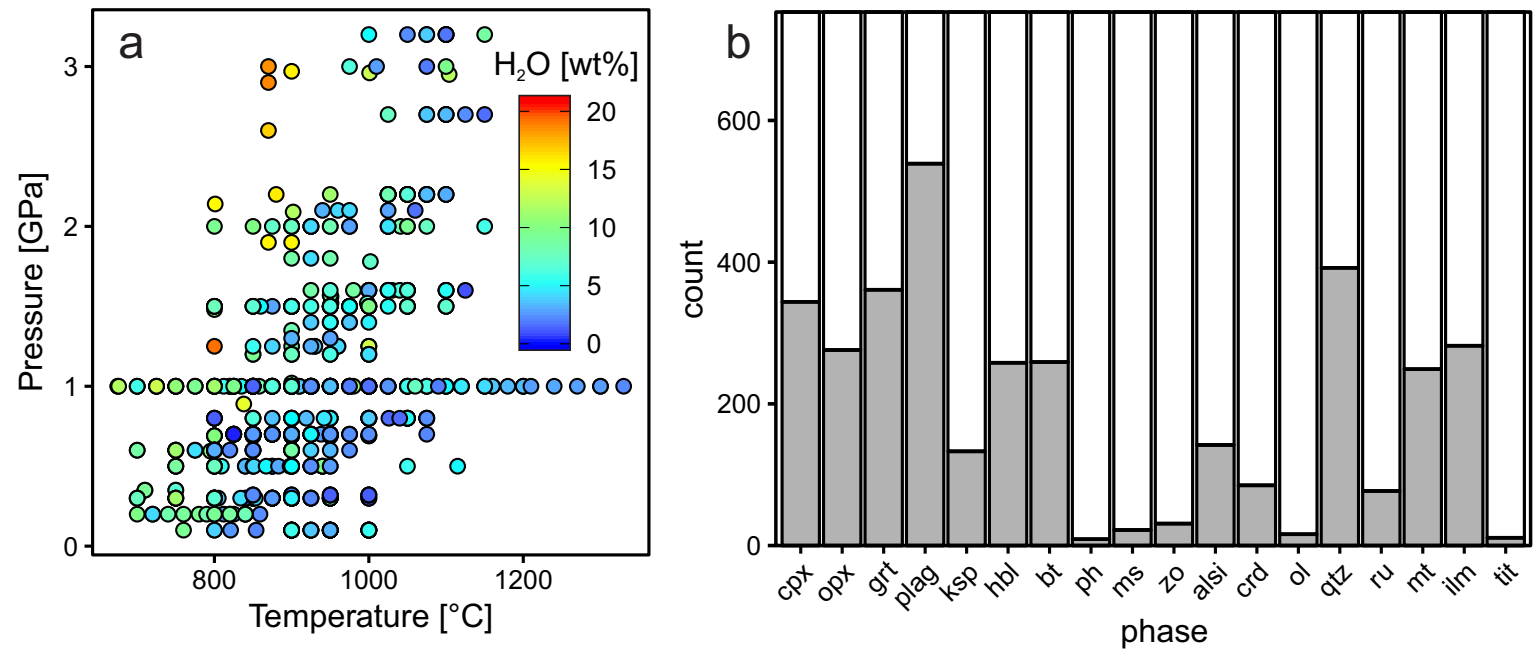

Figure 5.2: a: Pressure and temperature conditions and $\mathrm{H}_{2} \mathrm{O}$ dissolved in the experimental melts. b: Abundance of different phases in the experimental dataset. cpx $=$ clinopyroxene, opx $=$ orthopyroxene, grt $=$ garnet, plag $=$ plagioclase, $\mathrm{ksp}=$ alkali feldspar, $\mathrm{hbl}=$ hornblende, $\mathrm{bt}=$ biotite, $\mathrm{ph}=$ phengite, $\mathrm{ms}=$ muscovite, $\mathrm{zo}=$ klinozoisite, alsi $=$ alumina silicate, $\mathrm{crd}=$ cordierite, $\mathrm{ol}=$ olivine, $\mathrm{qtz}=$ quartz, $\mathrm{ru}=$ rutile, $\mathrm{mt}=$ magnetite, $\mathrm{ilm}=$ ilmenite, tit $=$ titanite.

difference of the analytical total to $100 \%$. This estimation is too uncertain for the purpose of building a model. Therefore, I checked the reported $\mathrm{H}_{2} \mathrm{O}$ dissolved into the melt carefully for each experiment and where applicable, recalculated the amount of water dissolved based on the initial water content of the experiment, the amount of glass and hydrous phases present by mass balance. Approximated $\mathrm{H}_{2} \mathrm{O}$ concentrations for hydrous phases where taken from 
Gardien et al., 2000 (amphibole 2.0 wt $\% \mathrm{H}_{2} \mathrm{O}$; mica $\left(3.8\right.$ wt $\% \mathrm{H}_{2} \mathrm{O}$ ). The $\mathrm{H}_{2} \mathrm{O}$ content of amphiboles measured by Springer and Seck (1997) is also at $2 \mathrm{wt} \%$. The corrected values are only valid if they are lower than the difference of the reported total to $100 \%$. Subsequently I compared the theoretically calculated $\mathrm{H}_{2} \mathrm{O}$ value with the reported $\mathrm{H}_{2} \mathrm{O}$ of the study (fig. 5.3). The correction is applied to 291 experiments, the majority of samples have an appropriate $\mathrm{H}_{2} \mathrm{O}$ estimate. As visible in fig. 5.3 most samples are corrected by $0-3 \mathrm{wt} \%$, which is an appropriate error range for experimental glasses. However there are some experiments with corrections beyond $5 \mathrm{wt} \%$. Due to the uncertainty regarding these experiments, they are excluded from the following calculations. The sample size is therefore decreased to 740 . The reduced set also excludes experiments without reported $\mathrm{H}_{2} \mathrm{O}$. As a result, the reduced dataset contains experiments with dissolved $\mathrm{H}_{2} \mathrm{O}$ concentrations covering a range from 0.0 to $20.8 \mathrm{wt} \%$ (fig. 5.2).

The abundance of different phases in the experiments is displayed in fig. 5.2b. Three quarters

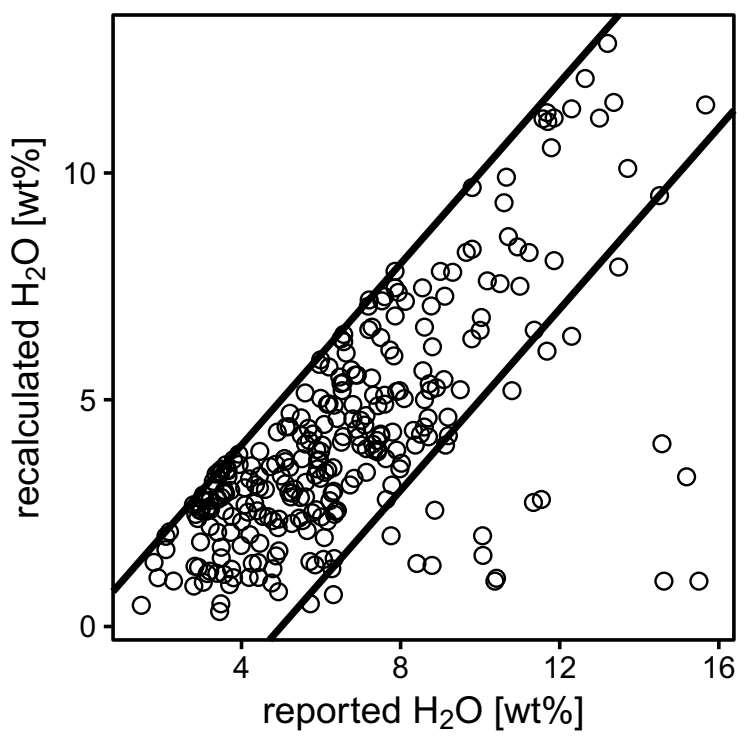

Figure 5.3: Recalculated $\mathrm{H}_{2} \mathrm{O}$ concentration plotted against reported values for 291 samples. The upper line is the 1:1 ratio for calculated and reported values, the lower line marks a $5 \mathrm{wt} \%$ difference.

of the experiments are saturated in plagioclase, approximately half in quartz, garnet and cpx, and one third in biotite, opx and amphibole. A minority of experiments is saturated in alumino-silicates, K-feldspar and cordierite. Most common accessory phases are magnetite and ilmenite, present in about one third of the experiments.

Major elements used for the temperature estimate are $\mathrm{SiO}_{2}, \mathrm{Al}_{2} \mathrm{O}_{3}, \mathrm{FeO}_{t}, \mathrm{MgO}, \mathrm{CaO}, \mathrm{Na}_{2} \mathrm{O}$ and $\mathrm{K}_{2} \mathrm{O}$. $\mathrm{TiO}_{2}$ and $\mathrm{P}_{2} \mathrm{O}_{5}$ concentrations are left out intentionally because both elements tend to form excess phases (Hellman and Green, 1979; Harrison and Watson, 1984). Their concentration in silicate melts is closely linked to their saturation and dependent on the amount of the respective element in the host rock. The nescience regarding their saturation 
in natural rocks is a factor of uncertainty that is best avoided by excluding both elements.

\subsubsection{Temperature calibration}

The model describing temperature is based on pressure, $\mathrm{H}_{2} \mathrm{O}, \mathrm{SiO}_{2}, \mathrm{Al}_{2} \mathrm{O}_{3}, \mathrm{FeO}_{t}, \mathrm{MgO}, \mathrm{CaO}$, $\mathrm{Na}_{2} \mathrm{O}$ and $\mathrm{K}_{2} \mathrm{O}$. Four different models are calibrated and tested, the first one only based on major elements (fig. 5.4a), the second one also including pressure (fig. 5.4b), a third model based on $\mathrm{H}_{2} \mathrm{O}$ and major elements and a fourth model based on pressure, $\mathrm{H}_{2} \mathrm{O}$ and major elements (fig. 5.4d). By this approach the influence of the two unconstrained parameters pressure and $\mathrm{H}_{2} \mathrm{O}$ can be evaluated.

Determining the temperature solely via selected major elements (fig. 5.4a) returns a good fit
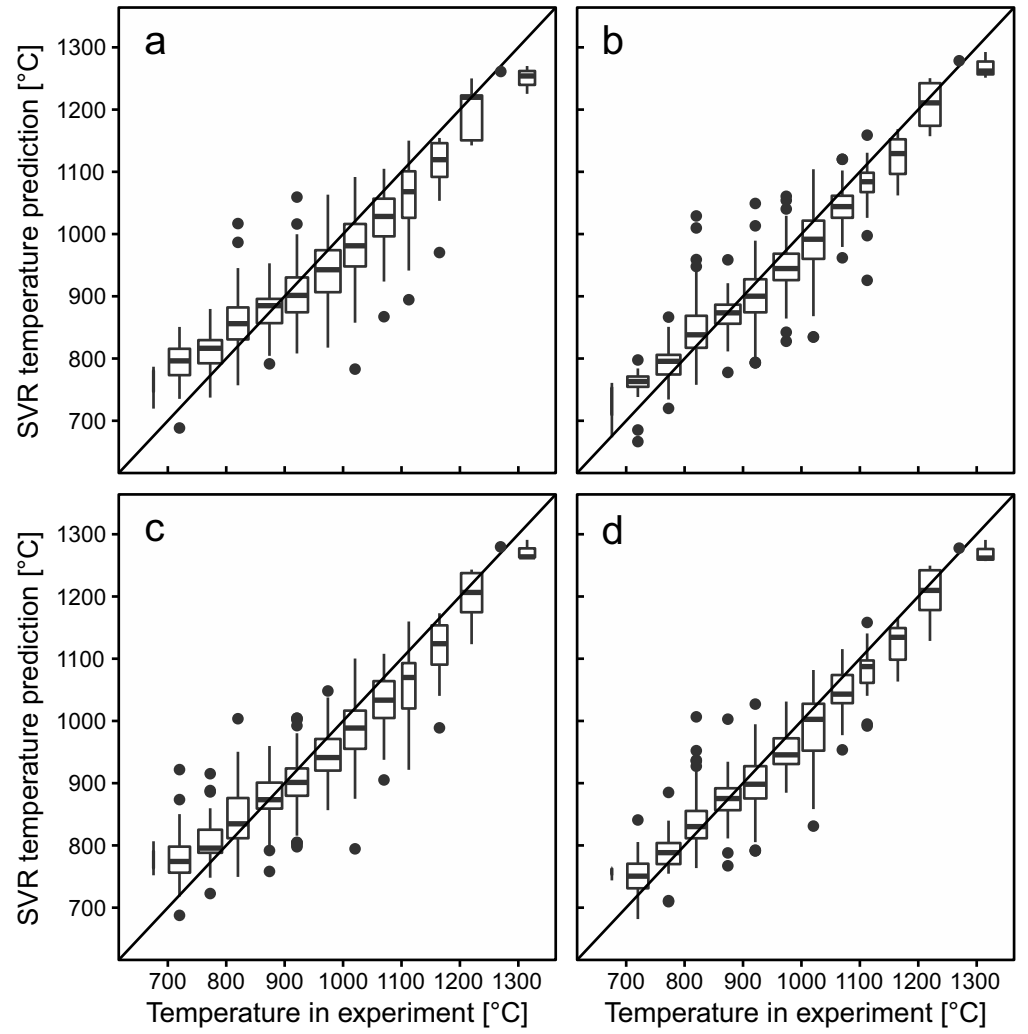

Figure 5.4: Box plots comparing estimated with recorded temperatures. The box width is $\leq 50{ }^{\circ} \mathrm{C}$. a: Temperature estimate based on major element composition. $\mathbf{b}$ : Temperature estimate based on pressure and major element composition. c: Temperature estimate based on $\mathrm{H}_{2} \mathrm{O}$ and major element composition $\mathbf{d}$ : Temperature estimate based on pressure, $\mathrm{H}_{2} \mathrm{O}$ and major element composition.

between 850 and $950{ }^{\circ} \mathrm{C}$. Temperatures below $850{ }^{\circ} \mathrm{C}$ are overestimated and above $950{ }^{\circ} \mathrm{C}$ underestimated within an range of approximately $50{ }^{\circ} \mathrm{C}$. High temperature experiments at $1200{ }^{\circ} \mathrm{C}$ are well described. However, there are a few outliers that deviated in their estimated temperature from the recorded one by more than $100{ }^{\circ} \mathrm{C}$. On average, over and underestimation cancel each other out resulting in a mean temperature deviation of $0.4{ }^{\circ} \mathrm{C}$ with a root mean square error (RMSE) of $54.4{ }^{\circ} \mathrm{C}$. The $\mathrm{R}^{2}$ for estimated and recorded 
temperature is 0.72 . The performance of all models is summarised in table 5.1.

The model using pressure and major elements (fig. 5.4b) improves in fit compared to the model using only major elements. Temperatures are well described over the whole range, however there are outliers with a deviation of more than $200{ }^{\circ} \mathrm{C}$. The model produces a negligible low bias with a mean deviation of $0.1{ }^{\circ} \mathrm{C}$ (table 5.1) The RMSE decreases to $45.6{ }^{\circ} \mathrm{C}$ and $\mathrm{R}^{2}$ increases to 0.81 . It is unexpected that adding pressure to the equation improves the model significantly. A possible explanation might be that the experimental dataset is biased by the positive correlation between temperature and pressure, artificially produced by the general experimental design of high pressure experiments at higher temperatures (fig. 5.2).

The model based on water and major elements performs slightly weaker than the model based on pressure and major elements. Temperatures below $850{ }^{\circ} \mathrm{C}$ are overestimated and temperatures above $950{ }^{\circ} \mathrm{C}$ are slightly underestimated. The performance in the low temperature range is the weakest for all four models by having the most and biggest outliers in that interval. As discussed in section 5.5.1, the $\mathrm{H}_{2} \mathrm{O}$ content of the melt is much more difficult to constrain and therefore prone to error and uncertainty. On average the deviation from the recorded temperature is at $-0.3{ }^{\circ} \mathrm{C}$ with a RMSE of $50.2{ }^{\circ} \mathrm{C} . \mathrm{R}^{2}$ is 0.76 .

Adding both pressure and $\mathrm{H}_{2} \mathrm{O}$ to the model (fig. 5.4d) decreases the mean temperature deviation to $-0.3{ }^{\circ} \mathrm{C}$ with a RMSE of $41.9{ }^{\circ} \mathrm{C}$. As graphically visible, the addition improves the prediction over the whole range of conditions, by shortening of the box plot whiskers. The greatest improvement is in the low temperature range, where temperatures are now only slightly overestimated. This is due to the high $\mathrm{H}_{2} \mathrm{O}$ content of low temperature melts. The overall improvement is reflected by $\mathrm{R}^{2}$ of 0.83 .

In section 5.8 the temperature estimation is further discussed with respect to the individual studies contributing to the database.

\subsubsection{Pressure calibration}

As for temperature, four different models are calibrated to estimate pressure conditions at which the experiments were conducted (fig. 5.5). The performance of the individual models is summarised in table 5.1. Pressure conditions estimated by the first model, using only major element data, are displayed as box plot in fig. 5.5a. The pressure is well estimated on average between 0.5 to $2.0 \mathrm{GPa}$ based on the major element chemistry, however there is a broad scatter and big outliers. Low pressure estimates are generally overestimated, while high pressures above 2.0 GPa are underestimated. Outstanding is the box describing pressure between 2.75-3.00 GPa due to an underestimation of 1.5 GPa. In average, the over- and underestimates cancel each other out, resulting in a mean pressure deviation of -0.005 GPa however the scatter results in a RMSE of $0.419 \mathrm{GPa}$. The $\mathrm{R}^{2}$ between estimated and recorded pressure is 0.59 .

Adding temperature to the estimate improves the pressure prediction (fig. 5.5b). On average there is a good pressure prediction below 1.75 GPa. Within this range most boxes and 
Table 5.1: Statistical evaluation of the cross validation on the various SVR models describing temperature $\left[{ }^{\circ} \mathrm{C}\right]$, pressure $[\mathrm{GPa}]$ and $\mathrm{H}_{2} \mathrm{O}$ [wt\%]. Abbreviations: $\mathrm{T}=$ temperature, $\mathrm{P}=$ pressure and $\mathrm{ME}=$ major elements.

\begin{tabular}{llccc}
\hline parameter & model input & mean deviation & RMSE & $\mathrm{R}^{2}$ \\
\hline $\mathrm{T}$ & $\mathrm{ME}$ & 0.4 & 54.4 & 0.72 \\
$\mathrm{~T}$ & $\mathrm{P}+\mathrm{ME}$ & 0.1 & 45.6 & 0.81 \\
$\mathrm{~T}$ & $\mathrm{H}_{2} \mathrm{O}+\mathrm{ME}$ & -0.3 & 50.2 & 0.76 \\
$\mathrm{~T}$ & $\mathrm{P}+\mathrm{H}_{2} \mathrm{O}+\mathrm{ME}$ & -0.3 & 41.9 & 0.83 \\
\hline $\mathrm{P}$ & $\mathrm{ME}$ & -0.005 & 0.419 & 0.59 \\
$\mathrm{P}$ & $\mathrm{T}+\mathrm{ME}$ & -0.018 & 0.364 & 0.69 \\
$\mathrm{P}$ & $\mathrm{H}_{2} \mathrm{O}+\mathrm{ME}$ & -0.016 & 0.384 & 0.66 \\
$\mathrm{P}$ & $\mathrm{T}+\mathrm{H}_{2} \mathrm{O}+\mathrm{ME}$ & -0.008 & 0.328 & 0.74 \\
\hline $\mathrm{H}_{2} \mathrm{O}$ & $\mathrm{ME}$ & -0.19 & 2.51 & 0.46 \\
$\mathrm{H}_{2} \mathrm{O}$ & $\mathrm{T}+\mathrm{ME}$ & -0.10 & 2.28 & 0.55 \\
$\mathrm{H}_{2} \mathrm{O}$ & $\mathrm{P}+\mathrm{ME}$ & -0.15 & 2.28 & 0.55 \\
$\mathrm{H}_{2} \mathrm{O}$ & $\mathrm{T}+\mathrm{P}+\mathrm{ME}$ & -0.15 & 2.14 & 0.61 \\
\hline Interdependent T-P-H & $\mathrm{O}$ model & & & \\
\hline $\mathrm{T}$ & $\mathrm{P}+\mathrm{H}_{2} \mathrm{O}+\mathrm{ME}$ & 17.2 & 63.2 & 0.65 \\
$\mathrm{P}$ & $\mathrm{T}+\mathrm{H}_{2} \mathrm{O}+\mathrm{ME}$ & 0.120 & 0.493 & 0.46 \\
$\mathrm{H}_{2} \mathrm{O}$ & $\mathrm{T}+\mathrm{P}+\mathrm{ME}$ & -0.24 & 2.65 & 0.40 \\
\hline Least squares approach & & & \\
\hline $\mathrm{P}$ & $\mathrm{T}+\mathrm{ME}$ & 0.378 & 0.75 & 0.22 \\
$\mathrm{H}_{2} \mathrm{O}$ & $\mathrm{T}+\mathrm{ME}$ & 2.83 & 5.50 & 0.05 \\
\hline
\end{tabular}

whiskers are reduced in size and the amount and deviation of outliers are both decreased. The estimate of higher pressures is better as well, however they are still underestimated. The box containing 2.75-3.00 GPa is strongly underestimated. In summary, pressures are slightly underestimated on average with $-0.018 \mathrm{GPa}$ and a RMSE of $0.364 . \mathrm{R}^{2}$ is 0.69 . The reason of temperature improving the prediction might at least be partially caused by the artificial positive correlation with pressure, as already discussed. An additional method to constrain pressure by using a least squares approach on the temperature prediction model (fig. 5.4b) is shown in the appendix fig. 5.15b. However the cross validation reveals a weak performance (table 5.1)

Estimating pressure with $\mathrm{H}_{2} \mathrm{O}$ and major elements (fig. 5.5c) is slightly worse as with temperature. While the estimation below 2.0 GPa is similar to the estimate including temperature, the amount of outliers increased. High pressures are underestimated, however the strong deviation of the box containing 2.75-3.00 GPa estimates is abrogated. The reason for $\mathrm{H}_{2} \mathrm{O}$ improving these experiments that significant might be that the box contains very high $\mathrm{H}_{2} \mathrm{O}$ content experiments by Laurie and Stevens (2012). On average the pressure is slightly underestimated by $-0.016 \mathrm{GPa}$ and a RMSE of $0.384 \mathrm{GPa} . \mathrm{R}^{2}$ is 0.66 . 

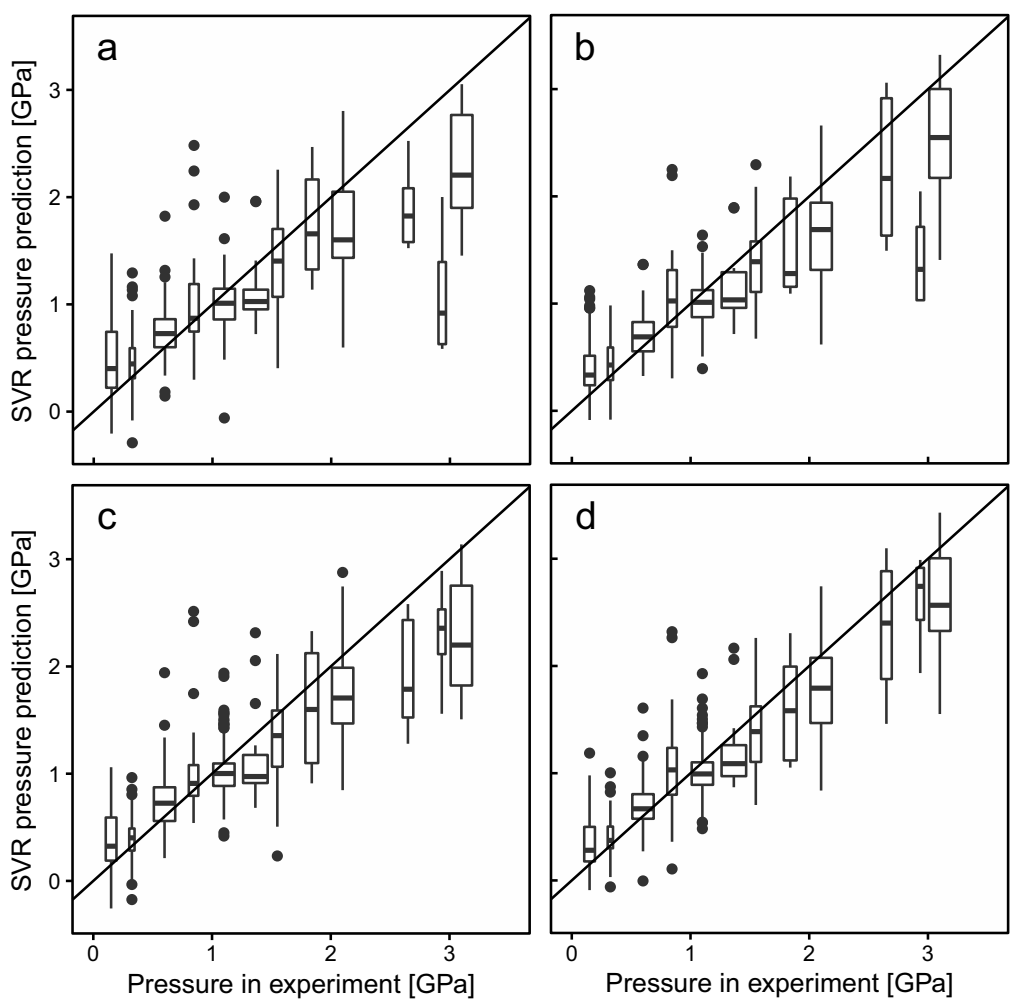

Figure 5.5: Box plots comparing estimated with recorded pressures. The box width is $\leq 0.25 \mathrm{GPa}$. a: Pressure estimate based on major element composition. b: Pressure estimate based on temperature and major element composition. c: Pressure estimate based on $\mathrm{H}_{2} \mathrm{O}$ and major element composition. d: Pressure estimate based on temperature, $\mathrm{H}_{2} \mathrm{O}$ and major element composition.

Using temperature, $\mathrm{H}_{2} \mathrm{O}$ and major elements improves the estimate over the whole pressure range (fig. 5.5d) and returns the best result of all four models. This is reflected by an increased $\mathrm{R}^{2}$ of 0.74 . While the number of outliers is not reduced, most boxes and whiskers decrease in range. The prediction of the high pressure experiments around $3 \mathrm{GPa}$ is improved, however they are still underestimated. In general, the pressure is slightly underestimated by -0.008 GPa with a RMSE of 0.328 GPa.

In summary, pressure can be estimated roughly. The RMSE of the best working model with known temperature and $\mathrm{H}_{2} \mathrm{O}$ is still at $0.328 \mathrm{GPa}$, being more than $10 \%$ of the whole pressure range of the dataset. In section 5.8 the pressure estimation is further discussed in respect to the individual studies contributing to the database.

\subsection{4 $\mathrm{H}_{2} \mathrm{O}$ calibration}

With the same approach as for temperature and pressure, the amount of water present in the experimental glasses is estimated. Results for the calibration on solely major elements are displayed in fig. 5.6a. An overestimation of $\mathrm{H}_{2} \mathrm{O}$ content below $5 \mathrm{wt} \%$ is observable, as well as an increasing underestimation of experiments containing more than $10 \mathrm{wt} \%$ of $\mathrm{H}_{2} \mathrm{O}$. The 
$\mathrm{H}_{2} \mathrm{O}$ content is on average underestimated by $-0.19 \mathrm{wt} \%$ with a RMSE of $2.51 \mathrm{wt} \%$. $\mathrm{R}^{2}$ for estimated and recorded $\mathrm{H}_{2} \mathrm{O}$ content is 0.46 .

The addition of temperature to the model improves the $\mathrm{H}_{2} \mathrm{O}$ estimate (fig. 5.6b), mainly observable in a decrease of outliers to the cost of slightly increased whisker lengths. The overall result of the model has not significantly changed in comparison to the major element dependent model. $\mathrm{H}_{2} \mathrm{O}$ contents are overestimated below $5 \mathrm{wt} \%$ while they are underestimated above $8 \mathrm{wt} \%$. On average, $\mathrm{H}_{2} \mathrm{O}$ is underestimated by $-0.10 \mathrm{wt} \%$ with a RMSE of $2.28 \mathrm{wt} \%$. $\mathrm{R}^{2}$ is 0.55 . An additional method to constrain $\mathrm{H}_{2} \mathrm{O}$ using a least squares approach on the temperature prediction model (fig. 5.4c) is shown in the appendix fig. 5.15a. As for the least squares calculation to estimate pressure, the model performance is very weak (table 5.1).

The model based on pressure and major elements (fig. 5.6c) performs quite similar to the two models already described, except for an improvement in estimates for $\mathrm{H}_{2} \mathrm{O}$ contents above $15 \mathrm{wt} \%$. On average, $\mathrm{H}_{2} \mathrm{O}$ contents are overestimated below $5 \mathrm{wt} \%$ and underestimated above $7 \mathrm{wt} \%$. The mean deviation of estimates is $-0.15 \mathrm{wt} \%$ with a RMSE of $2.28 \mathrm{wt} \%$. $\mathrm{R}^{2}$ is 0.55 , the same as for the model using temperature and major elements.

Using pressure, temperature and major elements for the $\mathrm{H}_{2} \mathrm{O}$ estimate improves the model by
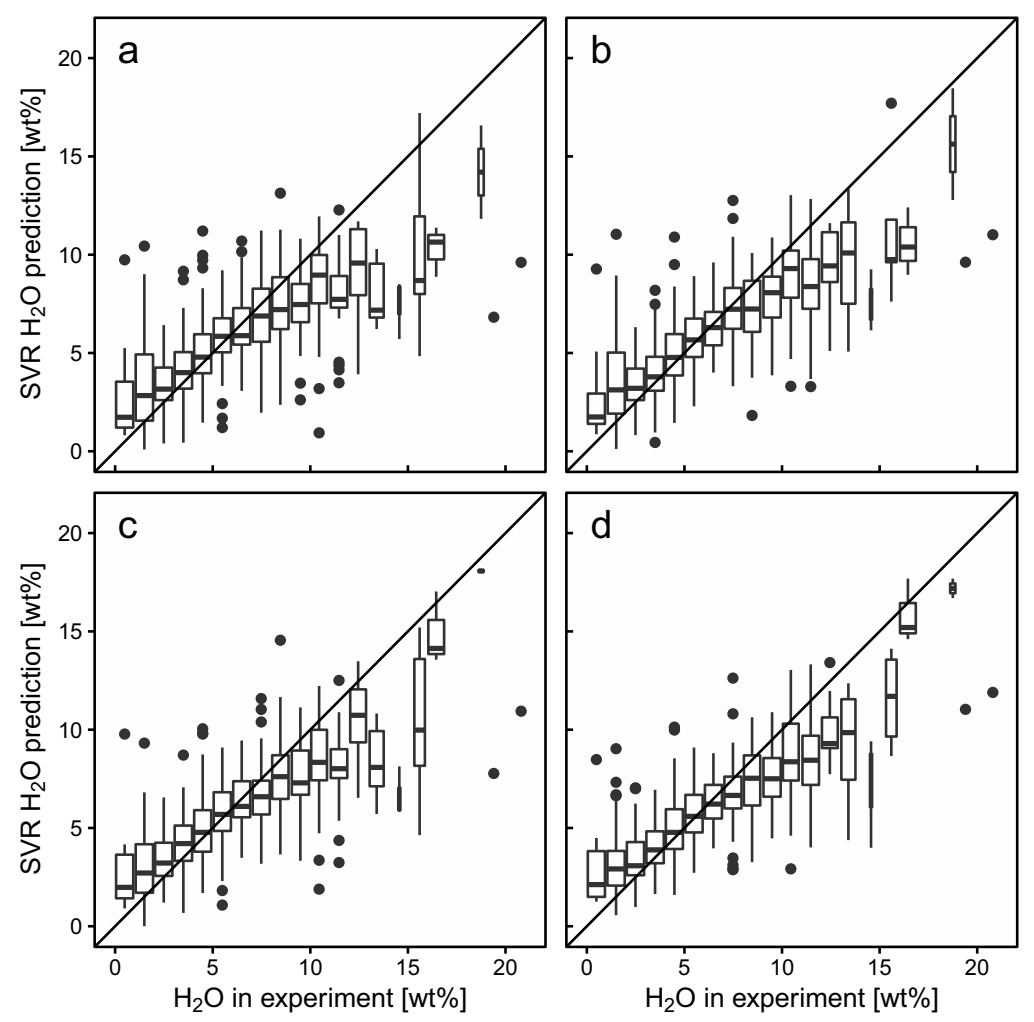

Figure 5.6: Box plots comparing estimated with recorded $\mathrm{H}_{2} \mathrm{O}$. The box width is $\leq 1 \mathrm{wt} \%$. a: $\mathrm{H}_{2} \mathrm{O}$ estimate based on major element composition. b: $\mathrm{H}_{2} \mathrm{O}$ estimate based on temperature and major element composition. c: $\mathrm{H}_{2} \mathrm{O}$ estimate based on pressure and major element composition. d: $\mathrm{H}_{2} \mathrm{O}$ estimate based on temperature, pressure and major element composition.

a reduction of the overall scatter (fig. 5.6d). However, low $\mathrm{H}_{2} \mathrm{O}$ contents are still overestimated 
and $\mathrm{H}_{2} \mathrm{O}$ above $7 \mathrm{wt} \%$ underestimated. Again, over- and underestimates cancel each other out resulting in a mean underestimation of $-0.15 \mathrm{wt} \%$ with a RMSE of $2.14 \mathrm{wt} \%$. The $\mathrm{R}^{2}$ is 0.61 .

As for pressure, the estimate of $\mathrm{H}_{2} \mathrm{O}$ dissolved works only roughly with a high uncertainty and bias. Complicating the estimate is the systematic offset that low contents are overestimated and high contents are underestimated. This leads to the situation in which the whiskers of the $1 \mathrm{wt} \%$ and the $15 \mathrm{wt} \%$ box overlap. Even though $\mathrm{H}_{2} \mathrm{O}$ contents in between these values are better constrained, especially the poor estimates on high $\mathrm{H}_{2} \mathrm{O}$ contents will cast uncertainty on any lower $\mathrm{H}_{2} \mathrm{O}$ estimate, when applied to natural samples.

A possible reason for the poor estimate is that $\mathrm{H}_{2} \mathrm{O}$ dissolved in the experimental melts are not well enough constrained, even though they were checked by mass balance. Another explanation might be that $\mathrm{H}_{2} \mathrm{O}$ simply can not be that well constrained by the parameters used. The major element features influenced by $\mathrm{H}_{2} \mathrm{O}$ might be superimposed by other factors as the diversity of starting compositions for the experiments. An example for that is the $\mathrm{K}_{2} \mathrm{O} / \mathrm{Na}_{2} \mathrm{O}$ ratio. At high $\mathrm{H}_{2} \mathrm{O}$ content the crystallisation of plagioclase is suppressed which results in a nearly constant ratio through a differentiation sequence (chapter 4). At low $\mathrm{H}_{2} \mathrm{O}$ concentrations the ratio would rise with differentiation. However, when the source of the melt is already rich in $\mathrm{K}_{2} \mathrm{O}$, the model cannot tell the difference, as information about the source are not included. This will bias the model.

In section 5.8 the $\mathrm{H}_{2} \mathrm{O}$ estimation is further discussed in respect to the individual studies contributing to the database.

\subsubsection{Interdependent T-P- $\mathrm{H}_{2} \mathrm{O}$ estimate}

In a next step the three individual models for temperature, pressure and $\mathrm{H}_{2} \mathrm{O}$ are combined, so that the only input parameters are major elements. As for the individual models, I use a $\mathrm{k}$-fold cross validation with $75 \%$ training and $25 \%$ test data. The calculation process though is different. For each sample three matrices are created based on the extend of the dataset:

(i) a temperature calculation matrix ranging from 0 to $3.5 \mathrm{GPa}$ by $0.25 \mathrm{GPa}$ increments and 0 to 20 wt $\% \mathrm{H}_{2} \mathrm{O}$ with $1 \mathrm{wt} \%$ increments;

(ii) a pressure calculation matrix ranging from 700 to $1350{ }^{\circ} \mathrm{C}$ by $25{ }^{\circ} \mathrm{C}$ increments and 0 to $20 \mathrm{wt} \% \mathrm{H}_{2} \mathrm{O}$ by $1 \mathrm{wt} \%$ increments;

(iii) a $\mathrm{H}_{2} \mathrm{O}$ calculation matrix ranging from 700 to $1350{ }^{\circ} \mathrm{C}$ by $25^{\circ} \mathrm{C}$ increments and 0 to 3.5 GPa by $0.25 \mathrm{GPa}$ increments.

Subsequently, values for each element in the matrices are calculated and stored as a three column data frames. The intersection of the three data frames in the T-P- $\mathrm{H}_{2} \mathrm{O}$ space is calculated via an euclidean distance nearest neighbour search matchpt of the $R$ package Biobase (Huber et al., 2015). The function is limited to finding the nearest neighbour of 2 matrices, wherefore it was run multiple times to define the nearest neighbour of the three 
matrices and an average intersect was calculated. Due to the computational intensive code, the number of iterations was decreased to 1000 . The results of the T-P- $\mathrm{H}_{2} \mathrm{O}$ estimate are displayed in fig. 5.7 and table 5.1.

There is a significant overestimation of temperatures below $900{ }^{\circ} \mathrm{C}$ and a slight underestima-
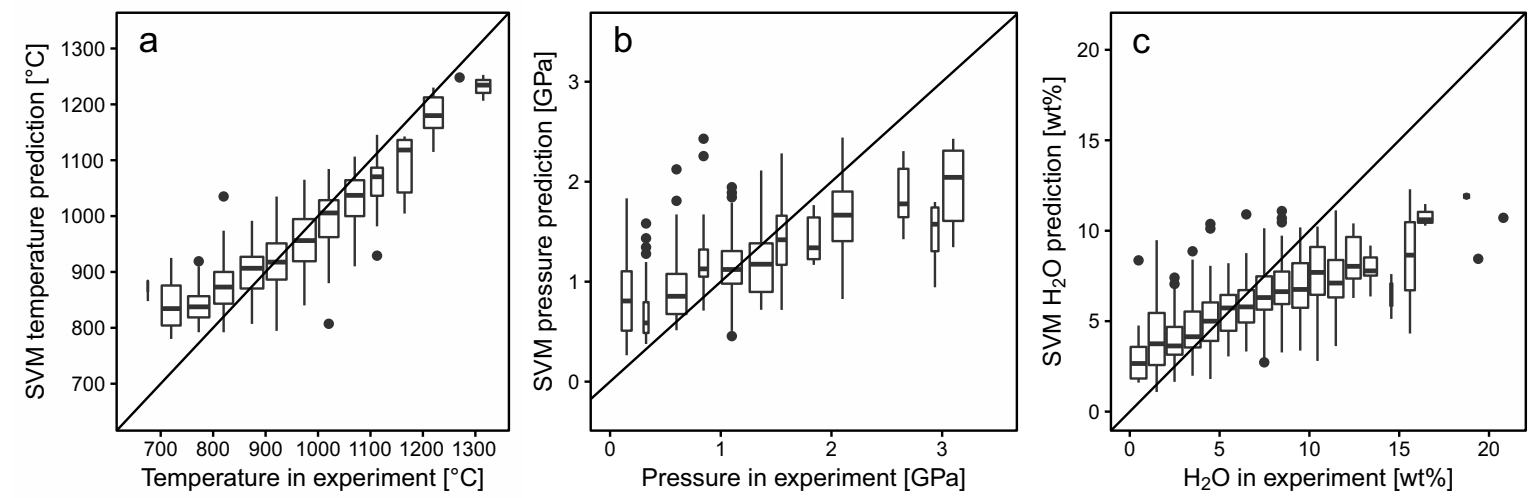

Figure 5.7: Boxplots for temperature (a), pressure (b) and $\mathrm{H}_{2} \mathrm{O}(\mathbf{c})$ estimates based on the interdependent model.

tion of temperatures above $1000{ }^{\circ} \mathrm{C}$ (fig. 5.7a). The model performs worse than the previous predictions (fig. 5.4) having a $\mathrm{R}^{2}$ of 0.65 . On average the temperature is overestimated by $19.3^{\circ} \mathrm{C}$ with a RMSE of $59.0^{\circ} \mathrm{C}$. The estimation of pressure (fig. $5.7 \mathrm{~b}$ ) is worse as well. $\mathrm{R}^{2}$ is decreased to 0.46 . Pressure conditions below 1.0 GPa are overestimated and pressure above 1.5 GPa is underestimated. On average the pressure is overestimated by $0.14 \mathrm{GPa}$ and has a RMSE of $0.5 \mathrm{GPa} . \mathrm{H}_{2} \mathrm{O}$ estimates are also inferior to the predictions displayed in fig. 5.6. $\mathrm{R}^{2}$ is $0.40 . \mathrm{H}_{2} \mathrm{O}$ concentrations below $5 \mathrm{wt} \%$ are overestimated and concentrations above $5 \mathrm{wt} \%$ are underestimated. On average, $\mathrm{H}_{2} \mathrm{O}$ is underestimated by $-0.30 \mathrm{wt} \%$ with an RMSE of 2.89 . The results show that the model does not work satisfactorily. It is not possible to extract information about pressure and $\mathrm{H}_{2} \mathrm{O}$ conditions from the model. However, temperatures above $900{ }^{\circ} \mathrm{C}$ are acceptably well described, though worse than the model using major elements only. As already discussed, the poor performance of the model might be due to poor constraints on $\mathrm{H}_{2} \mathrm{O}$ in the dataset, which biases the estimates on temperature and pressure. As a feedback loop, this worsens the estimate for $\mathrm{H}_{2} \mathrm{O}$. The underestimation of high $\mathrm{H}_{2} \mathrm{O}$ content is reflected in the overestimation of low temperatures.

However, this can not be sole reason, as the temperature prediction that includes determined $\mathrm{H}_{2} \mathrm{O}$ and pressure (fig. 5.4b) works well. It could be a systematic problem of the model, that uncertainties are too large to use three unconstrained parameters to iteratively define each other.

\subsection{Application to Archean TTGs}

I apply different models to the same filtered dataset TTG as used in chapter 3. First, only the liquidus temperature based on major elements and different $\mathrm{H}_{2} \mathrm{O}$ contents is estimated. 
$\mathrm{H}_{2} \mathrm{O}$ and pressure can not be estimated based on major elements due to identified weaknesses of the respective models (section 5.5.3 \& 5.5.4). Secondly, temperature, pressure and $\mathrm{H}_{2} \mathrm{O}$ are estimated via the interdependent model and thirdly, pressure and $\mathrm{H}_{2} \mathrm{O}$ are estimated for Ti saturated liquidus temperatures from chapter 3.

The TTG dataset comprises the data compilations of Moyen (2011) and Johnson et al. (2019), and further data from Nutman et al. (1999), Laurent et al. (2014) and O'Neil and Carlson (2017). The dataset is filtered for tonalitic, trondhjemitic and granodioritic compositions based on the feldspar diagram of O'Connor (1965). Furthermore samples are discarded if they have $\mathrm{La}<10, \mathrm{Yb}>2$ and an Eu-anomaly below 0.9 or above 1.1. To ensure that the TTGs are within the compositional range of the used experiments, I compare them in appendix fig. 5.16 via harker diagrams. Most TTGs plot well within the range of experimental melt compositions, however there are 12 samples that stand out by their high $\mathrm{MgO}$ content (fig. 5.16c). I remove them as they are most likely cumulates. This results in 345 out of 1860 samples. This filtering effort assures that only samples that could have been a magmatic liquid are considered for the model. A portion of TTGs might be at least partially affected by accumulation of plagioclase and amphiboles as described by Laurent et al. (2020) for samples from the Barberton.

The first model applied to TTGs is the temperature estimation solely based on the major element composition. This results in temperatures between $800-1100{ }^{\circ} \mathrm{C}$ with the majority of samples between 900 and $1000{ }^{\circ} \mathrm{C}$ (fig. 5.8). Statistical parameters of the model results and subsequent temperature estimate models are displayed in table 5.2.

Table 5.2: Statistical indices of the temperature distribution of TTGs from fig. 5.8 estimated by the models displayed in fig. 5.4a and fig. 5.4c.

\begin{tabular}{lcccccc}
\hline $\mathrm{H}_{2} \mathrm{O}$ [wt\%] & min. & $1^{\text {st }}$ qn. & median & mean & $3^{\text {rd }}$ qn. & max. \\
\hline- & 774 & 921 & 952 & 948 & 979 & 1122 \\
4 & 834 & 967 & 990 & 990 & 1014 & 1119 \\
8 & 774 & 905 & 950 & 948 & 988 & 1097 \\
12 & 705 & 827 & 882 & 882 & 936 & 1093 \\
\hline
\end{tabular}

In a second step I estimate the temperature with the model based on $\mathrm{H}_{2} \mathrm{O}$ and the major element composition, which is displayed in fig. 5.8. Since $\mathrm{H}_{2} \mathrm{O}$ is not constrained I select a range of water contents based on the liquidus temperature calculations from the Ti solubility study in chapter 3. There the amount of water dissolved in the melt was defined as 8-12 wt\%. Additionally I select $4 \mathrm{wt} \% \mathrm{H}_{2} \mathrm{O}$ to see if the model performs as expected. With 4 wt $\% \mathrm{H}_{2} \mathrm{O}$ present TTG liquidus temperatures are estimated to be between 900 and $1100{ }^{\circ} \mathrm{C}$, with most samples between 950 and $1050{ }^{\circ} \mathrm{C}$. At $8 \mathrm{wt} \% \mathrm{H}_{2} \mathrm{O}$ present, the estimated temperatures are between 800 and $1100{ }^{\circ} \mathrm{C}$ with approximately half of the samples between 900 and $1000{ }^{\circ} \mathrm{C}$. With $12 \mathrm{wt} \% \mathrm{H}_{2} \mathrm{O}$ the estimated temperatures are between 700 and $1100{ }^{\circ} \mathrm{C}$. More than half of the samples have temperatures between 800 and $950{ }^{\circ} \mathrm{C}$. As expected there is a decrease in 


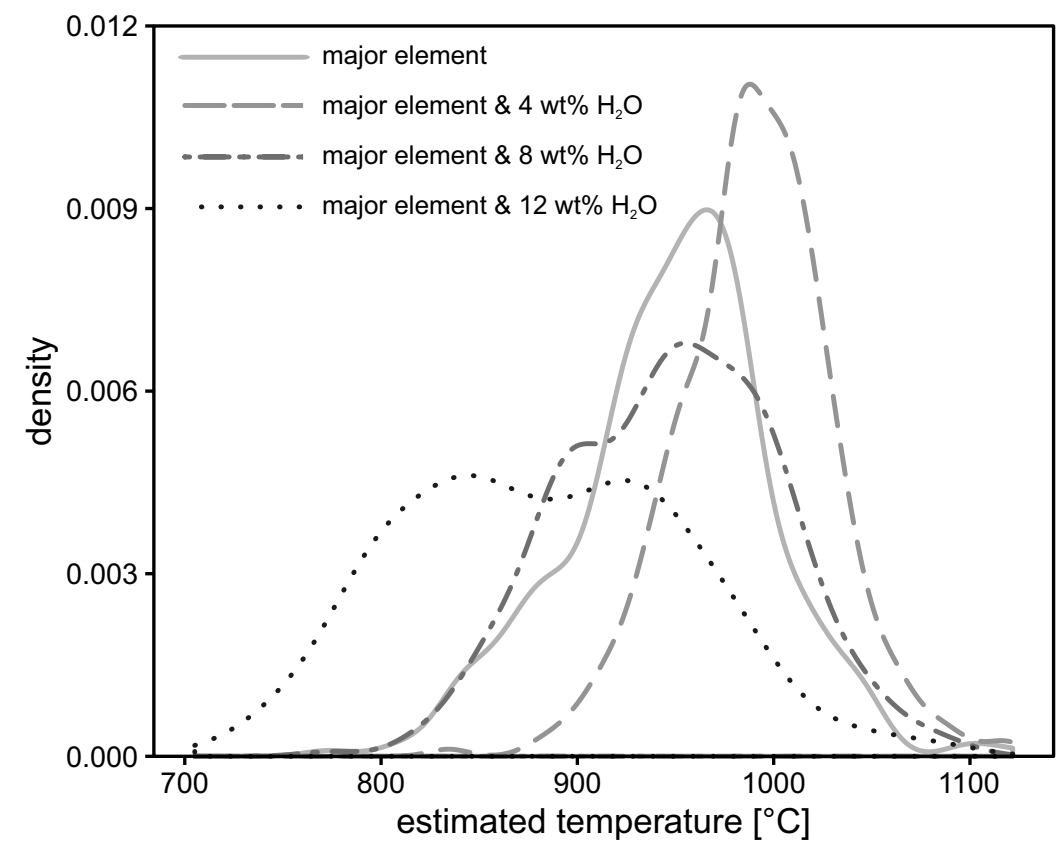

Figure 5.8: Temperature estimate distribution for natural TTGs (Nutman et al., 1999; Moyen, 2011; Laurent et al., 2014; O'Neil and Carlson, 2017; Johnson et al., 2019) calculated with the models displayed in fig. 5.4a and fig. 5.4c. The $\mathrm{H}_{2} \mathrm{O}$ dependend model is set with fixed values of 4,8 and $12 \mathrm{wt} \% \mathrm{H}_{2} \mathrm{O}$.

temperature with increasing $\mathrm{H}_{2} \mathrm{O}$ content, however the interval of temperatures also widens. A few high temperature samples only decrease marginal as displayed in table 5.2. Furthermore a trend to a bimodal distribution with increasing $\mathrm{H}_{2} \mathrm{O}$ content is observable, which might be an artefact of the model. A possible explanation is the conflict of high $\mathrm{H}_{2} \mathrm{O}$ and high $\mathrm{MgO}$ content, a combination that is outside the calibration range of the model (appendix fig. 5.17). The model without a $\mathrm{H}_{2} \mathrm{O}$ input and the model with 8 wt $\% \mathrm{H}_{2} \mathrm{O}$ have similar distributions. As both model calibrations perform similar (fig. 5.4a and c, 5.1) it is reasonable to assume that the amount of $\mathrm{H}_{2} \mathrm{O}$ in TTGs was around $8 \mathrm{wt} \%$ and the temperature range for the majority of TTGs around $850-1050{ }^{\circ} \mathrm{C}$. This temperature range is in good agreement with TTG liquid producing experiments (Rapp and Watson, 1995; Winther, 1996; Skjerlie and Patiño Douce, 2002; Adam et al., 2012; Laurie and Stevens, 2012; Hastie et al., 2016). The models also reflect the internal differentiation of TTGs, spanning over more than $15 \mathrm{wt} \%$ $\mathrm{SiO}_{2}$ by returning a temperature interval of $300-400{ }^{\circ} \mathrm{C}$ (table 5.2). However, without any further constraints on conditions, the informative value of these calculations regarding the formation conditions of TTGs remains limited as the temperature span can be arbitrarily shifted depending on the assumed $\mathrm{H}_{2} \mathrm{O}$ content.

\subsubsection{T-P- $\mathrm{H}_{2} \mathrm{O}$ estimate for TTGs with the interdependent model}

Even though the performance of the interdependent model is weak and biased (section 5.5.5) I apply the natural TTG compositions to the model. The results are displayed in fig. 5.9 as 
histograms. The temperature estimates (fig. 5.9a) lie between $750-1125{ }^{\circ} \mathrm{C}$, with a majority between 900 and $1050{ }^{\circ} \mathrm{C}$. Temperatures in the low range might be overestimated as it is for experimental data in section 5.5.5.

The results of the pressure estimates (fig. 5.9b) show a bimodal distribution for the pressure. The first peak is at $1.2 \mathrm{GPa}$ and the second at $1.8 \mathrm{GPa}$. Pressure estimates range from 0.7 to $3.2 \mathrm{GPa}$. A peculiar result is the occurrence of the high pressure results because the cross validation of experimental data (fig. 5.7b) returned a strong underestimation in this range without any estimates greater than 2.5 GPa.

The results for $\mathrm{H}_{2} \mathrm{O}$ (fig. 5.9c) are almost a Gaussian distribution around 8 wt\%, with a total range from 2 to $13 \mathrm{wt} \%$. This range is unambiguously a reflection of the model calibration (fig. 5.7c) that strongly underestimates $\mathrm{H}_{2} \mathrm{O}$ contents above $10 \mathrm{wt} \%$, and overestimates $\mathrm{H}_{2} \mathrm{O}$ below $5 \mathrm{wt} \%$.

The generally low $\mathrm{H}_{2} \mathrm{O}$ contents most likely causes the high temperature range, that is comparable to the ranges calculated for $4,8 \mathrm{wt} \%$ and independently of $\mathrm{H}_{2} \mathrm{O}$ (fig. 5.8 and table 5.2). A P-T diagram of the estimated results (fig. 5.9d) shows a positive correlation of pressure and temperature, quite similar to the one of the experimental data used for calibration (fig. 5.2). The error bars for temperature and pressure are the RMSE, as calculated by cross validation $\left(63.2{ }^{\circ} \mathrm{C}\right.$ and $0.493 \mathrm{GPa}$, table 5.1$) . \mathrm{H}_{2} \mathrm{O}$ shows an expected behaviour with low concentration at high temperatures and high concentration at low temperatures. There is only a weak or no correlation of estimated pressure and pressure sensitive trace element ratios (fig. $5.9 \mathrm{e}$ and f) supporting the previous suggestion that pressure estimates are strongly biased.

As expected from the cross validation results, the interdependent model does not work sufficiently well and therefore the results calculated here do not have any real significance.

\subsection{2 $\mathrm{H}_{2} \mathrm{O}$ and pressure estimate for Ti saturated liquidus temperatures}

Solely using the calibrated models, it is not possible to state anything definite about the formation conditions of TTGs as the temperature shifts with $\mathrm{H}_{2} \mathrm{O}$ and the interdependent model does not work sufficiently. However, in chapter 3 we independently calculated $\mathrm{Ti}$ saturated liquidus temperatures for TTGs which can be compared to the results of this study (fig. 5.10). The Ti saturation temperatures of potentially saturated TTGs $\left(750-900{ }^{\circ} \mathrm{C}\right)$ match the temperature estimates by choosing a $\mathrm{H}_{2} \mathrm{O}$ content between 8-14 wt\% for the model. This is slightly higher than the $\mathrm{H}_{2} \mathrm{O}$ in chapter $3\left(8-12 \mathrm{wt} \% \mathrm{H}_{2} \mathrm{O}\right.$ ) based upon graphical comparison of Ti saturated experiments and TTGs. The Ti study has a different methodology and database, that marginally overlaps with the database used here, but results in similar $\mathrm{H}_{2} \mathrm{O}$ estimates for Ti saturated liquidus temperatures of TTGs.

Furthermore, I use the Ti temperatures as an input for a $\mathrm{H}_{2} \mathrm{O}$ estimate using the calibration comprising temperature and major elements (fig. 5.6b). The resulting distribution of $\mathrm{H}_{2} \mathrm{O}$ content required for the samples to be at the liquidus is displayed in fig. 5.11a. It ranges from 

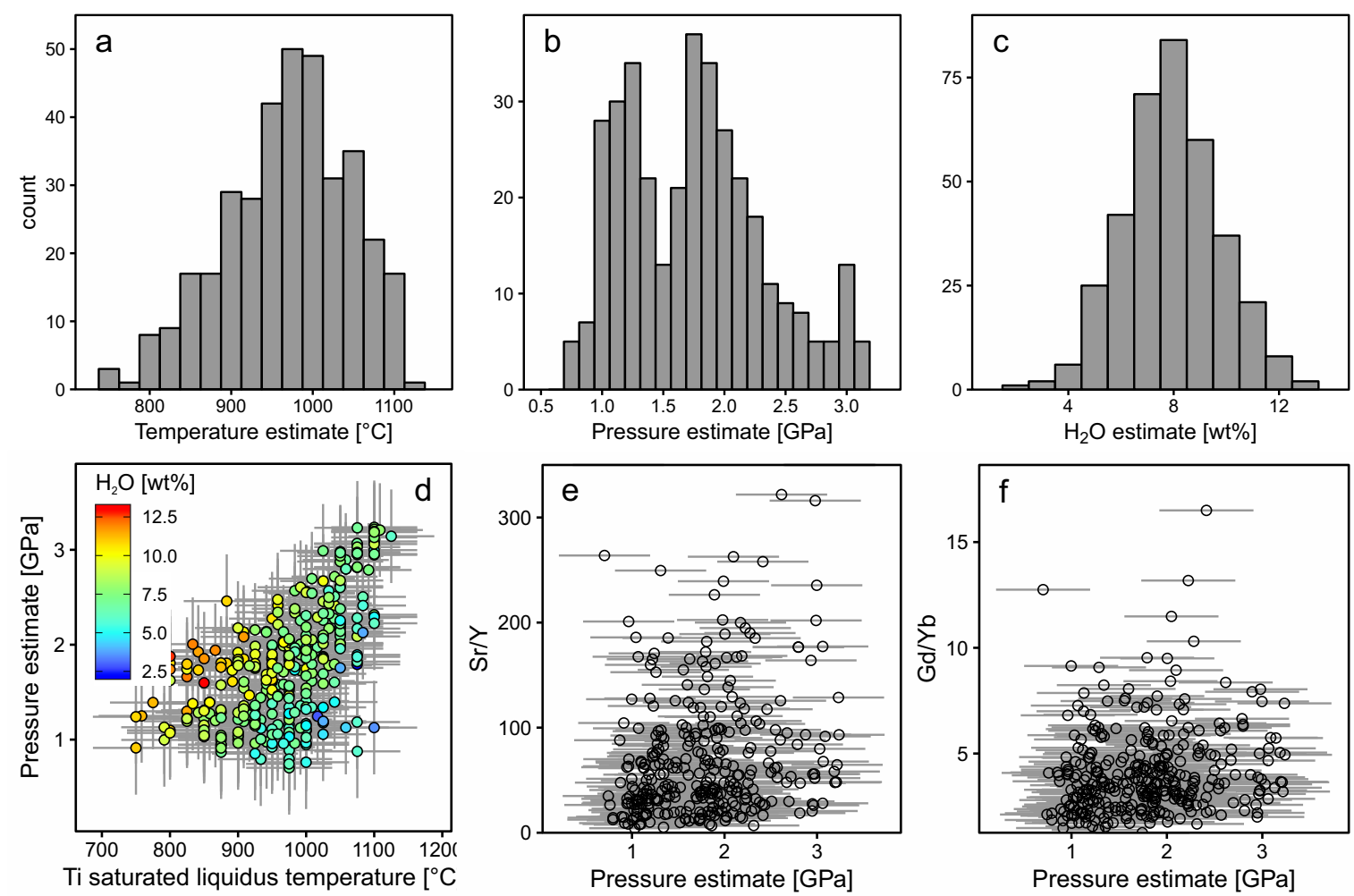

Figure 5.9: Result plots of the interdependent T-P-H2O model applied to natural TTGs (Nutman et al., 1999; Moyen, 2011; Laurent et al., 2014; O'Neil and Carlson, 2017; Johnson et al., 2019): a: Temperature results. b: Pressure results. c: $\mathrm{H}_{2} \mathrm{O}$ results. d: P-T diagram combining the estimates on pressure temperature and $\mathrm{H}_{2} \mathrm{O}$ content. The error bars represent the RMSE of the model calibration (5.1). e: Gd/Yb ratio of natural TTGs plotted against the estimated pressure. f: $\mathrm{Sr} / \mathrm{Y}$ ratio of natural TTGs plotted against the estimated pressure.

3-17 wt\% with the majority of samples in between 9 and $12 \mathrm{wt} \%$. However, this prediction needs to be set into context of the model bias, resulting in an underestimation of elevated $\mathrm{H}_{2} \mathrm{O}$ contents.

As for $\mathrm{H}_{2} \mathrm{O}$, we can estimate pressure based on Ti temperatures and major elements. The results cover a range of 0.5-2.1 GPa with the majority of TTGs within 1.0-1.5 GPa (fig. 5.11b). In context of the model bias (fig. 5.5b) high pressure might be underestimated.

With pressure, temperature and $\mathrm{H}_{2} \mathrm{O}$ given, a P-T diagram can be constructed (fig. 5.11c). The temperature error bars are the $11 \% 1 \sigma$ uncertainty of the Ti saturation model. Error bars for pressure where calculated accounting for the $11 \%$ input temperature uncertainty and the RMSE of $0.364 \mathrm{GPa}$ (table 5.1) of the model itself. On average, the error bars extend to $0.84 \mathrm{GPa}$. There is an issue with a few samples, especially the high temperature samples predictions. They plot at the verge or even outside of their error bars, which hints towards an over-determination of the model in these regions.

The P-T diagram reveals a slight negative correlation of pressure and temperature, exactly the opposite as the results of the interdependent estimates (fig. $5.9 \mathrm{~d}$ ). $\mathrm{H}_{2} \mathrm{O}$ behaves as expected 

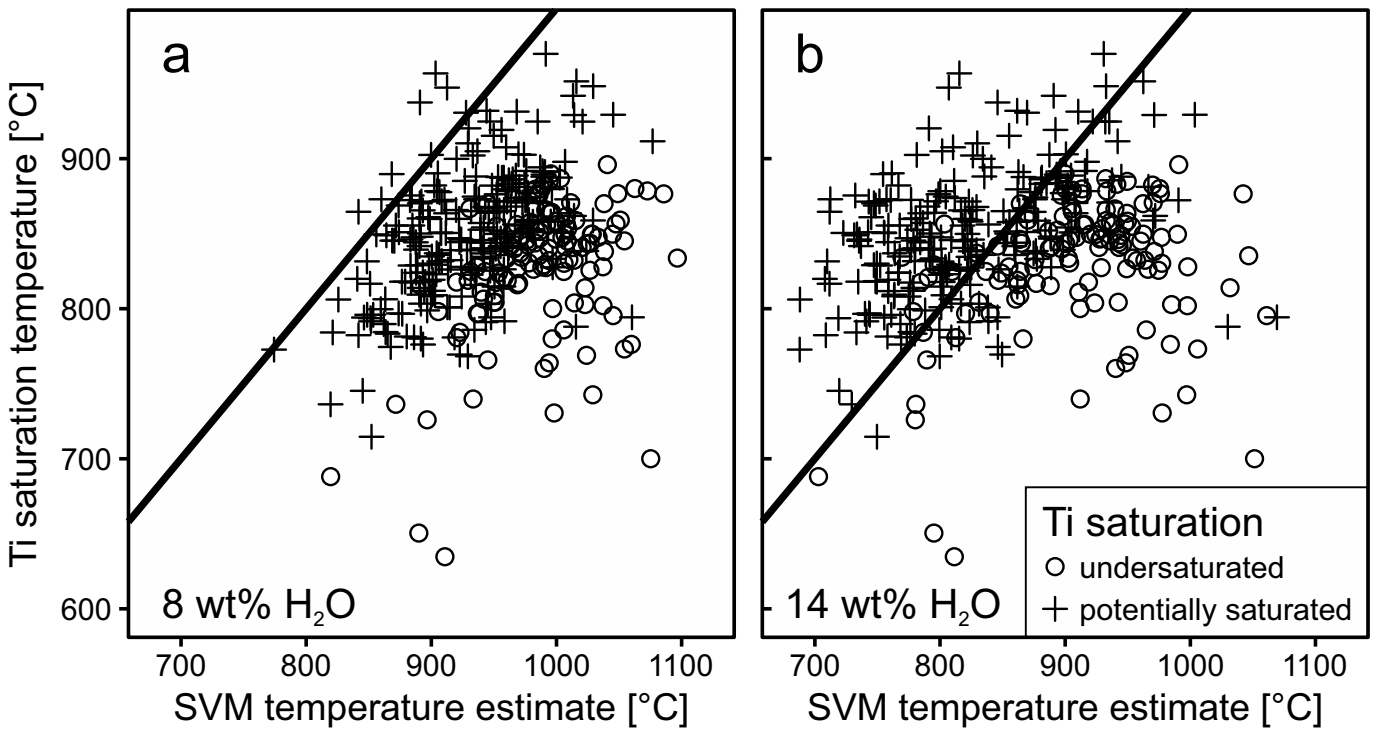

Figure 5.10: SVM based TTG temperature estimate calculated for different $\mathrm{H}_{2} \mathrm{O}$ contents $(\mathbf{a}=$ $8 \mathrm{wt} \%, \mathbf{b}=14 \mathrm{wt} \%$ ) compared with Ti saturation temperatatures (chapter 3) for natural TTGs (Nutman et al., 1999; Moyen, 2011; Laurent et al., 2014; O'Neil and Carlson, 2017; Johnson et al., 2019). The black line as a 1:1 slope.

in regard to temperature and there is a positive correlation with pressure, accounting for the increased solubility even though pressure and $\mathrm{H}_{2} \mathrm{O}$ were estimated independently.

It remains uncertain if the estimated pressures have any real significance, even though there are slight positive correlations of pressure estimates and pressure sensitive trace element ratios (fig. 5.11d, e). Even in case of a correct estimate, the uncertainty of the estimates are extremely high with almost $0.5 \mathrm{GPa}$. The estimated $\mathrm{H}_{2} \mathrm{O}$ content is more reliable than pressure, especially due to the overlapping in estimation with results from chapter 3 . This amount of water favours the presence of a fluid during melting as suggested by Laurie and Stevens (2012), Kleinhanns et al. (2003) and in chapter 3. 

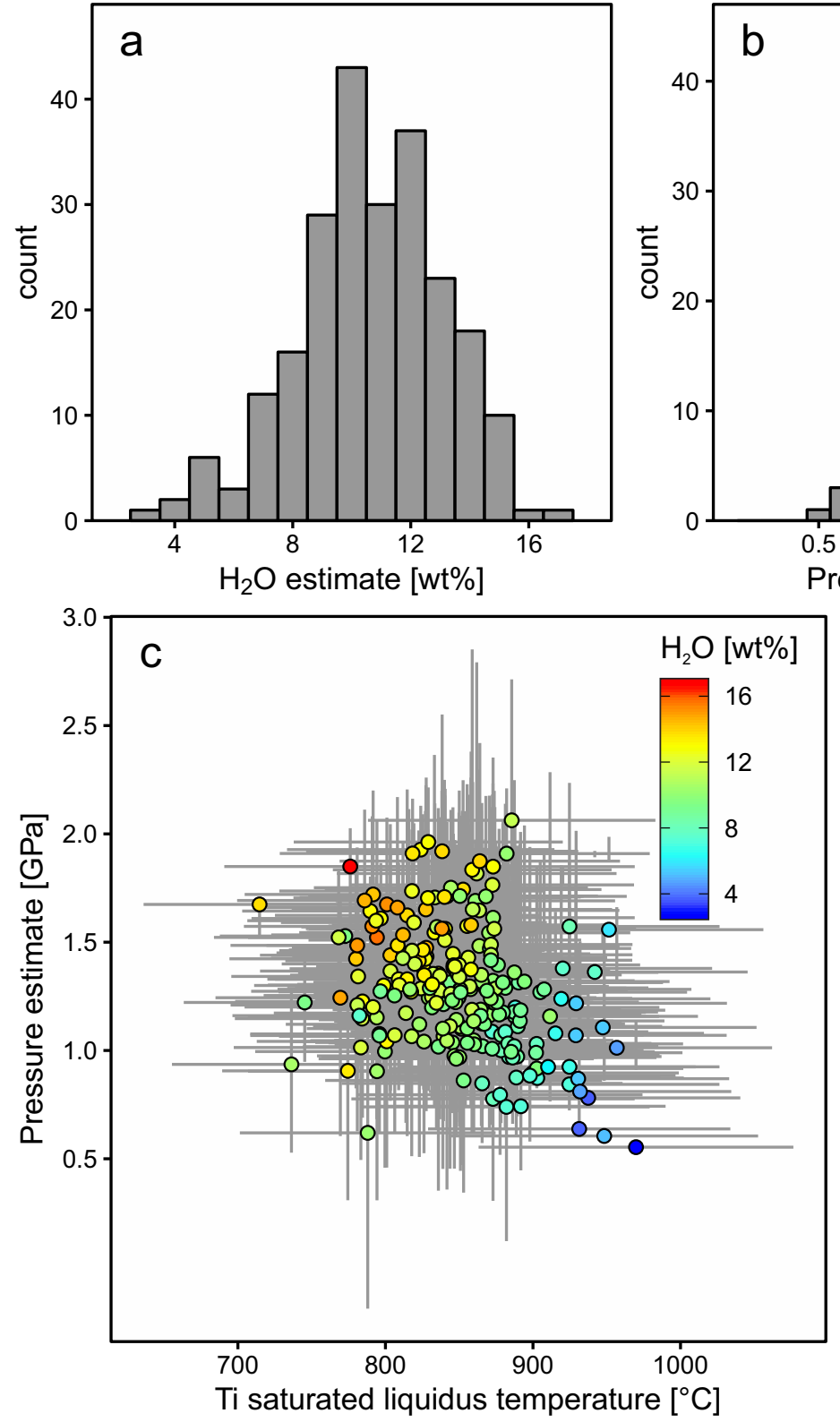
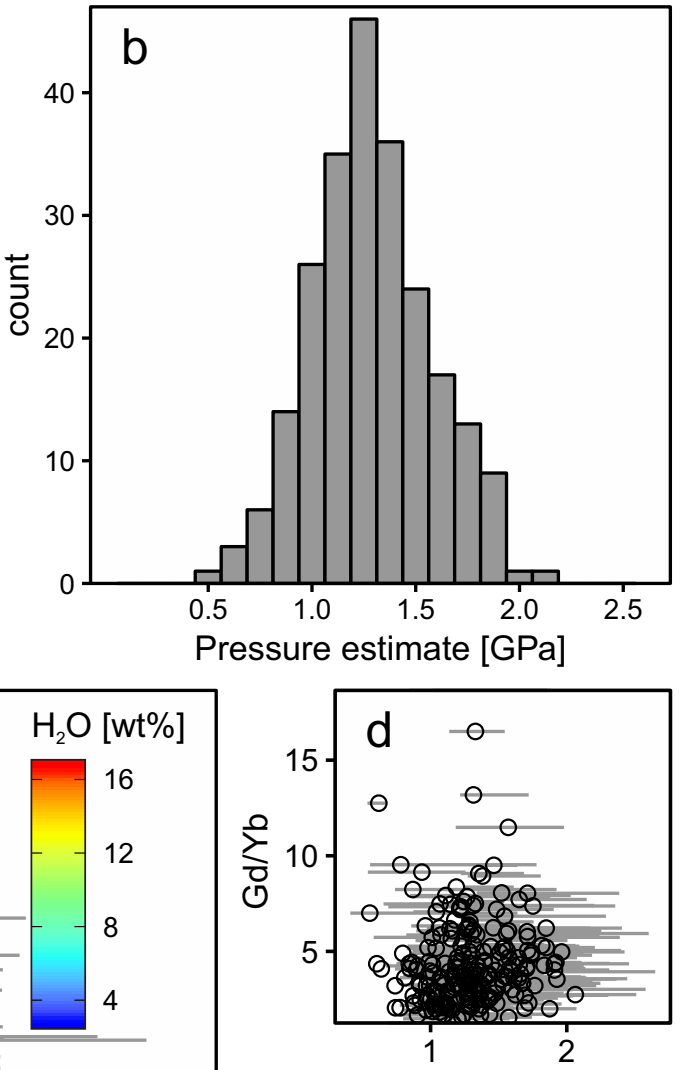

Pressure estimate [GPa]

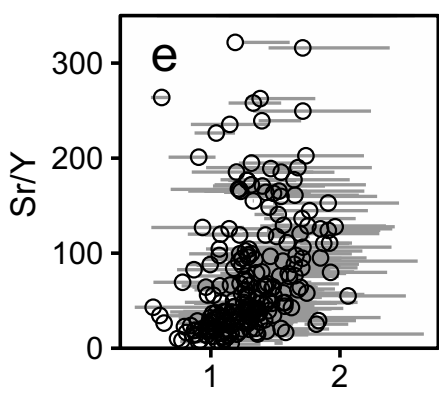

Pressure estimate [GPa]

Figure 5.11: a: $\mathrm{H}_{2} \mathrm{O}$ content of melts estimated for the Ti saturated liquidus temperature (chapter 3) of natural TTGs (Nutman et al., 1999; Moyen, 2011; Laurent et al., 2014; O'Neil and Carlson, 2017; Johnson et al., 2019). b: Pressure estimate for TTGs at the Ti saturated liquidus based on temperatures (chapter 3) and major elements. c: P-T diagram for the Ti saturated liquidus of TTGs based on temperatures from (chapter 3). Pressure and $\mathrm{H}_{2} \mathrm{O}$ are estimated as displayed in fig. 5.11a \& b. Temperature error bars are based on $11 \% 1 \sigma$ uncertainty of the Ti temperatures (chapter 3.) Pressure error bars are based on the pressure RMSE of 0.328 and the $11 \% 1 \sigma$ interval for temperature. $\mathbf{d}$ : Gd/Yb ratio of natural TTGs plotted against the pressure estimate of fig. 5.11c. Error bars are the same as in fig. 5.11c. e: Sr/Y ratio of natural TTGs plotted against the pressure estimate of fig. 5.11b. Error bars are the same as in fig. 5.11c 


\subsection{Summary and conclusions}

The calibration of a statistical model based on a SVR algorithm to predict temperature, pressure and $\mathrm{H}_{2} \mathrm{O}$ dissolved in the melt at liquidus conditions using a large database of hydrous melting experiments results in several models that each bear their own benefits and limitations. The objective to calibrate an interdependent model that accounts for the three unconstrained parameters simultaneously could not be achieved due to an artificial correlation of temperature and pressure in the experimental dataset, uncertainty in the $\mathrm{H}_{2} \mathrm{O}$ content of the experimental glasses and a masking of the influence of pressure and $\mathrm{H}_{2} \mathrm{O}$ on major element composition due to the diversity of starting materials. Therefore, the application of the model to TTGs solely based on their major element composition does not result in reasonable or reliable estimates.

Applying only a major element dependent temperature estimate on TTGs returns a temperature span with most samples being in between 850-1050 ${ }^{\circ} \mathrm{C} . \mathrm{A} \mathrm{H}_{2} \mathrm{O}$ dependent temperature estimate using $8 \mathrm{wt} \%$ set as input parameter results in a very similar distribution. Therefore $850-1050{ }^{\circ} \mathrm{C}$ with approximately $8 \mathrm{wt} \% \mathrm{H}_{2} \mathrm{O}$ present is the most reasonable output of the model for TTG formation temperatures.

Using Ti saturated liquidus temperatures for TTGs as an input parameter allows the usage of pressure and $\mathrm{H}_{2} \mathrm{O}$ prediction models that return reasonable results for $\mathrm{H}_{2} \mathrm{O}$ with most samples between 9-12 wt\%, in good agreement with previous findings. The pressure estimates between 0.5-2.0 GPa are realistic, but there is a large uncertainty and flaws of the model prohibit further conclusions. However, the elevated amount of $\mathrm{H}_{2} \mathrm{O}$ favours the presence of a free fluid during TTG melt formation, hence a convergent, subduction-like setting. 


\subsection{Appendix}

Figure 5.12 displays the mean temperature deviations grouped by publication to evaluate the consistency of experimental data in between different studies. For the temperature estimate, the model comprising pressure, $\mathrm{H}_{2} \mathrm{O}$ and major elements is used (fig. 5.4d). The broad majority of studies plot within the RMSE of the model, irrespective of the number of experiments used from the studies. It is apparent that studies with many experiments (e.g. Beard and Lofgren, $1991 \mathrm{n}=85$ ) influence the model stronger than studies with lesser experiments. Despite this, small studies like Skjerlie and Patiño Douce (1995) ( $\mathrm{n}=3$ ), Getsinger et al. (2009) $(n=6)$ or Laurie and Stevens $(2012)(n=6)$ are consistent with the rest of the data. However there is data that is inconsistent with the majority, which can be seen by the median of a study being outside of the RMSE range as for Skjerlie and Johnston (1993) and Springer and Seck (1997), or by broad whiskers and outliers (Rapp et al., 1991). Excluding individual mismatching experiments or studies does not improve the model. It reduces the amount of data, the model changes and in doing so produces other outliers or mismatching studies.

Figure 5.13 displays the mean pressure deviation grouped by publication to evaluate the consistency of experimental data in between different studies. The model used for the pressure estimate comprises temperature, $\mathrm{H}_{2} \mathrm{O}$ and major elements (fig. 5.5d). As for temperature (fig. 5.12), most studies are consistent within the dataset and only few differ significantly in their average pressure estimate. The study of Hastie et al. (2016) strongly diverges from the rest of the data and experiments of Rapp and Watson (1995) deviate strongly towards over and underestimation. The number of samples that individual studies contribute does not influence the consistency with studies of low sample size being in good alignment (Skjerlie and Johnston, 1992; Wolf and Wyllie, 1994; Skjerlie and Patiño Douce, 1995; Getsinger et al., 2009; Laurie and Stevens, 2012).

Figure 5.14 displays the mean $\mathrm{H}_{2} \mathrm{O}$ deviation grouped by publication to evaluate the consistency of experimental data in between different studies. The model used for the $\mathrm{H}_{2} \mathrm{O}$ estimate comprises temperature, pressure and major elements (fig. 5.6d). The majority of studies are consistent with three studies having their median outside of the 1 RMSE range (Wolf and Wyllie, 1994; Castro et al., 1999; García-Arias et al., 2012). There are more outliers present than for temperature and pressure (fig. 5.12 and ??), indicating the difficulties in constraining an accurate $\mathrm{H}_{2} \mathrm{O}$ content in experimental glasses. The consistency of a study is independent of the number of experiments it contributes to the model. Studies only comprising a few experiments are well predicted (Vielzeuf and Holloway, 1988; Skjerlie and Johnston, 1992; Gardien et al., 1995; Pickering and Johnston, 1998). 
Adam et al. 2012

Alonso-Perez et al., 2009

Beard and Lofgren, 1991

Castro et al., 1999

Castro et al., 2000

Conrad et al., 1988

García-Arias et al., 2012

Gardien et al., 1995

Gardien et al., 2000

Getsinger et al. 2009

Grant, 2004

Hastie et al. 2016

Holtz and Johannes, 1991

Koester et al., 2002

Laurie and Stevens, 2012

Patiño Douce and Beard, 1996

Patiño Douce and Harris, 1998

Patiño Douce and Johnston, 1991 Patiño Douce, 2005

Patiño Douce \& Beard 1995

Pickering and Johnston, 1998

Qian and Hermann, 2013

Rapp and Watson, 1995

Rapp et al., 1991

Sen and Dunn, 1994

Sisson et al., 2005

Skjerlie and Johnston, 1992

Skjerlie and Johnston, 1993

Skjerlie and Johnston, 1996

Skjerlie and Patiño Douce, 1995

Skjerlie et al., 1993

Spicer et al., 2004

Springer and Seck, 1997

Ulmer et al. 2018

Vielzeuf \& Montel,1994

Vielzeuf and Holloway, 1988

Winther et al., 1996

Wolf and Wyllie 1994

Xiong et al., 2005

\section{Temperature deviation $\left[{ }^{\circ} \mathrm{C}\right]$}

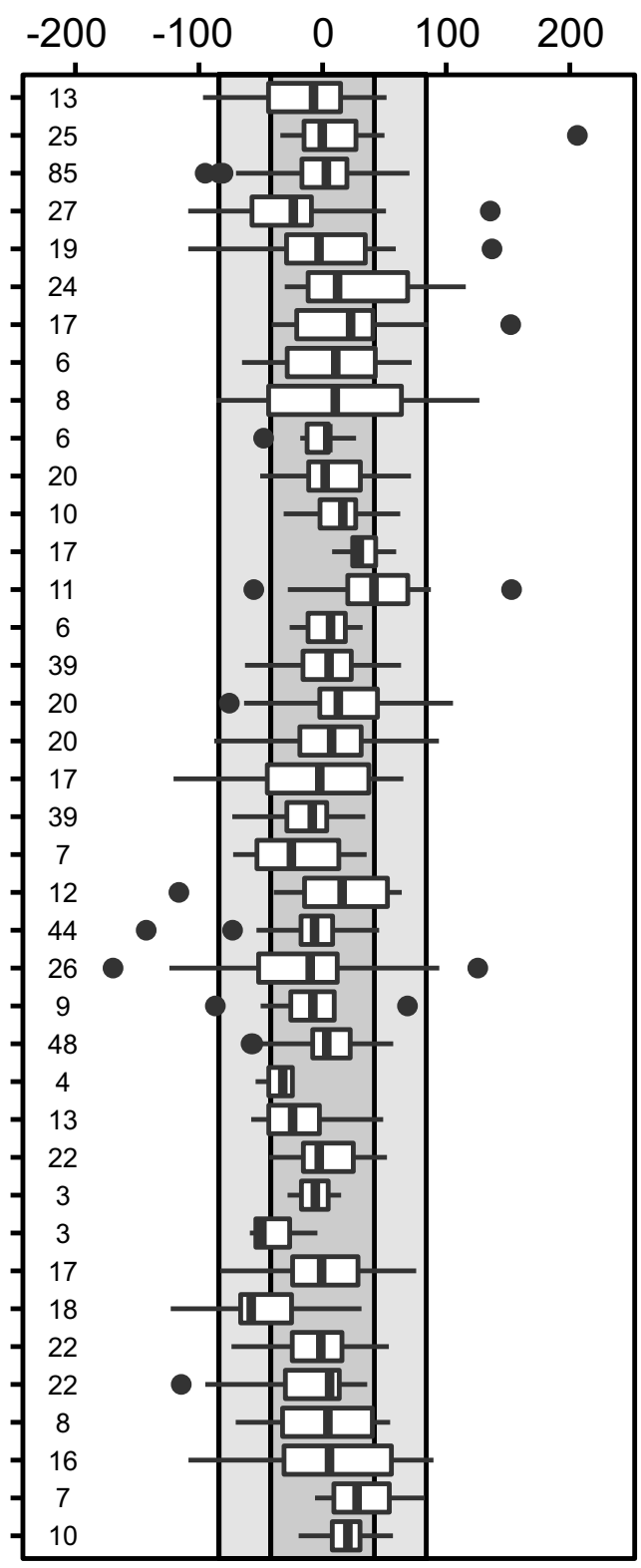

Figure 5.12: Box plot of temperature deviation based on the model estimating temperature by pressure, $\mathrm{H}_{2} \mathrm{O}$ and major elements (fig. $5.4 \mathrm{~d}$ ) with the results sorted by their studies. Leftside of the diagram the count of experiments from the respective study is displayed. The shaded areas represent the RMSE and $2^{*} \mathrm{RMSE}$ of the model (table 5.1). 
Adam et al. 2012

Alonso-Perez et al., 2009

Beard and Lofgren, 1991

Castro et al., 1999

Castro et al., 2000

Conrad et al., 1988

García-Arias et al., 2012

Gardien et al., 1995

Gardien et al., 2000

Getsinger et al. 2009

Grant, 2004

Hastie et al. 2016

Holtz and Johannes, 1991

Koester et al., 2002

Laurie and Stevens, 2012

Patiño Douce and Beard, 1996

Patiño Douce and Harris, 1998

Pressure deviation [GPa]

Patiño Douce and Johnston, 1991

Patiño Douce, 2005

Patiño Douce \& Beard 1995

Pickering and Johnston, 1998

Qian and Hermann, 2013

Rapp and Watson, 1995

Rapp et al., 1991

Sen and Dunn, 1994

Sisson et al., 2005

Skjerlie and Johnston, 1992

Skjerlie and Johnston, 1993

Skjerlie and Johnston, 1996

Skjerlie and Patiño Douce, 1995

Skjerlie et al., 1993

Spicer et al., 2004

Springer and Seck, 1997

Ulmer et al. 2018

Vielzeuf \& Montel,1994

Vielzeuf and Holloway, 1988

Winther et al., 1996

Wolf and Wyllie 1994

Xiong et al., 2005

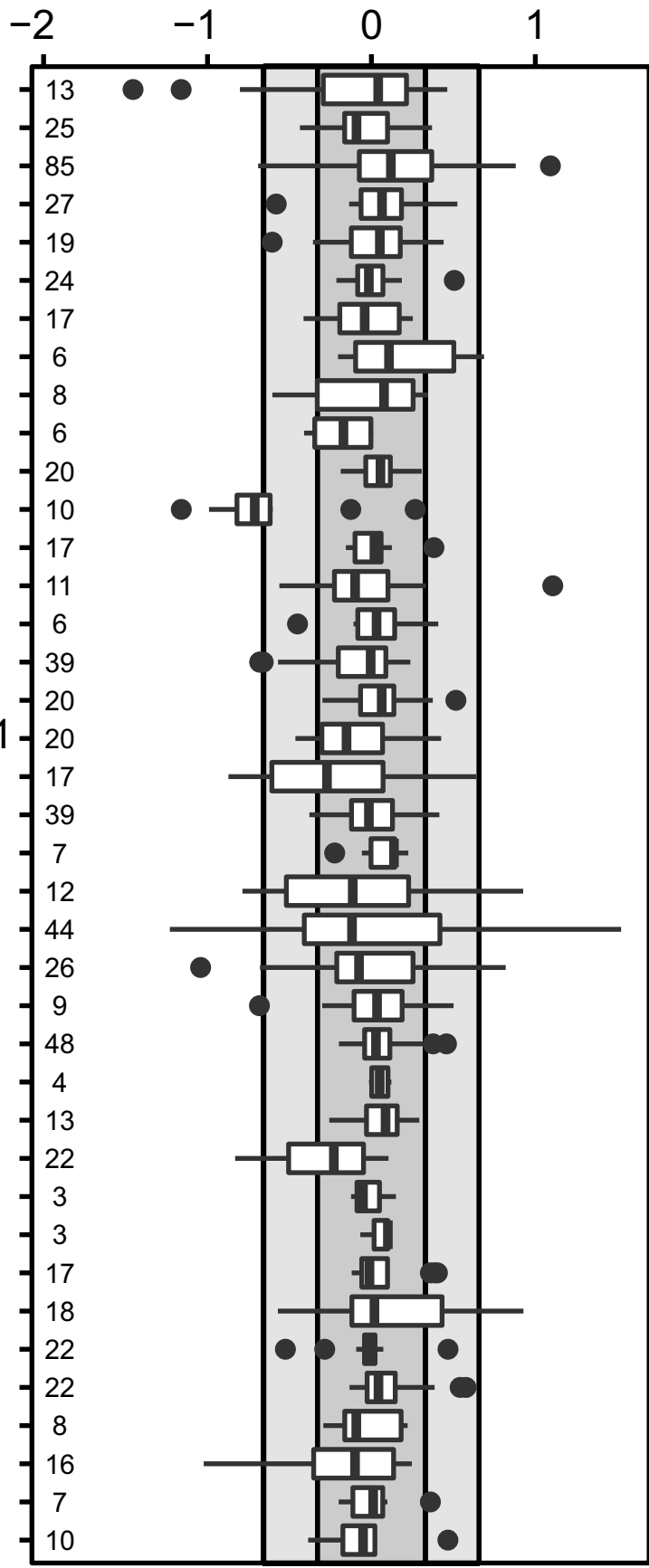

Figure 5.13: Box plot of pressure deviation based on the model estimating pressure by temperature, $\mathrm{H}_{2} \mathrm{O}$ and major elements (fig. 5.5d) with the results sorted by their studies. Leftside of the diagram the count of experiments from the respective study is displayed. The shaded areas represent the RMSE and $2 *$ RMSE of the model (table 5.1). 
Adam et al. 2012 Alonso-Perez et al., 2009 Beard and Lofgren, 1991

Castro et al., 1999

Castro et al., 2000

Conrad et al., 1988

García-Arias et al., 2012

Gardien et al., 1995

Gardien et al., 2000

Getsinger et al. 2009 Grant, 2004

Hastie et al. 2016

Holtz and Johannes, 1991

Koester et al., 2002

Laurie and Stevens, 2012

Patiño Douce and Beard, 1996

Patiño Douce and Harris, 1998

Patiño Douce and Johnston, 1991

Patiño Douce, 2005

Patiño Douce \& Beard 1995

Pickering and Johnston, 1998

Qian and Hermann, 2013

Rapp and Watson, 1995

Rapp et al., 1991

Sen and Dunn, 1994

Sisson et al., 2005

Skjerlie and Johnston, 1992

Skjerlie and Johnston, 1993

Skjerlie and Johnston, 1996

Skjerlie and Patiño Douce, 1995

Skjerlie et al., 1993

Spicer et al., 2004

Springer and Seck, 1997

Ulmer et al. 2018

Vielzeuf \& Montel,1994

Vielzeuf and Holloway, 1988

Winther et al., 1996

Wolf and Wyllie 1994

Xiong et al., 2005

$\mathrm{H}_{2} \mathrm{O}$ deviation [wt\%]

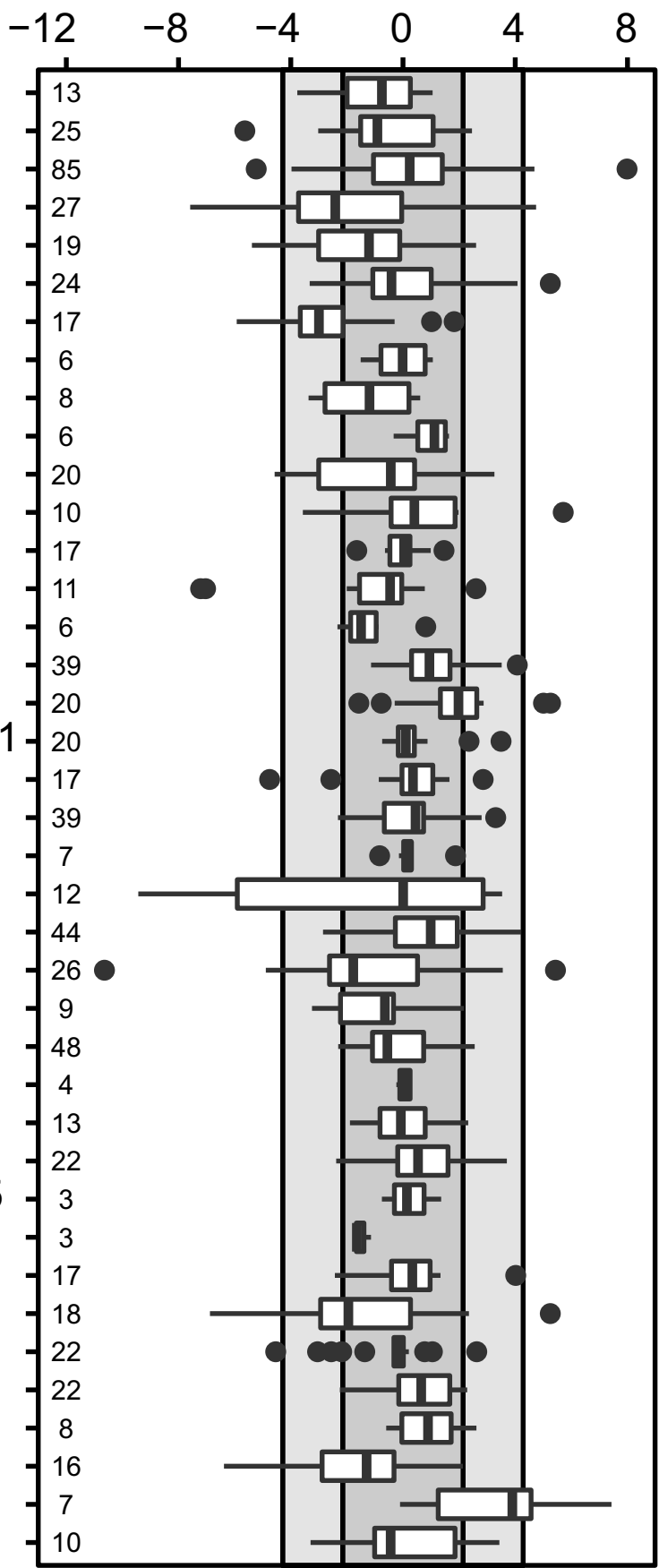

Figure 5.14: Box plot of $\mathrm{H}_{2} \mathrm{O}$ deviation based on the model estimating $\mathrm{H}_{2} \mathrm{O}$ by temperature, pressure and major elements (fig. 5.6d) with the results sorted by their studies. Left side of the diagram the count of experiments from the respective study is displayed. The shaded areas represent the RMSE and $2 *$ RMSE of the model (table 5.1). 

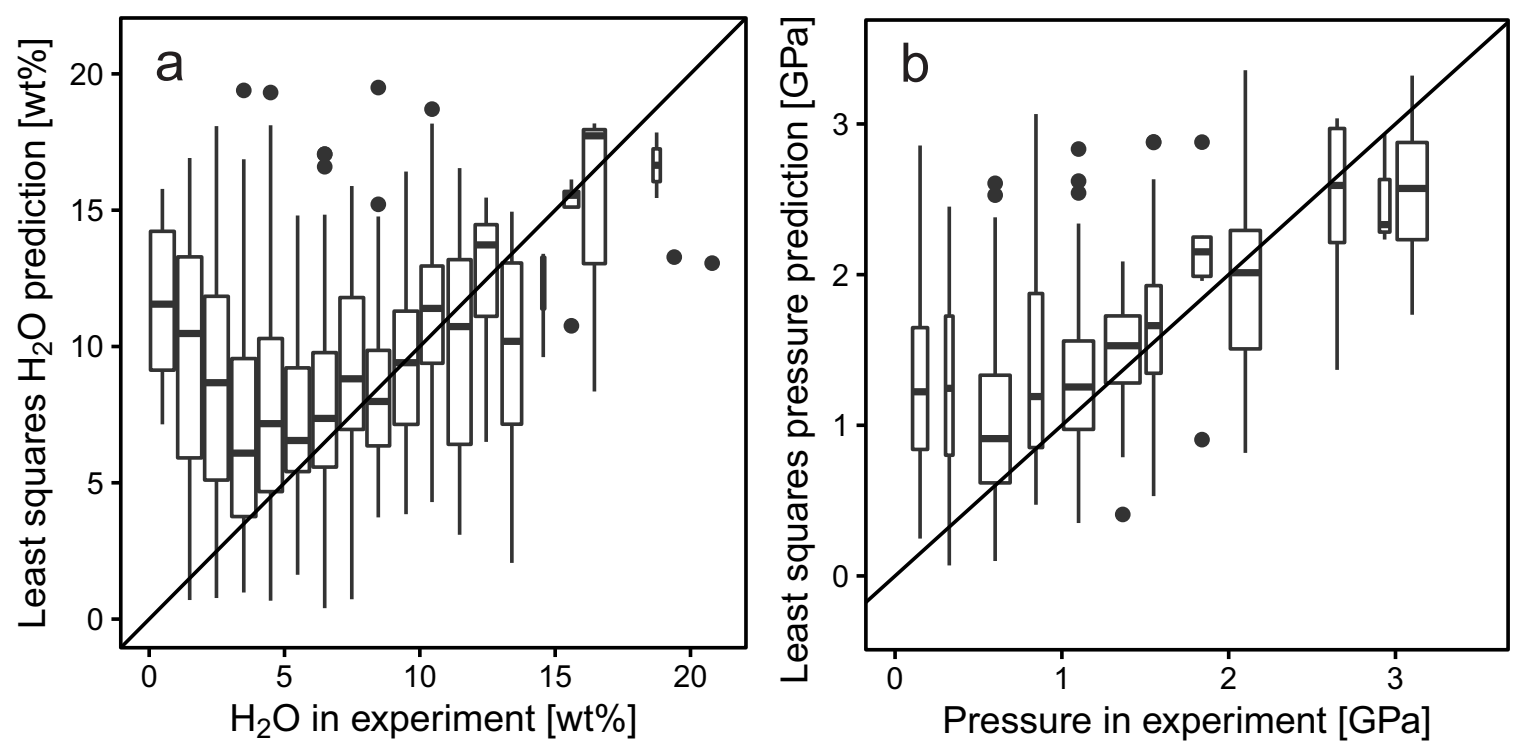

Figure 5.15: a: Evaluation of $\mathrm{H}_{2} \mathrm{O}$ prediction via least squares with the temperature estimating SVM model that depends on $\mathrm{H}_{2} \mathrm{O}$ and major elements (fig. 5.4c). $\mathrm{H}_{2} \mathrm{O}$ is varied as an input variable to minimise the difference between target and estimated temperature. The model is tested via $\mathrm{k}$-fold cross validation with 4000 iterations. The diagram is based on 707 experiments that have a difference of target- and estimated temperatures $\leq 1{ }^{\circ} \mathrm{C}$. $\mathbf{b}$ : Evaluation of pressure prediction via least squares with the temperature estimating SVR model that depends on pressure and major elements (fig. 5.4b). Pressure is varied as an input variable to minimise the difference between target and estimated temperature. The model is tested via k-fold cross validation with 4000 iterations. The diagram is based on 693 experiments that have a difference of target and estimated temperatures $\leq 1^{\circ} \mathrm{C}$. 

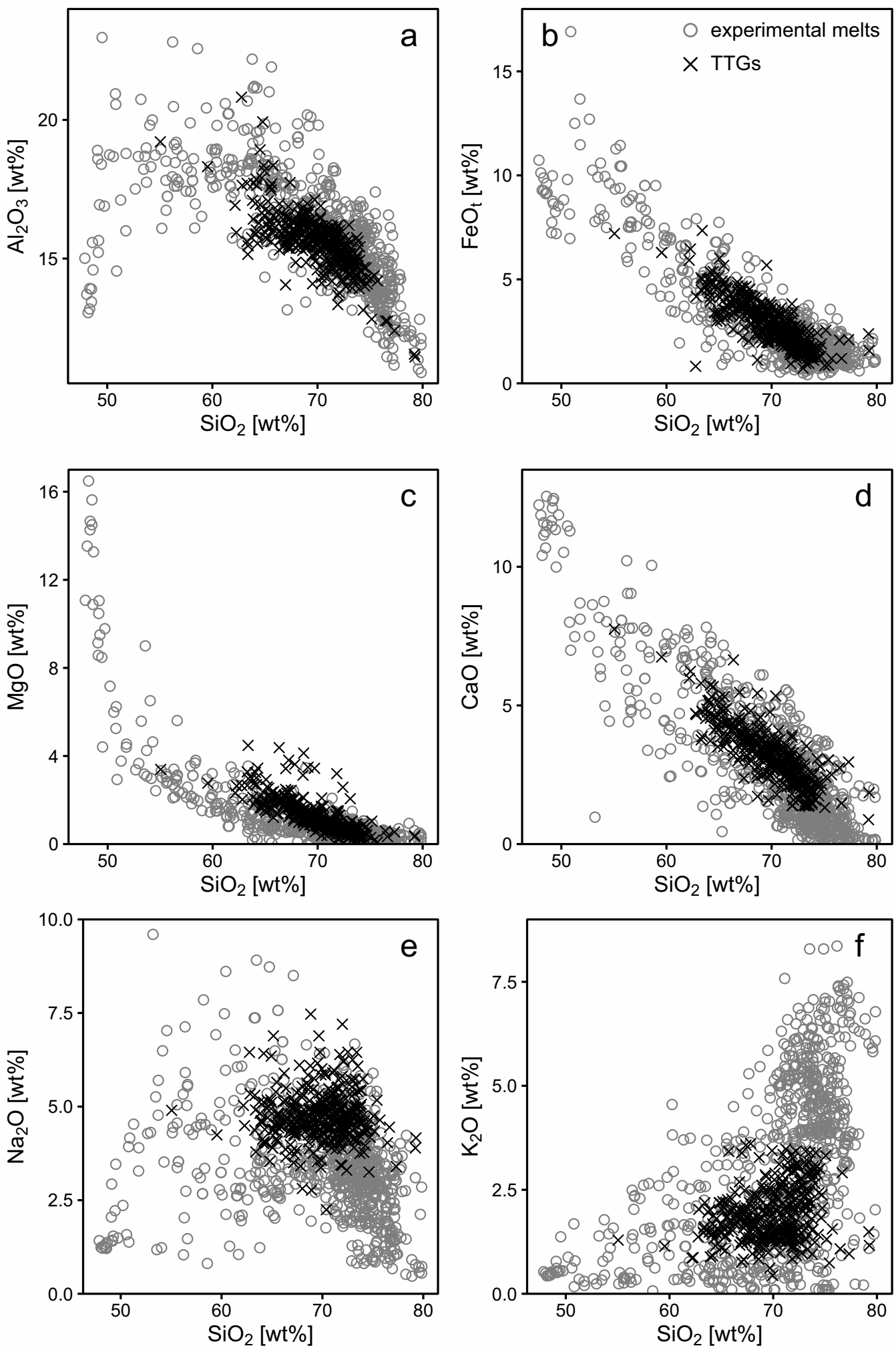

Figure 5.16: Harker diagrams displaying major elements of natural TTGs (Nutman et al., 1999; Moyen, 2011; Laurent et al., 2014; O'Neil and Carlson, 2017; Johnson et al., 2019) and the experimental glasses used for the model calibration. 


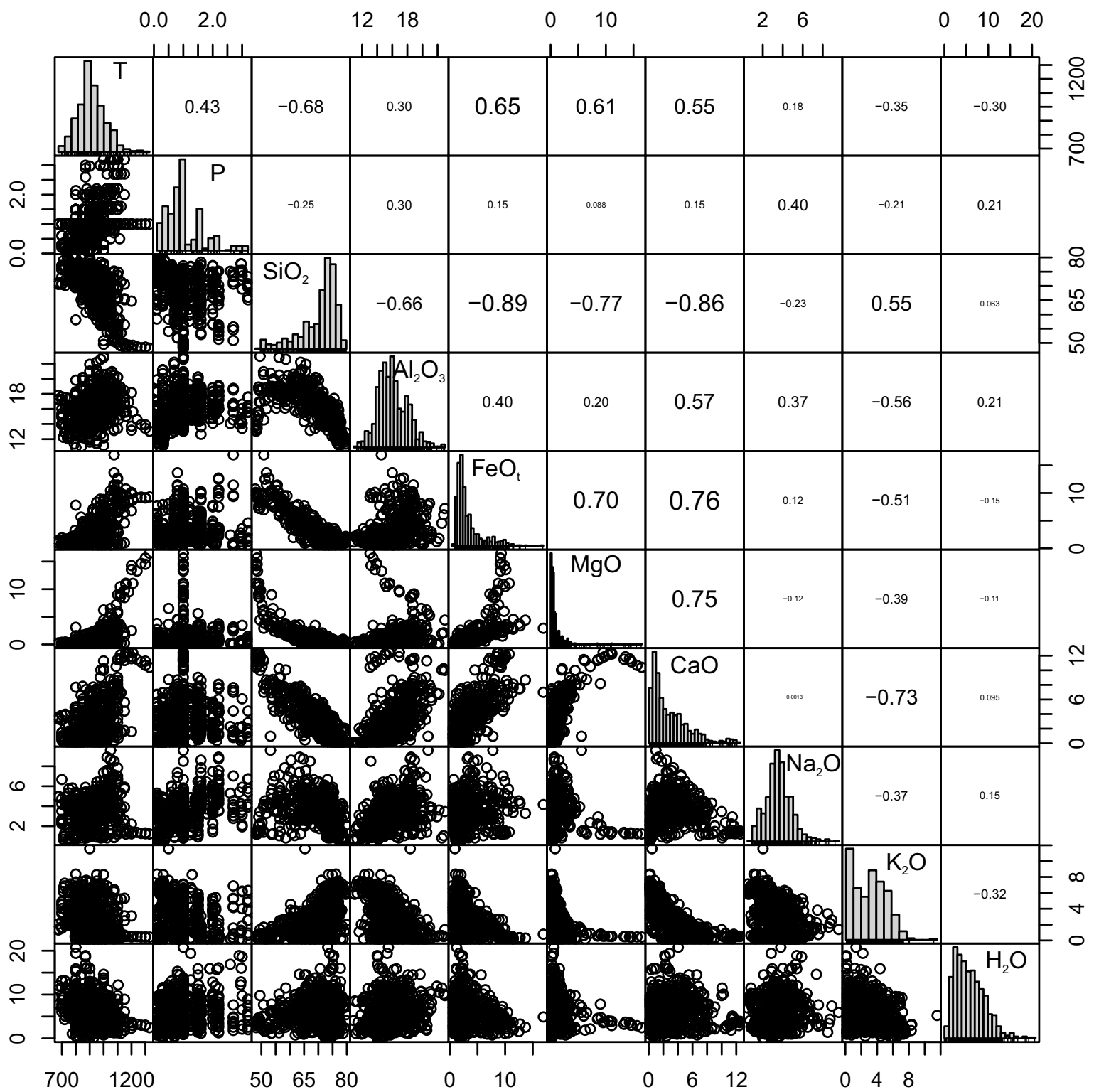

Figure 5.17: Correlation matrix for hydrous melting experiments from (Conrad et al., 1988; Vielzeuf and Holloway, 1988; Beard and Lofgren, 1991; Holtz and Johannes, 1991; Patiño Douce and Johnston, 1991; Rapp et al., 1991; Skjerlie and Johnston, 1992; Skjerlie and Johnston, 1993; Sen and Dunn, 1994; Vielzeuf and Montel, 1994; Wolf and Wyllie, 1994; Gardien et al., 1995; Patiño Douce and Beard, 1995; Rapp and Watson, 1995; Skjerlie and Patiño Douce, 1995; Patiño Douce and Beard, 1996; Skjerlie and Johnston, 1996; Winther, 1996; Springer and Seck, 1997; Patiño Douce and Harris, 1998; Pickering and Johnston, 1998; Castro et al., 1999, 2000; Gardien et al., 2000; Koester et al., 2002; Skjerlie and Patiño Douce, 2002; Grant, 2004; Spicer et al., 2004; López et al., 2005; Patiño Douce, 2005; Sisson et al., 2005; Xiong et al., 2005; Alonso-Perez et al., 2009; Getsinger et al., 2009; Adam et al., 2012; García-Arias et al., 2012; Laurie and Stevens, 2012; Qian and Hermann, 2013; Hastie et al., 2016) with recalculated $\mathrm{H}_{2} \mathrm{O}$ as shown in fig. 5.3. T is temperature in ${ }^{\circ} \mathrm{C}$ and $\mathrm{P}$ pressure in GPa. Pearson correlation coefficients are displayed in the upper right half of the matrix. The diagram was created via the $R$ package PerformanceAnalytics by Peterson and Carl (2020). 


\section{CHAPTER 6}

\section{Conclusions}

There are several aspects to consider when investigating the formation of TTGs. As discussed and shown in chapter 2, the composition of TTGs is the result of an interplay between partial melting, crystal fractionation and accumulation. Individual trace or major element ratios cannot be used to constrain processes. The $\mathrm{Sr} / \mathrm{Y}$ ratio is a great example for this as it is primarily used to constrain the depth of TTG melt formation, however is sensitive to the fractionation of hornblende and/or accumulation of plagioclase which can be constrained by the Eu-anomaly.

For TTGs that do not appear to have been affected by crystal fractionation or accumulation, I calculated Ti saturated liquidus temperatures with a Ti solubility model that I calibrated based on an extensive literature database comprising rutile and ilmenite bearing melting experiments. The critical assumption of the approach is that the selected TTGs represent primary magmatic liquids. Ti solubility is described as a function of temperature, non bridging oxygen per tetrahedra $(\mathrm{NBO} / \mathrm{T})$ and the ratio of single to doubly charged cations $(\mathrm{Na}+\mathrm{K}) /(\mathrm{Fe}+\mathrm{Mg}+\mathrm{Ca})$. Resulting temperatures are on average between 750 to $900{ }^{\circ} \mathrm{C}$. Many TTGs have temperatures that are below liquidus temperatures that would be expected based on their major element composition. Consequently these TTGs were most likely not saturated in either rutile or ilmenite during melt formation. This has an effect on the interpretation of the $\mathrm{Nb}$ depletion present in TTGs, irrespective if they could have been saturated with a $\mathrm{Ti}$ phase or not. The depletion must be either inherited from earlier processes or caused by other Ti-bearing minerals, for example amphibole or mica. The phases ilmenite and rutile might have played only a subordinate role in shaping the trace element pattern of TTGs, hence their saturation at liquidus conditions is uncertain. An implication of the low Ti saturated liquidus temperatures is that melt formation must have been hydrous with 8-12 wt\% dissolved $\mathrm{H}_{2} \mathrm{O}$ within the produced melt. At melting degrees of $20-30 \%$ this translates to a $\mathrm{H}_{2} \mathrm{O}$ content of the source rock between 2 - 4 wt\%. Hydrous low degree melting by amphibole breakdown can not account for these elevated concentrations, as the source would be either monomineralic, or a mixture of hydrous minerals which is implausible as it does not match the required TTG source composition. Hence fluid flux melting is a more realistic scenario. The requirement for high $\mathrm{H}_{2} \mathrm{O}$ contents is confirmed by the SVR based prediction model. The model estimates between 9-12 wt $\% \mathrm{H}_{2} \mathrm{O}$ required to reach Ti saturated liquidus conditions. 
In crystallisation experiments and thermodynamic modelling conducted on the Eoarchean Nuvvuagittuq granodiorite PC-103 (chapter 4), the importance of $\mathrm{H}_{2} \mathrm{O}$ is apparent for the evolution/differentiation paths of TTGs. The suppression of feldspar crystallisation under hydrous conditions ( $>5 \mathrm{wt} \%$ ) allows for crystal fractionation from tonalitic to trondhjemitic compositions by maintaining an almost constant $\mathrm{K}_{2} \mathrm{O} / \mathrm{Na}_{2} \mathrm{O}$ ratio. Under dryer conditions, the suite evolves towards granodioritic to granitic compositions by feldspar fractionation dominating the liquid line of descent. The amount of $\mathrm{H}_{2} \mathrm{O}$ present might therefore be one of the major differences compared to post-Archean magmatic systems.

A further necessity for the generation of TTG liquids is the availability of a $\mathrm{K}_{2} \mathrm{O}$ poor source.

The calibration of an interdependent T-P- $\mathrm{H}_{2} \mathrm{O}$ model was unsuccessful due to several reasons. One source of error is the dataset of experiments used to calibrate the model. Temperature and pressure have an artificial correlation, the $\mathrm{H}_{2} \mathrm{O}$ dissolved in glasses is not well constrained and the variety of starting materials overlay major element variations caused by pressure and $\mathrm{H}_{2} \mathrm{O}$. The second source of error, or limitation of the model is its inability to differentiate appropriately with these effects as it is of pure statistical nature. However, the temperature prediction based on major elements and $\mathrm{H}_{2} \mathrm{O}$ content works sufficiently. By using both models together, the most probable formation temperature of TTGs is between $850-1050{ }^{\circ} \mathrm{C}$ at approximately $8 \mathrm{wt} \% \mathrm{H}_{2} \mathrm{O}$.

In respect of the geodynamic environment in which TTGs form, a subduction-like setting is most plausible based on the investigation in this thesis. While it is not possible to directly infer a geodynamic process from the results, the constraints set by them require an elevated amount of $\mathrm{H}_{2} \mathrm{O}$. Especially the formation of trondhjemites requires more $\mathrm{H}_{2} \mathrm{O}$ than possibly provided by dehydration melting. Subduction is a convenient mechanism to transport $\mathrm{H}_{2} \mathrm{O}$ to the region of melt formation. However, where structural field relations refute a convergent setting, as in the Pilbara, $\mathrm{H}_{2} \mathrm{O}$ must have had a different source. 


\section{Bibliography}

Adam, J., T. Rushmer, J. O'Neil, and D. Francis (2012): 'Hadean greenstones from the Nuvvuagittuq fold belt and the origin of the Earth's early continental crust'. Geology, vol. 40(4): pp. 363-366 (cit. on pp. 5-9, 28, 37, 43, 45-49, 62, 86, 96, 108).

Adam, J., S. Turner, and T. Rushmer (2016): 'The genesis of silicic arc magmas in shallow crustal cold zones'. Lithos, vol. 264: pp. 472-494 (cit. on p. 82).

Allen, J. and A. Boettcher (1978): 'Amphiboles in andesite and basalt; II, Stability as a function of P-T- $f \mathrm{H}_{2} \mathrm{O}-f \mathrm{O}_{2}$ '. American Mineralogist, vol. 63(11-12): pp. 1074-1087 (cit. on p. 5).

- (1983): 'The stability of amphibole in andesite and basalt at high pressures'. American Mineralogist, vol. 68(3-4): pp. 307-314 (cit. on p. 5).

Allen, J., A. Boettcher, and G. Marland (1975): 'Amphiboles in andesite and basalt: I. Stability as a function of P-T- $f \mathrm{O}_{2}$ '. American Mineralogist, vol. 60(11-1): pp. 1069-1085 (cit. on p. 5).

Alonso-Perez, R., O. Müntener, and P. Ulmer (2009): 'Igneous garnet and amphibole fractionation in the roots of island arcs: experimental constraints on andesitic liquids'. Contributions to Mineralogy and Petrology, vol. 157(4): p. 541 (cit. on pp. 23, 40, 86, 108).

André, L., K. Abraham, A. Hofmann, L. Monin, I. C. Kleinhanns, and S. Foley (2019): 'Early continental crust generated by reworking of basalts variably silicified by seawater'. Nature Geoscience, vol. 12(9): pp. 769-773 (cit. on p. 5).

Arth, J. G. and F. Barker (1976): 'Rare-earth partitioning between hornblende and dacitic liquid and implications for the genesis of trondhjemitic-tonalitic magmas'. Geology, vol. 4(9): pp. 534-536 (cit. on p. 13).

Arth, J. G., F. Barker, Z. E. Peterman, and I. Friedman (1978): 'Geochemistry of the gabbrodiorite-tonalite-trondhjemite suite of southwest Finland and its implications for the origin of tonalitic and trondhjemitic magmas'. Journal of Petrology, vol. 19(2): pp. 289-316 (cit. on p. 45).

Beard, J. S. and G. E. Lofgren (1991): 'Dehydration melting and water-saturated melting of basaltic and andesitic greenstones and amphibolites at 1, 3, and 6. $9 \mathrm{~kb}$. Journal of Petrology, vol. 32(2): pp. 365-401 (cit. on pp. 5, 23, 40, 86, 102, 108). 
Bédard, J. H. (2003): 'Evidence for regional-scale, pluton-driven, high-grade metamorphism in the Archaean Minto Block, northern Superior Province, Canada'. The Journal of Geology, vol. 111(2): pp. 183-205 (cit. on p. 38).

- (2006a): 'A catalytic delamination-driven model for coupled genesis of Archaean crust and sub-continental lithospheric mantle'. Geochimica et Cosmochimica Acta, vol. 70(5): pp. 1188-1214 (cit. on pp. 5, 7, 8, 14, 21, 44, 45, 62, 83).

- (2006b): 'Trace element partitioning in plagioclase feldspar'. Geochimica et Cosmochimica Acta, vol. 70(14): pp. 3717-3742 (cit. on pp. 14, 15).

- (2018): 'Stagnant lids and mantle overturns: Implications for Archaean tectonics, magmagenesis, crustal growth, mantle evolution, and the start of plate tectonics'. Geoscience Frontiers, vol. 9(1): pp. 19-49 (cit. on pp. 4, 20, 21, 44).

Belousova, E., Y. Kostitsyn, W. L. Griffin, G. C. Begg, S. Y. O'Reilly, and N. J. Pearson (2010): 'The growth of the continental crust: constraints from zircon Hf-isotope data'. Lithos, vol. 119(3-4): pp. 457-466 (cit. on p. 82).

Boyd, F. and J. England (1960): 'Apparatus for phase-equilibrium measurements at pressures up to 50 kilobars and temperatures up to $1750^{\circ} \mathrm{C}$ '. Journal of Geophysical Research, vol. 65(2): pp. $741-748$ (cit. on pp. 29, 49).

Brophy, J. G. (2008): 'A study of rare earth element (REE)- $\mathrm{SiO}_{2}$ variations in felsic liquids generated by basalt fractionation and amphibolite melting: a potential test for discriminating between the two different processes'. Contributions to Mineralogy and Petrology, vol. 156(3): pp. 337-357 (cit. on p. 4).

Brown, M., T. Johnson, and N. J. Gardiner (2020): 'Plate tectonics and the Archean Earth'. Annual Review of Earth and Planetary Sciences, vol. 48 (cit. on p. 2).

Burnham, A., A. Berry, H. Halse, P. Schofield, G. Cibin, and J. Mosselmans (2015): 'The oxidation state of europium in silicate melts as a function of oxygen fugacity, composition and temperature'. Chemical Geology, vol. 411: pp. 248-259 (cit. on p. 16).

Castillo, P. (2012): 'Adakite petrogenesis'. Lithos, vol. 134: pp. 304-316 (cit. on pp. 3, 44, 83). Castro, A., L. Guillermo Corretgé, M. El-Biad, H. El-Hmidi, C. Fernández, and A. E. Patiño Douce (2000): 'Experimental constraints on Hercynian anatexis in the Iberian Massif, Spain'. Journal of Petrology, vol. 41(10): pp. 1471-1488 (cit. on pp. 86, 108).

Castro, A., A. E. Patiño Douce, L. G. Corretgé, D. Jesús, M. El-Biad, and H. El-Hmidi (1999): 'Origin of peraluminous granites and granodiorites, Iberian massif, Spain: an experimental test of granite petrogenesis'. Contributions to Mineralogy and Petrology, vol. 135(2-3): pp. 255-276 (cit. on pp. 23, 40, 86, 102, 108).

Cates, N. and S. Mojzsis (2007): 'Pre-3750 Ma supracrustal rocks from the Nuvvuagittuq supracrustal belt, northern Québec'. Earth and Planetary Science Letters, vol. 255(1-2): pp. 9-21 (cit. on p. 8).

Cawood, P. A., C. J. Hawkesworth, S. A. Pisarevsky, B. Dhuime, F. A. Capitanio, and O. Nebel (2018): 'Geological archive of the onset of plate tectonics'. Philosophical Transactions 
of the Royal Society A: Mathematical, Physical and Engineering Sciences, vol. 376(2132): p. 20170405 (cit. on p. 2).

Clemens, J. and D. Vielzeuf (1987): 'Constraints on melting and magma production in the crust'. Earth and Planetary Science Letters, vol. 86(2-4): pp. 287-306 (cit. on p. 38).

Clemens, J., L. Yearron, and G. Stevens (2006): 'Barberton (South Africa) TTG magmas: Geochemical and experimental constraints on source-rock petrology, pressure of formation and tectonic setting'. Precambrian Research, vol. 151(1-2): pp. 53-78 (cit. on p. 7).

Coldwell, B., J. Adam, T. Rushmer, and C. Macpherson (2011): 'Evolution of the East Philippine Arc: experimental constraints on magmatic phase relations and adakitic melt formation'. Contributions to Mineralogy and Petrology, vol. 162(4): p. 835 (cit. on p. 45).

Collins, W., M. Van Kranendonk, and C. Teyssier (1998): 'Partial convective overturn of Archaean crust in the east Pilbara Craton, Western Australia: driving mechanisms and tectonic implications'. Journal of Structural Geology, vol. 20(9-10): pp. 1405-1424 (cit. on pp. $3,21,44,83)$.

Condie, K. C. (1981): Archean greenstone belts. Amsterdam: Elsevier (cit. on pp. 1, 7).

- (2005): 'TTGs and adakites: are they both slab melts?' Lithos, vol. 80(1-4): pp. 33-44 (cit. on p. 21).

Conrad, W., I. Nicholls, and V. Wall (1988): 'Water-saturated and -undersaturated melting of metaluminous and peraluminous crustal compositions at $10 \mathrm{~kb}$ : Evidence for the origin of silicic magmas in the Taupo Volcanic Zone, New Zealand, and other occurrences'. Journal of Petrology, vol. 29(4): pp. 765-803 (cit. on pp. 23, 40, 86, 108).

Crow, C. and K. C. Condie (1987): 'Geochemistry and origin of late Archean volcanic rocks from the Rhenosterhoek Formation, Dominion Group, South Africa'. Precambrian research, vol. 37(3): pp. 217-229 (cit. on pp. 5, 37).

Dalpé, C. and D. R. Baker (2000): 'Experimental investigation of large-ion-lithophile-element-, high-field-strength-element-and rare-earth-element-partitioning between calcic amphibole and basaltic melt: the effects of pressure and oxygen fugacity'. Contributions to Mineralogy and Petrology, vol. 140(2): pp. 233-250 (cit. on p. 16).

David, J., L. Godin, R. Stevenson, J. O'Neil, and D. Francis (2009): 'U-Pb ages (3.8-2.7 Ga) and $\mathrm{Nd}$ isotope data from the newly identified Eoarchean Nuvvuagittuq supracrustal belt, Superior Craton, Canada'. Geological Society of America Bulletin, vol. 121(1-2): pp. 150-163 (cit. on pp. 8, 9).

Deering, C. and O. Bachmann (2010): 'Trace element indicators of crystal accumulation in silicic igneous rocks'. Earth and Planetary Science Letters, vol. 297(1-2): pp. 324-331 (cit. on p. 13).

Defant, M. and M. Drummond (1990): 'Derivation of some modern arc magmas by melting of young subducted lithosphere'. Nature, vol. 347(6294): p. 662 (cit. on p. 3). 
Dessimoz, M., O. Müntener, and P. Ulmer (2012): 'A case for hornblende dominated fractionation of arc magmas: the Chelan Complex (Washington Cascades)'. Contributions to Mineralogy and Petrology, vol. 163(4): pp. 567-589 (cit. on p. 13).

Drummond, M. S. and M. J. Defant (1990): 'A model for trondhjemite-tonalite-dacite genesis and crustal growth via slab melting: Archean to modern comparisons'. Journal of Geophysical Research: Solid Earth, vol. 95(B13): pp. 21503-21521 (cit. on p. 3).

Emmermann, R., L. Daieva, and J. Schneider (1975): 'Petrologic significance of rare earths distribution in granites'. Contributions to Mineralogy and Petrology, vol. 52(4): pp. 267-283 (cit. on p. 12).

Foley, S., M. Tiepolo, and R. Vannucci (2002): 'Growth of early continental crust controlled by melting of amphibolite in subduction zones'. Nature, vol. 417(6891): p. 837 (cit. on pp. 21,37).

Foley, S. F. (2011): 'A reappraisal of redox melting in the Earth's mantle as a function of tectonic setting and time'. Journal of Petrology, vol. 52(7-8): pp. 1363-1391 (cit. on pp. 14, $17)$.

Foley, S. F., S. Buhre, and D. E. Jacob (2003): 'Evolution of the Archaean crust by delamination and shallow subduction'. Nature, vol. 421(6920): p. 249 (cit. on p. 83).

Fulmer, E. C., O. Nebel, and W. van Westrenen (2010): 'High-precision high field strength element partitioning between garnet, amphibole and alkaline melt from Kakanui, New Zealand'. Geochimica et Cosmochimica Acta, vol. 74(9): pp. 2741-2759 (cit. on p. 13).

Gaetani, G. A., P. D. Asimow, and E. M. Stolper (2008): 'A model for rutile saturation in silicate melts with applications to eclogite partial melting in subduction zones and mantle plumes'. Earth and Planetary Science Letters, vol. 272(3-4): pp. 720-729 (cit. on pp. 23, 40).

Gao, P., Y.-F. Zheng, and Z.-F. Zhao (2016): 'Experimental melts from crustal rocks: A lithochemical constraint on granite petrogenesis'. Lithos, vol. 266: pp. 133-157 (cit. on p. 82).

García-Arias, M., L. Corretgé, and A. Castro (2012): 'Trace element behavior during partial melting of Iberian orthogneisses: An experimental study'. Chemical Geology, vol. 292: pp. 1-17 (cit. on pp. 23, 40, 86, 102, 108).

Gardien, V., A. B. Thompson, D. Grujic, and P. Ulmer (1995): 'Experimental melting of biotite + plagioclase + quartz \pm muscovite assemblages and implications for crustal melting'. Journal of Geophysical Research: Solid Earth, vol. 100(B8): pp. 15581-15591 (cit. on pp. 23, $40,86,102,108)$.

Gardien, V., A. B. Thompson, and P. Ulmer (2000): 'Melting of biotite + plagioclase + quartz gneisses: the role of $\mathrm{H}_{2} \mathrm{O}$ in the stability of amphibole'. Journal of Petrology, vol. 41(5): pp. 651-666 (cit. on pp. 86, 87, 108).

Getsinger, A., T. Rushmer, M. Jackson, and D. Baker (2009): 'Generating high Mg-numbers and chemical diversity in tonalite-trondhjemite-granodiorite (TTG) magmas during melting 
and melt segregation in the continental crust'. Journal of Petrology, vol. 50(10): pp. 19351954 (cit. on pp. 40, 86, 102, 108).

Glikson, A. (1981): 'Uniformitarian assumptions, plate tectonics and the Precambrian Earth'. Developments in Precambrian Geology. Vol. 4. Elsevier: pp. 91-104 (cit. on p. 1).

Grant, J. (2004): 'Liquid compositions from low-pressure experimental melting of pelitic rock from Morton Pass, Wyoming, USA'. Journal of Metamorphic Geology, vol. 22(2): pp. 65-78 (cit. on pp. 86, 108).

Greber, N. D., N. Dauphas, A. Bekker, M. P. Ptáček, I. N. Bindeman, and A. Hofmann (2017): 'Titanium isotopic evidence for felsic crust and plate tectonics 3.5 billion years ago'. Science, vol. 357(6357): pp. 1271-1274 (cit. on p. 20).

Green, D. (1976): 'Experimental testing of "equilibrium" partial melting of peridotite under water-saturated, high-pressure conditions'. The Canadian Mineralogist, vol. 14(3): pp. 255268 (cit. on pp. 29, 50).

Green, E., R. White, J. Diener, R. Powell, T. Holland, and R. Palin (2016): 'Activitycomposition relations for the calculation of partial melting equilibria in metabasic rocks'. Journal of Metamorphic Geology, vol. 34(9): pp. 845-869 (cit. on p. 49).

Green, T. H. (1972): 'Crystallization of calc-alkaline andesite under controlled high-pressure hydrous conditions'. Contributions to Mineralogy and Petrology, vol. 34(2): pp. 150-166 (cit. on pp. 5, 7).

Green, T. H. and J. Adam (2002): 'Pressure effect on Ti- or P-rich accessory mineral saturation in evolved granitic melts with differing $\mathrm{K}_{2} \mathrm{O} / \mathrm{Na}_{2} \mathrm{O}$ ratios'. Lithos, vol. 61(3-4): pp. 271-282 (cit. on p. 23).

Green, T. H. and N. Pearson (1986): 'Ti-rich accessory phase saturation in hydrous mafic-felsic compositions at high P, T'. Chemical Geology, vol. 54(3-4): pp. 185-201 (cit. on pp. 22, 23, 40).

Green, T. H. and A. Ringwood (1968): 'Genesis of the calc-alkaline igneous rock suite'. Contributions to Mineralogy and Petrology, vol. 18(2): pp. 105-162 (cit. on p. 5).

- (1972): 'Crystallization of garnet-bearing rhyodacite under high-pressure hydrous conditions'. Journal of the Geological Society of Australia, vol. 19(2): pp. 203-212 (cit. on p. 7).

Green, T. H., A. Ringwood, and A. Major (1966): 'Friction effects and pressure calibration in a piston-cylinder apparatus at high pressure and temperature'. Journal of Geophysical Research, vol. 71(14): pp. 3589-3594 (cit. on pp. 29, 49).

Grove, T. L., N. Chatterjee, S. W. Parman, and E. Médard (2006): 'The influence of $\mathrm{H}_{2} \mathrm{O}$ on mantle wedge melting'. Earth and Planetary Science Letters, vol. 249(1-2): pp. 74-89 (cit. on p. 3).

Guitreau, M., J. Blichert-Toft, S. J. Mojzsis, A. S. Roth, and B. Bourdon (2013): 'A legacy of Hadean silicate differentiation inferred from Hf isotopes in Eoarchean rocks of the Nuvvuagittuq supracrustal belt (Québec, Canada)'. Earth and Planetary Science Letters, vol. 362: pp. 171-181 (cit. on pp. 8, 9). 
Harrison, T. and E. Watson (1984): 'The behavior of apatite during crustal anatexis: equilibrium and kinetic considerations'. Geochimica et Cosmochimica Acta, vol. 48(7): pp. 14671477 (cit. on p. 87).

Hastie, A. R., J. G. Fitton, G. D. Bromiley, I. B. Butler, and N. W. Odling (2016): 'The origin of Earth's first continents and the onset of plate tectonics'. Geology, vol. 44(10): pp. 855-858 (cit. on pp. 2, 3, 5, 6, 20, 21, 38, 44-46, 48, 83, 86, 96, 102, 108).

Hawkesworth, C., P. A. Cawood, and B. Dhuime (2019): 'Rates of generation and growth of the continental crust'. Geoscience Frontiers, vol. 10(1): pp. 165-173 (cit. on p. 82).

Hawkesworth, C. J., B. Dhuime, A. Pietranik, P. Cawood, A. I. Kemp, and C. Storey (2010): 'The generation and evolution of the continental crust'. Journal of the Geological Society, vol. 167(2): pp. 229-248 (cit. on p. 2).

Hayden, L. and E. Watson (2007): 'Rutile saturation in hydrous siliceous melts and its bearing on Ti-thermometry of quartz and zircon'. Earth and Planetary Science Letters, vol. 258(3-4): pp. 561-568 (cit. on pp. 23-25, 40).

Hellman, P. L. and T. H. Green (1979): 'The role of sphene as an accessory phase in the high-pressure partial melting of hydrous mafic compositions'. Earth and Planetary Science Letters, vol. 42(2): pp. 191-201 (cit. on pp. 22, 87).

Hickman, A. H. and M. J. Van Kranendonk (2012): 'Early Earth evolution: evidence from the 3.5-1.8 Ga geological history of the Pilbara region of Western Australia'. Episodes, vol. 35(1): pp. 283-297 (cit. on p. 3).

Hirschmann, M. M., M. S. Ghiorso, L. Wasylenki, P. D. Asimow, and E. M. Stolper (1998): 'Calculation of peridotite partial melting from thermodynamic models of minerals and melts. I. Review of methods and comparison with experiments'. Journal of Petrology, vol. 39(6): pp. 1091-1115 (cit. on p. 7).

Hoffmann, J. E., C. Münker, T. Næraa, M. T. Rosing, D. Herwartz, D. Garbe-Schönberg, and H. Svahnberg (2011a): 'Mechanisms of Archean crust formation inferred from high-precision HFSE systematics in TTGs'. Geochimica et Cosmochimica Acta, vol. 75(15): pp. 4157-4178 (cit. on pp. 21, 44).

Hoffmann, J. E., C. Münker, A. Polat, M. T. Rosing, and T. Schulz (2011b): 'The origin of decoupled $\mathrm{Hf}-\mathrm{Nd}$ isotope compositions in Eoarchean rocks from southern West Greenland'. Geochimica et Cosmochimica Acta, vol. 75(21): pp. 6610-6628 (cit. on pp. 5, 37).

Hoffmann, J. E., T. J. Nagel, C. Münker, T. Næraa, and M. T. Rosing (2014): 'Constraining the process of Eoarchean TTG formation in the Itsaq Gneiss Complex, southern West Greenland'. Earth and Planetary Science Letters, vol. 388: pp. 374-386 (cit. on pp. 5, 45).

Hoffmann, J. E., C. Zhang, and T. Nagel (2019): 'The Formation of Tonalites-TrondjhemiteGranodiorites in Early Continental Crust'. Earth's oldest rocks. Ed. by Van Kranendonk, M., V. Bennet, and J. Hoffmann. Elsevier (cit. on pp. 5, 6, 21). 
Holland Tim J Band Powell, R. (2003): 'Activity-composition relations for phases in petrological calculations: an asymmetric multicomponent formulation'. Contributions to Mineralogy and Petrology, vol. 145(4): pp. 492-501 (cit. on p. 49).

Holland, T. and J. Blundy (1994): 'Non-ideal interactions in calcic amphiboles and their bearing on amphibole-plagioclase thermometry'. Contributions to Mineralogy and Petrology, vol. 116(4): pp. 433-447 (cit. on p. 85).

Holland, T. J. B., E. C. Green, and R. Powell (2018): 'Melting of peridotites through to granites: a simple thermodynamic model in the system KNCFMASHTOCr'. Journal of Petrology, vol. 59(5): pp. 881-900 (cit. on p. 49).

Holland, T. J. B. and R. Powell (2011): 'An improved and extended internally consistent thermodynamic dataset for phases of petrological interest, involving a new equation of state for solids'. Journal of Metamorphic Geology, vol. 29(3): pp. 333-383 (cit. on p. 49).

Holtz, F. and W. Johannes (1991): 'Genesis of peraluminous granites I. Experimental investigation of melt compositions at 3 and $5 \mathrm{~kb}$ and various $\mathrm{H}_{2} \mathrm{O}$ activities'. Journal of Petrology, vol. 32(5): pp. 935-958 (cit. on pp. 86, 108).

Holtz, F. and W. Johannes (1994): 'Maximum and minimum water contents of granitic melts: implications for chemical and physical properties of ascending magmas'. Lithos, vol. 32(1-2): pp. 149-159 (cit. on p. 7).

Huang, H., A. Polat, and B. J. Fryer (2013): 'Origin of Archean tonalite-trondhjemitegranodiorite (TTG) suites and granites in the Fiskenæsset region, southern West Greenland: implications for continental growth'. Gondwana Research, vol. 23(2): pp. 452-470 (cit. on pp. $22,35,45,46,59,61,63-67)$.

Huber, W. et al. (2015): 'Orchestrating high-throughput genomic analysis with Bioconductor'. Nature Methods, vol. 12(2): pp. 115-121 (cit. on p. 93).

Jagoutz, O., M. W. Schmidt, A. Enggist, J.-P. Burg, D. Hamid, and S. Hussain (2013): 'TTG-type plutonic rocks formed in a modern arc batholith by hydrous fractionation in the lower arc crust'. Contributions to Mineralogy and Petrology, vol. 166(4): pp. 1099-1118 (cit. on pp. 5, 8, 45).

Jahn, B., A. Glikson, J. Peucat, and A. Hickman (1981): 'REE geochemistry and isotopic data of Archean silicic volcanics and granitoids from the Pilbara Block, Western Australia: implications for the early crustal evolution'. Geochimica et Cosmochimica Acta, vol. 45(9): pp. 1633-1652 (cit. on pp. 1, 44).

Janoušek, V., C. Farrow, and V. Erban (2006): 'Interpretation of whole-rock geochemical data in igneous geochemistry: Introducing Geochemical Data Toolkit (GCDkit)'. Journal of Petrology, vol. 47(6): pp. 1255-1259 (cit. on pp. 14, 16, 35).

Jenner, F., V. Bennett, A. Nutman, C. Friend, M. Norman, and G. Yaxley (2009): 'Evidence for subduction at $3.8 \mathrm{Ga}$ : Geochemistry of arc-like metabasalts from the southern edge of the Isua Supracrustal Belt'. Chemical Geology, vol. 261(1-2): pp. 83-98 (cit. on pp. 3, 5, $37)$. 
Johnson, T. E., M. Brown, N. J. Gardiner, C. L. Kirkland, and R. H. Smithies (2017): 'Earth's first stable continents did not form by subduction'. Nature, vol. 543(7644): p. 239 (cit. on pp. $5-7,21,37,38,47)$.

Johnson, T. E., M. Brown, B. J. Kaus, and J. A. VanTongeren (2014): 'Delamination and recycling of Archaean crust caused by gravitational instabilities'. Nature Geoscience, vol. 7(1): p. 47 (cit. on p. 83).

Johnson, T. E., C. Kirkland, N. Gardiner, M. Brown, R. Smithies, and M. Santosh (2019): 'Secular change in TTG compositions: Implications for the evolution of Archaean geodynamics'. Earth and Planetary Science Letters, vol. 505: pp. 65-75 (cit. on pp. 22, 35, 45, $46,59,61,63-67,95,96,98-100,107)$.

Johnston, A. D. and P. J. Wyllie (1988): 'Constraints on the origin of Archean trondhjemites based on phase relationships of Nûk Gneiss with $\mathrm{H}_{2} \mathrm{O}$ at 15 kbar'. Contributions to Mineralogy and Petrology, vol. 100(1): pp. 35-46 (cit. on p. 5).

Kamber, B. S., A. Ewart, K. D. Collerson, M. C. Bruce, and G. D. McDonald (2002): 'Fluidmobile trace element constraints on the role of slab melting and implications for Archaean crustal growth models'. Contributions to Mineralogy and Petrology, vol. 144(1): pp. 38-56 (cit. on p. 45).

King, S. D. (2020): 'Do impacts impact global tectonics?' Geology, vol. 48(2): pp. 205-206 (cit. on p. 4).

Klein, M., H.-G. Stosch, and H. Seck (1997): 'Partitioning of high field-strength and rare-earth elements between amphibole and quartz-dioritic to tonalitic melts: an experimental study'. Chemical Geology, vol. 138(3-4): pp. 257-271 (cit. on p. 13).

Kleinhanns, I. C., J. D. Kramers, and B. S. Kamber (2003): 'Importance of water for Archaean granitoid petrology: a comparative study of TTG and potassic granitoids from Barberton Mountain Land, South Africa'. Contributions to Mineralogy and Petrology, vol. 145(3): pp. 377-389 (cit. on pp. 5, 8, 45, 62, 99).

Klemme, S., J. D. Blundy, and B. J. Wood (2002): 'Experimental constraints on major and trace element partitioning during partial melting of eclogite'. Geochimica et Cosmochimica Acta, vol. 66(17): pp. 3109-3123 (cit. on pp. 23, 40).

Koester, E., A. R. Pawley, L. A. Fernandes, C. C. Porcher, and E. Soliani Jr (2002): 'Experimental melting of cordierite gneiss and the petrogenesis of syntranscurrent peraluminous granites in southern Brazil'. Journal of Petrology, vol. 43(8): pp. 1595-1616 (cit. on pp. 86, 108).

Komiya, T., S. Maruyama, T. Masuda, S. Nohda, M. Hayashi, and K. Okamoto (1999): 'Plate tectonics at 3.8-3.7 Ga: field evidence from the Isua accretionary complex, southern West Greenland'. The Journal of Geology, vol. 107(5): pp. 515-554 (cit. on p. 3).

Kourou, K., T. P. Exarchos, K. P. Exarchos, M. V. Karamouzis, and D. I. Fotiadis (2015): 'Machine learning applications in cancer prognosis and prediction'. Computational and Structural Biotechnology Journal, vol. 13: pp. 8-17 (cit. on p. 82). 
Kowalczyk, A. (2017): 'Support vector machines succinctly'. Syncfusion Inc, vol. (cit. on pp. 82, 83).

Kronz, A., A. M. Van den Kerkhof, and A. Müller (2012): 'Analysis of low element concentrations in quartz by electron microprobe'. Quartz: Deposits, Mineralogy and Analytics. Springer: pp. 191-217 (cit. on p. 31).

Lambert, I. and P. Wyllie (1974): 'Melting of tonalite and crystallization of andesite liquid with excess water to 30 kilobars'. The Journal of Geology, vol. 82(1): pp. 88-97 (cit. on p. 5).

Laurent, O., J. Björnsen, J. Wotzlaw, S. Bretscher, M. P. Silva, J.-F. Moyen, P. Ulmer, and O. Bachmann (2020): 'Earth's earliest granitoids are crystal-rich magma reservoirs tapped by silicic eruptions'. Nature Geoscience, vol.: pp. 1-7 (cit. on pp. 2, 5, 6, 8, 13, 45, 95).

Laurent, O., H. Martin, J.-F. Moyen, and R. Doucelance (2014): 'The diversity and evolution of late-Archean granitoids: Evidence for the onset of "modern-style" plate tectonics between 3.0 and 2.5 Ga'. Lithos, vol. 205: pp. 208-235 (cit. on pp. 22, 35, 44-46, 59, 61, 63-67, 95, 96, 98-100, 107).

Laurie, A. and G. Stevens (2012): 'Water-present eclogite melting to produce Earth's early felsic crust'. Chemical Geology, vol. 314: pp. 83-95 (cit. on pp. 3, 6, 7, 23, 40, 44-46, 48, 62, $86,90,96,99,102,108)$.

Laurie, A., G. Stevens, and J. van Hunen (2013): 'The end of continental growth by TTG magmatism'. Terra Nova, vol. 25(2): pp. 130-136 (cit. on p. 83).

Lebouteiller, A. and P. Courtine (1998): 'Improvement of a bulk optical basicity table for oxidic systems'. Journal of Solid State Chemistry, vol. 137(1): pp. 94-103 (cit. on p. 16).

Liou, P. and J. Guo (2019): 'Generation of Archaean TTG Gneisses Through AmphiboleDominated Fractionation'. Journal of Geophysical Research: Solid Earth, vol. 124(4): pp. 3605-3619 (cit. on pp. 5, 8, 13, 17, 45, 62).

López, S., A. Castro, and A. Garcia-Casco (2005): 'Production of granodiorite melt by interaction between hydrous mafic magma and tonalitic crust. Experimental constraints and implications for the generation of Archaean TTG complexes'. Lithos, vol. 79(1-2): pp. 229-250 (cit. on pp. 86, 108).

Macpherson, C., S. Dreher, and M. Thirlwall (2006): 'Adakites without slab melting: high pressure differentiation of island arc magma, Mindanao, the Philippines'. Earth and Planetary Science Letters, vol. 243(3-4): pp. 581-593 (cit. on pp. 8, 45).

Martin, H. (1986): 'Effect of steeper Archean geothermal gradient on geochemistry of subduction-zone magmas'. Geology, vol. 14(9): pp. 753-756 (cit. on pp. 11, 20).

Martin, H., R. Smithies, R. Rapp, J. Moyen, and D. Champion (2005): 'An overview of adakite, tonalite-trondhjemite-granodiorite (TTG), and sanukitoid: relationships and some implications for crustal evolution'. Lithos, vol. 79(1-2): pp. 1-24 (cit. on pp. 3, 20, 21, 44, $83)$. 
Martin, H. (1987): 'Petrogenesis of Archaean trondhjemites, tonalites, and granodiorites from eastern Finland: Major and trace element geochemistry'. Journal of Petrology, vol. 28(5): pp. 921-953 (cit. on p. 13).

- (1993): 'The mechanisms of petrogenesis of the Archaean continental crust - Comparison with modern processes'. Lithos, vol. 30(3-4): pp. 373-388 (cit. on pp. 5, 8, 45).

Martin, H., J.-F. Moyen, M. Guitreau, J. Blichert-Toft, and J.-L. Le Pennec (2014): 'Why Archaean TTG cannot be generated by MORB melting in subduction zones'. Lithos, vol. 198: pp. 1-13 (cit. on pp. 5, 44).

Masuda, A., N. Nakamura, and T. Tanaka (1973): 'Fine structures of mutually normalized rare-earth patterns of chondrites'. Geochimica et Cosmochimica Acta, vol. 37(2): pp. 239248 (cit. on p. 11).

Matthews, W., R. L. Linnen, and Q. Guo (2003): 'A filler-rod technique for controlling redox conditions in cold-seal pressure vessels'. American Mineralogist, vol. 88(4): pp. 701-707 (cit. on p. 50).

McCulloch, M. T. and J. Gamble (1991): 'Geochemical and geodynamical constraints on subduction zone magmatism'. Earth and Planetary Science Letters, vol. 102(3-4): pp. 358374 (cit. on p. 3).

McDonough, W. F. and S.-S. Sun (1995): 'The composition of the Earth'. Chemical geology, vol. 120(3-4): pp. 223-253 (cit. on pp. 12, 36, 37).

Meyer, D., E. Dimitriadou, K. Hornik, A. Weingessel, F. Leisch, C.-C. Chang, and C.-C. Lin (2018): e1071: Misc Functions of the Department of Statistics, Probability Theory Group (Formerly: E1071), Tu Wien. R package version 1.7-0 (cit. on pp. 83, 84).

Möller, P. and G. K. Muecke (1984): 'Significance of Europium anomalies in silicate melts and crystal-melt equilibria: a re-evaluation'. Contributions to Mineralogy and Petrology, vol. 87(3): pp. 242-250 (cit. on pp. 12, 13).

Moore, W. B. and A. A. G. Webb (2013): 'Heat-pipe earth'. Nature, vol. 501(7468): pp. 501505 (cit. on p. 3).

Moyen, J. and G. Stevens (2006): Archean Geodynamics and Environments. Ed. by Benn, K., J.-C. Mareschal, and K. Condie (cit. on pp. 5, 6, 13, 21, 38, 44).

Moyen, J. (2011): 'The composite Archaean grey gneisses: petrological significance, and evidence for a non-unique tectonic setting for Archaean crustal growth'. Lithos, vol. 123(1): pp. 21-36 (cit. on pp. 2, 21, 22, 35, 44-46, 59, 61, 63-67, 95, 96, 98-100, 107).

Moyen, J. and O. Laurent (2018): 'Archaean tectonic systems: a view from igneous rocks'. Lithos, vol. 302: pp. 99-125 (cit. on p. 20).

Moyen, J. and H. Martin (2012): 'Forty years of TTG research'. Lithos, vol. 148: pp. 312-336 (cit. on pp. 1, 2, 5-7, 11, 12, 14-17, 20, 21, 44-46, 48, 82, 83).

Nagel, T. J., J. E. Hoffmann, and C. Münker (2012): 'Generation of Eoarchean tonalitetrondhjemite-granodiorite series from thickened mafic arc crust'. Geology, vol. 40(4): pp. 375378 (cit. on pp. $3,6,21,44,47$ ). 
Nandedkar, R. H., N. Hürlimann, P. Ulmer, and O. Müntener (2016): 'Amphibole-melt trace element partitioning of fractionating calc-alkaline magmas in the lower crust: an experimental study'. Contributions to Mineralogy and Petrology, vol. 171(8-9): p. 71 (cit. on pp. 13, 15, 16).

Noble, W. S. (2006): 'What is a support vector machine?' Nature Biotechnology, vol. 24(12): p. 1565 (cit. on p. 82).

Nutman, A. P., V. C. Bennett, and C. R. Friend (2015): 'The emergence of the Eoarchaean proto-arc: evolution of a c. 3700 Ma convergent plate boundary at Isua, southern West Greenland'. Geological Society, London, Special Publications, vol. 389(1): pp. 113-133 (cit. on pp. 3, 21, 44, 83).

Nutman, A. P., V. C. Bennett, C. R. Friend, and M. D. Norman (1999): 'Meta-igneous (non-gneissic) tonalites and quartz-diorites from an extensive ca. $3800 \mathrm{Ma}$ terrain south of the Isua supracrustal belt, southern West Greenland: constraints on early crust formation'. Contributions to Mineralogy and Petrology, vol. 137(4): pp. 364-388 (cit. on pp. 22, 35, 45, $46,59,61,63-67,95,96,98-100,107)$.

O'Connor, J. (1965): 'A classification for quartz-rich igneous rocks based on feldspar ratios'. US Geological Survey Professional Paper B, vol. 525: pp. 79-84 (cit. on pp. 2, 9, 28, 46, 57, $59,61,95)$.

O'Hara, M. J. (1968): 'The bearing of phase equilibria studies in synthetic and natural systems on the origin and evolution of basic and ultrabasic rocks'. Earth-Science Reviews, vol. 4: pp. 69-133 (cit. on pp. 45, 46, 58-61).

- (1965): 'Primary magmas and the origin of basalts'. Scottish Journal of Geology, vol. 1(1): pp. 19-40 (cit. on p. 57).

O'Neil, J. and R. W. Carlson (2017): 'Building Archean cratons from Hadean mafic crust'. Science, vol. 355(6330): pp. 1199-1202 (cit. on pp. 8, 9, 22, 35, 45, 46, 59, 61, 63-67, 95, 96, 98-100, 107).

O'Neil, J., R. W. Carlson, D. Francis, and R. K. Stevenson (2008): 'Neodymium-142 evidence for Hadean mafic crust'. Science, vol. 321(5897): pp. 1828-1831 (cit. on pp. 8, 9, 45, 47).

O'Neil, J., R. W. Carlson, J.-L. Paquette, and D. Francis (2012): 'Formation age and metamorphic history of the Nuvvuagittuq Greenstone Belt'. Precambrian Research, vol. 220: pp. 23-44 (cit. on pp. 1, 8, 9, 28, 47, 49, 59, 63-65).

O'Neil, J., R. W. Carlson, D. Papineau, E. Y. Levine, and D. Francis (2019): 'The Nuvvuagittuq Greenstone Belt'. Earth's oldest rocks. Ed. by Van Kranendonk, M., V. Bennet, and J. Hoffmann. Elsevier (cit. on p. 9).

O'Neil, J., D. Francis, and R. W. Carlson (2011): 'Implications of the Nuvvuagittuq greenstone belt for the formation of Earth's early crust'. Journal of Petrology, vol. 52(5): pp. 985-1009 (cit. on p. 9).

O'Neill, C., S. Marchi, S. Zhang, and W. Bottke (2017): 'Impact-driven subduction on the Hadean Earth'. Nature Geoscience, vol. 10(10): pp. 793-797 (cit. on p. 4). 
O'Neill, H. S. C. (2016): 'The smoothness and shapes of chondrite-normalized rare Earth element patterns in basalts'. Journal of Petrology, vol. 57(8): pp. 1463-1508 (cit. on p. 17).

Palin, R. M., R. W. White, and E. C. Green (2016): 'Partial melting of metabasic rocks and the generation of tonalitic-trondhjemitic-granodioritic (TTG) crust in the Archaean: Constraints from phase equilibrium modelling'. Precambrian Research, vol. 287: pp. 73-90 (cit. on pp. 6, 38, 47, 83).

Park, R. G. (1982): 'Archaean tectonics'. Geologische Rundschau, vol. 71(1): pp. 22-37 (cit. on p. 1).

Parks, J., S. Lin, D. W. Davis, X.-M. Yang, R. A. Creaser, and M. T. Corkery (2014): 'Meso- and Neoarchean evolution of the Island Lake greenstone belt and the northwestern Superior Province: Evidence from lithogeochemistry, $\mathrm{Nd}$ isotope data, and $\mathrm{U}-\mathrm{Pb}$ zircon geochronology'. Precambrian Research, vol. 246: pp. 160-179 (cit. on pp. 5, 37).

Patiño Douce, A. E. (2005): 'Vapor-absent melting of tonalite at 15-32 kbar'. Journal of Petrology, vol. 46(2): pp. 275-290 (cit. on pp. 23, 40, 86, 108).

Patiño Douce, A. E. and J. S. Beard (1995): 'Dehydration-melting of biotite gneiss and quartz amphibolite from 3 to 15 kbar'. Journal of Petrology, vol. 36(3): pp. 707-738 (cit. on pp. 5, $23,40,86,108)$.

- (1996): 'Effects of $\mathrm{P}, \mathrm{f}\left(\mathrm{O}_{2}\right)$ and $\mathrm{Mg} / \mathrm{Fe}$ ratio on dehydration melting of model metagreywackes'. Journal of Petrology, vol. 37(5): pp. 999-1024 (cit. on pp. 23, 40, 86, 108).

Patiño Douce, A. E. and N. Harris (1998): 'Experimental constraints on Himalayan anatexis'. Journal of Petrology, vol. 39(4): pp. 689-710 (cit. on pp. 86, 108).

Patiño Douce, A. E. and A. D. Johnston (1991): 'Phase equilibria and melt productivity in the pelitic system: implications for the origin of peraluminous granitoids and aluminous granulites'. Contributions to Mineralogy and Petrology, vol. 107(2): pp. 202-218 (cit. on pp. 23, 40, 86, 108).

Pearce, J. A. and I. J. Parkinson (1993): 'Trace element models for mantle melting: application to volcanic arc petrogenesis'. Geological Society, London, Special Publications, vol. 76(1): pp. 373-403 (cit. on p. 2).

Pearce, J. A. and M. K. Reagan (2019): 'Identification, classification, and interpretation of boninites from Anthropocene to Eoarchean using Si-Mg-Ti systematics'. Geosphere, vol. 15(4): pp. 1008-1037 (cit. on p. 3).

Pertermann, M. and M. M. Hirschmann (2003): 'Anhydrous partial melting experiments on MORB-like eclogite: phase relations, phase compositions and mineral-melt partitioning of major elements at 2-3 GPa'. Journal of Petrology, vol. 44(12): pp. 2173-2201 (cit. on pp. 23, 40).

Peterson, B. G. and P. Carl (2020): PerformanceAnalytics: Econometric Tools for Performance and Risk Analysis. R package version 2.0.4 (cit. on p. 108). 
Petrelli, M. and D. Perugini (2016): 'Solving petrological problems through machine learning: the study case of tectonic discrimination using geochemical and isotopic data'. Contributions to Mineralogy and Petrology, vol. 171(10): p. 81 (cit. on p. 82).

Pickering, J. M. and D. A. Johnston (1998): 'Fluid-absent melting behavior of a two-mica metapelite: experimental constraints on the origin of Black Hills granite'. Journal of Petrology, vol. 39(10): pp. 1787-1804 (cit. on pp. 23, 40, 86, 102, 108).

Polat, A. and A. Hofmann (2003): 'Alteration and geochemical patterns in the 3.7-3.8 Ga Isua greenstone belt, West Greenland'. Precambrian Research, vol. 126(3-4): pp. 197-218 (cit. on p. 3).

Polat, A., L. Wang, and P. W. Appel (2015): 'A review of structural patterns and melting processes in the Archean craton of West Greenland: Evidence for crustal growth at convergent plate margins as opposed to non-uniformitarian models'. Tectonophysics, vol. 662: pp. 67-94 (cit. on pp. 3, 21).

Powell, R., T. Holland, and B. Worley (1998): 'Calculating phase diagrams involving solid solutions via non-linear equations, with examples using THERMOCALC'. Journal of metamorphic Geology, vol. 16(4): pp. 577-588 (cit. on pp. 47, 49, 52).

Puchtel, I., K. Haase, A. Hofmann, C. Chauvel, V. Kulikov, C.-D. Garbe-Schönberg, and A. Nemchin (1997): 'Petrology and geochemistry of crustally contaminated komatiitic basalts from the Vetreny Belt, southeastern Baltic Shield: evidence for an early Proterozoic mantle plume beneath rifted Archean continental lithosphere'. Geochimica et Cosmochimica Acta, vol. 61(6): pp. 1205-1222 (cit. on pp. 5, 37).

Qian, Q. and J. Hermann (2013): 'Partial melting of lower crust at 10-15 kbar: constraints on adakite and TTG formation'. Contributions to Mineralogy and Petrology, vol. 165(6): pp. 1195-1224 (cit. on pp. 23, 40, 86, 108).

R Core Team (2017): R: A Language and Environment for Statistical Computing. R Foundation for Statistical Computing. Vienna, Austria (cit. on pp. 26, 85).

Rapp, R. P., N. Shimizu, and M. D. Norman (2003): 'Growth of early continental crust by partial melting of eclogite'. Nature, vol. 425(6958): p. 605 (cit. on p. 22).

Rapp, R. P. and E. B. Watson (1995): 'Dehydration melting of metabasalt at 8-32 kbar: implications for continental growth and crust-mantle recycling'. Journal of Petrology, vol. 36(4): pp. 891-931 (cit. on pp. 5, 6, 23, 40, 45, 46, 48, 58, 62, 86, 96, 102, 108).

Rapp, R. P., E. B. Watson, and C. F. Miller (1991): 'Partial melting of amphibolite/eclogite and the origin of Archean trondhjemites and tonalites'. Precambrian Research, vol. 51(1-4): pp. 1-25 (cit. on pp. 5, 23, 40, 86, 102, 108).

Rozel, A., G. J. Golabek, C. Jain, P. J. Tackley, and T. Gerya (2017): 'Continental crust formation on early Earth controlled by intrusive magmatism'. Nature, vol. 545(7654): pp. 332-335 (cit. on p. 3).

Rudnick, R. L. (1992): 'Restites, Eu anomalies and the lower continental crust'. Geochimica et Cosmochimica Acta, vol. 56(3): pp. 963-970 (cit. on p. 13). 
Rushmer, T. (1991): 'Partial melting of two amphibolites: contrasting experimental results under fluid-absent conditions'. Contributions to Mineralogy and Petrology, vol. 107(1): pp. 41-59 (cit. on pp. 5, 38).

Ryerson, F. J. and E. Watson (1987): 'Rutile saturation in magmas: implications for Ti-Nb-Ta depletion in island-arc basalts'. Earth and Planetary Science Letters, vol. 86(2-4): pp. 225239 (cit. on pp. 22-25, 40).

Sandiford, M., M. J. Van Kranendonk, and S. Bodorkos (2004): 'Conductive incubation and the origin of dome-and-keel structure in Archean granite-greenstone terrains: A model based on the eastern Pilbara Craton, Western Australia'. Tectonics, vol. 23(1) (cit. on p. 3).

Sen, C. and T. Dunn (1994): 'Dehydration melting of a basaltic composition amphibolite at 1.5 and 2.0 GPa: implications for the origin of adakites'. Contributions to Mineralogy and Petrology, vol. 117(4): pp. 394-409 (cit. on pp. 5, 23, 40, 86, 108).

Sisson, T. (1994): 'Hornblende-melt trace-element partitioning measured by ion microprobe'. Chemical Geology, vol. 117(1-4): pp. 331-344 (cit. on p. 16).

Sisson, T., K. Ratajeski, W. Hankins, and A. Glazner (2005): 'Voluminous granitic magmas from common basaltic sources'. Contributions to Mineralogy and Petrology, vol. 148(6): pp. $635-661$ (cit. on pp. $23,40,86,108$ ).

Sizova, E., T. Gerya, K. Stüwe, and M. Brown (2015): 'Generation of felsic crust in the Archean: a geodynamic modeling perspective'. Precambrian Research, vol. 271: pp. 198-224 (cit. on pp. 2, 3, 83).

Skjerlie, K. P. and A. D. Johnston (1992): 'Vapor-absent melting at 10 kbar of a biotiteand amphibole-bearing tonalitic gneiss: Implications for the generation of A-type granites'. Geology, vol. 20(3): pp. 263-266 (cit. on pp. 23, 40, 86, 102, 108).

- (1996): 'Vapour-absent melting from 10 to 20 kbar of crustal rocks that contain multiple hydrous phases: implications for anatexis in the deep to very deep continental crust and active continental margins'. Journal of Petrology, vol. 37(3): pp. 661-691 (cit. on pp. 23, 40, 86, 108).

Skjerlie, K. P. and A. Johnston (1993): 'Fluid-absent melting behavior of an F-rich tonalitic gneiss at mid-crustal pressures: Implications for the generation of anorogenic granites'. Journal of Petrology, vol. 34(4): pp. 785-815 (cit. on pp. 23, 40, 86, 102, 108).

Skjerlie, K. P. and A. Patiño Douce (1995): 'Anatexis of interlayered amphibolite and pelite at 10 kbar: Effect of diffusion of major components on phase relations and melt fraction'. Contributions to Mineralogy and Petrology, vol. 122(1-2): pp. 62-78 (cit. on pp. 5, 23, 40, $86,102,108)$.

- (2002): 'The fluid-absent partial melting of a zoisite-bearing quartz eclogite from 1.0 to $3.2 \mathrm{GPa}$; Implications for melting in thickened continental crust and for subduction-zone processes'. Journal of Petrology, vol. 43(2): pp. 291-314 (cit. on pp. 5, 6, 45, 46, 48, 86, 96, 108). 
Smit, M. A., A. Scherstén, T. Næraa, R. B. Emo, E. E. Scherer, P. Sprung, W. Bleeker, K. Mezger, A. Maltese, Y. Cai, et al. (2019): 'Formation of Archean continental crust constrained by boron isotopes'. Geochemical Perspectives Letters, vol. 12: pp. 23-26 (cit. on p. 5).

Smithies, R. H. (2000): 'The Archaean tonalite-trondhjemite-granodiorite (TTG) series is not an analogue of Cenozoic adakite'. Earth and Planetary Science Letters, vol. 182(1): pp. 115-125 (cit. on p. 21).

Smithies, R. H., D. C. Champion, and M. J. Van Kranendonk (2009): 'Formation of Paleoarchean continental crust through infracrustal melting of enriched basalt'. Earth and Planetary Science Letters, vol. 281(3-4): pp. 298-306 (cit. on pp. 3, 7, 20, 21, 37, 44).

Smithies, R. H., D. C. Champion, M. J. Van Kranendonk, H. M. Howard, and A. H. Hickman (2005): 'Modern-style subduction processes in the Mesoarchaean: geochemical evidence from the $3.12 \mathrm{Ga}$ Whundo intra-oceanic arc'. Earth and Planetary Science Letters, vol. 231(3-4): pp. 221-237 (cit. on p. 3).

Smithies, R., D. Champion, and K. Cassidy (2003): 'Formation of Earth's early Archaean continental crust'. Precambrian Research, vol. 127(1-3): pp. 89-101 (cit. on p. 1).

Smithies, R. H., Y. Lu, T. E. Johnson, C. L. Kirkland, K. F. Cassidy, D. C. Champion, D. R. Mole, I. Zibra, K. Gessner, J. Sapkota, et al. (2019): 'No evidence for high-pressure melting of Earth's crust in the Archean'. Nature Communications, vol. 10(1): pp. 1-12 (cit. on pp. 2, 5, 8, 13, 45).

Smola, A. J. and B. Schölkopf (2004): ‘A tutorial on support vector regression'. Statistics and Computing, vol. 14(3): pp. 199-222 (cit. on pp. 82, 84).

Spandler, C., G. Yaxley, D. H. Green, and A. Rosenthal (2008): 'Phase relations and melting of anhydrous K-bearing eclogite from 1200 to $1600{ }^{\circ} \mathrm{C}$ and 3 to 5 GPa'. Journal of Petrology, vol. 49(4): pp. 771-795 (cit. on pp. 23, 40).

Spear, F. S. (1981): 'An experimental study of hornblende stability and compositional variability in amphibolite'. American Journal of Science, vol. 281(6): pp. 697-734 (cit. on p. 16).

Spicer, E. M., G. Stevens, and I. S. Buick (2004): 'The low-pressure partial-melting behaviour of natural boron-bearing metapelites from the Mt. Stafford area, central Australia'. Contributions to Mineralogy and Petrology, vol. 148(2): pp. 160-179 (cit. on pp. 23, 27, 40, 86, 108).

Springer, W. and H. A. Seck (1997): 'Partial fusion of basic granulites at 5 to 15 kbar: implications for the origin of TTG magmas'. Contributions to Mineralogy and Petrology, vol. 127(1-2): pp. 30-45 (cit. on pp. 5, 23, 40, 86, 87, 102, 108).

Stepanov, A. S. and J. Hermann (2013): 'Fractionation of Nb and Ta by biotite and phengite: Implications for the "missing Nb paradox". Geology, vol. 41(3): pp. 303-306 (cit. on pp. 22, $37)$. 
Stern, R. J., M. Reagan, O. Ishizuka, Y. Ohara, and S. Whattam (2012): 'To understand subduction initiation, study forearc crust: To understand forearc crust, study ophiolites' Lithosphere, vol. 4(6): pp. 469-483 (cit. on p. 9).

Tang, M., K. Chen, and R. L. Rudnick (2016): 'Archean upper crust transition from mafic to felsic marks the onset of plate tectonics'. Science, vol. 351(6271): pp. 372-375 (cit. on pp. 2, 20,44).

Thorpe, R., P. Potts, and M. Sarre (1977): 'Rare earth evidence concerning the origin of granites of the Isle of Skye, northwest Scotland'. Earth and Planetary Science Letters, vol. 36(1): pp. 111-120 (cit. on p. 12).

Thurston, P. C. and B. J. Fryer (1983): 'The geochemistry of repetitive cyclical volcanism from basalt through rhyolite in the Uchi-Confederation greenstone belt, Canada'. Contributions to Mineralogy and Petrology, vol. 83(3-4): pp. 204-226 (cit. on pp. 5, 37).

Tiepolo, M., R. Oberti, A. Zanetti, R. Vannucci, and S. F. Foley (2007): 'Trace-element partitioning between amphibole and silicate melt'. Reviews in Mineralogy and Geochemistry, vol. 67(1): pp. 417-452 (cit. on pp. 7, 13).

Turner, S., T. Rushmer, M. Reagan, and J.-F. Moyen (2014): 'Heading down early on? Start of subduction on Earth'. Geology, vol. 42(2): pp. 139-142 (cit. on pp. 2, 9, 20, 44, 83).

Tuttle, O. F. and N. L. Bowen (1958): Origin of granite in the light of experimental studies in the system $\mathrm{NaAlSiO}_{8}-\mathrm{KALSi}_{3} \mathrm{O}_{8}-\mathrm{SiO}_{2}-\mathrm{H}_{2} \mathrm{O}$. Geological Society of America (cit. on p. 82). Upadhyay, D., S. Chattopadhyay, E. Kooijman, K. Mezger, and J. Berndt (2014): 'Magmatic and metamorphic history of Paleoarchean tonalite-trondhjemite-granodiorite (TTG) suite from the Singhbhum craton, eastern India'. Precambrian research, vol. 252: pp. 180-190 (cit. on p. 1).

Van Kranendonk, M. J. (2010): 'Two types of Archean continental crust: Plume and plate tectonics on early Earth'. American Journal of Science, vol. 310(10): pp. 1187-1209 (cit. on pp. 2, 8, 21).

Van Kranendonk, M. J., R. Hugh Smithies, A. H. Hickman, and D. C. Champion (2007): 'Review: secular tectonic evolution of Archean continental crust: interplay between horizontal and vertical processes in the formation of the Pilbara Craton, Australia'. Terra Nova, vol. 19(1): pp. 1-38 (cit. on p. 83).

Van Kranendonk, M. J., R. H. Smithies, W. L. Griffin, D. L. Huston, A. H. Hickman, D. C. Champion, C. R. Anhaeusser, and F. Pirajno (2015): 'Making it thick: a volcanic plateau origin of Palaeoarchean continental lithosphere of the Pilbara and Kaapvaal cratons'. Geological Society, London, Special Publications, vol. 389(1): pp. 83-111 (cit. on p. 3).

Vapnik, V. N. (1995): The nature of statistical learning. New York: Springer (cit. on pp. 82, $84)$.

Vielzeuf, D. and J. R. Holloway (1988): 'Experimental determination of the fluid-absent melting relations in the pelitic system'. Contributions to Mineralogy and Petrology, vol. 98(3): pp. $257-276$ (cit. on pp. 86, 102, 108). 
Vielzeuf, D. and J. M. Montel (1994): 'Partial melting of metagreywackes. Part I. Fluidabsent experiments and phase relationships'. Contributions to Mineralogy and Petrology, vol. 117(4): pp. 375-393 (cit. on pp. 86, 108).

Virgo, D., B. O. Mysen, and I. Kushiro (1980): 'Anionic constitution of 1-atmosphere silicate melts: implications for the structure of igneous melts'. Science, vol. 208(4450): pp. 13711373 (cit. on p. 26).

Wark, D. A. and E. B. Watson (2006): 'TitaniQ: a titanium-in-quartz geothermometer'. Contributions to Mineralogy and Petrology, vol. 152(6): pp. 743-754 (cit. on p. 31).

Watkins, J. M., J. D. Clemens, and P. J. Treloar (2007): 'Archaean TTGs as sources of younger granitic magmas: melting of sodic metatonalites at 0.6-1.2 GPa'. Contributions to Mineralogy and Petrology, vol. 154(1): pp. 91-110 (cit. on p. 45).

Webb, A. A. G., T. Müller, J. Zuo, P. J. Haproff, and A. Ramirez-Salazar (2020): 'A nonplate tectonic model for the Eoarchean Isua supracrustal belt'. Lithosphere, vol. 12(1): pp. 166-179 (cit. on p. 3).

Weill, D. F. and M. J. Drake (1973): 'Europium anomaly in plagioclase feldspar: experimental results and semiquantitative model'. Science, vol. 180(4090): pp. 1059-1060 (cit. on p. 13).

White, R. W., R. M. Palin, and E. C. R. Green (2017): 'High-grade metamorphism and partial melting in Archean composite grey gneiss complexes'. Journal of Metamorphic Geology, vol. 35(2): pp. 181-195 (cit. on p. 1).

White, R. W., R. Powell, T. J. B. Holland, T. E. Johnson, and E. C. R. Green (2014): 'New mineral activity-composition relations for thermodynamic calculations in metapelitic systems'. Journal of Metamorphic Geology, vol. 32(3): pp. 261-286 (cit. on p. 49).

White, R. W., R. Powell, and G. Clarke (2002): 'The interpretation of reaction textures in Fe-rich metapelitic granulites of the Musgrave Block, central Australia: constraints from mineral equilibria calculations in the system $\mathrm{K} 2 \mathrm{O}-\mathrm{FeO}-\mathrm{MgO}-\mathrm{Al}_{2} \mathrm{O}_{3}-\mathrm{SiO}_{2}-\mathrm{H}_{2} \mathrm{O}-\mathrm{TiO}_{2}-$ $\mathrm{Fe}_{2} \mathrm{O}_{3}$ '. Journal of metamorphic Geology, vol. 20(1): pp. 41-55 (cit. on p. 49).

Wickham, H. (2016): ggplot2: Elegant Graphics for Data Analysis. New York: Springer-Verlag (cit. on pp. 12, 22, 85).

Wickham, H., R. François, L. Henry, and K. Müller (2018): dplyr: A Grammar of Data Manipulation. R package version 0.7.6 (cit. on p. 26).

Wiemer, D., C. E. Schrank, D. T. Murphy, L. Wenham, and C. M. Allen (2018): 'Earth's oldest stable crust in the Pilbara Craton formed by cyclic gravitational overturns'. Nature Geoscience, vol. 11(5): p. 357 (cit. on pp. 3, 20, 21, 44, 83).

Windley, B. F. and A. A. Garde (2009): 'Arc-generated blocks with crustal sections in the North Atlantic craton of West Greenland: crustal growth in the Archean with modern analogues'. Earth-Science Reviews, vol. 93(1-2): pp. 1-30 (cit. on p. 3).

Winther, K. T. (1996): 'An experimentally based model for the origin of tonalitic and trondhjemitic melts'. Chemical Geology, vol. 127(1-3): pp. 43-59 (cit. on pp. 5, 6, 45, 46, $48,86,96,108)$. 
Wolf, M. B. and P. J. Wyllie (1994): 'Dehydration-melting of amphibolite at 10 kbar: the effects of temperature and time'. Contributions to Mineralogy and Petrology, vol. 115(4): pp. 369-383 (cit. on pp. 86, 102, 108).

Wyllie, P. J., W.-L. Huang, C. R. Stern, and S. Maaløe (1976): 'Granitic magmas: possible and impossible sources, water contents, and crystallization sequences'. Canadian Journal of Earth Sciences, vol. 13(8): pp. 1007-1019 (cit. on p. 7).

Wyllie, P., M. Wolf, and S. Van der Laan (1997): 'Conditions for formation of tonalites and trondhjemites: magmatic sources and products'. Oxford monographs on Geology and Geophysics, vol. (35): pp. 256-266 (cit. on pp. 5, 7, 38, 43, 45).

Xiong, X., J. Adam, and T. Green (2005): 'Rutile stability and rutile/melt HFSE partitioning during partial melting of hydrous basalt: implications for TTG genesis'. Chemical Geology, vol. 218(3-4): pp. 339-359 (cit. on pp. 5, 23, 86, 108).

Xiong, X., H. Keppler, A. Audétat, G. Gudfinnsson, W. Sun, M. Song, W. Xiao, and L. Yuan (2009): 'Experimental constraints on rutile saturation during partial melting of metabasalt at the amphibolite to eclogite transition, with applications to TTG genesis'. American Mineralogist, vol. 94(8-9): pp. 1175-1186 (cit. on pp. 23-25, 34, 35, 40).

Xiong, X., H. Keppler, A. Audétat, H. Ni, W. Sun, and Y. Li (2011): 'Partitioning of Nb and Ta between rutile and felsic melt and the fractionation of $\mathrm{Nb} / \mathrm{Ta}$ during partial melting of hydrous metabasalt'. Geochimica et Cosmochimica Acta, vol. 75(7): pp. 1673-1692 (cit. on pp. 21, 23, 40).

Yakymchuk, C., C. Kirkland, J. Hollis, J. Kendrick, N. Gardiner, and K. Szilas (2020): 'Mesoarchean partial melting of mafic crust and tonalite production during high-T-lowP stagnant tectonism, Akia Terrane, West Greenland'. Precambrian Research, vol. 339: p. 105615 (cit. on p. 3).

Yearron, L. M. (2003): 'Archaean granite petrogenesis and implications for the evolution of the Barberton Mountain Land, South Africa'. PhD thesis. Kingston University: p. 315 (cit. on pp. 23, 40).

Yoder, H. and C. E. Tilley (1962): 'Origin of basalt magmas: an experimental study of natural and synthetic rock systems'. Journal of Petrology, vol. 3(3): pp. 342-532 (cit. on pp. 82, $85)$.

Zhang, C.-L., H.-K. Li, M. Santosh, Z.-X. Li, H.-B. Zou, H. Wang, and H. Ye (2012): 'Precambrian evolution and cratonization of the Tarim Block, NW China: Petrology, geochemistry, Nd-isotopes and U-Pb zircon geochronology from Archaean gabbro-TTGpotassic granite suite and Paleoproterozoic metamorphic belt'. Journal of Asian Earth Sciences, vol. 47: pp. 5-20 (cit. on p. 1). 


\section{List of Figures}

2.1 a: Eu-anomaly of TTGs categorised by their most likely formation conditions based on the classification of Moyen and Martin (2012). The dataset is from Moyen and Martin (2012). The dotted lines represent an Eu-anomaly of $1 \pm$ 0.1. b: Correlation between $\mathrm{Sr} / \mathrm{Y}$ and the Eu-anomaly for TTGs. The $\mathrm{Sr} / \mathrm{Y}$ ratio is plotted as $\log _{10}$. c: The two pressure indicating ratios $\mathrm{Sr} / \mathrm{Y}$ and $(\mathrm{Gd} / \mathrm{Yb})_{P M}$ plotted colour coded by their pressure classification from Moyen and Martin (2012). Both ratios are plotted as $\log _{10} \mathbf{d}$ : Scatter plot without a correlation between $(\mathrm{La} / \mathrm{Yb})_{P M}$ and the Eu-anomaly. The dotted lines represent an Eu-anomaly of $1 \pm 0.1$. (La/Yb) $P M$ is plotted as $\log _{10}$. Theses and following diagrams were created via the $R$ package ggplot2 (Wickham, 2016). The primitive mantle (PM) composition is from McDonough and Sun (1995).

2.2 Modelling results for trace and major element evolution by fractional crystallisation of hornblende and accumulation of feldspar starting from an average Eu-anomaly free TTG composition (table 2.1). Values along evolution lines represent the amount of fractionation/accumulation in \%. Natural TTG compositions from from Moyen and Martin (2012) are plotted as open circles. a: Change in Eu-anomaly and $\mathrm{Sr} / \mathrm{Y}$ ratio by feldspar accumulation calculated via partitioning coefficients from Bédard (2006b). The Sr/Y ratio is plotted as $\log _{10}$. b: Change in Eu-anomaly and $\mathrm{Sr} / \mathrm{Y}$ ratio by hornblende fractionation calculated via partitioning coefficients from Nandedkar et al. (2016). The $\mathrm{Sr} / \mathrm{Y}$ ratio is plotted as $\log _{10}$. c: Change in Eu-anomaly and $\mathrm{K}_{2} \mathrm{O} / \mathrm{Na}_{2} \mathrm{O}$ by plagioclase accumulation and hornblende fractionation. Both are modelled for $\log f \mathrm{O}_{2}=-17$. d: Change in Eu-anomaly and $\mathrm{SiO}_{2}$ by plagioclase accumulation and hornblende fractionation. Both are modelled for $\log \mathrm{fO}_{2}=$ -17 .

$3.1 \mathrm{TiO}_{2}$ vs $\mathrm{SiO}_{2}$ for TTGs. Data from Nutman et al. (1999), Moyen (2011), Huang et al. (2013), Laurent et al. (2014), O'Neil and Carlson (2017) and Johnson et al. (2019). After merging the data, duplicates are identified by the normalised major element composition and removed. This and all following images were made with ggplot2 (Wickham, 2016). 
3.2 Published Ti-solubility models of a: Ryerson and Watson (1987), b: Hayden and Watson (2007) and c: Xiong et al. (2009) applied to the Ti excess phase saturated experiments (table 3.5). Calculated temperatures are plotted against recorded experimental temperatures.

3.3 a: $\mathrm{P}-\mathrm{T}$ plot of the filtered literature dataset comprising 389 rutile and/or ilmenite saturated experiments. Grey areas on the secondary axes display the density distribution of experiments regarding pressure and temperature settings without a scale. $\mathbf{b}$ : The model calibrated on the modified dataset (table 3.1) applied to the filtered dataset shown in fig. 3.3a. Outlying data from Spicer et al. (2004) are melts produced in pelite melting with very high $\mathrm{K}_{2} \mathrm{O}$ content.

3.4 Literature experimental data plotted to display the relation of $\mathrm{NBO} / \mathrm{T}(\mathbf{a})$ and the cation ratio (b) with Ti concentration in silicate melts.

3.5 a: Na loss over time during analysis at different beam diameters. The cps is a 10 second average. $\mathbf{b}$ : Effect of secondary Ti-fluorescence in glass close to Ti phases. Profiles were measured in sample 2075 adjacent to ilmenite. c: $\mathrm{TiO}_{2}$ content of melts produced in experiments on tonalite PC-103. The natural composition of $\mathrm{PC}-103$ is plotted as a the grey triangle.

3.6 Calculated temperatures compared to actual conditions for PC-103 experiments (black bars) using the calibration model based on the modified and unmodified dataset. The modified dataset has reduced bias and scatter due to statistical operations explained in Section 3.5. Temperatures using the Xiong et al. (2009) calibration are given for comparison. 2103 and 2104 are doped with titanite. PC-103 is the natural composition. Uncertainty for Xiong et al. (2009) is a $10 \%$ interval as given in their paper. Calculation of the natural rock PC-103 Ti-saturation temperature with Xiong et al. (2009) is based on a $1 \mathrm{GPa}$ and a $5 \mathrm{wt} \% \mathrm{H}_{2} \mathrm{O}$ estimate.

3.7 a) Ti saturated liquidus temperatures calculated from with our model for the natural TTG dataset. The Ti saturated experimental melts are plotted with colour-coded $\mathrm{H}_{2} \mathrm{O}$. The red line separates potentially saturated from undersaturated TTG compositions based on the extend of experimental data. b) Box plot of the $\mathrm{Nb}$ depletion for $\mathrm{Ti}$ excess phase saturated and undersaturated TTGs in comparison. Y-axis is a $\log _{10}$ scale. The $\mathrm{Nb}$ signature is calculated as $N b / N b^{*}=N b_{P M} / \sqrt{\left(U_{P M} * L a_{P M}\right)}$. The decision of saturation is based on the red line in fig. 3.7a. PM is from McDonough and Sun (1995). 
4.1 a: Feldspar diagram of O'Connor (1965) with experimental melt compositions from Rapp and Watson (1995), Winther (1996), Skjerlie and Patiño Douce (2002), Adam et al. (2012), Laurie and Stevens (2012), and Hastie et al. (2016) plotted together with natural TTG data from Nutman et al. (1999), Moyen (2011), Huang et al. (2013), Laurent et al. (2014), and O'Neil and Carlson (2017) and Johnson et al. (2019). The compilation is filtered for samples only containing tonalites, trondhjemites and granodiorites; La $>10$, $\mathrm{Yb}<2$ and an Eu-anomaly in between 0.9 and 1.1. By this procedure, compositions not being TTG and affected by fractionation or accumulation are avoided. b: P-T condition plot of the experimental melts that match TTG composition. c: Qtz-Fo-An plot with the same data as in fig. 4.1a, recalculated as CMAS (O'Hara, 1968) d: Experiments by Rapp and Watson (1995) on an migmatic amphibolite at 1.6 GPa with interpreted cotectic path. 46

4.2 a: Na loss over time during analysis at different beam diameters. The cps is a 10 second average. b: Comparison of different matrix correction methods normalised to the values calculated from phi-rho-Z. The error bars are the $1 \sigma$ sd of 10 glass analysis in experiment R174 (chapter 3).

4.3 P-T sections for PC-103 based on crystallisation experiments with a: $5 \mathrm{wt} \%$ $\mathrm{H}_{2} \mathrm{O}$ and b: $10 \mathrm{wt} \% \mathrm{H}_{2} \mathrm{O}$ present. Black filled circles are the P-T conditions at which experiments were conducted. Abbreviations: $\mathrm{cpx}=$ clinopyroxene, opx $=$ orthopyroxene, plag $=$ plagioclase and $\mathrm{clz}=$ clino-zoisite.

4.4 P-T pseudosections of PC-103 with $\mathrm{Fe}^{3+} / \mathrm{Fe}^{2+}$ ratio of 0.3 and $\mathbf{a}: 2$, $\mathbf{b}: 5$ and c: $10 \mathrm{wt} \% \mathrm{H}_{2} \mathrm{O}$. Abbreviations: $\mathrm{L}=$ liquid, $\mathrm{hb}=$ hornblende, $\mathrm{g}=$ garnet, aug $=$ clinopyroxene, $\mathrm{opx}=$ orthopyroxene, $\mathrm{mu}=$ muscovite, $\mathrm{bi}=$ biotite, $\mathrm{ep}=$ epidote, $\mathrm{pl}=$ plagioclase, $\mathrm{ksp}=$ alkali feldspar, $\mathrm{q}=$ quartz, $\mathrm{ru}=$ rutile, $\mathrm{ilm}=$ ilmenite.

4.5 Feldspar diagram of O'Connor, 1965 with our experimental melts for a: 5 and b: 10 wt\% $\mathrm{H}_{2} \mathrm{O}$, Nuvvuagittuq TTGs (O'Neil et al., 2012) and other natural TTG data (Nutman et al., 1999; Moyen, 2011; Huang et al., 2013; Laurent et al., 2014; O'Neil and Carlson, 2017; Johnson et al., 2019). Diagrams c and d contain the same datasets as a \& b, recalculated to CMAS components (O'Hara, 1968) and projected in the Qtz-Fo-An plane. The diagrams are reduced in extend to $60 \%$ Qtz and Fo. Abbreviations: plag = plagioclase, opx $=$ orthopyroxene, $\mathrm{cpx}=$ clinopyroxene, grt $=$ garnet, $\mathrm{hbl}=$ hornblende, $\mathrm{clz}=$ clinozoisite. 
4.6 Feldspar diagram (O'Connor, 1965) with isobaric melt compositions profiles for a: 2, b: 5 and c: $10 \mathrm{wt} \% \mathrm{H}_{2} \mathrm{O}$ calculated with THERMOCALC for different $\mathrm{H}_{2} \mathrm{O}$ contents with $\mathrm{Fe}^{3+} / \mathrm{Fe}^{2+}$ ratio of 0.3 . Natural TTG data is from Nutman et al. (1999), Moyen (2011), Huang et al. (2013), Laurent et al. (2014), and O'Neil and Carlson (2017) and Johnson et al. (2019). The sub-figures d, e \& f display the same data recalculated as CMAS (O'Hara, 1968) and plotted into the Qtz-Fo-An plane. The diagrams are reduced in extend to $60 \% \mathrm{Qtz}$ and Fo. Modes of the isobaric profiles are in appendix fig. 4.9, $4.10 \& 4.11$. Abbreviations: plag $=$ plagioclase, opx $=$ orthopyroxene, $\mathrm{hbl}=$ hornblende, grt $=$ garnet.

4.7 Major element scatter plots for glass compositions from PC-103 experiments with $5 \mathrm{wt} \% \mathrm{H}_{2} \mathrm{O}$, the Nuvvuagittuq Suite (O'Neil et al., 2012) and other natural TTGs (Nutman et al., 1999; Moyen, 2011; Huang et al., 2013; Laurent et al., 2014; O'Neil and Carlson, 2017; Johnson et al., 2019).

4.8 Major element scatter plots for glass compositions from PC-103 experiments with $10 \mathrm{wt} \% \mathrm{H}_{2} \mathrm{O}$, the Nuvvuagittuq Suite (O'Neil et al., 2012) and other natural TTGs (Nutman et al., 1999; Moyen, 2011; Huang et al., 2013; Laurent et al., 2014; O'Neil and Carlson, 2017; Johnson et al., 2019).

4.9 a-d: Modes for different pressure sections through the P-T pseudosection of PC-103 calculated with $2 \mathrm{wt} \%$ of $\mathrm{H}_{2} \mathrm{O}$ (fig. 4.4a). Abbreviations : $\mathrm{L}=$ liquid, $\mathrm{hb}=$ hornblende, opx $=$ orthopyroxene, $\mathrm{pl}=$ plagioclase, $\mathrm{ilm}=$ ilmenite, $\mathrm{bi}=$ biotite, $\mathrm{q}=$ quartz, $\mathrm{ksp}=\mathrm{K}$-feldspar, aug = augite, $\mathrm{mu}=$ muscovite, $\mathrm{ep}=$ epidote. e-j: Harker diagrams for melt compositions based on the profiles of a-d plotted with the Nuvvuagittuq TTGs (O'Neil et al., 2012) and natural TTG (Nutman et al., 1999; Moyen, 2011; Huang et al., 2013; Laurent et al., 2014; O'Neil and Carlson, 2017; Johnson et al., 2019).

4.10 a-d: Modes for different pressure sections through the P-T pseudosection of PC-103 calculated with 5 wt $\%$ of $\mathrm{H}_{2} \mathrm{O}$ (fig. 4.4b). Abbreviations : $\mathrm{L}=$ liquid, $\mathrm{hb}=$ hornblende, opx $=$ orthopyroxene, $\mathrm{pl}=$ plagioclase, $\mathrm{ilm}=$ ilmenite, $\mathrm{bi}=$ biotite, $\mathrm{q}=$ quartz, aug = augite, $\mathrm{mu}=$ muscovite, $\mathrm{ep}=$ epidote. $\mathbf{e}-\mathbf{j}$ : Harker diagrams for melt compositions based on the profiles of a-d plotted with the Nuvvuagittuq TTGs and natural TTG (Nutman et al., 1999; Moyen, 2011; Huang et al., 2013; Laurent et al., 2014; O'Neil and Carlson, 2017; Johnson et al., 2019) 
4.11 a-d: Modes for different pressure sections through the P-T pseudosection of PC-103 calculated with $10 \mathrm{wt} \%$ of $\mathrm{H}_{2} \mathrm{O}$ (fig. 4.4c). Abbreviations : $\mathrm{L}=$ liquid, $\mathrm{hb}=$ hornblende, $\mathrm{opx}=$ orthopyroxene, $\mathrm{pl}=$ plagioclase, $\mathrm{ilm}=$ ilmenite, $\mathrm{bi}=$ biotite, $\mathrm{q}=$ quartz, aug = augite, $\mathrm{mu}=$ muscovite, $\mathrm{ep}=$ epidote. $\mathbf{e}-\mathrm{j}$ : Harker diagrams for melt compositions based on the profiles of a-d plotted with the Nuvvuagittuq TTGs and natural TTG (Nutman et al., 1999; Moyen, 2011; Huang et al., 2013; Laurent et al., 2014; O'Neil and Carlson, 2017; Johnson et al., 2019)

5.1 Residual plots for a linear regression and a SVR predicting temperature (a), pressure (b) and $\mathrm{H}_{2} \mathrm{O}$ (c) of an experimental data compilation described in section 5.5.1. These and all subsequent diagrams are made with ggplot2 (Wickham, 2016) in $R$ (R Core Team, 2017).

5.2 a: Pressure and temperature conditions and $\mathrm{H}_{2} \mathrm{O}$ dissolved in the experimental melts. $\mathbf{b}$ : Abundance of different phases in the experimental dataset. $\mathrm{cpx}=$ clinopyroxene, $\mathrm{opx}=$ orthopyroxene, grt $=$ garnet, plag $=$ plagioclase, $\mathrm{ksp}=$ alkali feldspar, $\mathrm{hbl}=$ hornblende, $\mathrm{bt}=$ biotite, $\mathrm{ph}=$ phengite, $\mathrm{ms}=$ muscovite, $\mathrm{zo}=$ klinozoisite, alsi = alumina silicate, $\mathrm{crd}=$ cordierite, $\mathrm{ol}=$ olivine, $\mathrm{qtz}=$ quartz, $\mathrm{ru}=$ rutile, $\mathrm{mt}=$ magnetite, $\mathrm{ilm}=$ ilmenite, tit $=$ titanite.

5.3 Recalculated $\mathrm{H}_{2} \mathrm{O}$ concentration plotted against reported values for 291 samples. The upper line is the 1:1 ratio for calculated and reported values, the lower line marks a $5 \mathrm{wt} \%$ difference.

5.4 Box plots comparing estimated with recorded temperatures. The box width is $\leq 50{ }^{\circ} \mathrm{C}$. a: Temperature estimate based on major element composition. $\mathbf{b}$ : Temperature estimate based on pressure and major element composition. c: Temperature estimate based on $\mathrm{H}_{2} \mathrm{O}$ and major element composition $\mathbf{d}$ : Temperature estimate based on pressure, $\mathrm{H}_{2} \mathrm{O}$ and major element composition. 88

5.5 Box plots comparing estimated with recorded pressures. The box width is $\leq 0.25 \mathrm{GPa}$. a: Pressure estimate based on major element composition. $\mathbf{b}$ : Pressure estimate based on temperature and major element composition. c: Pressure estimate based on $\mathrm{H}_{2} \mathrm{O}$ and major element composition. d: Pressure estimate based on temperature, $\mathrm{H}_{2} \mathrm{O}$ and major element composition.

5.6 Box plots comparing estimated with recorded $\mathrm{H}_{2} \mathrm{O}$. The box width is $\leq 1$ wt\%. a: $\mathrm{H}_{2} \mathrm{O}$ estimate based on major element composition. b: $\mathrm{H}_{2} \mathrm{O}$ estimate based on temperature and major element composition. c: $\mathrm{H}_{2} \mathrm{O}$ estimate based on pressure and major element composition. d: $\mathrm{H}_{2} \mathrm{O}$ estimate based on temperature, pressure and major element composition. 
5.7 Boxplots for temperature (a), pressure (b) and $\mathrm{H}_{2} \mathrm{O}(\mathbf{c})$ estimates based on the interdependent model.

5.8 Temperature estimate distribution for natural TTGs (Nutman et al., 1999; Moyen, 2011; Laurent et al., 2014; O’Neil and Carlson, 2017; Johnson et al., 2019) calculated with the models displayed in fig. 5.4a and fig. 5.4c. The $\mathrm{H}_{2} \mathrm{O}$ dependend model is set with fixed values of 4,8 and $12 \mathrm{wt} \% \mathrm{H}_{2} \mathrm{O}$.

5.9 Result plots of the interdependent T-P-H2O model applied to natural TTGs (Nutman et al., 1999; Moyen, 2011; Laurent et al., 2014; O'Neil and Carlson, 2017; Johnson et al., 2019): a: Temperature results. b: Pressure results. c: $\mathrm{H}_{2} \mathrm{O}$ results. d: $\mathrm{P}-\mathrm{T}$ diagram combining the estimates on pressure temperature and $\mathrm{H}_{2} \mathrm{O}$ content. The error bars represent the RMSE of the model calibration (5.1). e: Gd/Yb ratio of natural TTGs plotted against the estimated pressure. f: $\mathrm{Sr} / \mathrm{Y}$ ratio of natural TTGs plotted against the estimated pressure.

5.10 SVM based TTG temperature estimate calculated for different $\mathrm{H}_{2} \mathrm{O}$ contents ( $\mathbf{a}=8 \mathrm{wt} \%, \mathbf{b}=14 \mathrm{wt} \%)$ compared with Ti saturation temperatatures (chapter 3) for natural TTGs (Nutman et al., 1999; Moyen, 2011; Laurent et al., 2014; O’Neil and Carlson, 2017; Johnson et al., 2019). The black line as a 1:1 slope.

5.11 a: $\mathrm{H}_{2} \mathrm{O}$ content of melts estimated for the Ti saturated liquidus temperature (chapter 3) of natural TTGs (Nutman et al., 1999; Moyen, 2011; Laurent et al., 2014; O'Neil and Carlson, 2017; Johnson et al., 2019). b: Pressure estimate for TTGs at the Ti saturated liquidus based on temperatures (chapter 3) and major elements. c: P-T diagram for the Ti saturated liquidus of TTGs based on temperatures from (chapter 3). Pressure and $\mathrm{H}_{2} \mathrm{O}$ are estimated as displayed in fig. 5.11a \& b. Temperature error bars are based on $11 \% 1 \sigma$ uncertainty of the Ti temperatures (chapter 3.) Pressure error bars are based on the pressure RMSE of 0.328 and the $11 \% 1 \sigma$ interval for temperature. $\mathbf{d}: \mathrm{Gd} / \mathrm{Yb}$ ratio of natural TTGs plotted against the pressure estimate of fig. 5.11c. Error bars are the same as in fig. 5.11c. e: Sr/Y ratio of natural TTGs plotted against the pressure estimate of fig. 5.11b. Error bars are the same as in fig. $5.11 \mathrm{c}$

5.12 Box plot of temperature deviation based on the model estimating temperature by pressure, $\mathrm{H}_{2} \mathrm{O}$ and major elements (fig. $5.4 \mathrm{~d}$ ) with the results sorted by their studies. Leftside of the diagram the count of experiments from the respective study is displayed. The shaded areas represent the RMSE and $2 *$ RMSE of the model (table 5.1). 
5.13 Box plot of pressure deviation based on the model estimating pressure by temperature, $\mathrm{H}_{2} \mathrm{O}$ and major elements (fig. $5.5 \mathrm{~d}$ ) with the results sorted by their studies. Leftside of the diagram the count of experiments from the respective study is displayed. The shaded areas represent the RMSE and $2 *$ RMSE of the model (table 5.1).

5.14 Box plot of $\mathrm{H}_{2} \mathrm{O}$ deviation based on the model estimating $\mathrm{H}_{2} \mathrm{O}$ by temperature, pressure and major elements (fig. 5.6d) with the results sorted by their studies. Left side of the diagram the count of experiments from the respective study is displayed. The shaded areas represent the RMSE and $2^{*}$ RMSE of the model (table 5.1).

5.15 a: Evaluation of $\mathrm{H}_{2} \mathrm{O}$ prediction via least squares with the temperature estimating SVM model that depends on $\mathrm{H}_{2} \mathrm{O}$ and major elements (fig. 5.4c). $\mathrm{H}_{2} \mathrm{O}$ is varied as an input variable to minimise the difference between target and estimated temperature. The model is tested via k-fold cross validation with 4000 iterations. The diagram is based on 707 experiments that have a difference of target- and estimated temperatures $\leq 1{ }^{\circ} \mathrm{C}$. $\mathbf{b}$ : Evaluation of pressure prediction via least squares with the temperature estimating SVR model that depends on pressure and major elements (fig. 5.4b). Pressure is varied as an input variable to minimise the difference between target and estimated temperature. The model is tested via k-fold cross validation with 4000 iterations. The diagram is based on 693 experiments that have a difference of target and estimated temperatures $\leq 1{ }^{\circ} \mathrm{C}$.

5.16 Harker diagrams displaying major elements of natural TTGs (Nutman et al., 1999; Moyen, 2011; Laurent et al., 2014; O’Neil and Carlson, 2017; Johnson et al., 2019) and the experimental glasses used for the model calibration. 
5.17 Correlation matrix for hydrous melting experiments from (Conrad et al., 1988; Vielzeuf and Holloway, 1988; Beard and Lofgren, 1991; Holtz and Johannes, 1991; Patiño Douce and Johnston, 1991; Rapp et al., 1991; Skjerlie and Johnston, 1992; Skjerlie and Johnston, 1993; Sen and Dunn, 1994; Vielzeuf and Montel, 1994; Wolf and Wyllie, 1994; Gardien et al., 1995; Patiño Douce and Beard, 1995; Rapp and Watson, 1995; Skjerlie and Patiño Douce, 1995; Patiño Douce and Beard, 1996; Skjerlie and Johnston, 1996; Winther, 1996; Springer and Seck, 1997; Patiño Douce and Harris, 1998; Pickering and Johnston, 1998; Castro et al., 1999, 2000; Gardien et al., 2000; Koester et al., 2002; Skjerlie and Patiño Douce, 2002; Grant, 2004; Spicer et al., 2004; López et al., 2005; Patiño Douce, 2005; Sisson et al., 2005; Xiong et al., 2005;

Alonso-Perez et al., 2009; Getsinger et al., 2009; Adam et al., 2012;

García-Arias et al., 2012; Laurie and Stevens, 2012; Qian and Hermann, 2013; Hastie et al., 2016) with recalculated $\mathrm{H}_{2} \mathrm{O}$ as shown in fig. 5.3. $\mathrm{T}$ is temperature in ${ }^{\circ} \mathrm{C}$ and $\mathrm{P}$ pressure in GPa. Pearson correlation coefficients are displayed in the upper right half of the matrix. The diagram was created via the $R$ package PerformanceAnalytics by Peterson and Carl (2020). 


\section{List of Tables}

1.1 Major element composition of the sample PC-103 from O'Neil et al. (2012) in wt $\%$.

1.2 Contribution to individual manuscripts

2.1 Average Eu-anomaly free $(1 \pm 0.1)$ TTG element concentrations based on the database of Moyen and Martin (2012) and the temperature used for calculating partition coefficients. Oxides are in given in wt\% and trace elements in ppm. An is the molar anorthite content calculated by CIPW norm via the $R$ package GCDkit (Janoušek et al., 2006).

3.1 Statistical evaluation of parameters controlling Ti solubility: temperature, FM, pressure and $\mathrm{H}_{2} \mathrm{O}$. Ti is described as $\log _{10}$ in mol\%. RSE is the residual standard error.

3.2 Regression analysis for Ti solubility on the original and the modified dataset. Ti is described as $\log _{10}$ in mol\%. RSE is the residual standard error.

3.3 Experimental run conditions and phase assemblages. The phase abundance was calculated via mass balance with the quality of fit presented by $\Sigma \mathrm{r}^{2}$ with $\mathrm{Na}$ correction. " $\mathrm{x}$ " indicates the presence of a phase without quantification. "tr" is an abundance insignificant to the mass balance calculation but detected by microprobe. "*" The value includes a correction for Fe loss.

3.4 Major element glass analyses of the experiments in wt\%. Bracketed numbers are the respective standard deviation on the values last digit. Sum is given as hydrous, with presented oxides normalised to anhydrous. $\mathrm{Na}_{2} \mathrm{O}^{*}$ is calculated by mass balance adjusting for loss during analysis. b.d. = below detection. $\mathrm{FeO}_{t}$ is not corrected for Fe-loss. Fe-loss is presented as relative loss [\%] based on mass balance calculation.

3.5 List of studies containing Ti phase saturated experiments. $\mathrm{H}_{2} \mathrm{O}$ is the amount dissolved in the melt, either given or estimated by the difference to $100 \%$ total of the analyses.

4.2 Major element composition of the sample PC-103 from O'Neil et al. (2012) in wt\%. 
4.1 Partial melting experiments that result in glasses of TTG composition as defined in Moyen and Martin (2012).

4.3 PC-103 input composition for THERMOCALC at different $\mathrm{H}_{2} \mathrm{O}$ contents displayed in mol\% if not indicated otherwise in the column head.

4.4 Experimental run conditions and phase assemblages. The phase abundance was calculated via mass balance with the quality of fit presented by $\Sigma \mathrm{r}^{2}$ on $\mathrm{Na}_{2} \mathrm{O}$ loss corrected major element compositions. " $\mathrm{x}$ " indicates the presence of a phase without quantification. " $\operatorname{tr} "$ is an abundance insignificant to the mass balance calculation but detected by microprobe.

4.5 Major element glass analyses of the experiments in wt\%. Bracketed numbers are the respective standard deviations on the values last digit. Sum is given as hydrous, with presented oxides normalised to anhydrous. $\mathrm{Na}_{2} \mathrm{O}^{*}$ is calculated by mass balance adjusting for loss during analysis. b.d. = below detection. $\mathrm{FeO}_{t}$ is not corrected for Fe-loss. Fe-loss is presented as relative loss [\%] based on mass balance calculation.

4.6 Melt compositions extracted from isobaric profiles of the calculated P-T sections (fig. 4.4) $\mathrm{H}_{2} \mathrm{O}^{i}$ is the water content in the system, $\mathrm{H}_{2} \mathrm{O}^{m}$ is dissolved in the melt. If not stated otherwise data is given in wt\%.

5.1 Statistical evaluation of the cross validation on the various SVR models describing temperature $\left[{ }^{\circ} \mathrm{C}\right]$, pressure $[\mathrm{GPa}]$ and $\mathrm{H}_{2} \mathrm{O}$ [wt\%]. Abbreviations: $\mathrm{T}$ $=$ temperature, $\mathrm{P}=$ pressure and $\mathrm{ME}=$ major elements.

5.2 Statistical indices of the temperature distribution of TTGs from fig. 5.8 estimated by the models displayed in fig. $5.4 \mathrm{a}$ and fig. $5.4 \mathrm{c}$. 